\title{
Global Carbon Pricing
}

\section{The Path to Climate Cooperation}

edited by Peter Cramton, David JC MacKay, Axel Ockenfels, and Steven Stoft

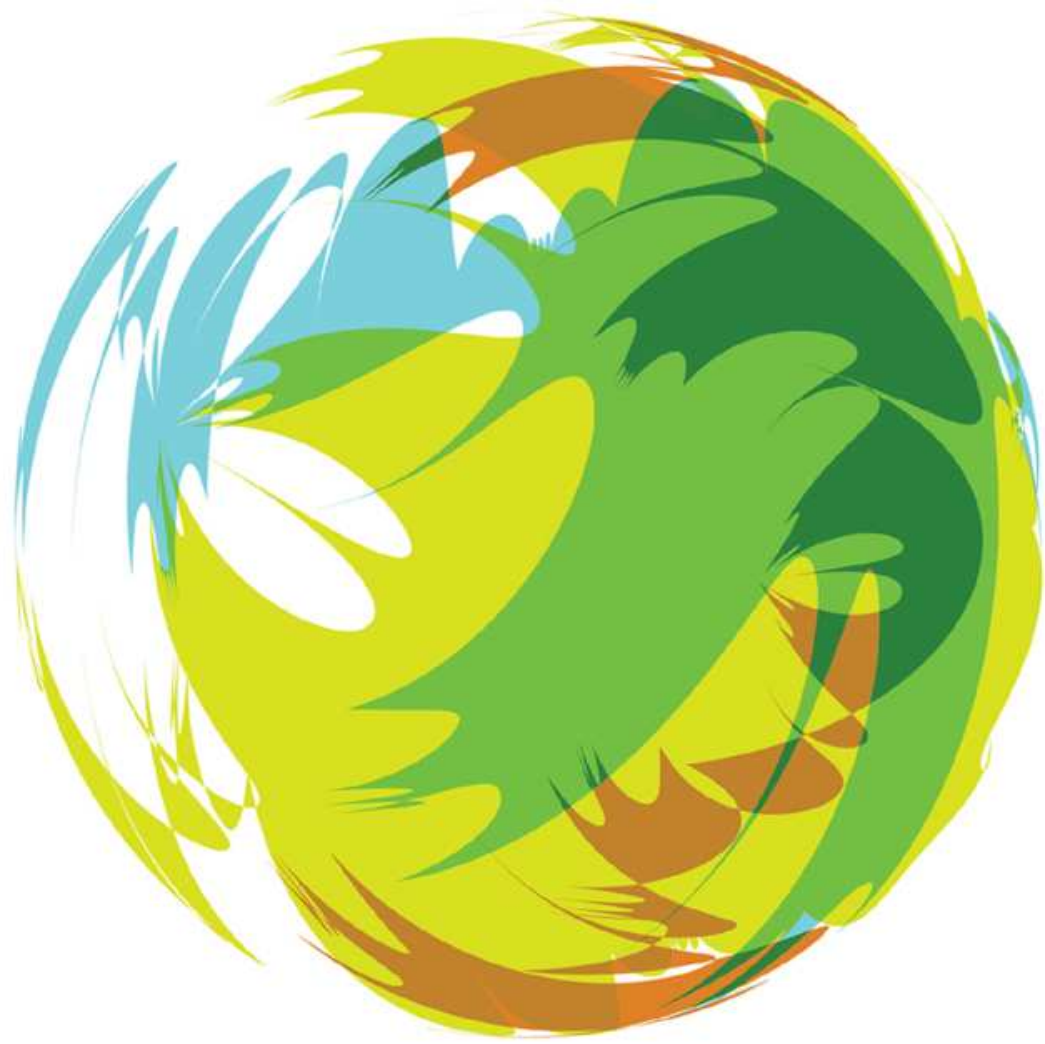



Global Carbon Pricing 



\section{Global Carbon Pricing}

The Path to Climate Cooperation

Edited by Peter Cramton, David JC MacKay, Axel Ockenfels, and Steven Stoft

The MIT Press

Cambridge, Massachusetts

London, England 
(C) 2017 Massachusetts Institute of Technology

All rights reserved. No part of this book may be reproduced in any form by any electronic or mechanical means (including photocopying, recording, or information storage and retrieval) without permission in writing from the publisher.

An electronic edition of this book is available under a Creative Commons BY-NC-ND 4.0, Attribution-NonCommercial-NoDerivatives International 4.0 license at http:// mitpress.mit.edu.

This book was set in ITC Stone Sans Std and ITC Stone Serif Std by Toppan Best-set Premedia Limited. Printed and bound in the United States of America.

Library of Congress Cataloging-in-Publication Data

Names: Cramton, Peter C., editor. | MacKay, David J. C., editor. | Ockenfels, Axel, editor.

Title: Global carbon pricing : the path to climate cooperation / edited by Peter Cramton, David JC MacKay, Axel Ockenfels, and Steven Stoft.

Description: Cambridge, MA : MIT Press, [2017] | Includes bibliographical references and index.

Identifiers: LCCN 2016045856 | ISBN 9780262036269 (hardcover : alk. paper)

Subjects: LCSH: Carbon taxes. | Environmental impact charges. | Greenhouse gas mitigation.

Classification: LCC HJ5316 .G56 2017 | DDC 363.738/746--dc23 LC record available at https://lccn.loc.gov/2016045856

$\begin{array}{llllllllll}10 & 9 & 8 & 7 & 6 & 5 & 4 & 3 & 2 & 1\end{array}$ 
To Sir David JC MacKay 



\section{Contributors}

Richard N. Cooper is Maurits C. Boas Professor of International Economics at Harvard University, a member of the Council on Foreign Relations, and author of Environment and Resource Policies for the World Economy.

Peter Cramton is Professor of Economics at the University of Maryland and a leading expert in auction theory and practice, and has consulted for a number of governments regarding climate policies.

Ottmar Edenhofer is Professor of the Economics of Climate Change at the TU Berlin, Director of the Mercator Research Institute on Global Commons and Climate Change in Berlin, and Chief Economist at the Potsdam Institute for Climate Impact Research. From 2008 to 2015, he served as Co-chair of Working Group III of the Intergovernmental Panel on Climate Change.

Christian Gollier is Director of the Toulouse School of Economics, winner of the 2001 Paul A. Samuelson Award, and author of Pricing the Planet's Future: The Economics of Discounting in an Uncertain World.

Éloi Laurent is a senior economist and scientific advisor at OFCE (SciencesPo Center for economic research, Paris) and visiting professor (Stanford University). He was an aide to the French prime minister (2000-2002).

David JC MacKay, FRS FInstP, was the Regius Professor of Engineering in the Department of Engineering at the University of Cambridge and from 2009 to 2014 was Chief Scientific Adviser to the UK Department of Energy and Climate Change.

William Nordhaus was President of the American Economic Association in 2014 and is the Sterling Professor of Economics at Yale University. He has been publishing papers on climate change since 1977. 
Axel Ockenfels is Professor of Economics at the University of Cologne, Speaker of the Excellence Center for Social and Economic Behavior, recipient of the Gottfried-Wilhelm-Leibniz prize, and has consulted firms and governments regarding climate policies and market design.

Ian Parry is Principal Environmental Fiscal Policy Expert in the IMF's Fiscal Affairs Department, specializing in fiscal analysis of climate change, environment, and energy issues.

Joseph E. Stiglitz is the 2001 Nobel Laureate in Economics, recipient of the John Bates Clark Medal (1979), and a professor at Columbia University. He is a former senior vice president and chief economist of the World Bank.

Steven Stoft holds a PhD in Economics from the University of California at Berkeley and has consulted for the World Bank, the US Department of Energy, and the United Kingdom's Department of Energy and Climate Change.

Jean Tirole is the 2014 Nobel Laureate in Economics and Chairman of the Board of the Jean-Jacques Laffont Foundation at the Toulouse School of Economics.

Martin L. Weitzman is Professor of Economics at Harvard University. Previously he was on the faculties of the Massachusetts Institute of Technology and Yale. He specializes in environmental economics. 


\section{Contents}

Preface $x i$

Three Introductory Chapters

1 Why Paris Did Not Solve the Climate Dilemma 1

Richard N. Cooper, Peter Cramton, Ottmar Edenhofer, Christian Gollier, Éloi Laurent, David JC MacKay, William Nordhaus, Axel Ockenfels, Joseph Stiglitz, Steven Stoft, Jean Tirole, and Martin L. Weitzman

2 Price Carbon-I Will If You Will 7

David JC MacKay, Peter Cramton, Axel Ockenfels, and Steven Stoft

3 Reflections on the International Coordination of Carbon

Pricing 13

Ian W. H. Parry

Nine Perspectives on Cooperation and Global Carbon Pricing

$4 \quad$ Global Carbon Pricing 31

Peter Cramton, Axel Ockenfels, and Steven Stoft

$5 \quad$ The Case for Pricing Greenhouse Gas Emissions 91

Richard N. Cooper

6 Overcoming the Copenhagen Failure with Flexible

Commitments 99

Joseph E. Stiglitz

7 Climate Clubs and Carbon Pricing 109

William Nordhaus 
8 How a Minimum Carbon-Price Commitment Might Help to Internalize the Global Warming Externality 125

Martin L. Weitzman

9 Climate Policy at an Impasse 149

Ottmar Edenhofer and Axel Ockenfels

10 Effective Institutions against Climate Change 165

Christian Gollier and Jean Tirole

11 From the Paris Agreement to the Carbon Convergence 205 Éloi Laurent

12 An International Carbon-Price Commitment Promotes Cooperation 221

Peter Cramton, Axel Ockenfels, and Steven Stoft

Acknowledgments 243

Index 245 


\section{Preface: Change the Game}

Pledge-and-review was invented for the United Nations Framework Convention on Climate Change (UNFCCC) by Japan in 1991, and it hasn't changed much since. It's what happened in Kyoto, although they tried hard to avoid the fate of each country simply pledging to do whatever it wanted followed by unenforced reviews. It's what happened under the Copenhagen Accord and the Cancún Agreements. And it's what happened again in Paris.

At least under Kyoto there was a bit of structure. Countries picked commitment levels relative to 1990. But within the European Union (EU), these ranged from a $30 \%$ cut to a $40 \%$ increase. There was virtually no structure in Paris; countries pledged almost anything. Now they will review it. And then there may be more pledges and more reviews.

Elinor Ostrom, a political scientist, won the 2009 Nobel Prize in economics for her lifelong studies of common-pool dilemmas-one of which is climate change. And her work is part of an enormous literature describing hundreds of real-world systems, thousands of laboratory experiments, and a great deal of theory. Yet after 25 years of failure, climate negotiations stick with an approach that ignores what we know about human cooperation.

To save the commons, the users of the commons must cooperate. That requires trust, and trust requires a reciprocal agreement-we will if you will, and you will if we will. For a group, especially a group of 10 or 100 countries, finding a reciprocal agreement requires simplification to a common commitment. Finding that commitment, and finding how to strengthen and stabilize it-that's the job undertaken by this book. But before you delve into that, we would like to show you a sort of magic trick. 
Negotiation design matters. We will now take a group of 10 completely selfish individuals and show you how they cut each other's throats in one game. Then, changing one rule-so they make common commitments instead of individual commitments-you will see those very same people, their temperaments unchanged, cooperate like angels.

You and nine other cut-throat individuals (representing countries) play a game. Each player has $\$ 10$, of which each must simultaneously pledge some part to the common pot. A referee makes sure they honor their pledges but uses two different rules, one per game, for what it means to "honor a pledge." Every dollar (for $\mathrm{CO}_{2}$ abatement) placed in the pot will be doubled (by natural climate benefits) and distributed evenly to all players. So any dollar placed in the pot will be doubled to $\$ 2$, and 20 cents will be returned to each player.

First, in the "individual commitment" game, all pledges are independent of those of others. So the referee makes sure each contributes exactly what he or she pledges. This is the classic public-goods game, and the rational strategy for the narrowly self-interested player is to contribute nothing because this makes a player better off no matter what the others do. The result is the famous tragedy of the commons. Cooperation does not occur, except perhaps on the part of a few committed altruists, who correctly note that if only everyone cooperated, everyone would be better off.

Second, consider the "common commitment" game, in which the rule is that the referee interprets a pledge of $\$ \mathrm{x}$ to mean a player will contribute up to $\$ \mathrm{x}$, but only as much as the lowest pledge. As before, this involves enforcement, but enforcement is weaker in the sense that, unlike before, the referee will not enforce contributions greater than the lowest pledge. This is a reciprocal agreement. It says, "I will if you will." But it does not say what anyone must do. Any outcome from "all contribute $\$ 0$ " to "all contribute $\$ 10$ " is possible, each is free to pledge from $\$ 0$ to $\$ 10$, and no one is forced to contribute more than his or her pledge. As before, after enforcing these common-commitment pledges (under the new rule), the money is doubled and distributed evenly.

This changes everything. Pledging \$0 will mean simply keeping your \$10, whereas pledging $\$ 10$ could result in ending up with anything between $\$ 10$ (if the lowest pledge is \$0) and \$20 (if the lowest pledge is \$10), depending on what others pledge. So, even though you are completely selfish, because you cannot lose and could gain by pledging $\$ 10$, that's what you would do. 
So, assuming that all play in their narrow self-interest, all pledge $\$ 10$, and the group's \$100 is doubled and divided evenly, and all end up with the maximum amount of $\$ 20$.

Because the common commitment protects against free-riding, selfish behavior has been changed from "contribute nothing" to "contribute everything," and the outcome is changed from no cooperation to full cooperation. With the common commitment, all know that "We are in this together." This demonstrates a key point. We will get better outcomes from the same players if we design better rules, even if those players do not increase their political will or ambition at all.

Of course, there is still a long way to go before we turn these ideas into a viable climate treaty, but there's something refreshing about seeing that human behavior can be changed without increasing enforcement power, changing human nature, or increasing ambition or political will. The referee fully enforced pledges in both games, and players were just as greedy in the second game as in the first. That the design of the negotiations can dramatically change human behavior allows a more optimistic interpretation of the climate predicament. It says, we are not as uncooperative as we have appeared to be for the last 25 years. The problem was just that we were trapped in the wrong game.

A focus on cooperation. This book is about climate cooperation-what it means, why it's needed, and how to attain it. The first three introductory chapters set the stage. They explain that, although COP21 in Paris formulated an ambitious global climate goal, this is only progress if the collective goal will be translated into a reciprocal, common climate commitment (MacKay et al., chapter 2). Indeed, Paris led to an unresolved gap between what is collectively needed and the intended national climate policies (Cooper et al., chapter 1). Narrow self-interest, responding to domestic pollution concerns and technological miracles, will not be enough to solve the dilemma (Parry, chapter 3), and neither will altruistic ambition. Cooperation is what is needed-and it is a feasible alternative to simply relying on narrow self-interest or altruistic ambition: If the game is changed to involve a reciprocal common commitment, national self-interests will be realigned with the public good. Ambition will follow automatically.

The second part of the book includes nine chapters that each provides different perspectives on the same theme: how the simple idea of a common commitment, illustrated by the previous example, can actually be 
turned into a viable climate treaty. A key insight of all chapters is that narrow self-interest as well as Paris' "pledge-and-review" approach will fail as long as it is based on individual commitments (Gollier and Tirole, chapter 10). Rather, all contributors agree that the best candidate for a common commitment is carbon pricing. Global carbon pricing is a natural comparison standard for abatement efforts, facilitating reciprocity (Cramton et al., chapter 12) and enforcement (Nordhaus, chapter 7); it substantially simplifies negotiations by focusing on a single minimum price variable, as opposed to many different quantity targets (Weitzman, chapter 8); it is efficient and flexible with respect to national climate policies (Stiglitz, chapter $6)$; it can help to make other, idiosyncratic climate policies more effective (Edenhofer and Ockenfels, chapter 9); it substantially reduces countries' risks and makes it easier to take into account "differentiated responsibilities" (e.g., because all proceeds from global carbon pricing stay in the country) (Cramton et al., chapter 12; Laurent, chapter 11). Overall, there is a remarkable consensus among the different contributors to our book regarding the most fundamental role of a reciprocal common price commitment for successful climate policy, although the contributors come from different backgrounds, including game theory, cooperation science, economic design, political science, engineering, risk analysis, climate negotiations, climate policy, and climate economics. That said, there are, of course, still many controversies and details that need to be addressed along the way. Gollier and Tirole, for instance, put forward monitoring reasons for why they personally favor an international cap-and-trade agreement to implement a global carbon price, whereas all others prefer a minimum price agreement. Cooper (chapter 5), for instance, discusses the likely impossibility of negotiating a global cap-and-trade scheme because the global "caps" would be too high and because the allocation of permits to domestic agents would invite corruption. Cramton et al. (chapter 4) provide a survey of the merits of global carbon pricing for negotiating international cooperation.

We emphasize that, although global carbon pricing facilitates cooperation and is an essential climate policy, it is of course not the only policy needed to effectively address climate change. Investments in green research are needed, too, and there is a role for some command-and-control style regulation, such as building standards. But the lack of a common commitment on carbon pricing is the primary source of the problem, and so correcting this is what this book is about. 
A common commitment says, "We will do what is required for the common good as long as you do as well." This type of reciprocity is almost universally what drives human cooperation. It is not new. It is ancient and has now been well documented by the various sciences that study human cooperation. It is universally used by governments when, for example, they fund highways or toxic waste cleanup. It is more difficult to achieve without the strong arm of a government. Explaining how that is done is the point of Ostrom's and many others' research on cooperation, and the conclusion is: "trust and reciprocity." Explaining how to apply this to the earth's atmosphere is the purpose of this book. 



\section{Why Paris Did Not Solve the Climate Dilemma}

Richard N. Cooper, Peter Cramton, Ottmar Edenhofer, Christian Gollier, Éloi Laurent, David JC MacKay, William Nordhaus, Axel Ockenfels*, Joseph Stiglitz, Steven Stoft, Jean Tirole, and Martin L. Weitzman

Paris Formulated a Collective Goal, Yet Individual Contributions Do Not Add Up

COP21 in Paris reconfirmed the customary global climate goal: warming should stay "well below $2^{\circ} \mathrm{C}$ " and added that by 2050 the world should no longer produce net greenhouse gas emissions. The breadth of this international consensus represents important progress, but only if the collective goal will be translated into a common climate commitment. Paris participants tried and will continue to try hard to promote ambitious national climate policies, but so far the Paris approach neglects the free-rider problem. National ambition comes with trust in others' cooperation, and trust comes with a common, reciprocal commitment. With its focus on collective goals rather than on common commitments, the Paris agreement could inhibit progress, if setting goals are seen as simply tantamount to success.

The Paris talks were based in part on the assumption that narrow selfinterest is enough for solving climate change. As Christina Figueres put it, "Frankly, none of them are doing it [agreeing to their pledges] to save the planet. Let us be very clear. They're doing it for what I think is a much more powerful political driving force, which is for the benefit of their own economy." ${ }^{1}$ As a consequence, COP21 elicited individual and largely independent commitments.

However, climate change is a problem of the commons, and it likely remains one in the foreseeable future (see next section). If each country had its own climate, then self-interested countries would reach the climate

* Ockenfels thanks the German Research Foundation (DFG) for financial support through the Research Unit "Design \& Behavior" (FOR 1371). 
goal-much like self-interested countries provide education, transportation infrastructure, parks, and other public goods. But with a shared climate, a $\mathrm{CO}_{2}$-abating country receives only a small fraction of the benefits, yet incurs the full costs of its abatement. The self-interested response is to freeride. This is particularly true in a globalized economy, where the costs of energy substantially affect economic competitiveness. Self-interested countries would let others do what is in the common interest.

Not all countries selfishly ignore the benefits of national climate policies to others. But even those that do not are unlikely to fully internalize the external benefits, in particular when they see that their cooperation gets exploited. This is why countries can sincerely agree with an ambitious collective goal and at the same time only commit to mostly self-interested individual abatement strategies, which do not add up to the collective goal. Indeed, for example, many African countries are heavily investing in oil extraction or allowing international oil companies to explore within their territories, Australia is predicted to be the world's largest coal exporter by 2020, China's emission level will increase until around 2030 (the ongoing process of reducing China's $\mathrm{CO}_{2}$ emission growth seems to simply reflect what China intended to do anyway-to reduce deaths from local air pollution), India submitted no intention to peak or decrease $\mathrm{CO}_{2}$ emissions and their coal production is predicted to double in the next decade, and the United States is focusing on shale gas, which reduces domestic emissions but leads to rising coal exports. Countries rationally prefer to let others make the costly efforts needed to reach the collective goal.

As a result, even if all Intended Nationally Determined Contributions (INDCs) fully materialize, total emissions and emissions per year will increase until 2030. According to the last IPCC report, a $2^{\circ} \mathrm{C}$ goal would yield a carbon budget of $630-1180 \mathrm{GtCO}_{2}\left(90-310 \mathrm{GtCO}_{2}\right.$ with a $1.5^{\circ} \mathrm{C}$ goal) until 2100 , yet the INDCs, if fully and unconditionally implemented, would already yield emissions that sum up to approximately 815 $\mathrm{GtCO}_{2}$ until 2030. Reaching the collective goal after 2030 would then require drastic and rapid emission reductions, including possibly the need for massive negative emissions, making free-riding an even more attractive option. Moreover, the large amounts of already built and currently planned coal-fired capacities seem inconsistent with many of the INDCs in Paris' agreement; they alone are predicted to eat up $450 \mathrm{GtCO}_{2}$ of the 
remaining budget (Edenhofer et al., 2016; Steckel et al., 2015). There is an insurmountable gap between what is collectively needed and national climate policies.

\section{Ratcheting Up or Ratcheting Down?}

The lack of ambition in Paris, when it comes to individual commitments as opposed to the collective goal, explains why negotiators established a review process. The hope is that, as the lack of individual cooperation becomes more apparent and the technology for reducing emissions becomes cheaper, ambition will "ratchet up." But this hope relies on wishful thinking, not on what we know about cooperation, and not on guarantees concerning technology.

Cooperation. The strong attraction of the free-riding strategy, when there is no common commitment, is a consistent theme across theory, field, and experiment that has been extensively studied not only in static but also in dynamic environments. For instance, in a typical laboratory experiment, players contribute to the public good in the first round, which produces a collective benefit that is distributed evenly to all. This allows players to review the collective contribution. The contribute-and-review process is then repeated several times. The most common outcome by far is that some ambition is shown in the first round, but less is shown in subsequent rounds because parties observe others acting in their narrow self-interest, and nobody likes being taken advantage of. That is, the initial ambition, if any, tends to vanish, and behavior tends to move toward the selfish equilibrium (Ledyard, 1995). The failed Kyoto process provides another example of the attraction of the selfish equilibrium.

Independent climate action and positive leadership that induces others to follow is often thought to be a source for the desired ratcheting up effect. Unfortunately, the effect of independent action is often just the opposite: Without a common commitment, one country's abatement can increase the emissions in other countries (carbon leakage), increase aggregate world emissions, and reduce the chance of effective subsequent climate negotiations (Hoel, 1991; Sinn, 2008). However, laboratory studies find that unilateral commitment can also enhance cooperation; the effect is typically small, in particular with heterogeneous agents (Levati, Sutter, and van der Heijden, 2007). 
Finally, theory suggests and the field work by Elinor Ostrom and numerous experiments confirm that comparability and reliable monitoring of efforts are needed for cooperation to be stable (Bereby-Meyer, 2012; Ostrom, 1990). Yet in the context of the intended review process after Paris, individual pledges and efforts are hardly comparable and differently monitored, reported, and verified.

For all these reasons, it seems likely that the review process, as long as it is based on individual commitments only, will fail to significantly increase ambition. Indeed, it will likely lead to a ratcheting down of cooperation.

Technology. Before Paris, there was general agreement that simply buying the cheapest energy with no thought for global consequences was the source of the climate problem. But the Paris agreement seems partly driven by the reverse assumption: that the cost of clean energy sources will fall so fast that fossil fuel use will become uneconomic - a bold assumption given that as demand for fossil fuels declines, so too do fossil fuel prices (e.g., Covert et al., 2016). Under this scenario, countries would be induced to give up all fossil fuel use by 2050 simply because clean energy is the cheapest alternative. Although this optimistic scenario may be technically possible, this seems a risky bet, especially given the rather short time horizon before the carbon budget is eaten up and the plans in many countries to massively expand coal-based power plants that run for decades. It would not be wise to depend on it.

\section{This Book: A Reciprocal, Common Commitment Is Needed}

The failure of Paris to address the free-rider problem is the motivation for this book. We will argue, from different perspectives, that to promote cooperation and discipline free-riders, a collective goal must be translated into a reciprocal, common commitment: an agreement to abide by rules that specify ambitious behavior, provided others abide by the same rules (MacKay et al., 2015). This holds for practically all cooperation problems, from dish washing in shared apartments to international trade and disarmament, to laboratory evidence (e.g., Kosfeld et al., 2009). The commonality of the commitment creates a shared understanding of what can be expected from each other, so that the reciprocity principle, which can include various forms of enforcement, can be implemented to promote cooperation and mutual trust that one's cooperation will not be exploited. 
The best candidate for a common commitment in international climate policy is carbon pricing. Indeed, carbon pricing is recommended by the vast majority of economists and many policymakers as the preferred climate policy instrument. A carbon price directly, efficiently, and transparently addresses the central problem of overusing the limited storage space in the atmosphere as a free dumping ground for greenhouse gases. This has been known for a long time. The main contribution of this book is to present analyses and arguments which show that a common commitment to carbon pricing is also useful to promote international cooperation (see also Cramton et al., 2017).

We hope to convince you with this book that, now that Paris has reached a consensus about the collective goal, there is a chance-maybe the last chance-to bring together what is needed to overcome self-interest and initiate serious cooperation: carbon pricing and reciprocity.

\section{Note}

1. http://edition.cnn.com/2015/12/01/world/cop21-amanpour-figueres/.

\section{References}

Bereby-Meyer, Y. 2012. Reciprocity and uncertainty. Behavioral and Brain Sciences $1(0): 18-19$.

Covert, T., M. Greenstone, and C. R. Knittel. 2016. Will we ever stop using fossil fuels? Journal of Economic Perspectives 30 (1): 117-138.

Cramton, P., A. Ockenfels, and J. Tirole. 2017. Policy Brief-Translating the collective climate goal into a common commitment. Review of Environmental Economics and Policy. In press.

Edenhofer, O., J. C. Steckel, M. Jakob, and C. Bertram. 2016. Reading the writing on the wall: Coal and the Paris agreement. Mimeo.

Hoel, M. 1991. Global environmental problems: The effects of unilateral actions taken by one country. Journal of Environmental Economics and Management 20:55-70.

Kosfeld, M., A. Okada, and A. Riedl. 2009. Institution formation in public goods games. American Economic Review 99 (4): 1335-1355.

Ledyard, J. 1995. Public goods: A survey of experimental research. In The Handbook of Experimental Economics, ed. H. Kagel and A. E. Roth, 111-194. Princeton, NJ: Princeton University Press. 
Levati, V., M. Sutter, and E. van der Heijden. 2007. Leading by example in a public goods experiment with heterogeneity and incomplete information. Journal of Conflict Resolution 51 (5): 793-818.

MacKay, D., P. Cramton, A. Ockenfels, and S. Stoft. 2015. Price carbon-I will if you will. Nature 526:315-316.

Ostrom, E. 1990. Governing the Commons: The Evolution of Institutions for Collective Action. Cambridge, UK: Cambridge University Press.

Sinn, H.-W. 2008. Public policies against global warming: A supply side approach. International Tax and Public Finance 15:360-394.

Steckel, J. C., O. Edenhofer, and M. Jakob. 2015. Drivers for the renaissance of coal. Proceedings of the National Academy of Sciences of the United States of America 112 (29): E3775-E3781. 


\section{Price Carbon-I Will If You Will*}

\section{David JC MacKay, Peter Cramton, Axel Ockenfels, and Steven Stoft}

Negotiations at the United Nations (UN) climate summit in Paris in December 2015 adopted a "pledge-and-review" approach to cutting global carbon emissions. Countries promised to reduce their emissions by amounts that will be revised later. The narrative is that this will "enable an upward spiral of ambition over time" (Ad Hoc Working Group on the Durban Platform, 2014). History and the science of cooperation predict that quite the opposite will happen.

Climate change is a serious challenge because the atmosphere gives a free ride to countries that emit. If some nations sit back and rely on others' efforts, the incentives for anyone to act are weakened. Review of the first phase of the Kyoto Protocol at the 2012 UN climate meeting in Doha, for instance, resulted in Japan, Russia, Canada, and New Zealand leaving the agreement, frustrating those who kept their promises.

Success requires a common commitment not a patchwork of individual ones. Negotiations need to be designed to realign self-interests and promote cooperation. A common commitment can assure participants that others will match their efforts and not free-ride. A strategy of "I will if you will" stabilizes higher levels of cooperation. It is the most robust pattern of cooperation seen in laboratory and field studies of situations open to free-riding (Kraft-Todd et al., 2015).

A global carbon price-so far excluded from consideration in international negotiations-would be the ideal basis for a common commitment in our view. A price is easy to agree and handle, relatively fair, less vulnerable to gaming than global cap-and-trade systems, and consistent

* First published in Nature, 526, 315-316 (October 15, 2015), doi:10.1038/526315a, by Nature Publishing Group. 
with climate policies already in place, such as fossil-fuel taxes and emissions cap-and-trade.

Only a common commitment can lead to a strong treaty. Forty years of empirical and theoretical literature on cooperation confirms that individual commitments do not deliver strong collective action. Cooperators find that defectors take advantage of them. Ambition declines when others are revealed to be free-riding (Ledyard, 1995). Dishes often stack up in the sinks of shared apartments. But in the Alps, villagers have successfully managed shared land for hundreds of years with a common commitment governing grasslands (Ostrom, 1990).

\section{Common Commitment}

Imagine that you and nine other self-interested players (representing countries) take part in a game. Each player has $\$ 10$, some or all of which the players may simultaneously pledge to a common pot. A referee makes sure that they honor their pledges. Every dollar (for carbon dioxide abatement) placed in the pot will be doubled (by climate benefits) and distributed evenly to all players. So putting $\$ 1$ in the pot will return 20 cents to each player.

Consider two variants of the game. First, in the "individual commitment" version, pledges are made independently. This is the classic publicgoods game, in which the rational selfish strategy is to contribute nothing because this makes a player better off no matter what the others do. The result is the famous tragedy of the commons. Cooperation does not occur, even though everyone would gain from it.

Second, in the "common commitment" version, players condition their contributions on others' pledges: a referee ensures that all contribute the amount of the lowest pledge. After enforcing this common commitment, the money is doubled and distributed evenly, exactly as before.

This changes everything. Pledging \$0 will mean simply keeping your $\$ 10$, whereas pledging $\$ 10$ could result in ending up with anything between $\$ 10$ and \$20 depending on what others pledge. If you cannot lose and could gain by pledging $\$ 10$, then that is what you would do, even if you are completely selfish. Because all parties would pledge $\$ 10$, the group's $\$ 100$ is doubled, and all players end up with the maximum amount of \$20. 
Selfish behavior has been changed from "contribute nothing" to "contribute everything" because the common commitment protects against free-riding.

In 1997, the Kyoto negotiators initially tried to agree on a common commitment, expressed as a formula for national emissions caps, but they failed. In the end, each nation was simply asked to submit their final numbers for insertion into the draft annex (Depledge, 2000). The result was a patchwork of weak and unstable commitments. Similarly, in response to the 2009 Copenhagen Accord, China pledged emissions equal to those considered "business as usual" before the accord, and India pledged even less.

Enforcement is widely thought to be the missing ingredient in the Kyoto Protocol and crucial for the success of the Paris agreement. This is only half right-both enforcement and a common commitment are required. For example, if drivers chose their own speed limits, there would be no use enforcing them because everyone would drive at their desired speed. Instead, because it limits others as well, people agree to a common speed limit that is lower than almost everyone's individual limit. In other words, with individual commitments, there is nothing meaningful to enforce, whereas enforcement strengthens a common commitment.

What could all countries commit to? National limits on the quantity of emissions will not work. Kyoto negotiators suggested at least 10 formulae to determine the reductions that each nation should make but could not agree on. When attention turned to reducing emissions by some percentage relative to 1990 levels, individual commitments ranged from an 8\% decrease to a $10 \%$ increase. The United States and developing countries made no commitments at all.

Percentage pledges failed because countries differ; for instance, some economies declined after 1990, whereas some grew. Developing countries fear caps that curb their growth. Instead they see it as fair to allocate emission permits on an equal per capita basis. Because permit sales would result in huge wealth transfers to poor countries, rich countries find such proposals unacceptable (Stiglitz, 2006).

There is no longer any serious discussion of a common commitment to reduce the quantity of carbon emissions. 


\section{Global Carbon Price}

We, and others, propose an alternative: a global carbon-price commitment (Cramton et al., 2015). Each country would commit to place charges on carbon emissions from fossil-fuel use (e.g., by taxes or cap-and-trade schemes) sufficient to match an agreed-on global price, which could be set by voting - by a super-majority rule that would produce a coalition of the willing.

A uniform carbon price is widely accepted as the most cost-effective way to curb emissions. Carbon pricing is flexible, allowing fossil taxes, capand-trade, hybrid schemes, and other national policies to be used (unlike a global carbon tax). All that is required of a country is that its average carbon price-cost per unit of greenhouse gas emitted-be at least as high as the agreed-on global carbon price.

Unlike global cap-and-trade, carbon pricing allows countries to keep all carbon revenues, eliminating the risk of needing to buy expensive credits from a rival country. Taxes need not rise if a nation performs a green tax shift-reducing taxes on good things such as employment by charging for pollution. Shifting taxes from good things to bad things could mean there is no net social cost to pricing carbon, even before counting climate benefits (Bovenberg, 1999).

A global price does not automatically result in acceptable burden sharing. A "Green Climate Fund" will be needed to transfer funds from rich to poor countries. To minimize disputes, the objective of climate-fund transfers should be to maximize the global price of carbon. This can be implemented in a way that encourages rich countries to be generous and poor countries to vote for a higher global carbon price (Cramton and Stoft, 2012), for example, by making all climate-fund payments proportional to the agreed-on carbon price.

After decades of failure, a fresh approach is needed-one that is guided by the science of cooperation. A common price commitment would harness self-interest by aligning it with the common good. Nothing could be more fundamental.

\section{References}

Ad Hoc Working Group on the Durban Platform. UNFCCC. 2014. Parties' Views and Proposals on the Elements for a Draft Negotiating Text ADP.2014.6 Available at http://go.nature.com/x1fjcd. 
Bovenberg, A. L. 1999. Green tax reforms and the double dividend: An updated reader's guide. International Tax and Public Finance 6:421-443.

Cramton, P., A. Ockenfels, and S. Stoft. 2015. An international carbon-price commitment promotes cooperation. Economics of Energy \& Environmental Policy 4:51-64.

Cramton, P., and S. Stoft. 2012. Global climate games: How pricing and a green fund foster cooperation. Economics of Energy \& Environmental Policy 1 (2).

Depledge, J. 2000. The Origins of the Kyoto Protocol. Bonn, Germany: UN Framework Convention on Climate Change.

Kraft-Todd, G., E. Yoeli, S. Bhanot, D. Rand, et al. 2015. Promoting cooperation in the field. Current Opinion in Behavioral Sciences 3:96-101.

Ledyard, J. 1995. Public goods: A survey of experimental research. In The Handbook of Experimental Economics, ed. H. Kagel and A. E. Roth, 111-194. Princeton, NJ: Princeton University Press.

Ostrom, E. 1990. Governing the Commons: The Evolution of Institutions for Collective Action. Cambridge, UK: Cambridge University Press.

Stiglitz, J. 2006. Making Globalization Work. New York: Norton. 



\section{Reflections on the International Coordination of Carbon Pricing}

Ian W. H. Parry*

\section{Introduction}

This chapter makes two basic points about international coordination of carbon pricing.

The first is that just because climate externalities cause a global freerider problem (i.e., the reluctance of one country to move ahead unilaterally with carbon pricing because it bears the costs while all countries benefit from a more stable global climate system), this does not mean we have to solve that problem to make a good start on reducing climate externalities. In fact, a significant amount of carbon pricing is in many countries' own national interests (before even counting the global climate benefits) because the domestic environmental benefits (most important, public health benefits from reduced local air pollution), and perhaps also the domestic fiscal benefits, easily outweigh the climate mitigation costs. So countries can move ahead on their own with carbon pricing and make themselves better off-they do not need to wait for large emitters to act in a coordinated way. This is an important message that policymakers need to communicate to legislators, the general public, and stakeholders as they start to move forward on their mitigation pledges for the 2015 Paris Agreement on climate change.

The second point is that, as countries seek to build on domestic pricing initiatives through international coordination, they should consider the possibility of international carbon price floor arrangements (in preference to linked trading systems). These arrangements provide some protection against free-rider issues and losses in competitiveness, while allowing

\footnotetext{
* I am grateful to Steven Stoft for valuable comments on an earlier draft.
} 
individual countries the flexibility to set prices higher than the floor, which makes sense if they have relatively high domestic environmental benefits or high fiscal needs, or if higher prices are more politically acceptable in that country than in other countries. Some operationalizing issues need to be worked out (e.g., accounting for broader changes in energy taxes and subsidies and country-level needs for special provisions in carbon pricing programs), but the practicalities should be manageable.

The following two sections elaborate on the above points.

\section{Is Carbon Pricing in Countries' Own Interests?}

The main focus of this section is on the domestic environmental benefits of carbon pricing ${ }^{1}$ as the evidence on their magnitude is more solid than for the fiscal benefits (i.e., the economic efficiency benefits from substituting carbon taxes for distortionary taxes on labor, consumption, and capital).

\section{Domestic Environmental Considerations}

Leaving aside the global climate benefits, carbon pricing can generate substantial domestic environmental benefits, most important the reduction in premature deaths from exposure to local air pollution as carbon pricing reduces the use of coal and other polluting fuels and (less important) the reduction in traffic congestion, accidents, and road damage externalities, to the extent that carbon pricing reduces vehicle use and these externalities are not reflected in road fuel excises. ${ }^{2}$

Clearly, there are much more efficient instruments than carbon pricing for addressing these domestic environmental externalities. For example, the most efficient way to reduce local air pollution is to impose a Pigouvian tax, either through directly charging emissions or (which may be administratively easier for some countries) an upfront tax on fuel use combined with rebates for entities demonstrating emissions capture during the combustion process. And (for given road infrastructure) traffic congestion is most efficiently addressed through congestion fees on busy roads, rising and falling progressively over the course of the rush hour.

It is also clear, however, that it will take a long time before these ideal charging systems are widely implemented across large carbon emitting countries. With the odd exception (e.g., Chile), countries have yet to introduce a comprehensive set of charges on the major air pollutants with 
charges aligned to estimates of air pollution $\operatorname{costs}^{3}$ (technology mandates and other regulations are common, but they do not fully internalize the externality). Certainly no country comes anywhere near close to having a set of finely tuned congestion fees, varying with marginal external costs across time of day, on all links in the road network with non-free-flowing traffic.

For the interim, therefore, it is entirely appropriate to account for the unpriced domestic environmental benefits when assessing the welfare effects of near-term carbon pricing schemes. Not doing do violates longestablished principles of welfare measurement, ${ }^{4}$ implying that the welfare impacts of new charges in fuel markets hinge critically on preexisting distortions in those markets, whether they be from prior fuels taxes, externalities, or other sources.

Methodology for Measuring Domestic Environmental Benefits The conceptual framework for assessing the domestic efficiency benefits (or costs) of carbon pricing is basically straightforward. Consider figure 3.1, which shows the demand and supply ${ }^{5}$ for a fuel product such as coal or gasoline. In the absence of any noncarbon externalities, preexisting fuel taxes or subsidies, or other distortions, the welfare cost of a new carbon charge in this market is the usual darker-shaded triangle-the "Harberger triangle" - with base equal to the reduction in fuel use induced by the carbon charge and height equal to the carbon charge, that is, the fuel's $\mathrm{CO}_{2}$ emissions factor times the charge on $\mathrm{CO}_{2}$ emissions.

If there are noninternalized, noncarbon externalities associated with use of the fuel, however, like local air pollution damages, then it is possible for the carbon charge to generate a net welfare gain, indicated by the lightershaded trapezoid in figure 3.1, equal to the (noninternalized) domestic environmental benefits-damages per unit of fuel use times the reduction in fuel use-less the Harberger triangle. The prospects for an overall welfare gain in the fuel market are clearly greater (1) the greater the size of the noncarbon externality, relative to the carbon charge; and (2) the less any internalization of the externality through preexisting fuel taxes.

In fact, if the fuel is subsidized rather than taxed-as has (at least up until recently) been the case for petroleum products and natural gas in a number of Middle East and North African countries ${ }^{6}$-and if a carbon charge were superimposed on top of unreformed subsidies, then the 


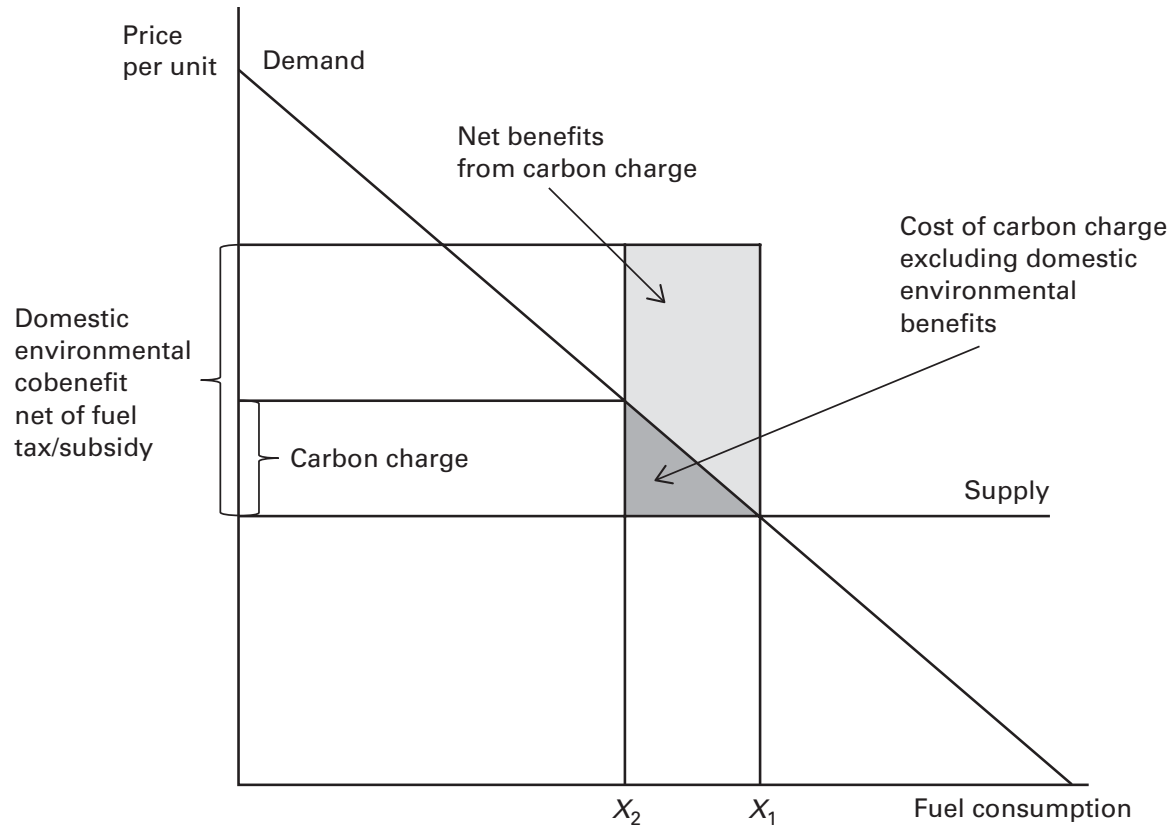

Figure 3.1

Welfare Effect of a Carbon Charge in a Fuel Market

prospects for a welfare gain are further enhanced. However, although coal and natural gas are generally not subject to substantial excises, road fuels in most countries are, and in cases (e.g., some European countries) where they may exceed estimates of noncarbon environmental costs, carbon charges will induce welfare losses in road fuel markets despite domestic environmental benefits.

Of course many countries are using domestic (usually regulatory) measures to reduce air emission rates, but this does not eliminate the domestic efficiency gains from carbon pricing. This point is illustrated in figure 3.2 , where a regulation, such as requirements for technologies on new coal plants to reduce sulfur dioxide emissions, shifts up the industry average supply curve (inclusive of technology operation costs) for coal generation and shifts down the industry average environmental damages per unit of coal use, but not to zero. For example, plants operating these technologies still emit some sulfur dioxide, the technologies may not always be switched on, older plants may not have these technologies, and plants produce other 


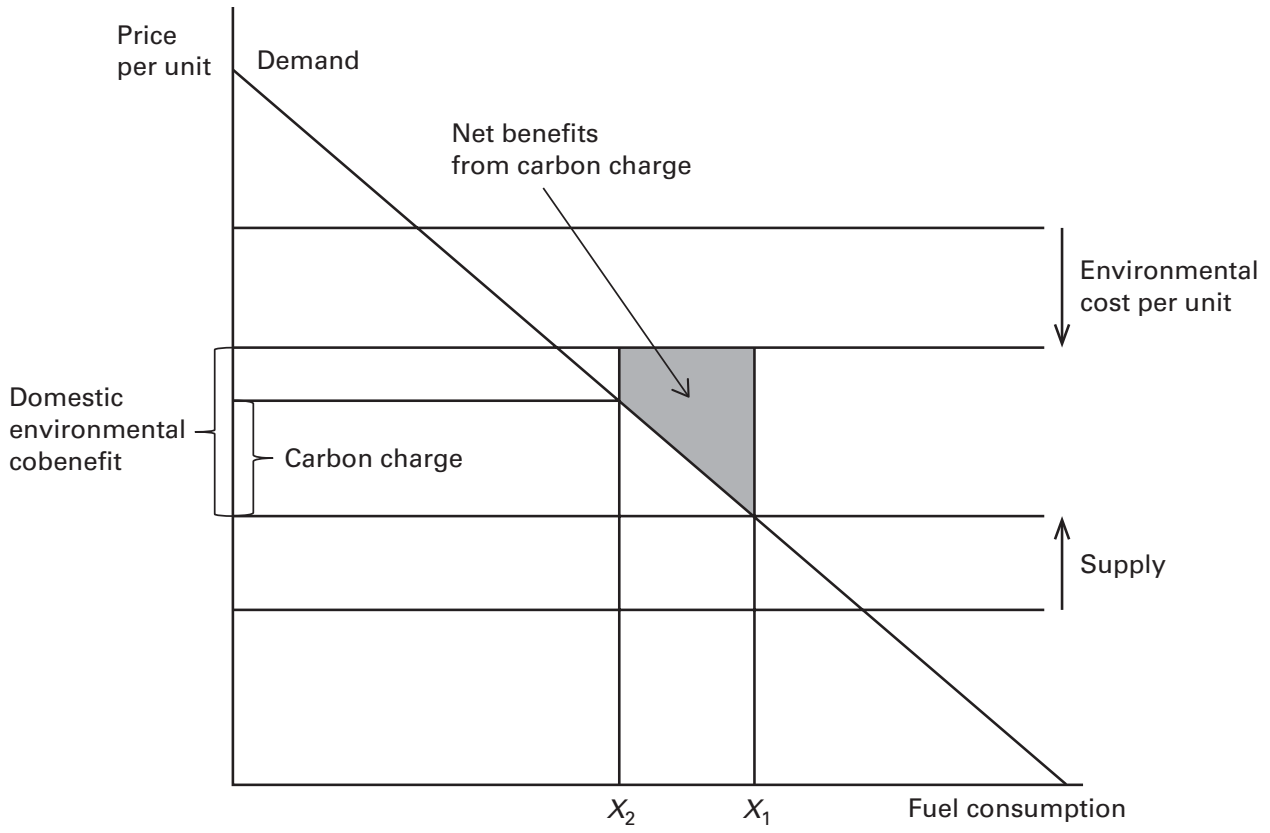

Figure 3.2

Prior Air Pollution Regulation and the Welfare Effect of a Carbon Charge

air emissions, such as nitrogen oxides and direct fine particulates. The carbon charge still has the potential to induce a net welfare gain (indicated by the shaded trapezoid), albeit a smaller one than in the absence of other regulations.

The (second-best) nationally efficient carbon price-that is, the price warranted by domestic environmental benefits (before counting global climate benefits) - is obtained by differentiating the sum of welfare gains (or welfare losses) in the markets for coal, natural gas, and petroleum products with respect to the carbon price. Not surprisingly, the efficient tax (see Parry, Veung, and Heine, 2014) is higher (1) the greater the magnitude of non- $\mathrm{CO}_{2}$ externalities net of any prior fuel taxes, and (2) the greater the share of $\mathrm{CO}_{2}$ reductions that come from fuels with relatively high noninternalized environmental damages.

Parry, Veung, and Heine (2014) estimated nationally efficient carbon prices for large emitters for 2010 using fuel consumption data (from the International Energy Agency), fuel price and tax/subsidy data (from IMF 
sources), $\mathrm{CO}_{2}$ emissions factors for fuels, ${ }^{7}$ fuel price elasticities from the empirical literature, ${ }^{8}$ and estimates of domestic environmental costs by fuel product and by country from an IMF database developed by Parry, Heine, Lis, and $\mathrm{Li}(2014)^{9}$ - the appendix to this chapter provides more details on the measurement of these environmental costs.

Ideally, estimates of nationally efficient carbon prices would be projected forward (say to 2030, a typical year for meeting countries' emissions pledges for Paris), accounting for future changes in the fossil fuel mix, changes in fuel prices (which affect the proportionate change in fuel prices from carbon pricing), tightening domestic environmental regulations, rising valuations of air pollution mortality risks with growth in per capita income, and so on. Nonetheless, the estimates discussed below are still useful in providing some broad sense of the size of domestic environmental benefits and the extent of variation across countries.

Results Figure 3.3 shows estimates of nationally efficient carbon prices for the top 20 emitting countries in 2010. These estimates indicate the price levels up to which incremental increases in prices are in countries' own interests because the extra domestic environmental benefits outweigh the extra mitigation costs-only beyond these prices do incremental abatement costs start to rise above domestic environmental benefits (the point at which, in theory, the free-rider problem should start to kick in).

Although the precise numbers in the figure should not be taken too literally, the two key points are first that the nationally efficient $\mathrm{CO}_{2}$ prices can be substantial and second that the efficient prices differ greatly across countries.

Averaging over the top 20 , the nationally efficient price is $\$ 57$ per ton of $\mathrm{CO}_{2}$, which is a large number-about $60 \%$ higher than the social cost of carbon in 2010 according to US Inter-Agency Working Group (2013).

For China, the nationally efficient $\mathrm{CO}_{2}$ price is $\$ 63$ per ton, which essentially reflects the domestic air pollution benefits from reducing coal usethese benefits are relatively high given that China is densely populated with a lot of exposure to coal plant emissions. ${ }^{10}$ Although air pollution deaths per unit of coal combustion are dramatically lower in the United States (about one-twelfth of that for China), the nationally efficient $\mathrm{CO}_{2}$ price is still $\$ 36$ per ton, in part because the valuation of health risks is assumed to be about four times higher for the United States than for China, 


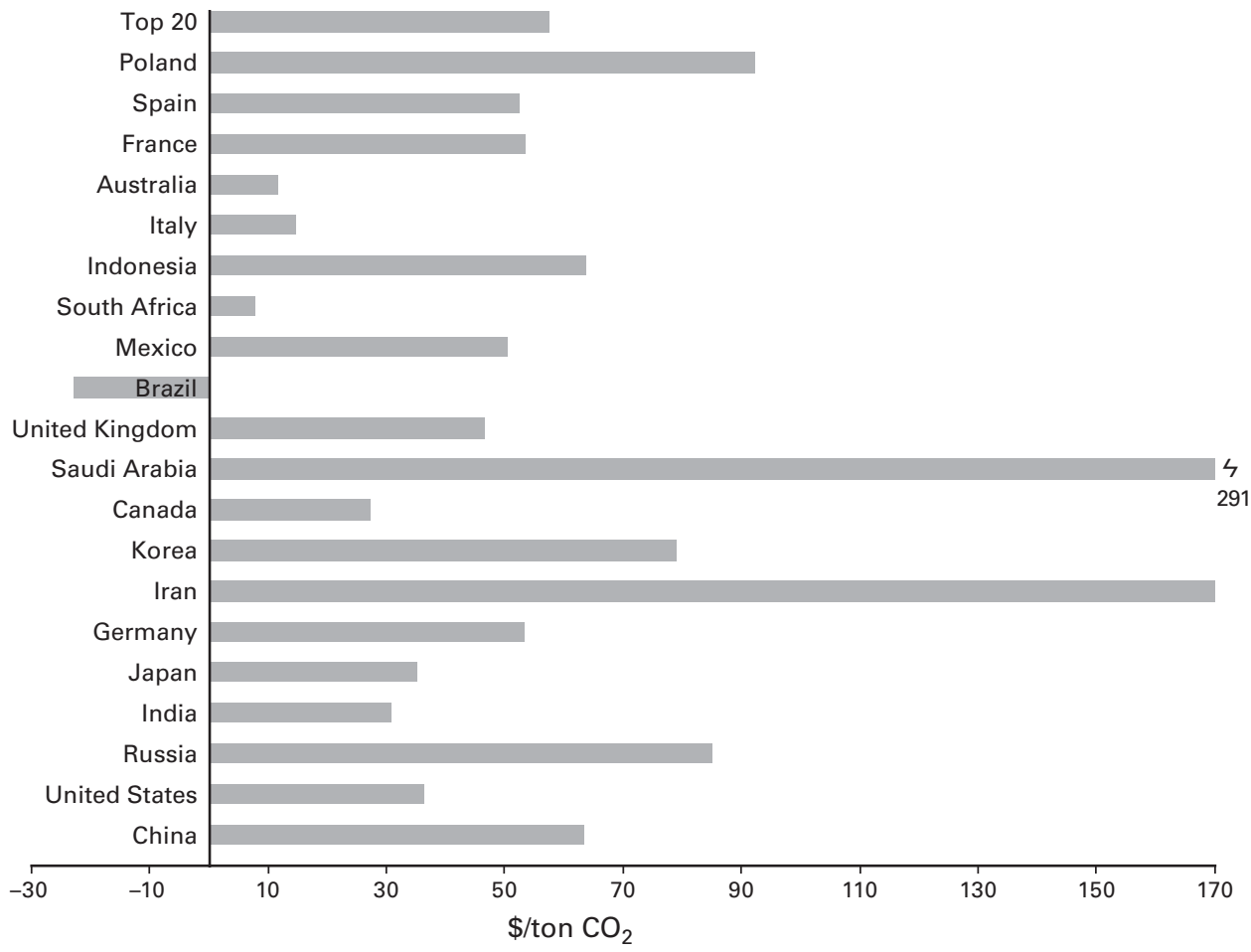

Figure 3.3

Nationally Efficient $\mathrm{CO}_{2}$ Prices, 2010. Note: Top 20 averages across countries weighting by their emissions shares.

Source: Parry, Veung, and Heine (2014).

and a more significant portion of the $\mathrm{CO}_{2}$ reductions come from reductions in road fuels, which are substantially undertaxed from a domestic perspective in the United States.

In contrast, the nationally efficient $\mathrm{CO}_{2}$ price is more moderate in Australia at $\$ 12$ per ton, in part reflecting the much more limited exposure to air pollution (due to low population density and the coastal location of power plants, where much of the emissions disperse harmlessly over the oceans). The nationally efficient $\mathrm{CO}_{2}$ price is negative for Brazil, where there is little coal use, and a significant portion of the $\mathrm{CO}_{2}$ reduction comes from reduced gasoline use, which is already overtaxed from a domestic perspective. Also striking are Saudi Arabia and Iran, where domestic subsidies for petroleum and natural gas were large in 2010, implying large efficiency 
gains in the (unlikely) event that carbon pricing were imposed on top of unreformed subsidies (although both countries have since been scaling back these subsidies).

\section{Fiscal Considerations}

Besides environmental impacts, carbon pricing also raises substantial amounts of revenue, for example, the carbon prices shown in figure 3.3 would have raised estimated revenues averaging 1.9\% of GDP across the top 20 emitters in 2010 (Parry, Veung, and Heine, 2014). This raises the issue of whether-leaving aside environmental benefits-raising these revenues from carbon pricing imposes lower costs on the economy than raising them through broader fiscal instruments. If so, fiscal considerations constitute another reason that carbon pricing is in countries' own domestic interests.

The combined effect of broader fiscal instruments, including personal income taxes, payroll taxes, corporate income taxes, and general consumption taxes, is to distort the economy in two main ways. First, they reduce the overall level of economic activity by reducing real factor returns, thereby deterring work effort and investments in human and physical capital. Second, they distort the composition of economic activity by shifting activity to the informal sector and promoting excessive spending on tax favored goods (e.g., housing, untaxed fringe benefits). In measuring the efficiency costs of broader taxes, it is standard to capture (in a reduced form way) both types of distortion by estimating the responsiveness of the tax base to higher tax rates (e.g., Saez et al., 2012).

Carbon taxes interact with these broader distortions from the fiscal system in two ways. First, using the revenues from carbon pricing to cut the rates of broader taxes produces efficiency gains-termed the "revenuerecycling effect" - and a key theme of the literature is that these efficiency gains are relatively large, so forgoing them (e.g., through using revenues for low value spending or giving away free allowances in trading systems) greatly increases the overall costs of carbon pricing for the economy (e.g., Parry, Williams, and Goulder, 1999). Second, by increasing energy prices and thereby reducing overall economic activity, carbon taxes tend to compound some of the distortions created by broader taxes-the "taxinteraction effect." 
Up to a point, the revenue-recycling effect tends to dominate the taxinteraction effect, implying a negative cost from carbon tax shifts. This is because cutting broader taxes alleviates distortions both in the overall level of economic activity and its composition, whereas (loosely speaking) higher energy prices compound distortions to the level of economic activity but not its composition. The prospects for negative costs are greater when the composition effect accounts for a substantial portion of the overall efficiency costs of broader taxes, which can apply to countries with large informal sectors (many developing countries) or with large preferences in the tax code (e.g., the United States). ${ }^{11}$ However, accurately quantifying the efficiency gains from carbon tax shifts, and at what carbon price the incremental efficiency impact changes from positive to negative, is hampered by a lack of systematic empirical work across countries on the absolute efficiency costs of broader taxes and the relative contribution of the level and composition effects. Nevertheless, some rough calculations in Parry, Veung, and Heine (2014) suggest that the efficiency gain could, for some countries, be as large as the efficiency benefits from addressing domestic environmental benefits.

\section{The Bottom Line}

The bottom line from the above discussion is that many countries can start the process of fulfilling their emissions mitigation pledges for the Paris Agreement through unilateral carbon pricing that addresses local (environmental and fiscal) needs while also contributing to relieving a global problem-it is not necessary to wait for other countries to act on carbon pricing.

Viewed another way, once an international agreement to enhance and strengthen domestic initiatives has been implemented, it might be a little less challenging to enforce it than previously thought because countries make themselves worse off by reneging on the agreement. The costs of reneging to the general public might be highly visible, for example, in the form of more severe air pollution in emerging market economies, where urban residents see and deal with the health effects of polluted air on a daily basis and air pollution statistics are routinely reported, or in the form of higher direct and indirect taxes that might be needed to compensate for scaling back a large revenue stream from carbon pricing.

But what form should such an international agreement take? 


\section{The Rationale for, and Design of, Carbon Price Floor Arrangements}

\section{Rationale}

Underpricing from an international perspective is familiar from situations where countries compete for mobile tax bases, in which context some progress has been made through tax agreements, for example, in the European Union for value added taxes and excises on alcohol, tobacco, and energy products. A key lesson here is that it seems easier for countries to agree on tax floors than tax rates, not surprisingly given, for example, heterogeneity among countries in the public health benefits from these taxes (depending on the prevalence of smoking, alcohol abuse, etc.), their fiscal needs, and the political acceptability of higher taxes.

The carbon pricing analog would be a coordinated $\mathrm{CO}_{2}$ price floor among a coalition of willing countries, which could be pursued alongside the Paris process. This arrangement would provide some degree of protection for industries competing with imports from other countries that are party to the agreement and some protection against free-riding and crossborder fuel smuggling. Yet individual countries could set prices exceeding the floor, which is efficient if they have relatively high domestic environmental benefits or fiscal needs. More generally, the political acceptability of carbon pricing differs considerably across countries, and those countries willing and able to set higher prices should not be held back. In contrast, linked emissions trading systems (in their pure form) impose a uniform price across participating countries, and policies (e.g., the UK carbon tax floor) to raise the overall domestic carbon price in one country will only reduce allowance prices without any effect on system-wide emissions, which are fixed by the regional cap.

\section{Design Practicalities}

A carbon price floor agreement could initially be negotiated among a limited number of willing (preferably large emitting) countries and progressively expanded over time with additional participants. ${ }^{12}$ The arrangement could accommodate both countries with carbon taxes and with trading systems, although in the latter case the systems would need to have explicit mechanisms that permanently withdraw allowances from the system to prevent the price falling below a target level. ${ }^{13}$ 
One challenge is how to account for idiosyncratic, special provisions among countries with carbon pricing programs, such as exemptions or reduced rates for influential or vulnerable sectors. Another is how to account for changes in existing energy taxes or subsidies that can enhance or offset the emissions impact of a direct price on carbon.

In principle, both challenges could be addressed through monitoring "effective carbon prices," which convert direct carbon pricing programs and existing taxes/subsidies on fossil fuel products, electricity, and possibly other products (e.g., vehicles) into an aggregate carbon price. This involves converting all carbon pricing schemes and broader energy taxes/subsidies into an economy-wide average carbon price equivalent. For a carbon price scheme with incomplete coverage, the price needs to be weighted by the fraction of emissions reductions that would come from the covered sector under economy-wide pricing. ${ }^{14}$ For broader taxes/subsidies on energy products, these should be converted to carbon price equivalents by dividing the tax/subsidy rate by $\mathrm{CO}_{2}$ emissions per unit of the product and then weighting by the share of reductions that would come from that product under economy-wide carbon pricing. ${ }^{15}$

Figure 3.4 shows some calculations of effective carbon prices across selected countries for 2010. The calculations are highly simplified-just accounting for taxes/subsidies on fossil fuel products ${ }^{16}$ —and somewhat outdated (e.g., Mexico and Indonesia have since scaled back fuel subsidies), but the main point here is that effective carbon prices differ substantially across countries. For example, effective $\mathrm{CO}_{2}$ prices are relatively high (more than $\$ 40$ per ton) in France, where road fuels account for a relatively high share of nationwide emissions and there are already high road fuel excises, but effective carbon prices are below $\$ 10$ per ton in most other cases. Given such wide dispersion, achieving convergence in effective carbon prices is likely impractical. But nor is it desirable, as fuel taxes may in part be addressing domestic environmental and fiscal needs rather than $\mathrm{CO}_{2}$ emissions.

Instead, an agreement might focus on raising effective carbon prices in each country by a target amount (e.g., \$20 per ton in 2020 and $\$ 70$ per ton by 2030) relative to the effective price in that country in a (previous) baseline year. Effective carbon prices would need to be independently assessed and consistently measured across countries, although the practicalities should be manageable once countries have agreed to analytical conventions (e.g., over fuel price responsiveness assumptions). 


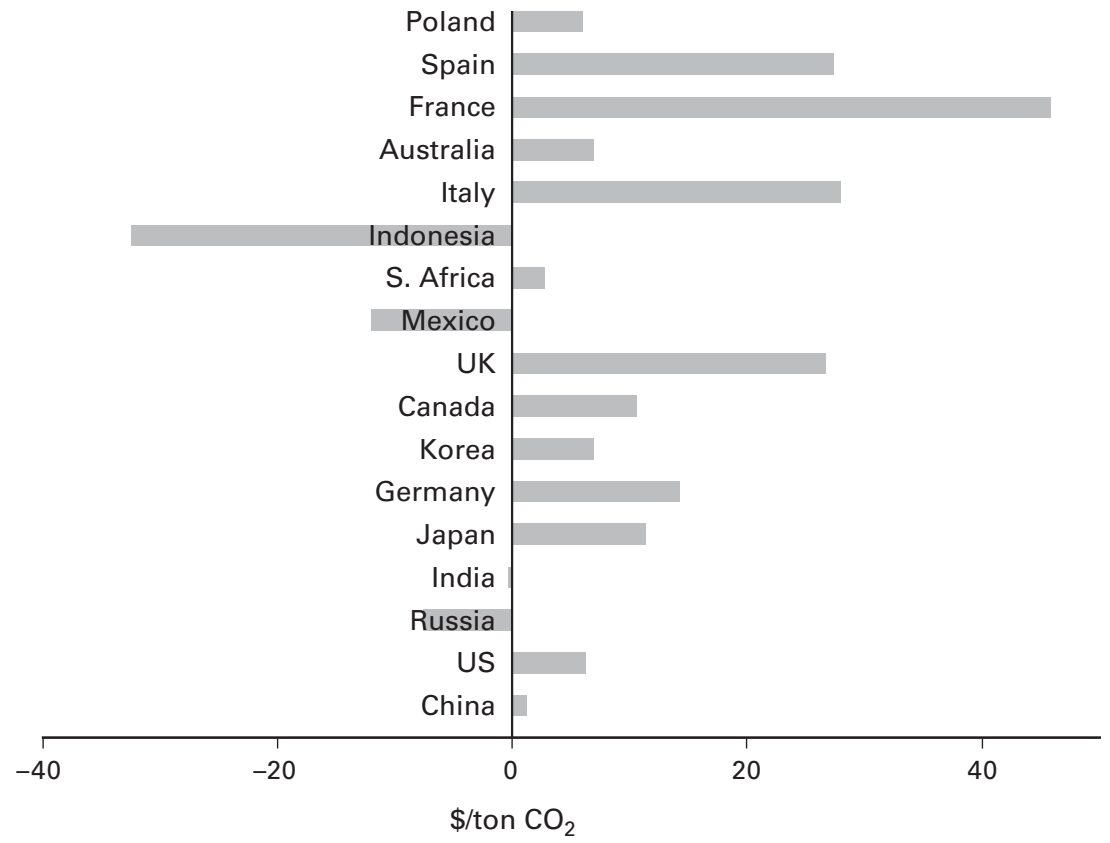

Figure 3.4

Effective Carbon Prices, Selected Countries 2010

Source: Author's calculations using data compiled in Parry, Veung, and Heine (2014).

\section{Conclusion}

This chapter pushes back on two notions about global carbon policy implied by economic models that do not account for noninternalized, noncarbon externalities in fossil fuel markets and broader distortions to economic activity from the fiscal system.

The first is the rather pessimistic notion that acting unilaterally on carbon pricing inevitably makes an individual country worse off, and, as a consequence, meaningful progress on carbon pricing will not occur until a pricing agreement among large emitters with credible enforcement mechanisms is in place. In contrast, this chapter argues that carbon pricing is in many countries' own national interests when account is taken of noninternalized local externality benefits, which (up to a point) exceed domestic mitigation costs. Fiscal considerations reinforce this argument to the extent that the efficiency costs of raising revenues from carbon pricing are initially 
lower than those for broader fiscal instruments (when the full range of distortions created by the latter are properly considered).

It is not inconceivable that policymakers can get these important but arcane-sounding points across to stakeholders with more accessible messages about estimated lives saved from breathing healthier air, improvements in their international urban air quality rankings, specific commitments to cut burdensome taxes or address underinvestment in hospitals, schools, and infrastructure, with the proceeds from carbon pricing, and so on. In this way, significant headway on carbon pricing at the local level might be made, whereas at the international level policymakers and organizations continue dialogue on the practicalities of coordinated regimes for eventually building on local pricing initiatives.

The second notion is that the long-term goal should be a uniform global carbon price. That has always looked impractical, given the principle of common but differentiated responsibilities, and the reluctance (especially in current times of historically high fiscal pressures) of advanced countries to transfer large side payments to developing countries that might otherwise be unwilling to impose the same carbon price. A key point from the current chapter is that a globally uniform carbon price is not economically efficient either, given the wide dispersion across countries in the magnitude of noncarbon externalities from fuel use and the dim prospects as far as the eye can see for perfectly internalizing them through other pricing policies, as well as differences in the efficient amount of carbon pricing from a fiscal perspective.

In short, there are both pragmatic and economic arguments for flexible international regimes built around carbon price floor arrangements. Discussions about these regimes should be welcomed by delegates to the annual UN Framework Convention on Climate Change meetings because they would complement and strengthen the mitigation commitment process already initiated by the landmark 2015 Paris Agreement.

\section{Appendix: Procedures for Measuring Domestic Environmental Externalities}

\section{Air Pollution Damages from Coal Plants}

Parry, Heine, Lis, and Li (2014) used four main steps to quantify the air pollution damage from coal plants. 
First, data on the geographical location of coal plants in different countries was mapped to granular data on the number of people living at different distance classifications from each plant (up to 2,000 km away, given the potential long-range transport of emissions from tall smokestacks). These data are used to extrapolate "intake fractions" - the average portion of a particular pollutant that ends up being inhaled (as fine particulates) by exposed populations-for different pollutants, from a widely cited study for China, adjusting for population exposure in other countries relative to that in China. Although this approach does not account for differences in meteorological conditions (e.g., wind speeds) between other countries and China, which affects regional pollution formation, some cross-checks with air quality models in a limited number of cases suggest the bias from omitting these factors is not necessarily large and does not follow a systematic pattern.

The second step is to obtain elevated mortality risks by country from additional pollution emissions by linking intake fractions to two pieces of information from the World Health Organization's Global Burden of Disease project. One is baseline mortality rates in different regions for illnesses (heart, pulmonary and lung diseases, and strokes) whose prevalence is increased by exposure to pollution. ${ }^{17}$ The other is evidence on the relationship between pollution exposure and additional mortality risk, or "concentration-response" functions. ${ }^{18}$ One noteworthy issue here is that, although at lower pollution concentrations the concentration-response function is approximately linear, some (although not all) evidence suggests it may flatten out at especially severe concentration levels as people's channels for absorbing pollution become saturated. Paradoxically, this would imply (given other factors) lower marginal environmental benefits for small pollution reductions in severely polluted regions-this possibility is not taken into account in the estimates presented here.

The third step is to monetize mortality risks. For this purpose, Parry, Heine, Lis, and Li (2014) use estimates of the value per premature mortality for the average OECD country (\$3.7 million, updated to 2010) and the elasticity of mortality valuation with respect to income (0.8) - both based on the literature-to extrapolate mortality values for all countries.

The final step is to convert damages per ton of emissions into damages per unit of coal use using a country-level database of coal plant air emissions factors compiled by the International Institute for Applied Systems 
Analysis. The results presented earlier are based on those for a representative sample of plants with emissions control technologies and are therefore lower than the industry average emission rates (the latter including plants with no control technologies), a possible justification being that industry average emission rates will gradually converge to the former over time as older, dirtier plants are retired from the fleet.

\section{Air Pollution from Other Sources}

The same steps as discussed previously were used to assess environmental damages for natural gas used in power generation.

Local air emissions from ground-level sources-principally vehicles and residential heating-tend to stay locally concentrated (rather than being transported long distances), which simplifies assessment of their intake fractions. Parry, Heine, Lis, and Li (2014) obtain (from other studies) ground-level intake fractions for air emissions from more than 3,000 cities, extrapolate these to the country level, and then follow the three steps mentioned previously.

\section{Other Motor Vehicle Externalities}

In the absence of better data, Parry, Heine, Lis, and Li (2014) regress travel delays from a city-level database on various transportation indicators and then extrapolate delays to the national level using the regression coefficients and country-wide measures of those same indictors. Marginal delay (the delay one extra kilometer driven in one vehicle imposes on other road users) is assumed to be four times the average delay, loosely based on specifications commonly used by transportation engineers. The result is scaled by vehicle occupancy and monetized based on literature, suggesting the value of congested travel time is around $60 \%$ of the wage. These estimates likely understate marginal congestion costs; for example, cars impose greater delay to other road users when buses (which have high vehicle occupancies) are a significant share of vehicles on the road.

Parry, Heine, Lis, and Li (2014) estimate accident externalities by country using data on people killed in traffic accidents and assumptions about the decomposition between internal and external risks, for example, injury risks to occupants in single-vehicle collisions are assumed to be internal, whereas risks to pedestrians/cyclists and a portion of injuries 
in multivehicle collisions are taken to be external. Other components of external costs (e.g., medical and property damages borne by third-parties, a portion of nonfatal injuries) are extrapolated from several country case studies. Road damage costs, which apply to heavy (diesel) vehicles, are obtained from data on road maintenance expenditures (where it is available and extrapolated from other countries where it is not) and assumptions about the portion of wear and tear due to vehicle traffic as opposed to other factors such as climate.

Mileage-related externalities (congestion, accidents, road damage, and local pollution where emissions regulations are expressed on a per mile basis) are scaled back by around 50\% in computing Pigouvian taxes, given that only about half of the long run reduction in fuel use from higher road fuel taxes comes from reductions in vehicle mileage (the other half coming from long-run improvements in average fleet fuel economy, which essentially have no effect on mileage-related externalities).

\section{Notes}

1. Other mitigation instruments - coal taxes, emission rate standards for power generation, clean fuel subsidies, and so on-may also have domestic environmental benefits. However, there is broad acceptance among analysts, governments, and businesses that carbon pricing is (by far) the most efficient instrument for reducing $\mathrm{CO}_{2}$ emissions (see http://www.carbonpricingleadership.org/carbon-pricing-panel). To maintain a tight focus, the discussion here is limited to carbon pricing.

2. The discussion in this subsection draws from Parry, Veung, and Heine (2014).

3. See Parry, Heine, Lis, and Li (2014).

4. For example, Harberger (1964).

5. The latter is drawn as perfectly elastic, which is generally reasonable with internationally integrated fuel markets.

6. See Clements et al. (2013) and Coady et al. (2015).

7. These are well established and (per unit of energy for coal and natural gas and per liter for petroleum products) vary little across countries.

8. Parry, Veung, and Heine (2014) used price elasticities of -0.25 for coal and natural gas and -0.5 for road fuels for each country. Although elasticities are uncertain and will vary somewhat across countries, typically the estimates of nationally efficient carbon prices are only moderately sensitive to different assumptions. For example, if coal is more price-responsive, it will tend to raise the nationally efficient carbon 
price through increasing the share of $\mathrm{CO}_{2}$ reductions coming from coal, which generally has relatively high domestic environmental costs.

9. The database is available at http://www.imf.org/environment.

10. As noted in the appendix, air pollution damages are conservatively estimated in the sense that emissions rates are based on those at representative plants with emission control technologies rather than the industry average (which is higher due to the inclusion of other plants without control technologies).

11. See, for example, Parry and Bento (2000) and Bento et al. (2012).

12. Starting out with a limited number of countries should improve prospects for an agreement. For example, the European Energy Tax Directive specifying minimum taxes for fuels outside of the EU emissions trading system was implemented just prior to the large expansion in the number of EU member states. Later attempts to reform the Directive have stalled due to the difficulty of reaching agreement among many member states with highly divergent priorities.

13. The agreement could be made even more flexible by allowing countries to fall short of the price floor in a particular year providing they purchase sufficient carbon credits from countries exceeding the floor price (see Cramton et al., chapter 12, this volume).

14. For example, if a carbon price is applied to the power and large industry sector and this sector accounts for $50 \%$ of $\mathrm{CO}_{2}$ emissions, but (due to relatively low cost mitigation opportunities) $75 \%$ of the $\mathrm{CO}_{2}$ reductions that would occur under economy-wide pricing, then the carbon price should be weighted by 0.75 rather than 0.5 .

15. For example, if electricity generation accounts for $40 \%$ of economy-wide $\mathrm{CO}_{2}$ emissions but reductions in electricity demand would account for only $10 \%$ of $\mathrm{CO}_{2}$ reductions under economy-wide carbon pricing, then any tax on electricity use (which only reduces emissions through reducing electricity demand) should be weighted by 0.1 rather than 0.4 .

16. See Organization for Economic Cooperation and Development (2015) for a more sophisticated treatment.

17. Mortality rates are relatively high in Eastern Europe, where there is high consumption of alcohol and tobacco, and relatively low in African countries, where people are more prone to dying from other non-pollution-related diseases.

18. The key assumption here is that each 10 microgram/cubic meter increase in fine particulate concentrations increases all-cause mortality risks by $10 \%$, which is similar to assumptions used in modeling by the US Environmental Protection Agency. 


\section{References}

Bento, A., M. Jacobsen, and A. A. Liu. 2012. Environmental Policy in the Presence of an Informal Sector. Discussion paper. Ithaca, NY: Cornell University Press.

Clements, B., D. Coady, S. Fabrizio, S. Gupta, T. Alleyene, and C. Sdralevich, eds. 2013. Energy Subsidy Reform: Lessons and Implications. Washington, DC: International Monetary Fund.

Coady, D., I. Parry, L. Sears, and B. Shang. 2015. How Large Are Global Energy Subsidies? Working Paper 15/105. Washington, DC: International Monetary Fund.

Harberger, A. C. 1964. The measurement of waste. American Economic Review 54:58-76.

Organization for Economic Cooperation and Development. 2015. Taxing Energy Use 2015: OECD and Selected Partner Economies. Paris, France: OECD Publishing.

Parry, I. W. H., and A. M. Bento. 2000. Tax deductions, Environmental policy, and the "double dividend" hypothesis. Journal of Environmental Economics and Management 39:67-96.

Parry, I. W. H., R. C. Williams, and L. H. Goulder. 1999. When can carbon abatement policies increase welfare? The fundamental role of distorted factor markets. Journal of Environmental Economics and Management 37:52-84.

Parry, I. W. H., C. Veung, and D. Heine. 2014. How Much Carbon Pricing is in Countries' Own Interests? The Critical Role of Co-Benefits. Working Paper 14174. Washington, DC: International Monetary Fund.

Parry, I. W. H., D. Heine, S. Li, and E. Lis. 2014. Getting Energy Prices Right: From Principle to Practice. Washington, DC: International Monetary Fund.

Saez, E., J. Slemrod, and S. H. Giertz. 2012. The elasticity of taxable income with respect to marginal tax rates: A critical review. Journal of Economic Literature 50:3-50.

US Inter-Agency Working Group. 2013. Technical Update of the Social Cost of Carbon for Regulatory Impact Analysis Under Executive Order 12866. Washington, DC: US Inter-Agency Working Group. 


\section{Global Carbon Pricing}

Peter Cramton, Axel Ockenfels, and Steven Stoft*

\section{Why Is Cooperation So Important? ${ }^{1}$}

\section{Narrow Self-Interest}

Do we need cooperation? The $2^{\circ} \mathrm{C}$ goal, or even more ambitious goals, could be met purely due to national self-interests if technological progress is fast enough-if the price of nonfossil energy falls quickly enough relative to the price of fossil energy - and if countries would rationally address the domestic damage being done by greenhouse gas emissions. It has been suggested that this will be the case, and so the only real problem is getting countries, such as the United States, to recognize and act in their self-interest (for a discussion of this view, see Cooper et al., chapter 1, this volume; for an example, see Green, 2015).

Of course, it would be convenient if technology is about to allow humankind to achieve its goals through pure self-interest. Such a technology miracle would imply that no transfers from rich to poor will be needed (although they would still be laudable). Also, no additional round of negotiations would be necessary to ratchet up agreements. The reason is that there is no need for agreements to get countries to do what is in their narrow self-interest. International education might be necessary, but we do not make international agreements to provide city parks or clean drinking water, public goods that present no international free-rider problem.

However, no one in Paris seemed to believe either of these conclusions, which would follow from the assumption of a timely technology rescue. Indeed, no one has offered any proof of such a miracle. Actual

* Ockenfels thanks the German Research Foundation (DFG) for financial support through the Research Unit "Design \& Behavior" (FOR 1371). 
developments, plans, and behaviors suggest that there is no relief in sight, but that we should rather expect the opposite: a continuing global "coal renaissance" together with increasing greenhouse gas emissions (Covert et al., 2016; Edenhofer and Ockenfels, chapter 9, this volume; Edenhofer et al., 2016).

There are more reasons that the world's nations will need to cooperatively take individual costly actions to achieve the greater collective benefit that will result from meeting (or at least coming closer to) the Paris objectives. It is true that $\mathrm{CO}_{2}$ abatement policies to address local pollution can help mitigate global warming. But the damages from local pollution and global warming due to $\mathrm{CO}_{2}$ emissions are additive. That is, if a country suffers a local negative externality equivalent to $\$ 60 /$ ton of $\mathrm{CO}_{2}$ and the negative climate externality is $\$ 50 /$ ton, a carbon price of $\$ 60 /$ ton is not optimal. Instead, only a carbon price of $\$ 110 /$ ton would efficiently address both externalities. So, even if all countries abate to fully address domestic pollution, they would not sufficiently address climate change. This is independent of technological progress-unless and until self-interest takes us to a corner solution where the negative climate externality vanishes.

In other words, narrow self-interest in local pollution issues will always provide too little mitigation incentive by the exact amount of the negative climate externality at every point in time. Also note that $\mathrm{CO}_{2}$ causes no local externalities whatsoever, so local incentives are helpful only to the extent that $\mathrm{CO}_{2}$ continues to correlate with other pollutants such as particulates and $\mathrm{SO}_{2}$. This means that technology may gravitate toward solutions, such as scrubbers and natural-gas substitution, which target the local pollutants and have a limited or even at times a negative impact on $\mathrm{CO}_{2}$ mitigation. Furthermore, history indicates that local pollution has been significantly undermitigated, especially in the early stages of economic development. So even in the case where narrow self-interest should be sufficient, realism would suggest a cautious approach.

Besides climate, an additional international externality calls for cooperation on carbon abatement. In a global economy, unilateral abatement reduces a country's competitiveness (and, by related mechanisms, often comes with carbon leakage effects), so that it is, in fact, not in a country's self-interest to fully address local pollution. Regardless of how one looks at this: narrow self-interest is unlikely to solve the climate dilemma, although it can certainly provide climate benefits and help with kick-starting global 
carbon pricing. In other words, self-interest can be part of the solution as well as the central problem.

\section{Ambition and Aligned Self-Interest}

Christiana Figueres called 2014 the Year of Climate Ambition. Ten thousand UNFCCC web pages tell us that ambition is essential for a strong agreement. The UNFCCC newsroom informs us that developed countries are expected to lead the global drive to raise ambition. Ambition is what we want. But how do we get it if narrow self-interest is not enough?

Elinor Ostrom, a political scientist, won the 2009 Nobel Prize in economics for a lifetime studying "common-pool resource dilemmas" (such as global warming). She worked in the field, analyzed a thousand field studies by others, did game-theory experiments, and developed her own theories. She never mentions ambition. Instead, in her report on climate policy to the World Bank (Ostrom, 2009), she says her research on collective action identifies a "necessary central core of trust and reciprocity."

Indeed, reciprocity is what changes self-interest. I will do X for you if you do $\mathrm{Y}$ for me. It is not in your self-interest to hand $\$ 20$ to your local cleaners. and it is not in their self-interest to clean your coat. But if you want your coat cleaned and they tell you that would cost $\$ 20$, then you may well decide to change their self-interest and make them want to clean your coat. Or perhaps that's too much money. So you may negotiate to see whether you can change their self-interest at a lower cost. You are good at changing the self-interest of others.

It's trickier for a group to change its self-interests. That requires a special form of reciprocity, a common commitment. I will do $\mathrm{X}$ if all of you also do $X$. (Of course, $X$ can be a rule that takes circumstances into account in the same way for all players.) It's trickier still when there is no government to organize or enforce the common commitment. But we know it's possible. Ostrom's (2009) central point is that people can self-organize what she calls "self-governance" when there is no government to do it for them. ${ }^{2}$

All disciplines dealing with human cooperation find that the reciprocity of a common commitment-I will if you will—is the key principle underlying collective human cooperation. Ostrom goes on to note that, "Trust and reciprocity are mutually reinforcing. A decrease in either can generate a downward cascade leading to little or no cooperation" (Poteete et al., 2010). In other words, insufficient reciprocity will not lead to an "upward spiral of 
ambition," ${ }^{3}$ as is hoped for with "pledge-and-review" (the approach exercised in Paris). This is the crucial lesson for international climate policy after Paris: ambitious aspirations mean little, and trust cannot be legislated, but reciprocity can be designed into a treaty. If that design is effective, then trust will follow, and then ambition.

This chapter, and this book, is about how to design a climate treaty that builds on reciprocity.

The Paris approach omitted built-in reciprocity. So it leaves out Ostrom's (2009) "necessary central core." The consequence is that the "Intended Nationally Determined Contributions" (INDCs) submitted in Paris are far from being ambitious enough to solve the climate dilemma, and there is no hope that, without a reciprocal, common commitment, pledge-andreview will succeed (Cooper et al., chapter 1, this volume). This is one conclusion of every chapter in this book. Instead of ambition, the chapters collected here focus on designs that, when put into practice, produce reciprocity.

What Ostrom (2009) and many others find in every successful cooperative system are rules governing everyone's contributions to, and use of, the common resource, as well as penalties for breaking those rules. These rules and penalties are the reciprocity mechanisms, and they build trust. Exhortation to be ambitious is helpful but not enough. Common rules and sanctions for breaking them are required in real-world settings. ${ }^{4}$

\section{Free-Riding and Cooperation}

The atmosphere is a common-pool resource, a type of public good, and so it is susceptible to overuse. It's a global public good. But imagine for a moment that it was not. Imagine that the United States could only damage its own climate and the same for other countries. What would change? We would still need climate science. But there would be no reason for international negotiations. There would be no reason for any other country to be upset with US or Chinese emissions because they would not affect anyone else. Domestic pollution and domestic climate change could be addressed fully by narrowly self-interested countries.

So, the reason for international negotiations is the public-goods nature of the atmosphere. The essence of a common-pool resource is that everyone has access to the common pool, and hence all can overuse it to their own 
benefit and to the detriment of others. This is the definition of free-riding. So the only reason that international negotiations over ambition levels are needed, or make sense, is because of free-riding.

Deniers of Free-Riding Sometimes we have noticed climate advocates denying the importance of free-riding. One reason given is that climate deniers make use of the free-riding argument. But your opponent's use of a fact does not make the fact wrong.

Another reason for dismissing the importance of free-riders is a simple lack of understanding. One highly placed climate policy expert has argued that free-riding means doing little and expecting to "benefit sufficiently from other countries' mitigation." The expert then pointed out that there is currently not much action from which to benefit. In other words, if there are few actions to free-ride on, then free riding can't be a big problem.

This is backward. The main characteristic of the most severe free-rider problem is that when we all try to free-ride, there is no one left to give rides. In the most severe version of the free-rider problem, there is no free-riding!

But this confusion runs even deeper. The destruction of trust is the most pernicious aspect of free-riding. It causes those with no inclination to freeride to act just like free-riders. This is the insidious mechanism that causes the unraveling of cooperation. Here's one way that could happen.

One Bad Apple Spoils the Bunch Consider 10 equal countries, nine of which do not want to free-ride but also don't want to be taken advantage of. However, one nice but poor country (a "classic" free-rider) will not cooperate even if others do their part. Also suppose that:

- One country will tolerate no defecting (free-riding) countries

- One will tolerate one defector

- One will tolerate two defectors

- And so on down to the most tolerant country that will tolerate eight defectors.

What happens? Well, the classic free-rider country defects, so the zerotolerance country defects, so two have now defected, and the country that 
will only tolerate one defector defects, and so on down to complete unravelling. Although only 1 in 10 was a free-rider in the classic sense of wanting to do nothing, disaster ensued. Also notice that, in the end, no one had anyone to free-ride on, even though free-riding was what caused the whole problem.

This example has only one equilibrium-no cooperation. A common commitment by itself will not fix this version of the problem because the poor country would not be willing to sign any commitment that involves ambitious contributions by everyone. But a common commitment that included a green climate-fund payment to the poor country could well work and achieve total cooperation. So reciprocity could overcome free-riding.

In other examples, everyone will cooperate if enough others cooperate. But the world can still get stuck with no cooperation if there's no trust to start with. But then all it takes is a common commitment to serve as a coordinating mechanism to shift everyone from no cooperation to full cooperation.

Not Being a Sucker Ostrom (2009) described another aspect of the problem in her climate report to the World Bank. "When participants fear they are being 'suckers' for taking costly actions while others free-ride, more substantial effort is devoted to finding deceptive ways of appearing to reduce emissions while not doing so." This is what pledge-andreview will lead to. The free-rider problem is so essential that at the start of her classic book, Governing the Commons, she defines her "central question" as finding out "how a group ... can organize and govern themselves to obtain continuing joint benefits when all face temptations to free-ride."

These are not theoretical judgments. For example, as Ostrom (2009) reported, in Törbel, Switzerland, the common-commitment rule is "no citizen can send more cows to the alp than he could feed during the winter," and this is still enforced by "substantial fines for any attempt by villagers to appropriate a larger share of grazing rights." Those two reciprocity mechanisms prevent free-riding and generate trust. There are numerous other field studies like this. 
What the US Senate Understood During the Kyoto negotiations, developing countries said "you go first" to the others. The US Senate voted 95 to 0 to say, in effect, "No. You must come along with us. You can't free-ride." Even if this is not what the senators were thinking, there is a profoundly true message in that unprecedented vote. The message is, "Make a reciprocal deal we can trust."

Some claim the senators' expressions of concern were a cover for baser motives. But suppose that was true of all 95 senators. No one is more calculating and no one listens to the electorate better than professional politicians. When they calculate the same answer 95 to 0 , you'd be a fool not to listen. This is what they understood:

Americans have a powerful and abiding fear that they will be taken advantage of in the international arena. They don't trust "foreigners." So do not depend on their altruistic cooperation. They want a reciprocal deal they can trust.

That is the message of the Senate's vote on Kyoto. That is not just what the senators said, that is what they were betting their careers on.

In 2015, the main argument in the United States against the Iran nuclear treaty is, "You can't trust Iran" or any of our partners in the negotiationsChina, France, Russia, the United Kingdom, and Germany. Nothing has changed. But the United States is hardly alone in this. During the 2009 Copenhagen climate negotiations, China became convinced and angry that the United States, Europe, and other developed countries were actively trying to turn the developing world against it.

Similar issues came up in Paris. Japan's Paris pledge has been attacked by the Climate Action Network, a network of more than 950 nongovernmental organizations (http://www.climatenetwork.org/fossil-of-the-day). They claim that Japan is "using smoke and mirrors (shifting baselines) to fake ambition." That's a claim of free-riding. China's pledge is for slightly less than what they found they needed to do to curb domestic pollution (http:// climateparis.org/china-emissions-pledge). When they announced it, they made no claim that it was motivated by concern for the climate. This may be free-riding or fear of it. But we are not blaming China; it's just what one should expect from rational players who have no good reason to trust other players.

Those advocating national climate policies face climate-change deniers pointing out that other countries could free-ride on our efforts. In defense, 
they tend to deny the free-rider problem and make up baseless theories, such as $\mathrm{Al}$ Gore's notion that, "If we lead, China will follow." In the long run, it will be far more constructive to solve the free-rider problem-the most central problem of cooperation-rather than deny there is a problem. Solving the free-rider problem is the heart of the solution proposed in this volume.

\section{The Problem and the Solution}

For 20 years, almost all climate negotiators have agreed on the need for strong climate-change mitigation. Even before Paris, there was a strong consensus that $2^{\circ} \mathrm{C}$ should be the goal. But this aspiration has not been translated into commitments and actions.

\section{The Problem}

The real problem is not the climate or the lack of climate-science knowledge, and it's not the lack of a common aspiration or goal-Paris achieved that. It's not even the lack of blueprints for global action. The trouble is that negotiations end in acrimony or hollow victory statements. Paris was not different in that respect. So the problem is to find and fix the cause of these negotiation failures.

A better approach to negotiation is needed, and so we have made "how to negotiate" the focus of this book. This focus requires a distinction often overlooked. Two things matter most to the success of a negotiation: what outcome you aim for and how you go about getting there. Everyone knows this, but it is easier to focus on what you want than on how to structure the negotiations. So the "how" part is usually ignored and almost never analyzed systematically. In fact, the "how" part is so important that Weitzman (2014, chapter 8, this volume), Cramton and Stoft (2012a, 2012b), and Cramton et al. (chapter 12, this volume) argue it is decisive. But "what" and "how" are interrelated, and that just adds to the tendency for the "how" part to be forgotten.

Consider free-riding. As discussed in the previous section, an agreement that makes free-riding attractive will break down. As Ostrom (2007, p. 201) explains, it will "generate a downward cascade leading to little or no cooperation." But she is not concerned with how to negotiate, so this is purely a consideration of what works. But if negotiators see that an agreement allows 
free-riding, it is hard to negotiate a strong commitment within that framework. So the potential to free-ride-the "what" part-affects the negotiation process-the "how" part.

This is not a general principle. A treaty that will work poorly may be easy to negotiate because it demands little, whereas one that would solve the problem brilliantly may be impossible to negotiate because of coordination problems-parties can't agree on who should play which role.

Also, an agreement must cover three separate areas-abatement, burden sharing, and enforcement. It must get the "what" and "how" parts right in each area. But to avoid being too ambitious, we will only briefly speak to enforcement and leave that question mostly to Nordhaus (chapter 7, this volume). It is important to note, however, that enforcement is not a substitute for a common commitment but rather a complement (see MacKay et al., 2015). This leaves the two closely related areas: abatement and burden sharing. The challenge is to find a treaty design that solves the free-rider problem for abatement and the fair burden-sharing problem, as well as to find a way to negotiate the two solutions that will lead to a strong treaty and not to a deadlock or weak commitments.

\section{The Pledge-and-Review Non-Solution}

Pledge-and-review was first proposed by Japan in a memo to the UNFCCC in 1991 and was much discussed starting in 1992. It was the model for the Paris Agreement. Intended Nationally Determined Contributions (INDCs) are the pledges, and these will be reviewed and, it is hoped, upgraded occasionally. These are individual commitments, not common commitments, and so they do not address free-riding. But the situation is actually much worse than this statement implies.

The Kyoto Protocol was based on individual commitments, too, but all countries committed to some percentage (not a common percentage) of emission reduction below their 1990 emissions level. These commitments provided some hope of comparability. But the Paris pledge-and-review commitments are quite free-form even for developed countries and entirely free-form for developing countries. Hence, they are essentially impossible to compare.

Being both individual and noncomparable opens the door wide to freeriding. Many countries will do their best to either lock in a free-ride or prevent others from free-riding on them. Either strategy results in weak 
pledges. Hence, this approach will fail. For further discussion of actual outcomes in Paris, see Cooper (chapter 5, this volume) and the references cited therein. For a further general discussion of why individual commitments will fail to solve the climate dilemma, see Cramton et al. (chapter 12 , this volume), Weitzman (chapter 8 , this volume), and Gollier and Tirole (chapter 10, this volume).

\section{Problems with Cap-and-Trade}

Global cap-and-trade is likely the oldest of the three major approaches (global carbon pricing, pledge-and-review, global cap-and-trade), although the early (standard) versions were not global and worked quite differently. There are variations of global cap-and-trade, but for simplicity we will mostly adhere to the most up-to-date one, presented by Gollier and Tirole (chapter 10, this volume).

This approach first negotiates a global cap, $Q$, which is a quantity limit on emissions. However, no country is responsible for it, and at this stage, nothing has been decided about how to share responsibility for it. So what looks like simplicity has likely left us in a worse negotiating predicament than the one faced by the Kyoto negotiations. In Kyoto, countries just signed up for whatever abatement reduction they wanted. So naturally they reached agreement, just as they did in Paris with INDCs. However, that would not likely work under this global cap-and-trade approach because voluntary pledges probably would add up to more than the agreed $Q$. It is easy to be ambitious for the group when choosing $Q$, and again it is easy to allocate to your own country a lot of permits and explain that others should be taking fewer.

To solve this problem, it is necessary to agree on a formula for allocating any $Q$ that the players select. Weitzman (chapter 8, this volume) explains why this is nearly impossible, and we examine the 20-year search for such formulas and find that little progress has been made. Moreover, because the formula is negotiated after $Q$ is chosen, every country will evaluate the formula by computing its share of $Q$ under the formula and judging the formula on that basis. This will make a successful negotiation even more difficult than choosing a formula first (as was tried unsuccessfully in Kyoto).

There are many reasons that agreeing on a formula is difficult. There is no agreeable focal point for a "fair" allocation of $Q$ to all countries. Moreover, 
with this mechanism, assuming that the global $Q$ is actually credible, there is no built-in reciprocity that might help to discipline countries: the "I will do more if you do more" principle is not applicable because in the constant-sum-game that is being played when allocating a fixed $Q$ to many countries, "I will actually do less if you do more." The best strategy in this kind of game, even when players would in principle be willing to reciprocate others' cooperation, is to be competitive (Bolton and Ockenfels, 2000). This makes it impossible to build trust. Of course, this in turn implies that no ambitious global $Q$ can be made credible.

In addition, we will find that a strong global cap-and-trade would cause enormous trading risks. Concern over such risks will make negotiating a strong treaty even more difficult as poor countries seek large permit allocations for protection. In short, the chances of negotiating a global cap-andtrade agreement appear to have been receding for 20 years, and if a strong agreement were ever implemented, it seems likely to unravel due to unfair realized outcomes of trading risks.

\section{The Solution: A Global Carbon Price Commitment}

A global carbon price commitment evolved from the idea of a global carbon tax and (to our knowledge) was first published by Cooper (2008) and then Stoft (2008). One key feature in these publications was the idea that countries could commit to a minimum price and then meet that commitment with either standard cap-and-trade or fossil-fuel taxes. Compared with a uniform global tax on carbon, this allows tremendous flexibility, which is clearly necessary for political reasons.

When fleshed out, the proposal can be seen to be quite similar to global cap-and-trade but with quantities replaced by prices, as is shown in table 4.1 .

Table 4.1

Comparing Global Commitments: Cap-and-Trade versus Carbon Pricing

\begin{tabular}{llll}
\hline $\begin{array}{l}\text { Global } \\
\text { Commitment }\end{array}$ & Target & $\begin{array}{l}\text { Missed Target? } \\
\text { Buy or Sell: }\end{array}$ & $\begin{array}{l}\text { Allowed National } \\
\text { Policies }\end{array}$ \\
\hline Quantity cap, $Q$ & $Q i=?$ & Emission credits & Everything \\
Price, $P$ & $P i=P$ & Pricing credits & Cap, tax, or similar \\
\hline
\end{tabular}


Notice that no rule for allocating global target $Q$ to country $i$ is provided. This missing part of the specification is one of the main criticisms of global cap-and-trade. Also notice that global cap-and-trade allows any national (or regional or local) abatement policy, and hence it does not require the pricing of carbon emissions, whereas global pricing provides a great deal, but not complete, flexibility and does require carbon pricing.

Besides flexibility, there is a need for burden sharing. This would appear to be crucial for any effective global climate agreement. Hence, the defining features of global carbon pricing can be summarized as follows:

1. Negotiate green-climate-fund payments, $G_{i}=$ some formula, for each country $i$.

2. Negotiate a global price-floor, $P(t)$, to be flexibly met by each country.

The price path, $P(t)$, is the "common responsibility" of all countries, whereas climate-fund payments, $G_{i}$, are their "differentiated responsibilities" under the UNFCCC. It is essential that $P$ be a common commitment to solve the free-rider problem with trust and reciprocity as described by Ostrom. However, $P$ could be a flexible commitment, provided all countries are granted the same flexibility. For example, if a country's price is too low in one year, then it could be allowed to buy pricing credits ${ }^{5}$ from another country that has overperformed. Also note that $P(t)$ should be adjusted every five years or so as ambitions increase.

Price is defined flexibly within a country as total carbon revenues divided by total emissions. Carbon revenues include the market price of freely allocated cap-and-trade permits because these credits price carbon just as effectively as a tax. Because price is defined in terms of carbon revenue, tax rates on fossil fuels can vary from fuel to fuel and between customer classes.

It is important to negotiate the green climate fund first because the results determine what common price countries will accept. If the climate fund is meager, then poor countries will demand a low carbon price, whereas if it is too generous, rich countries will attempt to stymie the price negotiations. Consequently, we propose that the generosity of the green fund be determined with only one goal in mind-to maximize the global carbon price. To do this, it must satisfy both rich and poor reasonably well so that the second phase, price negotiations, will succeed. To arrive at such a fair compromise, we suggest that the generosity of the climate fund be decided by a group of countries that are midway between donors and recipients. These 
countries will care most about the success of the climate policy and worry least about their climate fund payments, either into or from the fund.

Summary This completes the sketch of the solution-the path to a strong and negotiable climate treaty. First, a common climate-fund formula is negotiated, guided by the goal of achieving the strongest possible climate commitment. This means it must be seen as reasonably fair by rich and poor alike. Then a common price commitment is negotiated, which prevents free-riding. ${ }^{6}$

\section{A Simple Treaty to Change Self-Interest}

When it is not kept in check, free-riding produces the tragedy of the commons. The Kyoto negotiations hoped to keep it in check with a uniform requirement $(\mathrm{X} \%)$ for emission reduction. The search for a commonly acceptable $\mathrm{X}$ failed, but the idea of a common $\mathrm{X}$ was based on good intuition. So failure led to a nearly permanent loss of the intuition that a common commitment is needed. Global carbon pricing searches along a different path and finds the common commitment that eluded the Kyoto negotiators. This section explains the basic idea of that common commitment and how it defeats free-riding.

Few doubt that self-interest is a powerful force, and few believe we can redirect it to solve the tragedy of the commons that now controls climate change. This pessimism is a bit surprising considering that Elinor Ostrom's work (and the work of many others) focuses on explaining how communities, many of them poor, have been doing this for centuries. In this section, we sketch a simple climate treaty that demonstrates the basic principles of promoting cooperation. It begins with an independent-commitment game among 10 purely self-interested countries and argues that they would be trapped as expected by the tragedy of the commons. We then change one rule in the negotiation game and nothing else. The result is that, although the 10 selfish countries remain as selfish as ever, they cooperate perfectly. The new rule is a common price commitment.

\section{A Simple Global Climate Model $^{7}$}

First, we need a simple model of the climate-policy world. Imagine that the world has 10 identical countries. If you weight countries by their size (so 
the little ones don't count much), the average-size country has about onetenth of the world's population. This turns out to be a good first model to use to find out how countries might cooperate or free-ride on each other's efforts.

Suppose that one ton of emissions does $\$ 50$ of climate damage to the whole world but only $\$ 5$ of damage to each country. So the world is better off if it stops emissions worth less (in nonclimate benefits) than $\$ 50$ / ton, and an individual country is better off stopping emissions worth less than $\$ 5 /$ ton.

A carbon price of $\$ 50 /$ ton will stop emissions that cause a net loss to the world, but a single selfish country will only want to price its carbon at $\$ 5$ / ton in order to allow local projects worth $\$ 6 /$ ton. These bring it a net benefit of $\$ 1$ but do $\$ 45$ of damage to the rest of the world. Remember that the tax itself does not cost the country anything, it just shifts money around. (From here on we will often drop the per-ton units.)

\section{Two Climate Treaties}

Enforcement. Can these 10 countries negotiate a strong treaty? The answer is "yes, if there is enforcement." So assume there will be enforcement but only of voluntary agreements. We won't force anyone to comply with an agreement they don't like. Imagine that if one country reneges, this enforcement will be carried out by the other nine countries (perhaps with trade sanctions). So if you voluntarily sign a deal to cut emissions by $20 \%$, it will be enforced. But if you don't like the treaty, you can just not sign it, and then nothing will be enforced. That's pretty mild enforcement-saving face might even be a strong enough motive to accomplish this. For simplicity, we assume that all countries are selfish.

An Individual-Commitment Treaty In the spirit of the 2015 Paris conference, all countries could agree to the following Individualistic treaty:

Treaty: Each country will pledge to implement a carbon price of its choosing.

Of course, this will be enforced as discussed earlier. There would be long negotiations and discussions first, but nothing would be known for sure until the written pledges are opened simultaneously on the deadline.

Selfish countries would set a carbon price no lower than $\$ 5$ because that would allow emissions that directly caused them more climate damage 
than the non-climate benefit they would gain. But self-interest will hold them down to that level.

So individual pledges made simultaneously will lead to a complete lack of cooperation. It takes reciprocity to prevent this outcome-and that's missing with the individualistic treaty.

Outcome: All countries would pledge $\$ 5$; that is, no country would cooperate to address climate change-the same outcome as if there were no negotiations.

A Common-Commitment Treaty. Suppose instead that the 10 countries ask their treaty-design team to invent a treaty and a way to negotiate it. The team reports back: Every country should pledge their "conditional price" with the understanding that they will only implement that price if all others pledge that much. Otherwise they will implement the lowest conditional price pledged by any country. With this treaty design, once the pledges are in, the lowest pledge becomes the common global price commitment. This will be enforced for all countries because all have voluntarily agreed to that particular price-the lowest "conditional price" that was pledged. So, as before, any country can pledge $\$ 5$ without any penalty, so it can fully defect.

Treaty: Every country agrees to price carbon at the lowest price pledged by any country.

With this treaty, all countries will pledge to price at $\$ 50$, so that the global carbon price is at its optimum. First, we check that any other outcome would make all countries worse off. Suppose the lowest price is lower, say $\$ 40$. Then companies in all countries would emit carbon that only had a $\$ 41$ benefit to them ( $\$ 1$ more than the tax they pay). But with identical countries, all would do this, and again with 10 countries each emitting 1 ton, the damage is $\$ 50$ per country, but they only get $\$ 41$ in local benefit from burning the fossil fuel. All the countries would lose. Similarly, if the lowest price is higher than $\$ 50$, say $\$ 60$, then this would stop them from all using a ton of fossil fuel that had a \$59 local benefit. But such a project is good because, with 10 of these there is only $\$ 50$ of climate damage per country, and they all gain a net benefit by $\$ 9$ (a $\$ 59$ local benefit and $\$ 50$ climate cost). So a $\$ 50$ carbon price is as high as anyone would want. 
To see why everyone pledges $\$ 50$, observe that one's pledge can only be relevant for the outcome if one has submitted the lowest price among all players. So if your pledge was lowest and it was less than $\$ 50$, then it would benefit everyone (including you) to raise it. If your pledge was lowest and above $\$ 50$, then it would benefit everyone to lower it. Just in case your pledge is the controlling minimum pledge, you will want to pledge $\$ 50$, which is optimal for all.

Outcome: All countries would pledge \$50, and that would be the global price of carbon-all countries would fully cooperate to optimally address climate change.

\section{Conclusion}

In a simple world with identical, completely selfish countries, and with enforcement of voluntary commitments, we can change the negotiation game and thereby change selfish behavior-even though the intention remains selfish. This can be done by introducing a common commitment into the negotiations. This changes the outcome from no cooperation to full cooperation. Note that the results in this section are robust: They hold when players are completely selfish as well as under weaker assumptions about players' motivations (e.g., even if most players are conditional cooperators and would be willing to match others' average contributions, there would be a complete lack of cooperation with an individualistic treaty as long as at least one player is at least "to some extent" selfish) (see Bolton and Ockenfels, 2000, for a more formal treatment). Note, however, that both a common commitment and some enforcement are required. After discussing some practicalities and fairness, we will return and discuss how to make this simple story more realistic.

\section{Does Global Cap-and-Trade Price Carbon?}

For economists, the central goal of global cap-and-trade, as well as standard, local cap-and-trade, has been economic efficiency-its ability to get the job done much more cheaply than traditional command-and-control approaches. It does this by (supposedly) putting a "uniform price" on carbon emissions. Standard cap-and-trade actually does do this-by requiring emitters to have emission permits. 
But global cap-and-trade, which works like the Kyoto Protocol, will fail to achieve the central objective of cap-and-trade for the same reason that Kyoto did-emitters are not required to have permits for their emissions or to price carbon at all. Here we explain this essential flaw in global cap-andtrade and how a global carbon price commitment would avoid this.

\section{Why Price Carbon Emissions?}

Until recently, emitting carbon (by which we mean emitting $\mathrm{CO}_{2}$ from fossil-fuel or certain other easy-to-track greenhouse gases) has generally been free. Disposing of carbon into the atmosphere, unlike taking your garbage to the dump, had a price of zero. But carbon emissions turned out to have a cost, which is increasing as the concentration of atmospheric carbon increases.

As with any good, when the price is too low, it is overused. However, burning carbon produces valuable services, and the damage from disposal may be only $\$ 30$ or $\$ 40$ per ton at present. Certainly, no one would suggest we immediately stop driving, heating, and using electricity. We must admit there is a tradeoff. Economics shows that if carbon is correctly priced and we are rational, we will make that tradeoff perfectly. The net benefit (value minus damage) will be maximized. The result won't actually be perfect, but to a reasonable approximation, it will maximize net benefit-carbon benefits minus climate damages.

Price Matters In 1972 and 1973, US $\mathrm{CO}_{2}$ emissions rose by $4.6 \%$ and $4.2 \%$, respectively. In October 1973, the Arabs declared an oil embargo, and oil prices rose sharply. In 1974 and 1975, $\mathrm{CO}_{2}$ emissions declined by $3.5 \%$ and $4.2 \%$, respectively. As figure 4.1 shows, at the end of 12 years-which is when the Saudis stopped propping up oil prices and took back their market share, emissions were down not up. Doubters claim this was caused by the introduction of nuclear power, but if all those plants had emitted as much $\mathrm{CO}_{2}$ as coal plants, then emissions would have been only $9 \%$ higher and still would have been down not up from 1973 levels. In fact, even in this fictitious (no nuclear) scenario, they would have been down about 37\% relative to a trend line based on GDP. Note also that the decline was not at all caused by a decline in GDP.

Prices work in an uncountable number of ways. For example, US refrigerators were made more efficient. But this was the direct result of work by the 


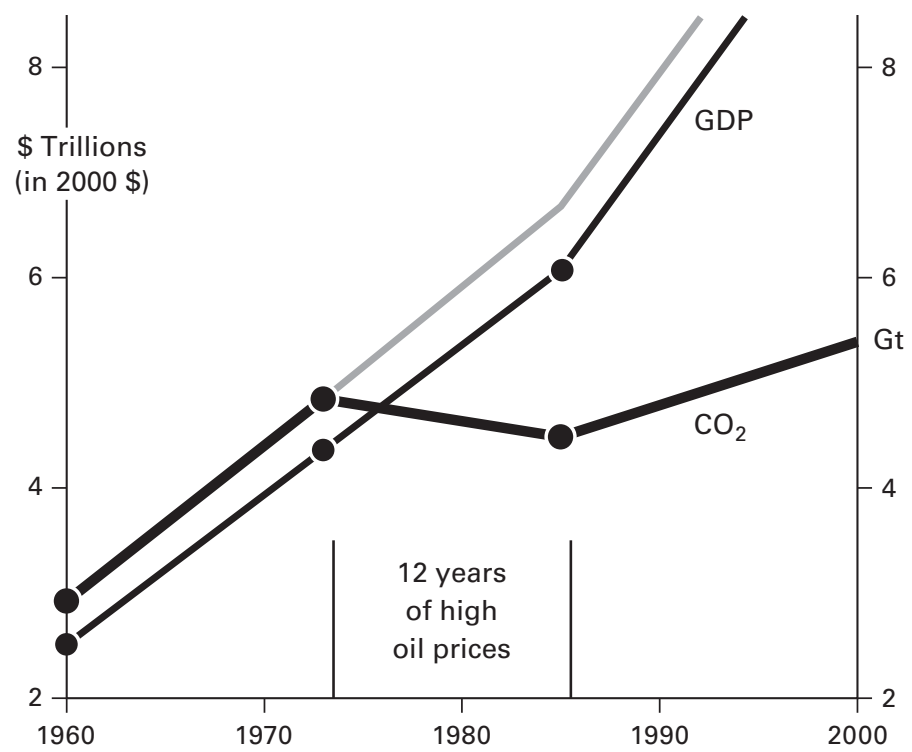

Figure 4.1

Oil price impact on US $\mathrm{CO}_{2}$ emissions

brilliant particle physicist Art Rosenfeld, who explained, "I was prompted by the 1973 Organization of Petroleum Exporting Countries (OPEC) oil embargo to switch to improving energy end-use efficiency, particularly in buildings." That was after he realized "why we in the United States used so much energy; oil and gas were as cheap as dirt or water, and so they were treated like dirt or water." Art Rosenfeld's brilliant work on energy efficiency was a direct result of higher carbon prices.

Of course prices also change individual consumer decisions, but it is important to remember their impact on politics, how cars are advertised, regulatory hearings, and the environmental movement. The impact is enormous, and most of it is long run so it is not immediately apparent.

Why Carbon Charges Are Cheap It is cheap to price carbon. For simplicity, think of a $\$ 100$ billion per year carbon tax. How much does that cost the country? The tax itself costs nothing. The money collected is not lost to the country and can either be returned directly to its citizens or used in place of some other tax-as a "tax swap." As long as revenues are not returned in proportion to the tax collected, the carbon charge will still do its job. For 
example, if a gasoline tax collects $\$ 500$ per person on average, and everyone is given a refund of $\$ 500$ regardless of their gasoline usage, every dollar of tax saved by buying less gasoline will be kept, and the incentive to use less is unaffected.

A direct and complete refund is the best way to prove the carbon charge costs nothing. It is also fair because it is equivalent to saying each person has an equal right to the atmosphere, and those who use more should have to buy extra rights from those who use less and not just take the rights for free (usually from the poor). Nonetheless, a tax swap will likely be politically more popular, and a swap also demonstrates that the tax itself is free (but only in the short run).

There is, however, an indirect and nearly invisible cost to pricing carbon. No matter how it is done or what is done with the revenues, pricing carbon will cause reduced emissions_abatement, and abatement is costly. It will cost somewhere between nothing and the price of carbon because there is no use in paying more-it's better to just pay the charge. So the standard formula for that cost is $P \times A / 2$, where $P$ is the carbon price and $\mathrm{A}$ is the amount abated. If a $\$ 30$ price reduces emissions from 1 billion tons to 0.8 billion, then 0.8 billion $\times \$ 30=\$ 24$ billion will be collected in revenue. However, because abatement is only 0.2 billion, the cost of abatement will be only $\$ 30 \times 0.2 / 2=\$ 3$ billion, eight times less than the carbon revenues collected (and recycled).

So to summarize, the carbon charge itself costs nothing. It just causes money to change hands. In contrast, the induced abatement does have a cost. However, people will be quite creative in figuring out how to minimize this cost and will consider far more possibilities than regulators possibly can. This is what makes carbon pricing much cheaper than regulatory subsidies (see Edenhofer and Ockenfels, chapter 9, this volume, for a similar argument regarding the German "Energiewende").

A uniform global carbon price is certainly not a full solution to the climate problem, but it is by far the broadest, simplest, and most efficient (cheapest) partial solution. So it should be high, perhaps even highest, on the list of important policies to implement. This is the well-known, traditional economic argument for pricing carbon.

A New Reason to Price Carbon The point of this section is that global capand-trade fails at its mission-pricing carbon emissions. But we don't want 
to give the impression that that is the only mission of global carbon pricing. The broken climate negotiations suggest an arguably more important reason to price carbon. As we just saw, free-riding and the fear of it have prevented the world from taking meaningful action to limit climate damage. To overcome this problem, we need a common commitment. As it turns out, global carbon pricing makes an ideal common commitment, and nothing else seems to work. So this is the new and probably most important reason to price carbon. We will return to this topic later. ${ }^{8}$

\section{How Can We Price Carbon Emissions?}

There are two well-known ways that governments can price carbon emissions: cap-and-trade and taxing fossil fuel. Although both of these could be operated as a global policy, it would require complex international institutions that presently seem quite improbable. Cap-and-trade would require that all emitters in all countries trade permits in one unified market. The European Union (EU) emissions trading scheme (ETS) is such a policy, but it only covers half of emissions and only exists because the EU has a government, which the world does not. A global tax would require that all fossil fuels be taxed at the same rate. This seems nearly as impossible as global cap-and-trade.

Consequently, it is far more realistic to consider simple global commitments instead of complex global policies. Global cap-and-trade only means committing to a set of country-specific permit allocations and to restricting emission to permits. A global price commitment only means national commitments to a global price. In both cases, countries would choose from such policies as domestic cap-and-trade, the EU ETS, various fossil fuel taxes, and other pricing policies. None of these policies would be governed from the top.

The Kyoto Protocol is a model for global cap-and-trade. It covers a broader territory than the EU, and so the Protocol has no corresponding government. A similar protocol could potentially support a global cap-andtrade treaty. But the Kyoto Protocol is a form of cap-and-trade that does not price carbon emissions, and neither would global cap-and-trade. We explain this next.

Global Cap-and-Trade The Kyoto Protocol implements a small version of global cap-and-trade, but it does not implement anything like the EU ETS, 
California's cap-and-trade, or Regional Greenhouse Gas Initiative (RGGI) in the eastern United States. All these markets require emitters to own carbon permits. They all price carbon emissions. The Kyoto Protocol does not.

Under the Kyoto Protocol, governments, not emitters, must own all the carbon permits for their whole country even if the government were to emit nothing. This creates a disconnection. Kyoto's international carbon permits are called Assigned Amount Units (AAUs). If the AAU market worked (which it does not) and priced AAUs at, say, \$30/ton, then that would not mean that any emitter would be charged $\$ 30$ for one ton of carbon emissions. The government must curb emissions, but it can do that however it pleases. It is not required to price carbon. Of course it is allowed to price carbon, and it might do so. But if the EU ETS is any guide, it will not price carbon emissions at the price of international carbon permits - the AAU price.

Suppose a government has 1.2 billion AAUs and its country is emitting only 1 billion tons of carbon. It can sell its 0.2 billion AAUs at the global market price of, say, \$30/ton, and it doesn't need to cut back on its emissions at all. Therefore, it has absolutely no need to price carbon. So why is there an almost universal pretense that global cap-and-trade would price all carbon emissions at a uniform AAU price?

In effect, the following is the economic story behind this pretense. The government will freely choose to tax carbon usage at $\$ 30$ per ton (the AAU price). It's a clever tax because it will cause the country to emit less than 1 billion tons, and this will free up more permits, say 0.1 billion more, to sell to other countries. Now the government can sell a total of 0.3 billion permits on the international market for $\$ 9$ billion instead of selling 0.2 billion permits for $\$ 6$ billion.

It's a nice theory. But for the government, there is a cost. It must impose a potentially unpopular carbon tax (or permit requirement) that collects $\$ 30$ times 0.9 billion tons, or \$27 billion domestically. Some will ask, why? Especially when the country has more than enough permits to start with.

It didn't work like the economists' theory predicted under the Kyoto Protocol. Russia and other East-European countries didn't do that. The same theory says that all of Europe would have done this, but no country did. The EU did implement the ETS, and some countries did impose a carbon tax, but not for this reason. Mainly, they chose to subsidize solar and efficiency measures, causing "implicit carbon prices" to range from 0 to $1,000 €$ 
or even more, instead of being uniform (Gollier and Tirole, chapter 10, this volume). In other words, in a major real-world test of global cap-and-trade, it did not price carbon emissions-it did not come even remotely close to accomplishing its central purpose.

A Global Carbon-Price Commitment A global carbon price commitment is a commitment made by countries to price their domestic carbon emissions, on average, at least as high as the agreed-on global carbon price. Like global cap-and-trade, a global carbon price commitment does not specify national policies. It would allow the EU ETS or fossil taxes, or a combination (as actually exists), and various other policies. But unlike global cap-and-trade, a global carbon price commitment will not count pure command-and-control policies. This does not mean countries cannot continue such policies. A global carbon price commitment simply ignores them.

In fact, command-and-control policies could even continue to be part of a separate international pledge-and-review system. Hopefully, the most wasteful of these policies would die out, and the beneficial, well-designed ones that plug holes in the carbon-pricing approach would be retained. (Later we will see that the climate fund used with a global carbon price commitment can provide incentives for good, nonprice policies.) A global carbon price commitment would also prominently raise the question of how much it is really costing a country to abate carbon. This will expose the wastefulness of some policies, and we believe this will strongly encourage greater efficiency through the use of price-based approaches.

A strict version of a global carbon price commitment would allow only true carbon pricing, such as cap-and-trade, fossil taxes, and bonus-malus (AKA feebate) pricing schemes. But at the start, it might be necessary, for political reasons, to count renewable energy subsidies as well. These would be credited only for carbon abated and not for the money spent on subsidies. An estimate would be made of the carbon price the country would have needed to abate as much without the renewable subsidies. It would then be credited with that carbon price.

So a global carbon price commitment, although not interfering with command-and-control measures, would actively encourage countries to engage in the efficient carbon pricing to meet their commitments. At first it would likely allow borderline pricing policies (like the renewable subsidies just mentioned), but eventually a global carbon price commitment would 
become far more efficient than global cap-and-trade is likely to be. But even then, a carbon price commitment will be tremendously flexible. Different emissions from different fuels and different polluters can be priced differently. Automobile efficiency can be subject to highly effective bonus-malus pricing to address consumer myopia. Of course countries can use cap-andtrade or even join regional or global cap-and-trade networks. Also price credits could be traded and banked from one year to the next.

Although this flexibility will not lead to a completely uniform price by any means, it should lead to a much more uniform cost of abatement (implicit price) than global cap-and-trade, and it would make sense to put some restriction on the nonuniformity of carbon prices used to meet the global price commitment.

Figure 4.2 illustrates both the similarities and differences between the two approaches. Both allow all possible climate polices, but global carbon pricing will not count pure command-and-control policies toward the global commitment, whereas global cap-and-trade will. Instead, carbon pricing

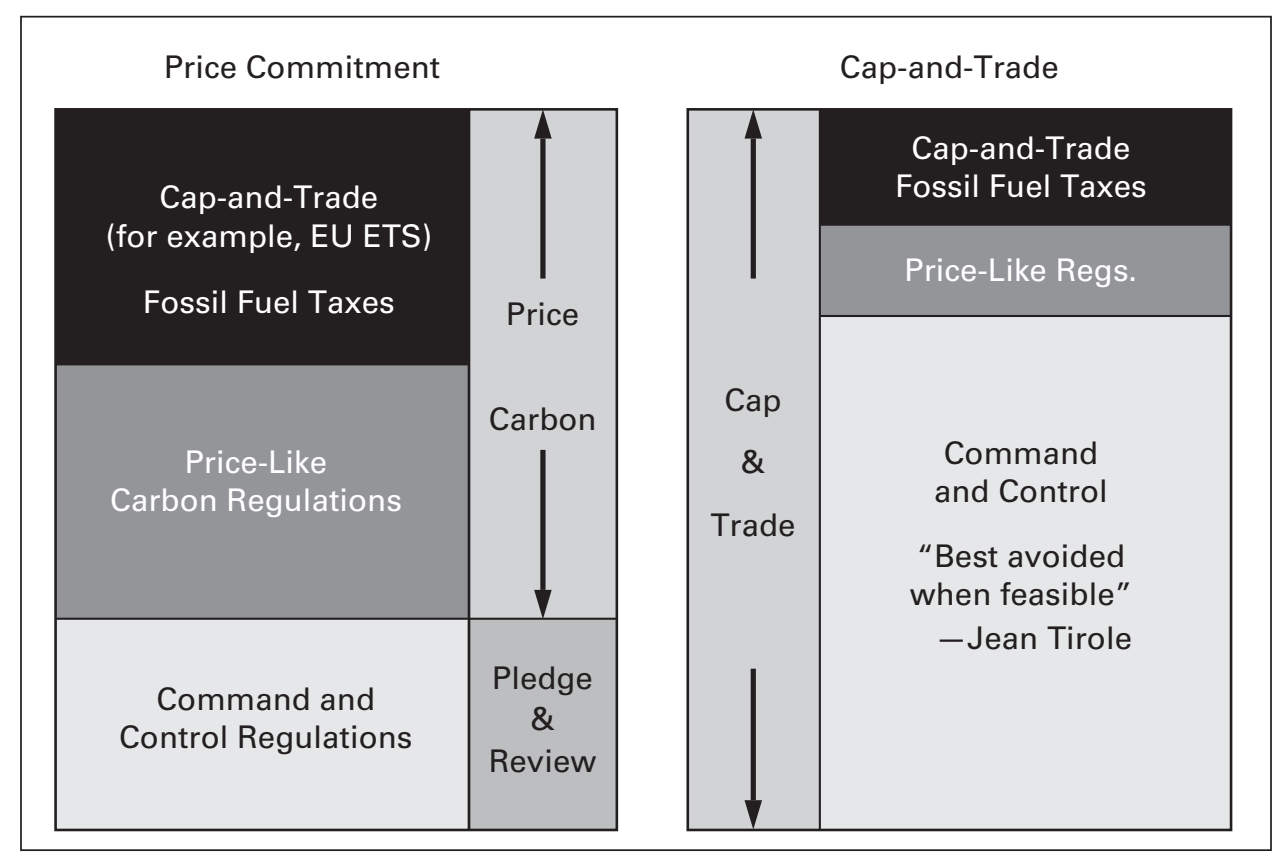

Figure 4.2

Pricing of carbon emissions 
will accommodate parallel pledge-and-review commitments, whereas global cap-and-trade will not. At least for a while at the beginning, policies such as subsidies for renewables would have their abatements counted toward pricing. In these ways, global carbon pricing will shift the policy mix away from command-and-control and toward pricing carbon emissions (although it will provide some incentive through climate-fund rules for good nonprice policies).

The end result will be that global cap-and-trade will do little, if anything, to price carbon emissions, whereas global carbon pricing will do much to shift national policies in this direction by only giving credit for true carbon pricing or for a price-equivalent value of measured abatement.

\section{Fairness}

Perhaps the toughest problem for international negotiations is burden sharing. Who will bear the cost of stopping further atmospheric damage? The essence of the problem would seem to be fairness, a subject notoriously susceptible to bias. But the only focal point for fairness is to divide rights to the atmosphere equally among the entire human population.

This proposal might be as fair as possible for a simple rule, but there are two decisive arguments against making use of it. First, it will continue to be blocked by a large number of claims for alternative "fair" ways to share the burden. Second, it would surely be blocked by many richer countries.

Because this approach is decisively blocked, we suggest considering a focal principle that is not based directly on fairness but that would nonetheless contain checks and incentives that would pull it substantially toward a fair solution. This principle can be stated as follows.

Burden-sharing principle: The costs of improving the climate should be assigned in such a way that the climate is most improved.

This is not such a new idea. It has been long employed by Frankel (1998) in his quest for an effective common-commitment formula for the allocation of free carbon-emission permits. It has also been used by Cramton and Stoft $(2010,2012 a, b)$ in their green climate-fund design for a number of years.

This principle has advantages, some important. First, its only built-in bias is toward countries that will be harmed most by climate changebecause its goal is to maximize climate benefits. In principle, this could be 
problematic. But in reality, there are stronger opposing biases, such as one caused by free-riding on future generations.

Second, the principle provides concrete guidance on how to negotiate equity transfers. In the next section, we use this principle to help allocate payments into and from the climate fund.

\section{A More Realistic Treaty Design}

We have now demonstrated how a common commitment to a carbon price could lead to cooperation in a highly simplified world. That involves a commitment to the lowest pledge submitted, which works perfectly, although it sounds like a weak approach. From here on we will refer to it as consensus voting because the lowest pledge is also the highest pledge that could elicit a consensus (100\%) in its favor. This section introduces the two toughest problems facing climate negotiators:

1. Low motivation

2. Fairness questions

For various reasons, some countries may want to do much less than others; hence, they might vote for a carbon price as low as zero. As a result, consensus voting is ruled out as an effective negotiation tool. Second, some countries will need help with the costs of abatement, so a climate fund will need to be included in negotiations.

\section{Preventing Too Low a Price}

The first problem, low motivation, arises for several reasons. First, poor countries may heavily discount the future because they are so concerned with the present. Second, some northern countries may be somewhat ambivalent about being warmer. Also, countries that export oil may want the carbon price to be zero because a higher price suppresses the demand for oil and reduces their profits.

Because some countries may want too low a price, the minimum-price rule of the previous section would produce an unacceptably low carbonprice commitment if applied to all countries. To fix this, we must limit voting rights by excluding, in some way, the lowest votes from the determination of the global price. This can be done by forming a "coalition of the willing," which is essentially the same as the idea of a Climate Club 
suggested by Nordhaus (chapter 7, this volume, and 2015). Such a coalition could be formed through informal negotiation or a formal voting procedure.

Although it is easy to think of a procedure, such as forming the coalition from countries that vote for the highest global price, there are subtle incentive problems with many of these, so an informal procedure may be best. It is clear, however, that if the coalition has some power to reward those who cooperate with its pricing policy or punish those who do not, it will be easier to form a large coalition that agrees on a high price. In fact, enforcement is recommended by Nordhaus (chapter 7, this volume), Stiglitz (chapter 6, this volume), and Gollier and Tirole (chapter 10, this volume).

Fortunately, enforcement may be less necessary than is predicted by standard economics. Ostrom (1990) finds that "the fines assessed in these [common-pool governance] settings are surprisingly low. Rarely are they more than a small fraction of the monetary value that could be obtained by breaking the rules."

In any case, we will postpone the discussion of enforcement until the next section and simply assume here that we can form a coalition that excludes uncooperative countries. Within this coalition, we can use consensus voting to select the highest global price that is acceptable to all.

\section{A Green Climate Fund}

The problem of burden sharing has been the most divisive and was addressed by the UN's famous phrase in its Framework Convention on Climate Change (UNFCCC, 1992), stating that countries have "common but differentiated responsibilities." The interpretation of this phrase has been most contentious. A global carbon-price commitment resolves this tension by making carbon pricing the common responsibility of all countries. Differentiated responsibilities are then handled by differing contributions to and receipts from a green climate fund.

Carbon prices should not be differentiated for two reasons. ${ }^{9}$ First, this wastes money. More important, as demonstrated in the prior example agreement, if coalition members commit to an enforceable common price, this eliminates free-riding at least within the coalition. This simplifies the negotiation and greatly strengthens the outcome. Because fixing the 20 -year-old negotiation impasse is our primary objective, it's best not to undo the progress we've made so far. 
So differentiation of responsibilities should be accomplished with a climate fund and not by differentiating prices. This poses the obvious problem of how much each country should contribute or receive, which could be as complex a problem (although smaller according to Weitzman, chapter 8 , this volume) as deciding carbon permit allocations under global cap-andtrade. But just as that problem is solved by replacing individual commitments with a common commitment, so can the climate-fund problem be solved with a common-commitment formula.

The most obvious climate-fund formula was invented independently by both cap-and-trade and carbon-pricing proponents and can be found in Stoft $(2008,2010)$, Cramton et al. $(2010,2012 a, b)$ and Gollier and Tirole (chapter 10, this volume). Admittedly, it is too simple, but it is quite instructive and demonstrates most of the good properties that could be approximated with a more realistic formula. The formula is ${ }^{10}$ :

Payment into the climate fund by country $i, G_{i}=g \times X_{i} \times P$, where $g$ is the generosity parameter, $X_{i}$ is the excess emissions of country $i$, and $P$ is the global price.

Excess emissions are defined as emissions above what would occur if the country had the global-average per capita emissions rate. Negative values of $G_{i}$ (resulting from below average per capita emissions) indicate a payment from the climate fund. Because there is a high correlation between emissions per capita and income per capita, this formula transfers funds from rich to poor countries. However, a realistic formula would need to be a bit more complicated to compensate for various anomalies.

The climate-fund formula has one primary effect and three beneficial side effects:

Primary effect: because of $g$, the formula makes successful negotiations possible.

1. It provides an incentive for poor countries to vote for a higher level of $P$.

2. It provides every country with an extra incentive to reduce emissions.

3. It can be used as a friendly enforcement mechanism for compliance with $P$.

The primary effect of the formula is to simplify the n-dimensional problem of negotiating payments for $n$ countries into a one-dimensional 
problem of negotiating $g$, the overall generosity of payments from rich to poor. Although this is essential, the side effects are also surprisingly beneficial and important.

The first side effect, an incentive to vote for a higher $P$, is most essential. As already noted, poor countries will tend to favor a low value for $P$. The climate-fund formula overcomes this problem because poor countries see that if the price is doubled, their climate-fund payments will double. This gives them an incentive to pledge and lobby for a higher carbon price, $P$.

The second beneficial side effect, an additional incentive to abate, happens automatically because any additional abatement reduces a country's excess emissions. So a country with high emissions would pay less and one with low emissions would receive more. The third benefit is activated by making a rule that the climate fund is paid only to countries that are in compliance with the global carbon price. This also makes rich countries feel like they are "getting something for their money," which makes these payments more palatable. However, requiring contributions from developed countries still makes them less likely to participate, but techniques described next, for maximizing the coalition's chosen price, should still help produce the strongest possible price agreement.

\section{How the Carbon Price and the Climate Fund Interact}

We have now specified a two-phase negotiation process that works as follows:

1. Negotiate climate-fund generosity $g$ (payment $=g \times X_{i} \times P$ ).

2. Negotiate a "Climate Club" price $P$ for a "coalition of the willing."

Breaking the negotiation in half, as this does, is enormously beneficial. Otherwise, when countries attempt to reduce their own burden, they unintentionally destroy the climate ambition of the treaty. This happens under cap-and-trade negotiations, where individual-country permit allocations add up to the total cap. As an additional benefit, these two negotiation phases also interact beneficially. These are the two complementary interactions:

1. The climate-fund negotiation over $g$ is used to improve $P$.

2. Subsequent negotiation over $P$ makes the $g$-outcome acceptable.

First, note that negotiating $g$ does not require unanimous agreement because countries can protect themselves in phase 2 . To understand 
interaction 1, note that if too high a level of $g$ is selected, then rich countries will pledge a low $P$ to hold down their payments into the climate fund (see the equation for the payment into the climate fund above). Similarly, if too low a level of $g$ is selected, poor countries will pledge a low $P$ to avoid the abatement costs that come with higher values of $P$. So with either extremely high or low values of generosity $g$, one group or the other will opt for a low global price.

If either rich or poor pledge too low a price, then the global carbon price will be too low. So, with a coalition of rich and poor, both extremes of $g$ must be avoided so that neither group will pledge too low. So by setting $g$ at the right intermediate value, the highest possible price will be agreed on. This is in keeping with the burden-sharing principle suggested earlier.

Consequently, it is best if $g$ is determined by countries that do not have a conflict of interest regarding climate-fund payments. These will be countries that have near-zero excess emissions and hence participate little in the climate fund. Such countries will be inclined to focus on getting a successful climate treaty with a high carbon price.

The second interaction guarantees that countries in the coalition of the willing will find both their climate-fund obligation and the global price acceptable. If they did not, then they would have pledged a lower value of $P$ and that value would have become the coalition's agreed-on value. In the extreme, this could lead to a price of zero and no climate-fund payments, but for two reasons this should not happen. First, the coalition will be selected to contain cooperative countries. Second, offering the protection of the second interaction will make those selecting $g$ especially careful to select a reasonable value. The result should be that few countries feel they need protection from the chosen $g$. So they will be willing to vote for a high global price in phase 2 of the negotiations.

\section{Conclusion}

We have considered two factors that tend to weaken a climate treaty: low motivation and fairness questions. Our strategy has been to avoid disrupting the common price commitment that serves to solve the free-rider problem. To maintain this common price, we have separated the "willing" from the unwilling and handled "differentiated responsibilities" with a climate fund.

To simplify climate-fund negotiations, we suggest using a formula. To make this easier to negotiate, we allow countries to opt out of a climate-fund 
formula they perceive as unfair by not joining the coalition, although there will eventually be some penalties for opting out. This also motivates construction of a fair formula so that few will opt out.

Why Price Negotiations Work Better Than Quantity Negotiations Compare this process with negotiating a Kyoto-style treaty. Such a treaty allocates quantities, $Q_{i}$, of free carbon permits to participating countries. These quantities serve double duty. The total of all $Q_{i}$ determines world carbon emissions, and individual $Q_{i}$ s determine wealth transfers to each country. If your $Q_{i}$ is higher by one ton, then you will be richer by the price of one ton of carbon. So every country will be paid handsomely to negotiate as high a $Q_{i}$ as possible, which means every country is paid to do all they can to increase global carbon emissions.

Price negotiations eliminate this incentive to obtain a free ride from the negotiations. Some will see this flexibility and accommodation as a weakness and will want to enforce the "scientifically correct" commitment. This view is backward. A heavy-handed approach will only produce conflict or, at best, a treaty that quickly unravels. The source of this weakness is the lack of a global government. Given this weakness, procedures that reduce risk and eliminate adverse free-riding incentives will produce the strongest possible sustainable treaty.

\section{Climate Clubs, Enforcement, and Reciprocity}

Some say enforcement is the key to cooperation. This is half true, but we've already seen that enforcing independent commitments does not produce cooperation. Think of a road speed limit. If we independently set our own speed limits, then there would not be much use enforcing them. But if the limit applies to all, we have good reason to choose a moderate limit, and then enforcement is necessary and effective.

Fortunately, there are gentle types of enforcement, such as "internal enforcement" discussed next, social pressure, and rewards for poor countries that comply with the common commitment. These will be particularly useful at the beginning. Nordhaus (chapter 7, this volume) discusses Climate Clubs (coalitions) and a strong style of enforcement but makes little mention of a common commitment. However, as he explains, he still considers a common price commitment essential. 
No other chapters in this volume focus on clubs, but several of them agree (and none disagree) that some enforcement, probably trade sanctions, will eventually be necessary. This section shows why Climate Clubs and carbon price commitments are just two different views of the same carbonpricing-with-enforcement policy, although Nordhaus (chapter 7, this volume) advocates stronger enforcement than some of the other authors.

\section{Internal Enforcement}

Scott Barrett (1994) discusses self-enforcing international environmental agreements, and the first type he discusses uses what Nordhaus (chapter 7, this volume) refers to as "internal enforcement." This enforcement is particularly gentle. To understand it, suppose the world consists of countries that are identical except for their size. This means that if one country is half the size of the other, then the larger country will experience twice the climate damage; if it abates the same amount per capita, then it will incur twice the abatement cost. Now suppose that the world has the following cost and benefit functions:

$C=c A^{2}$ and $B=b A$,

where $A$ is global abatement, $C$ is the cost of global abatement, $B$ is global benefit from reduced climate damage, and lowercase $c$ and $b$ are fixed parameters. These assumptions are typical and are the ones used by Nordhaus (chapter 7, this volume).

In this world, a single country acting on its own will realize that its own abatement will improve the climate and bring it some climate benefit. However, most of the benefit of its efforts will accrue to others. As it turns out, if a country is one-tenth the size of the world, then it will abate only $1 / 10$ of what would be optimal, and it will do this by setting a carbon price $1 / 10$ as high as it should. Of course the analogous rule holds for any other size country.

A Coalition of Two Equal Countries In a world with these cost and benefit formulas, would two identical countries be better off if they formed a coalition and made a common (enforceable) commitment? They will realize that a higher price would make more sense than when they acted alone because if they raise their joint price, then they will benefit from their own extra abatement and the same extra abatement from the other country. 
As mathematics confirms, they will be better off together, even though they spend more on abatement. Neither will want to leave and have their small coalition fall apart. We will call this "internal enforcement" because it only depends on the externalities driving the agreement and not on some "external" threat, such as trade sanctions.

The Coalition Size Limit for Internal Enforcement Sticking with our simple model, if a large country and a tiny country try to form a coalition, then the large country will already have a fairly high price, but the tiny country would have a low price. In an equal-price coalition, that means the little country would have to work much harder than it would selfishly choose to on its own. Of course this extra effort would benefit the large country much more than the small one. So tiny countries will not want to form or stay in coalitions with large countries. They will prefer to free-ride on the large country.

As it turns out, if the small country is bigger than half the size of the large country, then it will benefit from joining in a coalition, but if it is smaller, it will lose. Similarly, if three identical countries form a coalition, each will view itself as just half as big as the other two put together and will be indifferent about being in the coalition. Hence, three identical countries make a coalition that is just on the brink of falling apart.

If the three countries differ in size at all, then the smallest will want to leave and free-ride on a coalition of the other two. This is what Nordhaus (chapter 7, this volume) terms the "small-coalition paradox." It shows that internal enforcement is not strong enough to realistically hold more than two countries together, which is an argument for common commitments with external enforcement.

\section{A Real-World Coalition}

Fortunately, the real world may be more cooperative than the world of standard economic models. As noted previously, Ostrom (1990) found that penalties holding together successful public-goods arrangements were generally much weaker than what could be gained by cheating. There is now much evidence that weak and strong reciprocal interactions stabilize more cooperation than is generally predicted by standard economics that assumes static interaction. Let us consider just one possible outcome of this type that could be quite useful for getting started. 
If the EU can continue to act as a single country, then the world will have three large countries: China, the United States and the EU, accounting for about half of all emissions. Together these might be a good nucleus for a Climate Club. China, being the largest, would have a positive incentive to stay in the coalition, and the EU would (according to the "small coalition paradox") prefer to leave and free-ride on China and the United States. However, reciprocity, together with face saving and public pressure for good behavior, may push Europe into such a coalition. So internal enforcement, although not as strong as we need it to be, just might be strong enough to stabilize a coalition covering half of all emissions.

\section{External Enforcement}

Although Nordhaus (chapter 7, this volume) discusses internal enforcement, his Climate Clubs all rely on external enforcement. In particular, he favors trade sanctions that are simple yet powerful. These would be employed by Club members against those outside the club. Although some World Trade Organization (WTO) policies would need to be changed, he advocates placing a tariff of something like $5 \%$ on all goods sold by nonmembers to those in the Climate Club.

This approach is certainly logical in that failing to price carbon is a much larger problem than is indicated by the relatively small amount of carbon embodied in a country's exports. However, we would not like to depend on this legally complex approach to get started, and we do not believe this is necessary. Later, when climate measures need to be stricter and climate problems are more obvious, this approach may be needed and may be possible.

In the meantime, as was mentioned previously, a substantial climate fund can be made use of as external enforcement, and it would likely be far more acceptable to developing countries. As noted, it would pay climate funds only to countries that meet the common price commitment. Also "internal enforcement," discussed earlier, will help stabilize the initial coalition.

\section{Reciprocity and Enforcement}

Trust and reciprocity are essential to (and what Ostrom (2009) calls the "necessary central core") of successful collective action. Broadly speaking, positive reciprocity means responding kindly to kind actions, whereas 
negative reciprocity means responding unkindly to unkind actions. Both responses can act as enforcement.

Economics distinguishes two fundamental types of reciprocity: weak and strong. (Both can be positive or negative.) Strong reciprocity refers to actions that are similar to altruism, in that they do not serve narrow self-interest and often serve the common good. Weak reciprocity (more common) is motivated by narrow self-interest to gain better treatment by others. This is, of course, the point of any deliberate system of enforcement. Having explained this, we will discuss them all together and call any combination of them simply "reciprocity."

We have suggested several ways of including reciprocity in the design:

1. Coalition members only commit to a price as high as others.

2. Poor countries that join the coalition will be rewarded.

3. If a county does not join the coalition, then it could be subject to trade sanctions.

This approach to treaty design should not be surprising because all disciplines dealing with human cooperation find that reciprocity is the key principle underlying cooperation. It is the most robust pattern of cooperation seen in laboratory, field, and theoretical studies of free-rider situations, and it is consistently found to stabilize higher cooperation levels. This has been thoroughly explained by scholars across all disciplines dealing with human cooperation (Bowles and Gintis, 2013; Fudenberg and Tirole, 1991; Kraft-Todd et al., 2015; and Ostrom, 1990, among many others). Without reciprocity, a public goods dilemma such as climate change will result in the tragedy of the commons.

\section{Group Reciprocity Requires a Common Commitment}

With only two parties, it is quite common for reciprocity to be asymmetrical-I will fix your sink if you pay me $\$ 100$. With three parties, it becomes difficult. You may suggest I will do $\mathrm{x}$ if Alice does $\mathrm{y}$ and Charlie does z. But Charlie may think he should do less and Alice more, which would be OK with Alice if you did more too. So the negotiation quickly becomes more complex as the number of parties increases.

Under pledge-and-review, every pledge will be of a different type, and all will need to compare the others' pledges to their own. But in reality, they will not find that worthwhile and will just focus on their own contribution. So there will be little, if any, reciprocity. 
The complexity of many individual commitments makes effective reciprocity impossible without a common commitment. This could, in theory, take many forms, but none based on emissions quantities has been found to garner even modestly broad support. However, supporters of cap-and-trade and carbon pricing both agree that carbon prices around the world should be equal. That is the entire point of the "trade" in cap-and-trade, and that is all that is needed for a common price commitment-every country should commit to the same price.

\section{Conclusion}

Reciprocity is the key to cooperation, and enforcement is a form of reciprocity. To utilize reciprocity in a group, a common commitment is required. As previously suggested, this will need to take the form of a global carbon price. Simply agreeing to this common commitment is a form of reciprocity: "I will implement the global price if you will, and I won't if you won't." Trade sanctions and climate-fund payments are negative and positive forms of reciprocity that can stabilize and enlarge a Climate Club or a coalition of the willing.

One reason that negotiating a global carbon price strongly facilitates a common agreement is that a uniform price is efficient and fair and thus a salient focal point for the negotiation. A focal point greatly reduces the complexity of multiparty and multi-issue negotiations and thus enables successful coordination and cooperation (Schelling, 1960). There is no salient focal point when negotiating global cap-and-trade.

However, many other actions, such as tech transfer or support in various international forums, could be used informally to help stabilize and strengthen a climate treaty. The real message of this section is that all countries should stop thinking in terms of altruistic climate aid and think instead about reciprocal actions of many kinds to encourage and stabilize a strong climate commitment. But none of these will work well until we have a global treaty based on common commitments. This is the most fundamental message shared by all experts contributing to this book.

\section{The Enormous Risk of Trading}

We turn now to one of the most serious but rarely mentioned problems of global cap-and-trade. So far, all workable forms of global cap-and-trade 
require long-term allocations of permits to countries, so these must be based on long-term estimates of future business-as-usual emissions. When these estimates prove wrong, countries can find themselves with surprising windfall gains and losses, which have nothing to do with good climate policy.

Global cap-and-trade needs international trading of carbon permits for two reasons. First, some countries need to be given extra permits to sell as a way of reducing their burden. Second, some countries can abate more cheaply, so countries where abatement is costlier can (and should) take advantage of this efficiency gain by buying permits from them. This is equivalent to one country paying another to abate on its behalf.

Sometimes we may want to place no burden on a country by giving them all the permits we think they will need. However, by accident, we may give them too few permits, which could force them to spend a lot of money buying permits from foreign countries (or abating excessively, which would cost them even more). We call such trading "prediction-error" trading.

To understand the following example of prediction-error trading, it is useful to first understand two concepts: business-as-usual emissions and business-as-usual targets. Business-as-usual emissions are simply the emissions that would occur without a climate policy. Suppose this is one gigaton per year of emissions. In that case, a business-as-usual target gives the country one gigaton of free carbon permits per year. This means that it can ignore this climate policy and continue to emit one gigaton per year with no consequences because it has enough permits. But if it's smart, it will realize that it can find some cheap ways to abate more carbon; by taking these opportunities, it will find it has leftover permits, which it can sell to other countries at a profit. In this way, giving a country a business-as-usual target keeps it safe-it can do nothing and have no cost, and it also gives it an opportunity to abate and make some profit selling permits.

\section{Frankel on the Safety of Business-as-Usual Targets}

Jeffrey Frankel served on the US President's Council of Economic advisors during the Kyoto negotiations. In July 1998, he wrote, "Let us consider a plan under which developing countries commit to their 'business-as-usual' emission paths in 2008-2012." He considered that a bit more generous than was likely because, at that time, cap-and-trade advocates were favoring stricter targets than business-as-usual. 
Then he wrote about countries such as China: "The first thing you should notice is that this system is not going to hurt you." He explained exactly what we explained earlier about a business-as-usual target. However, his explanation and ours both apply to targets that actually do match business-as-usual emissions, and this is not what his claim of "not going to hurt you" applies to. He was talking about setting a target in 1998 for the Kyoto compliance period of 2008-2012, which is what the Kyoto treaty did. So there is no reason to believe there actually would be a perfect match between the so-called business-as-usual target (the allocations of free permits) and the actual future business-as-usual emissions of various countries.

\section{China Comes Up 29 Billion Permits Short}

Because Frankel mentions China in this discussion, let us look at how China might have fared. The US Department of Energy's (DOE) 1999 International Energy Outlook predicted that China's $\mathrm{CO}_{2}$ emissions in the target years would total 7.5 billion tons. In reality, they turned out to be 36.6 billion tons. So China would have been short 29.1 billion permits. At a permit price of $\$ 30 /$ ton, China would have had to spend $\$ 874$ billion buying permits, mostly from developed countries, had it not cut emissions.

Of course they would have found some emission that could be cut more cheaply than buying permits, so that might have brought the bill down to, say, $\$ 600$ billion, but then again trying to buy an unexpected 20 billion permits from the market might well have sent the price up above \$30/ton. In any case, the Chinese might have taken issue with Frankel's assurance that "this system is not going to hurt you," especially when they realized their rich trading partners would be selling them permits at the marginal cost of abatement, which is always higher than the average cost. Hence, rich countries would have profited from China's bad luck, quite possibly by more than $\$ 100$ billion.

\section{Frankel Proposed a Fix and Then Dropped It}

To be fair, a few pages after estimating that, "If China were to join, it would capture almost $\$ 4$ billion a year" in gains from trade, ${ }^{11}$ Frankel does issue a warning: "One problem is the uncertainty of the business-as-usual path. It is difficult to forecast ten years ahead what a country's emissions would be in the absence of policy change." 
He then suggests, "I have a possible response to this problem. It is a suggestion to index the emissions target, to such variables as GDP in the year 2007." This would have helped, but the GDP prediction for 2007 from back in 1999 was only $26 \%$ short of the mark, whereas the $\mathrm{CO}_{2}$ prediction was $80 \%$ too low. This correction technique, although helpful, would only have eliminated roughly one-third of the problem.

Frankel also suggested, in 1998, that the business-as-usual path could be determined by "objective experts," which would seem to correspond to the DOE forecast used previously. In 2014, when describing his most recent formulas for determining future free permit allocations for a global capand-trade system, he suggests, business-as-usual "is defined as the path ... countries would experience in the absence of an international agreement, preferably as determined by experts' projections" (italics added). So 16 years later, he has settled on the method (experts' projections) that produced the 29-billion-ton underestimate of the business-as-usual target, as still the best estimation method he can come up with. The point is not to fault Frankel but rather to indicate that the problem of setting even roughly accurate business-as-usual targets appears unsolvable.

\section{Comparing Global Price versus Global Cap Commitments}

Suppose that China had agreed to a global carbon price commitment instead of global cap-and-trade in 1999. Let us add some detail that, although speculative, is in no way implausible. Rather it consists of exactly the sort of assumptions the Chinese should have made, and perhaps did make, when determining whether to accept the type of "binding commitment" they were being asked for. Suppose, to make comparison simple, that the expected carbon price under either global cap-and-trade or a comparable global carbon price commitment would have been $\$ 30 /$ ton. Further assume that, given the surprising increase in China's business-as-usual emissions, the global carbon price under cap-and-trade would have risen to $\$ 45 /$ ton and a $\$ 30$ carbon price would cause $20 \%$ abatement and a $\$ 45$ price would cause a $30 \%$ abatement.

Under either system - a cap or a price-there would be abatement costs, which are reasonably and traditionally calculated with the following costof-abatement formula: $\mathrm{C}=P \times \mathrm{A} / 2$, where $P$ is the carbon price and $\mathrm{A}$ is the abatement. 
With this formula, we calculate the cost of abatement as $\$ 247$ billion under cap-and-trade and $\$ 110$ billion under carbon price commitment. The cost is less under a price commitment because the price cannot rise, whereas under a cap the surprise emission shock pushes it up to $\$ 45$ billion. But there would still be 25.6 gigatons of unabated emissions under cap-and-trade, only 7.5 of which China would have permits for. So it would have had to buy permits for 18.1 billion tons of emissions at $\$ 45$ / ton, for a cost of $\$ 817$ billion, and a total cost under global cap-and-trade of \$1.1 trillion over the five-year life of the Kyoto treaty.

But remember, some abatement cost ( $\$ 22$ billion) would have been expected under either system if the 1999 emission prediction had been accurate. Under cap-and-trade, the permits for the abated tons could have been sold at a profit of $\$ 44$ billion. The net gain (trading cost minus abatement cost under cap-and-trade) would have been $\$ 22$ billion if everything had turned out as expected.

The net unexpected cost under a carbon price commitment would have been $\$ 110-\$ 22=\$ 88$ billion (unexpected minus expected abatement costs). The final result is that the unexpected cost to China would have been more than 12 times greater under global cap-and-trade than under a matching global carbon price commitment, and it would have been more than $\$ 1$ trillion greater.

It should also be noted that, although the unexpected cost of $\$ 88$ billion (over five years) is still fairly large under a global carbon price commitment, this cost would have gone mainly toward cleaning up their coal industry and solving a major internal pollution problem. The $\$ 817$ billion spent on purchasing carbon permits from, say, the United States and EU would have caused unimaginable domestic political recriminations had it been carried out. These costs are illustrated in figure 4.3.

In figure 4.3, areas represent costs, and the sloped line represents the demand-curve for carbon emissions. The higher the price of carbon, the lower the emission level. The rectangle shows the cost to China of purchasing permits after doing extra abatement due to the unexpected $\$ 45 /$ ton cost of permits. China's unexpected abatement cost is the combined area of the two trapezoids. The smaller trapezoid (on the right) is the cost of unexpected abatement under a fixed global carbon price of $\$ 30$. The area of the triangle represents the cost of abatement that was expected under either system due to a $\$ 30$ carbon price and the DOE-predicted level of 


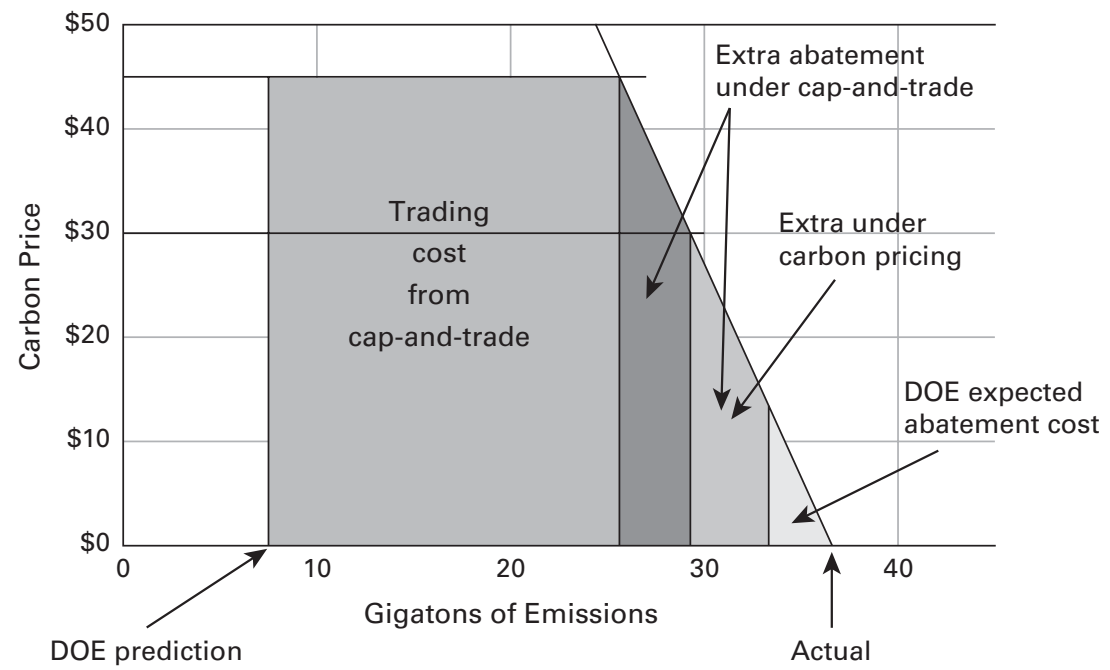

Figure 4.3

Prediction-error trading costs

emission. (The triangle has the right area but has been moved and reshaped from where its area was calculated—at the DOE prediction.) From China's perspective, abatement costs in the two trapezoidal areas have considerable benefit and, hence, low net cost. The trading costs under cap-and-trade are far larger, have no benefit, and carry a considerable political liability.

\section{Conclusion}

The previous example was not cherry picked. It was chosen by a leading advocate of global cap-and-trade, who simply was uncertain of what the future would bring. It should be noted that this is not the only surprising change in business-as-usual emissions we have witnessed. There was also the collapse of the Soviet Bloc and the Fukushima disaster, among others. Global cap-and-trade is designed so that it turns such unexpected shocks into huge windfall gains or losses, which will inevitably destroy any treaty with an effective carbon price based on this approach.

Almost all comparisons of global capping and pricing made by capping advocates have used what is called a "certainty equivalent" model. This ignores all prediction errors as if being right on average was the same as being right all the time. Yet two of the most serious problems with global cap-and-trade are due to price and business-as-usual uncertainty. Both of these are rendered invisible by certainty-equivalent models. 
In the case of business-as-usual uncertainty, it seems likely that, as Cooper (chapter 5, this volume) explains, developing countries will want caps that assume a business-as-usual $\mathrm{CO}_{2}$ growth rate something like China's because that might happen, and they do not want to be seen as projecting anything less than stellar growth. They also do not want to risk having to buy billions of dollars' worth of carbon permits from rich or rival countries. Accepting permit allocations that accommodate such hopes and fears will result in a global cap that is far too high to have any significant effect on the climate.

\section{Does Cap-and-Trade Have a Record of Success?}

Two systems claim to achieve a fairly uniform carbon price: global capand-trade and global carbon pricing. We have already made several comparisons, but one misconception still needs to be addressed. Has global cap-and-trade already been widely implemented and found to work quite well? If so, what is the point of analyzing its shortcomings?

The Kyoto Protocol is global cap-and-trade. It allocates international emissions permits (AAUs) and sets up a system for trading them. The argument for trying this was largely that standard cap-and-trade had been tried in the United States, and it worked well. In fact, it did work well for curbing sulfur emissions, but that argument is without merit. Global cap-and-trade and standard cap-and-trade are fundamentally different.

1. Standard cap-and-trade is run by a government, whereas global cap-and-trade is not.

2. Standard cap-and-trade can subsidize participants with somewhat hidden transfers, whereas global cap-and-trade transfers are far more transparent.

3. Standard cap-and-trade prices carbon emissions, whereas global capand-trade does not.

The only track record for global cap-and-trade is the dismal record of the Kyoto Protocol.

\section{There's No Government}

Under standard cap-and-trade, the government sets and enforces the cap. Under the Kyoto Protocol, because there is no global government, no one even talked about what the cap would be, and no one enforced it. The cap 
was determined indirectly, not by the Protocol, but by the sum of the AAUs eventually allocated to those who ratified the treaty. This is like having the coal-fired power plants discuss among themselves but decide individually how many sulfur emission permits each would get.

\section{Profits from Permits, but Not for Countries}

It is often claimed that global cap-and-trade will be good for hiding compensating transfers to polluters (Gollier and Tirole, chapter 10, this volume). This is true but could be misleading because these systems hide some of their transfers in a way that will not work under global cap-and-trade.

Standard cap-and-trade causes companies to raise their prices (due to the "opportunity cost" of not selling the permits, which we will not explain here). The result is that standard cap-and-trade can actually increase the profits of polluters without any money passing from the government to the polluters. This will not work for international financial transfers, however. Poor countries cannot profit by raising prices on their own citizens. As Gollier and Tirole (chapter 10, this volume) point out,

To be certain, the transfers made under national cap-and-trade programs are different in their economic and political nature from international payments for international permits.

... transfers associated with an allocation of free permits are not that hard to compute and one would imagine that politicians (privately or publicly) opposed to an ambitious climate change agreement would quickly publicize the numbers (if unfavorable to the country) so as to turn their domestic public opinion against the agreement.

In fact, under the Kyoto Protocol, AAU trading became so controversial that Japan had to publicly deny purchasing AAUs from countries previously in the Soviet Bloc (Cramton et al., chapter 12, this volume). The argument that standard (domestic) cap-and-trade demonstrates that global cap-andtrade can hide international transfers from the rich countries and their citizens while making them transparent to the poor countries and their citizens is questionable.

\section{Global Cap-and-Trade Will Not Price Carbon Emissions}

Previously, we showed that global cap-and-trade does not require countries to price emissions. In reality, under Kyoto, the AAU market was so 
illiquid and secretive that there was no "market price," and the price of few transactions was known. This did not result in any carbon pricing policies at all. The main Kyoto Protocol compliance policies were subsidies and requirements for wind, solar, and energy efficiency. These do not put a price on emissions even though the implicit cost of saving carbon ranged as high as 800 euros per ton (Gollier and Tirole, chapter 10, this volume). Global cap-and-trade is unlikely to cause much pricing of carbon emissions, unlike standard cap-and-trade, which requires the pricing of carbon emissions.

\section{Why Global Cap-and-Trade Negotiations Cannot Succeed}

The most decisive flaw in global cap-and-trade is that a strong treaty could never be negotiated, and if it could be, it would unravel. The three main parts to this argument are:

1. Trading risk would unravel a strong global cap-and-trade treaty

2. Free-style permit negotiations would likely end in deadlock

3. No common-commitment formula can be found to replace freestyle negotiations

Note that we cannot rule out a weak global cap-and-trade agreementone that has too little impact on the climate to warrant attention. However, we ignore this possibility because it is essentially useless, and instead we focus exclusively on the problems of strong global cap-and-trade agreements.

\section{The Risks of Prediction-Error Trading}

Earlier we discussed prediction-error trading risk in detail and concluded that unexpected shocks to business-as-usual emissions would lead to defections. This point is not necessary for the present argument because we will argue next that a strong treaty could not even be negotiated. However, this risk is reason enough not to embark on such an adventure. The cost in time (decades) and effort to put such a system into place should not be squandered on one that would have disintegrated in just 10 years had it been built 15 years ago.

We also argued that the knowledge of such individual country risks would drive the developing countries (and likely others) to demand 
larger allocations of carbon permits than they will likely need just to protect against risk (see Cooper, chapter 5, this volume). This factor, in addition to the ones we are coming to, will weaken any global cap-and-trade treaty.

\section{Why Freestyle Negotiations End in Deadlock}

As explained by Gollier and Tirole (chapter 10, this volume):

Free-style negotiations among $\mathrm{n}$ countries are exceedingly complex and are very likely to lead to a deadlock ... [concerning] the allocation of free permits among countries under cap-and-trade. ${ }^{12}$

The extreme complexity they mention is only half the reason that deadlock is inevitable, but it is still decisive. Such complexity is obvious from the dozen or so different variables that Kyoto negotiators attempted to account for when they tried to invent formulas for allocating permits (Depledge, 2000). Many factors were ignored-for example, access to renewable resources.

But Weitzman (2014, chapter 8, this volume) and Cramton and Stoft (2010, 2012a,b) emphasize a different problem with freestyle negotiations-free-riding. With freestyle negotiation of permit allocations, ever country's self-interest is to gain more free permits. This dramatically weakens freestyle commitments. As noted, the risks of prediction-error trading will make countries even more aggressive in their demands for free permits.

On top of the free-riding problem of freestyle negotiations, we have the extreme complexity noted by Gollier and Tirole (chapter 10, this volume), which includes the mixing of climate policy with burden sharing. This makes it that much easier to find excuses to hide behind when free-riding.

But none of these effects leads directly to a deadlock. Instead, they only seem to lead to weak national commitments, $Q_{i}$. Because the sum of all such commitments is the global cap $Q$, there will be a high (weak) global cap.

But Gollier and Tirole (chapter 10, this volume) make the first step in their negotiation process the selection of $Q$, the global cap, and assert that this should be consistent with a $2^{\circ} \mathrm{C}$ limit. Because the outcome of this first step in the negotiation does not commit any country to do anything 
in particular, all will want to show their "ambition" by agreeing to a tight cap, probably consistent with the $2^{\circ} \mathrm{C}$ limit, as has been the case with some previous aspirational agreements, including COP21's Paris agreement.

But with a $2^{\circ} \mathrm{C}$ cap locked in place, the weak individual-country commitments, which sum to a weak global cap, can now be seen to lead to deadlock. Deciding the global cap by two completely different processes, one that leads to unchecked optimistic aspirations and one that leads to nearly unchecked self-serving caution, will never produce consistent results. Hence, deadlock is inevitable.

\section{Why a Common-Commitment Formula Fails for Quantities}

As just seen, a freestyle negotiation leads to deadlock, but we have argued that a common-commitment simplifies negotiations and solves the free-rider problem. So why doesn't this work for a quantity-based treaty? We first noted that a 20-year search for a common quantity commitment has turned up no satisfactory proposal. This history of failure is no accident.

The root of the problem is the nature of the quantity approach. Every allocation of free permits plays two contradictory rolls. Permits are money with which to solve the burden-sharing problem, and, collectively, permits must curb emissions. In "theory," they could do both at once, but that requires the allocation of permits by a fair world government with perfect foresight.

Kyoto's Formulas The Kyoto negotiations first tried a simple ruleequal percentage reductions from 1990 emissions levels. When that failed, they went on to try nine more-complex rules (Cramton et al., chapter 12, this volume; Depledge, 2000). But all of these failed as well, and countries were left to choose their own commitments-a freestyle negotiation indeed.

Frankel's Formula After Kyoto, it was obvious that no acceptable allocation rule was in sight, and including the developing countries would make finding an acceptable rule far more difficult. It was also obvious from the US Senate's 95 to 0 vote that, without the developing countries, the United States would not join. Understanding this, Jeffrey Frankel (1998) took up 
the challenge and worked on politically acceptable allocation formulas. These evolved over the next 16 years and are quite sophisticated (Bosetti and Frankel, 2014). They specify free permit allocations in terms of several parameters, including business as usual emissions, emissions in 1990, and, for the initial-year formula, emissions in the year the country signs the cap-and-trade agreement. So far, there does not seem to be much interest in these formulas, which may not be as transparent as required for acceptability.

Stiglitz (2006a, 2006b) argued that it would be impossible to find a formula for free permits that the world could come close to agreeing on, and Weitzman (chapter 8 , this volume) has taken a similar position. History seems to be confirming these judgments.

\section{Conclusion}

The Kyoto negotiators knew they needed a common-commitment formula and invented 10 of them. They could not agree on any. After Kyoto, it became clear the problem would become far more difficult because developing countries would need to be included. Realizing this, Frankel began proposing formulas in 1998 that covered all countries. There has not been much interest in these perhaps because of their complexity, and after 16 years there seems to be less interest than ever.

The possibility that an easily agreed-on common-commitment formula for global cap-and-trade will someday be discovered cannot be ruled out with certainty. However, it seems that after 20 years of failure and a general loss of interest, it is time to take global cap-and-trade off the table.

\section{Problems with Global Carbon Pricing}

Although a global carbon price commitment is a more direct and simple approach to carbon pricing than is global cap-and-trade, a strong enough version of a carbon price commitment will still be difficult to implement. But difficult is better than impossible. Here we examine the points that may need the most attention from negotiators and researchers. The key problem areas are enforcement and climate-fund transfers. 


\section{Enforcement}

There are always two parts to enforcement: monitoring and incentives. To enforce, you must find out whether the party is in compliance. That's monitoring. To get them to comply, there must be an incentive. The incentive can be a carrot for compliance or a stick for lack of compliance.

Incentives The incentive problem is much the same for any climate commitment. There are social-pressure incentives and there are financial incentives. It is not clear whether the former will be strong enough, and it is not clear that the latter can be implemented. This is equally true of global capand-trade or a global carbon price commitment. But one thing is certain: in either case, the problem is much worse without a common commitment. As we argued earlier, such a commitment is almost certainly impossible for global cap-and-trade.

In fact, without a common commitment, strong enforcement is counterproductive. If you think you don't want to drive faster than $70 \mathrm{mph}$, then you might commit to that individually out of a spirit of cooperation with weak enforcement, but with strong enforcement, say a $\$ 10,000$ fine, you will certainly not commit to anything under $90 \mathrm{mph}$, "just in case." Although enforcement may be hard to arrange, at least with a global carbon price commitment, it is of some use and not counterproductive.

Monitoring The primary challenge for monitoring price is the possibility that a government will cook its books with regard to revenues collected from carbon charges. For most countries, this should not be a problem because they will either provide reasonably reliable public data (most of the Annex I countries under the Kyoto Protocol) or they will be poor countries receiving some climate-fund assistance that can be withdrawn if they do not fully open their books.

For the problematic countries, and there may be a couple of large ones, there are three recourses. First, if they do not open their books to careful auditing, they could be deemed noncompliant regardless of claims concerning carbon revenues. Second, four international organizations-the World Bank, the International Monetary Fund, the International Energy Agency, and the WTO-already conduct similar audits. In fact, such audits would 
be needed to monitor global cap-and-trade with regard to carbon pricing of exports-one of the most difficult segments of society to monitor. Of course, whichever organization performs this function will need additional funding, but that will be a small burden relative to other costs.

Finally, the price of most fossil fuels has easily visible public indicators. The price of gasoline is no secret, and that accounts for roughly one-third of fossil-fuel use. The price of electricity to residential and commercial users can also be discovered easily, as can the price of heating fuels to these groups. Monitoring will not be perfect, but with a little effort, it may well be as good as or better than the monitoring of emissions.

\section{Green Climate Fund Transfers}

We have discussed how to allocate responsibility for and benefits from a climate fund. A higher level question is perhaps just as difficult. How can significant funds be transferred from rich to poor countries without triggering too much political opposition in wealthy countries, especially those on the hook for larger transfers, due to their wealth and high emission levels?

Hiding Transfers One approach is to hide the transfers. This is often cited as a benefit of cap-and-trade, but as explained earlier, this is largely based on a fallacious analogy between global and national cap-and-trade programs.

However, Frankel suggests that poor countries could be given free permits, and they could give the permits to private companies, who would then sell them to private companies in rich countries. In this way, the financial transfers would be kept private and less visible than the financial transfers between governments that are generally envisioned for the Green Climate Fund.

This method would not be as surreptitious as it might seem because companies in the rich country will be required to return the permits to the $\mathrm{UN}$ in order to make use of them, and the UN will be required to keep a full accounting. This transfer will be made public, at which point the press will write stories about how much money went where. It may take a few years before this information is fully utilized by the forces that wish to gain political advantage from stopping the transfers, but that outcome seems inevitable. 
If this ruse is thought to be effective, then a similar process could be arranged under a global carbon price commitment. If the United States had been allocated a responsibility for $\$ 10$ billion of climate fund contributions and the global carbon price was set at $\$ 20 /$ ton, then half a billion carbon-price credits could be issued and marked as redeemable in the United States only. These could then be distributed to poor countries, which would give them to their businesses, which would sell them to US businesses, which would then not be charged for that many tons of carbon emissions.

One advantage of price-based climate-fund transfers (as opposed to permit transfers under a cap) is that their value would be far more predictable. For example, with global cap-and-trade, the carbon price would drop precipitously in the case of a global slowdown. In this case, permit transfers to poor countries would suddenly become far less valuable and perhaps nearly worthless. However, the global carbon price might spike while a developed country is in recession, and it would find itself making double or triple climate-equity payments at just the wrong time. Such risk would not be present under a global carbon price commitment.

Making Transfers More Appealing Jonathan Gruber, an economist who consulted on the design of President Obama's Affordable Care Act, is now famous for explaining that the "Lack of transparency is a huge political advantage" for "getting the bill passed." In the long run-and no policy is longer run than climate policy-attempting fairly transparent deceptions involving tens of billions of dollars may prove counterproductive. Better approaches are available.

The first principle for making equity transfers more palatable is to make sure they are reciprocal. Traditionally, this would mean requiring the money be used for some approved "green" project, hopefully related to climate. Unfortunately, history has shown that this leads to corruptionwitness the Clean Development Mechanism, the Joint Implementation Mechanism, and even the enormous subsidies for corn ethanol in the United States and elsewhere.

The basic formula for reciprocity should be that equity transfers are conditional on compliance with either a global cap-and-trade or a global carbon price commitment. This will provide funders with far more assurance 
that they are getting something worthwhile for their money while providing a useful incentive mechanism for enforcing compliance.

A number of other standard techniques are available for making transfers more palatable. One is to require funds to be spent in the donor country. This would not be possible with global cap-and-trade. Another way is to earmark tax receipts from the most unpopular domestic polluters to be used for equity transfers.

\section{Summary and Conclusion}

If steady progress was being made with global cap-and-trade, then even a promising new approach would seem questionable. But after 20 years of real-world testing and academic theorizing, no obvious progress can be seen. Our discussion leaves global cap-and-trade with four decisive failures, all of which are addressed by global carbon pricing.

\section{Carbon Pricing Eliminates Huge Trading Risks}

Global cap-and-trade needs to lock in targets for a decade or two. During this time, business-as-usual emissions change unpredictably. As shown previously, this can be extremely risky for participating countries. This leads to demands for more generous targets or even refusal to participate. If a strong treaty were ever implemented, then it would lead to defections and unraveling. Global carbon pricing nearly eliminates this source of risk.

\section{Carbon Pricing Actually Does Price Carbon Emissions}

Neither the Kyoto Protocol nor global cap-and-trade, as specified in this volume, requires that emitters acquire emission permits. Instead, governments must own permits similar to Kyoto's AAUs. In idealized economic theories, the price of AAUs would be transmitted, with the help of government regulations, to actual carbon emissions. There has been no sign of this under the Kyoto Protocol, and there is no reason to believe things would be different under a newly proposed global cap-and-trade policy. In contrast, global carbon pricing would require countries to price carbon emissions to meet the global carbon price commitment. So global carbon pricing would strongly promote efficiency, and global cap-and-trade would do little to promote efficiency. 


\section{Pricing Rewards Environmental Ambition}

A global cap, if it works as intended, will control the total emissions of the participating countries. If one country emits less, that will free up permits so other countries can emit more. If one emits more, others will be constrained to emit less.

The consequences are obvious. If any country, province, social group, or individual voluntarily does more than is in their narrow self-interest, it will not benefit the climate at all. All such altruistic efforts will be negated by the market. Ambitious action by some will simply make it cheaper for those who are not ambitions to do less, and they will do less. If they do not do enough less to negate all environmental ambition, then the market will depress the price of carbon even more and make sure selfish people do even less. The cap will be met.

Global carbon pricing does not discourage ambition at all. Extra abatement does not change the price faced by nonambitious groups and individuals, so the ambition of others does not encourage them to do any less. The result is that every ton of ambitious abatement reduces global emissions by a full ton. ${ }^{13}$

\section{Pricing Stops Free-Riding in the Negotiations}

Climate change is a problem of managing the collective commons, and the essence of that problem is that countries can free-ride on the use of the atmosphere. Requiring them to pledge some action, even if the action is to join a global cap-and-trade agreement and choose a "target" —an allocation of emission permits-does not prevent free-riding. Instead of free-riding by just emitting, countries can now free-ride by taking a high target and either emitting more or profiting from selling extra permits.

To stop free-riding, we need to replace individual commitments with a common commitment. For 20 years, Kyoto negotiators and academic economists have tried to find ever more complex formulas to create a common quantity commitment, with no signs of progress. Global carbon pricing provides an obvious solution. All countries should commit to price at the same global price. There is still a problem of negotiating climate-fund transfers, but decoupling these two problems greatly simplifies them and largely insulates climate policy from disputes over monetary transfers. 


\section{Conclusion}

Global carbon pricing was designed to facilitate negotiation and cooperation. To many this will seem backward-it should have been designed "for the climate." But the real problem is not the climate; the real problem is people-and their lack of cooperation. After 20 years of pretending to do what is right for the climate, and actually doing almost nothing, it is time for a change. We should design the negotiations and our policy goal to maximize cooperation and accept that we cannot do better than the best we can do. Unfortunately, COP21 in Paris was a step back from this perspective. Paris focused on nonbinding, nonenforceable, incomparable "intended nationally determined contributions," which is the opposite of a reciprocal, common commitment. As a result, contributions do not add up to what is required, and carbon pricing was hardly mentioned in the final agreement. This is a recipe for inaction, and thus disaster.

Carbon pricing is a simple idea. But the change of focus from supposedly scientific round numbers, 1 trillion tons, 2.0 degrees, $450 \mathrm{ppm}$ (or some say $350)$, to a focus on how people cooperate makes all the difference. Elinor Ostrom spent her life studying how people actually solve common-pool resource problems. She found the answer was always "trust and reciprocity," not numerology. Virtually all cooperation research agrees. Global carbon pricing is designed to build trust with reciprocity.

\section{Frequently Asked Questions About "Global Carbon Pricing"}

Q1. Does it mean a global tax? No. It does not require that any carbon taxes or fossil fuel taxes be implemented. See Q3.

Q2. What is it? An agreement between countries responsible for most of the world's greenhouse gas emissions to price their own fossil-fuel emissions at least as high (on average) as the agreed-on global price, $P$.

Q3. What does "to price their own emissions" mean? Quite simply, a country's average carbon price-carbon revenue per unit emissions-must be at least as high as the global carbon price. The simplest way would be with a carbon tax, which could be used to replace other taxes. Cap-and-trade could also be used, as well as other methods. Renewables could be given credit based on carbon saved and the global price.

Q4. What does "on average" mean? Countries could price gasoline at one level, diesel at another, and coal at another. All that matters is (total carbon 
revenue)/(total carbon emissions) $\geq P$. There could even be averaging from one year to the next.

Q5. Who would set the global price? It would be negotiated by a "coalition of the willing," AKA a Carbon Club. This coalition will be a group of countries that encompass most emission and are willing to set a reasonably high price.

Q6. Why does a price agreement help? It forms a common commitment, so each country in the coalition is saying, "We will price carbon at $P$ if all of you will too." Read the preface to see how this works.

Q7. Is it fair to poor countries? A green climate fund is needed because without one there would be no international payments. This negotiation must be separate but related. The UNFCC requires "common but differentiated responsibilities." The global price is the common part and the climate fund is the differentiated part.

Q8. Why not stick with global cap-and-trade? There's a reason it has been getting less popular for 20 years. It was accidentally designed to be hard to negotiate. The idea was to make it safe for the climate but risky for countries. Global pricing was scientifically designed for cooperation, and it can be adjusted to hit climate targets just as well, probably better, than global cap-and-trade.

Q9. Who's in favor of it? Everyone on the list of contributors to this book is in favor of global carbon pricing. The authors have alternative views on how best to implement it.

Q10. With your green climate fund, how big would the transfers be from rich to poor? At the start, a high-end estimate might be $€ 36$ billion per year, and a low-end estimate might be $€ 5$ or $€ 10$ billion. But this is, of course, speculative. It will be determined by negotiation, not science, so it can't really be calculated. Negotiators will balance rich-country reluctance against poor-country needs and demands.

Note that the high end is about one-third of what US Secretary of State Clinton promised at Copenhagen. To put this in perspective, this is about one-tenth of $1 \%$ of the rich country's GDP. This is for a $€ 30 /$ ton carbon price. Eventually, it would need to go much higher, but by then the world will likely have seen enough to be willing to spend more.

Consider the high estimate first. World $\mathrm{CO}_{2}$ emissions from fossil fuel are a bit less than 36 billion tons. China has said it doesn't need climate-fund 
subsidies, so that leaves about one-third of the emissions (12 billion) coming from poor countries that need climate funds. A tremendously strong start would be a $€ 30 /$ ton carbon price, and that might reduce emissions by as much as $20 \%$, or by 2.4 billion tons in poor countries. Some abatement will be cheap to free, and some would cost as much as the $€ 30$ carbon prices, so on average the cost would be about $€ 15 /$ ton, for a total cost of $15 \times 2.4=€ 36$ billion/year. So the high-end number assumes that rich countries pay $100 \%$ of the costs and somewhat more because when the poor countries stop subsidizing fossil fuel, that actual saves them money (it prevents waste).

But $€ 30 /$ ton is a high starting price, and $100 \%$ is a high subsidy rate, and not all of these countries will join and need subsidies (e.g., some of the OPEC countries). In fact, it may be necessary to begin quite slowly. But after 20 years without any global cooperative agreement, a slow but solid beginning would be enormous progress. Also remember that without any transfer from rich to poor, little is likely to get done.

Q11. What carbon price do you think the EU countries, for example, would vote for? This brings up the central advantage of global carbon pricing. But first, note that the United Kingdom is already paying more than $£ 100^{14}$ and more per ton of carbon saved, and the OECD ${ }^{15}$ finds that feed-in-tariffs cost an average of $€ 169$ per ton saved, and there are other subsidies on top of those.

Second, notice that a $\$ 100$ carbon tax, if implemented as a tax shift, would be close to free. The tax that was shifted away would return as much revenue as the carbon tax collected, and the distortions and inefficiencies of the old tax would be eliminated. These would roughly match the cost of carbon abatements, and those abatements would have the added benefit of reducing damage from domestic pollution. So not even counting the climate benefit, this policy might produce a net benefit. ${ }^{16}$

Now turn to our best feature. Global carbon pricing is not an individualistic approach. The EU would not be doing this without major partners, at least the United States and China, and probably more, even at the start. The agreement would be that all countries price as high as the global price. Now we have no illusion that the EU will suddenly impose a £100 carbon charge. More likely, it will be inclined toward some timid level, such as $€ 25 /$ ton. But with our proposal, the EU would then realize that if it advocates $€ 35$, then getting that accepted would bring China, the United States, 
and others along with it. So why not advocate $€ 35$ ? You only have to do that if you gain the satisfaction of finally bringing the United States and China along with you, and bringing them along would at least quadruple the impact of that $€ 10$ increase.

So we can't predict the EU's price proposal, and we certainly cannot predict what the coalition of the willing will agree to, but we can tell you that even a $€ 30$ price on carbon could save a lot of money while doing far more good for the climate than current policies.

Q12: What if some countries have large-scale, relatively cheap, and measurable carbon-capture potential (e.g., afforestation)? How could that potential be harnessed with a global carbon price? This will require an add-on mechanism, but a fairly simple one once the negative emissions become measurable. The measurement process would supply the negative-carbon facility with a one-ton carbon credit for each ton captured. The add-on mechanism would require that all private carbon emitters can use a negative-carbon credit (a negaton) in place of buying a carbon credit in their cap-and-trade market or in place of paying their fossil-fuel tax. Every country in the climate coalition would be required to allow this.

The negative-carbon credits would be purchased by those subject to the highest carbon prices anywhere within the coalition. Competition would then set the price of negatons of carbon at the highest carbon charge imposed, and because the global price, $P$, is the average of all such charges, the price of a negaton would always be higher than $P$.

Q13: Do you think global carbon pricing is all that is needed? No. Although global carbon pricing facilitates cooperation and is an essential climate policy, it is of course not the only policy needed to effectively address climate change. Investments in green research are needed, too, and there is a role for some command-and-control style regulation, such as building standards. But the lack of a common commitment on carbon pricing is the primary source of the problem, and so correcting this is what this chapter and book is about.

\section{Notes}

1. This first section does not cover global carbon pricing directly. Rather, it orients the reader to a different way of thinking about international climate negotiations. For a more direct approach, start with "The Solution." 
2. This can often be better than having it done by a higher government. However, Ostrom (2012) does not say this is always best: "People want to make me argue that community systems of governance are always the best: I will not walk into that trap." At the global level, there is no government. The chapters in this book discuss how the countries of the world can self-organize a global system of climate governance that builds in reciprocity and allows trust to develop. For a global public good, a global governance (not government) is required.

3. Ad Hoc Working Group on the Durban Platform. Non-Paper, ADP.2014.6. July 7, 2014.

4. We often refer to Elinor Ostrom (although she did not directly speak about cooperation among governments) because she has pioneered some of the most important cooperation research and was particularly concerned with solving common resource problems without top-down help from a government, which is the problem faced at the international level. Also, her work on the role of reciprocity for cooperation has been robustly supported by the general science of cooperation, and it is relevant for, and fully consistent with others' view of, international climate negotiations (see, e.g., MacKay et al., chapter 2, this volume).

5. These would likely be carbon-revenue credits-in other words, credit for collecting, say, \$1 million of revenue from carbon charges (see Stoft, 2009).

6. It would likely be best to start the negotiation process in a small group of big emitters so that certain basics are agreed on before involving the UN (see chapter 12, this volume).

7. See MacKay et al. (2015) for a similar treatment.

8. We note that what is proposed here is fully multilevel, in other words, "polycentric," as Ostrom uses that term. There would be an international agreement on price, but each country would decide all of the pricing details and what to do with revenues and monitoring and enforcement details. Countries would be free to delegate responsibility to provinces, and provinces could delegate to cities. Most actual change would happen at the local and even individual level.

9. We agree with Parry (chapter 3, this volume) that local carbon-related externalities are a reason for allowing countries to use different carbon prices, but we think this is best handled by a uniform price commitment and some form of tradable pricing credits.

10. Gollier and Tirole (chapter 10, this volume) give the formula in terms of permits; our equation converts it to dollar transfers by using the price of permits.

11. It would cleverly engage in some cheap abatement and sell the resulting excess permits. 
12. As they note, this also applies to negotiations over the Climate Fund contributions.

13. Of course, other aspects of the problem, particularly land use, technological progress, and the dissemination of accurate scientific information, are all consistent with carbon pricing.

14. Take the CFD strike prices for new onshore wind or new nuclear, roughly 90 per MWh, or recent RO bands (roughly 45 pounds per MWh subsidy). If this is substituting for gas-generated electricity at $450 \mathrm{~kg} / \mathrm{MWh}$, then we have a subsidy of 45 pounds per 0.45 t CO 2 abated, or 100 pounds per ton.

15. "Climate and Carbon: Aligning Prices and Policies," OECD Environment Policy Paper 1, OECD Publishing, Paris, 2013.

16. An economy-wide tax shift involving a carbon price of 100 pounds per ton and reductions of other taxes would have little effect on the budgets of a typical family, although there might need to be distributional corrections, such as already exist (e.g., winter fuel payments targeted at all old people and other social mechanisms to protect those in "fuel poverty").

\section{References}

Barrett, S. 1994. Self-enforcing international environmental agreements. Oxford Economic Papers 46:878-894.

Bolton, G. E., and A. Ockenfels. 2000. ERC: A theory of equity, reciprocity and competition. American Economic Review 90 (1): 166-193.

Bosetti, V., and J. Frankel. 2014, August. Sustainable cooperation in global climate policy: Specific formulas and emission targets. Climate Change Economics 5 (3).

Bowles, S., and H. Gintis. 2013. A Cooperative Species: Human Reciprocity and Its Evolution. Princeton, NH: Princeton University Press.

Cooper, R. N. 2008. The Case for Charges on Greenhouse Gas Emissions. Discussion Paper 08-10, Harvard Project on International Climate Agreements, Belfer Center for Science and International Affairs, Harvard Kennedy School.

Covert, T., M. Greenstone, and C. R. Knittel. 2016. Will we ever stop using fossil fuels? Journal of Economic Perspectives 30 (1): 117-138.

Cramton, P., A. Ockenfels, and J. Tirole. 2017. Policy Brief-Translating the collective climate goal into a common commitment. Review of Environmental Economics and Policy. In press.

Cramton, P., and S. Stoft. 2010, International climate games: From caps to cooperation. Research Paper No. 10-07, Global Energy Policy Center. 
Cramton, P., and S. Stoft. 2012a. Global climate games: How pricing and a green fund foster cooperation. Economics of Energy \& Environmental Policy 1 (2).

Cramton, P., and S. Stoft. 2012b. How to fix the inefficiency of global cap and trade. Economists' Voice.

Depledge, J. 2000. The origins of the Kyoto Protocol. Prepared under contract to the UNFCCC, FCCC/TP/2000/2.

Edenhofer, O., J. C. Steckel, M. Jakob, and C. Bertram. Reading the writing on the wall: Coal and the Paris Agreement. Mimeo.

Frankel, J. 1998, July. The Kyoto Agreement on mitigating global climate change: Gains to all from participation by developing countries. Keynote speech, Executive Program on Climate Change and Development, Harvard Institute for International Development.

Fudenberg, D., and J. Tirole. 1991. Game Theory. Cambridge, MA: MIT Press.

Green, F. 2015. Nationally self-interested climate change mitigation: a unified conceptual framework. Working Paper No. 224, Centre for Climate Change Economics and Policy.

Kraft-Todd, G. T., E. Yoeli, S. P. Bhanot, and D. G. Rand. 2015. Promoting cooperation in the field. Current Opinion in Behavioral Sciences 3:96-101.

MacKay, D., P. Cramton, A. Ockenfels, and S. Stoft. (October 15, 2015). Price carbon: I will if you will. Nature 526:315-316.

Nordhaus, W. 2015. Climate clubs: Overcoming free-riding in international climate policy. American Economic Review 105:4.

Ostrom, E. 1990. Governing the Commons: The Evolution of Institutions for Collective Action. Cambridge, UK: Cambridge University Press.

Ostrom, E. 2007. Collective Action Theory. In The Oxford Handbook of Comparative Politics, ed. Carles Boix and Susan C. Stokes, 186-208. Oxford: Oxford University Press.

Ostrom, E. 2009. A polycentric approach for coping with climate change. World Bank Report, WPS5095.

Ostrom, E. 2012. The Future of the Commons. London: Institute of Economic Affairs.

Poteete, A., M. Janssen, and E. Ostrom. 2010. Working Together: Collective Action, the Commons, and Multiple Methods in Practice. Princeton, NJ: Princeton University Press.

Schelling, T. C. 1960. The Strategy of Conflict. Cambridge, MA: Harvard University Press. 
Stiglitz, J. E. 2006a. A new agenda for global warming. Economists' Voice 3:7. doi:10.2202/1553-3832.1210.

Stiglitz, J. E. 2006b. Saving the Planet. In Making Globalization Work. New York: W. W. Norton \& Company.

Stoft, S. 2008. Carbonomics: How to Fix the Climate and Charge It to OPEC. Nantucket, MA: Diamond Press.

Stoft, S. 2009. "Flexible Global carbon pricing: A backward-compatible upgrade for the Kyoto Protocol.," Working Paper No. RSCAS 2009/35, European University Institute Working Paper No. RSCAS 2009/35.

Stoft, S. 2010. Dépasse Copenhague: Apprendre à coopérer. Translated by Mathieu Thomas. Paris, L'Harmattan.

United Nations Framework Convention on Climate Change (UNFCCC). 1992. Accessible at: https://unfccc.int/resource/docs/convkp/conveng.pdf

Weitzman, M. L. 2014. Can negotiating a uniform carbon price help to internalize the global warming externality? Journal of the Association of Environmental and Resource Economists 1 (1/2): 29-49. 



\title{
5 The Case for Pricing Greenhouse Gas Emissions*
}

\author{
Richard N. Cooper
}

\section{Introduction}

This chapter argues for imposing a globally uniform charge on all emissions of greenhouse gases (GHGs), insofar as practicable. It will focus for concreteness on carbon dioxide, the most prevalent and long-lasting greenhouse gas. It argues that such a charge would be superior to a system based on quantitative international targets with provisions for trading emission rights, global cap-and-trade for short.

Climate change is a global problem, not a localized one; to be effective, it requires a global approach to the reduction of GHG emissions. "Global" does not necessarily mean universal, although that would be desirable. It would be sufficient to engage the 30 to 40 largest emitting countries, at least for the next decade or two. These countries account for the overwhelming majority of fossil fuel consumption and also include countries covering the bulk of changes in land use that result in $\mathrm{CO}_{2}$ emissions.

But several economies, most notably the European Union (EU), have embarked on a cap-and-trade system. It is worth asking, therefore, whether the two systems can coexist and comply with a uniform international charge on carbon. The answer is affirmative, provided several conditions are met. These conditions would assure that the combined charges from fossil fuel taxes and carbon permits issued under cap-and-trade equaled the requirements of the uniform international charge (for further discussion, see Cooper, 2008).

The case for a charge on carbon as opposed to a global cap-and-trade scheme is based partly on the negatives associated with cap-and-trade and

* Originally published as "The Case for Charges on Greenhouse Gas Emissions," Discussion Paper 2008-2010, Cambridge, MA: Harvard Project on International Climate Agreements, October 2008. 
partly on the positives associated with the carbon charge. Let us take up the negative component first.

\section{International Cap-and-Trade}

How well would a cap-and-trade system work at the global level? It would require allocating emission targets, covering many years, to states. To be effective, the total targets would have to be tight enough to cut emissions significantly from what they would otherwise be. In my view, it will be impossible to negotiate meaningful national targets. The reason is straightforward. Developing countries understandably place a higher priority on economic development than they do on mitigation of climate change, and they will not agree to binding emission targets that they believe will compromise their development objectives (Stiglitz, 2006b; chapter 6, this volume). Moreover, we now have several examples of countries that have grown $8 \%$ to $10 \%$ for two decades or more, and most developing countries will aspire to achieve such growth rates, even though most countries will fail to achieve them. But aspirations, not ex post realities, will shape their positions in international negotiations. With generous targets allotted to the leading developing countries, the rich countries, especially the United States, will not agree to compensate with targets so stiff that they seriously threaten standards of living in those countries. In short, meaningful binding global targets are not feasible.

Even if this (decisive) argument is put to one side, there is another acute problem with a global system based on cap-and-trade. To work, the national targets (i.e., emission rights) must be allocated to the entities that actually make decisions about what kinds and how much fossil fuels to consume, that is, to electricity-generating firms and energy-intensive industrial firms. The idea of cap-and-trade is that each covered firm would be given an emission target for the coming year, perhaps declining from year to year, and each firm would either have to meet its target or purchase emission rights from other firms that had reduced emissions below their targets. This would require a market in emission permits, of which one has functioned in Europe since 2005. Although there were a number of glitches, Europeans have demonstrated that such a market can work. But the European system covers less than one half of European $\mathrm{CO}_{2}$ emissions. For compelling practical reasons, Europeans have not yet extended the system to all or even most emissions, particularly those in the transport and heating sectors, and in much of industry. 
Unless the permits are auctioned, raising the separate question of how a fair auction is ensured, the permits are allocated to the covered firms free of charge. In countries with loose governance (i.e., most countries), this is an invitation to favoritism: the government is allocating permits that have significant financial value, and most governments are likely to do that in a biased way. Put more bluntly, it is an open invitation to corruption. This is a fatal flaw in a global cap-and-trade system because well-governed democratic countries will be unwilling, and they should be unwilling, to impose burdens on their own citizens to enrich political favorites in less well-governed countries through international trade in emission permits. Concretely, no US senator who understood the process would vote in favor of a treaty with this implication. In other words, the United States would not participate in such a global scheme even if it had adopted a capand-trade system domestically.

Viewed from a slightly different perspective, what senator, once he or she understands the full implications of a trading regime, can vote for a procedure that could result in the unconditional transfer of billions of dollars, even tens of billions, to the government of communist China, to Castro's Cuba, or to Putin's Russia? That would be politically unacceptable, at least in the United States and probably elsewhere.

This implication of unwholesome international transfers could be avoided if each participating country had its own national cap-and-trade system (EU-wide in the case of the EU). But that would vitiate much of the "trade" part of a cap-and-trade system because we have reason to believe that emission reductions will be much less costly in many developing countries than they would be in many rich countries. Denying international trade in permits would reduce greatly the efficiency of the cap-and-trade system. High-cost emission reductions would yield to lower-cost reductions only on a national basis, not internationally.

That is the negative case for carbon charges: the main alternative, capand-trade, cannot be made to work effectively and efficiently at the global level. Yet a global solution is required.

\section{Carbon Charges}

The affirmative case for carbon charges contains a number of elements. First, it uses the price system, which is the only way to reach the billionplus decision makers around the world who decide what and how much 
energy to consume. They will be encouraged to either consume less or switch to less carbon-intensive sources of energy.

Second, the charge can be applied to all fossil fuels at choke points-oil refineries, main gas pipelines, and principal coal transit points-with high confidence that the charge would affect downstream prices, that is, those faced by businesses and households. Separate provision could be made for the relatively few exceptions (e.g., a power plant located at a coal mine).

Third, the charge can and should (by negotiation) be made uniform (with perhaps a time lag of a few years for some developing countries), thus neutralizing the important issue of competitiveness of national energyusing industries in international markets. For example, the steel industry in all important steel-making countries would pay the same carbon charge, so none could complain that they were being put at a competitive disadvantage by a different GHG regime in other countries. It is noteworthy that many European countries levy much lower electricity charges to business than they do to households, using "competitiveness" as the rationale; and they were disproportionately generous to some industries in the allocation of emission permits to some industries on similar grounds.

Fourth, a carbon charge would generate revenues for many years, badly needed by most governments these days (Norway and Qatar may be exceptions). These revenues could be used as each government saw fit, provided the use did not undermine the purposes of the agreement (viz. to reduce GHG emissions). Some would reduce deficits, some would finance needed expenditures, some (probably including the United States) would reduce other taxes, and many would perhaps help adaptation to climate change in poor countries. Properly used, the revenue from the charges could enhance growth. Auctioning permits in a cap-and-trade system would also produce revenues, but if the legislative process in Europe and the United States provides any guidance, auctions will be resisted strongly in favor of free allocation. The EU has agreed that in principle all permits will be auctioned by 2027-22 years after the first introduction of its cap-and-trade system —and it remains to be seen whether this agreement will actually be carried out. The carbon charge can be phased in gradually, on a certain timetable, to limit any unwanted macroeconomic effects of a significant new tax.

The impact of a carbon charge on economic growth would be low and could even be positive if the revenues are used in growth-enhancing ways (e.g., to reduce distortionary taxation or finance research, development, and dissemination of new knowledge). 
It will not be easy to negotiate a uniform charge among the major emitting countries. But "difficult" is much easier than "impossible," which I believe to be the case for a meaningful global cap-and-trade system. The current international negotiations through the conferences of parties to the Framework Convention on Climate Change cannot, in my view, lead to a meaningful mitigation of climate change (Gollier and Tirole, chapter 10, this volume). There are too many (193) participants, with too diverse interests and objectives, operating under a parliamentary rule of "consensus," which permits a small number of countries, even countries that are not relevant to GHG mitigation, to block action. The focus has been agreeing on binding quantitative restrictions on emissions for only a subset of relevant countries, although the last restriction seems to be easing. To get somewhere, the negotiators need to shift away from quantitative emission targets to meaningful actions (such as a common charge on $\mathrm{CO}_{2}$ emissions, although others are imaginable) by the relevant emitters, and initially only those emitters need to participate in the negotiations. It is much easier to focus on one quantitative target than on national targets of all members (see Cramton et al., chapter 4, this volume, and Weitzman, chapter 8, this volume).

Some will object that a charge on carbon will leave the resulting reduction in emissions uncertain because we do not know ahead of time how responsive businesses and households will be to the charge. That is entirely true. If the response is judged to be too slight, then the charge can be raised in future years after an initial trial period of 5 to 10 years. But the cap-andtrade system also has its uncertainties. As we learned from European experience, the permit price can decline to such a low level that conservation and fuel-switching is not encouraged at all, a result produced in part by two recessions that were not anticipated when decisions were announced on the permits to be allocated.

Moreover, from basic principles, it is preferable to have a stable emissions price than one that varies with macroeconomic conditions or other disturbances to supply or demand for energy (Weitzman, chapter 8, this volume). The stock of greenhouse gases in the atmosphere, not the current inflow, influences the climate. The "externality" of emissions pertains to stock, not to flows, and is the same per ton of $\mathrm{CO}_{2}$ whether the flow is low or high. Thus, the price on that externality should be relatively stable, not variable. Moreover, although European experience has been with unexpectedly low prices, it is a reasonable presumption that if the price had instead risen sharply to great heights, the political processes in Europe would have 
taken steps to limit the high price rather than see it generate an overall economic slowdown.

\section{Compliance}

What about compliance? This issue is for any international agreement that imposes unwelcome costs on the participants. The temptation to "free-ride" - to shirk while others are (presumably) carrying out their obligations-is ever-present. That is as true of a global cap-and-trade agreement as an agreement involving carbon charges. In either case, monitoring would be required, made easier by constant improvements in long-distance sensors, but on-the-ground sensors and international inspections should also be introduced. In the case of carbon charges, the national legislation introducing such charges would be relatively easy to track. Harder would be the actual collection of emission charges. But the Fiscal Department of the International Monetary Fund is already familiar with the tax systems of all member countries (only Cuba, North Korea, Taiwan, and the smallest economies are not members, all except Taiwan being low emitters). It could be charged with monitoring the collection of carbon charges by each participant in the agreement, which could then be compared with the information from the sensors and inspections.

If a country were found to be out of compliance, then it could be asked in informal consultations, and ultimately in formal international panel reviews, to explain its position. Systematic cheating could of course be possible on a small scale. It would be more difficult on a large scale and would have to involve the complicity of many officials, something that is increasingly difficult in the age of the Internet and whistle-blowers.

If a country were significantly and persistently out of compliance, then its exports could be subject to countervailing duties in importing countries. The conceptual and legal basis for such duties-to offset government subsidies to exports-has existed for many years and is embodied in the World Trade Organization (WTO) (Stiglitz, 2006a) as well as in national legislation. The new element is that, under the international agreement, the agreed charge on carbon emissions would be considered a cost of doing business, such that failure to pay the charge with government complicity would be considered a subsidy, subject to countervailing duty under existing procedures. Nonsignatory countries could also be subject to countervailing 
duties. WTO panels have found that imports can be restricted on a discriminatory basis if the originating country is in violation of an international environmental agreement (Stiglitz, chapter 6, this volume). This possibility would provide a potent incentive for most countries to comply with the agreement regardless of whether they were formal signatories. Of course, the sanction would apply only to exports, not to domestic sales, by the offending country.

\section{Summary}

In summary, I conclude that a uniform carbon charge in all major emitting countries, revenues to be kept at home, is far superior to cap-and-trade as a global arrangement for mitigating climate change. This is partly because agreement on an effective and efficient global cap-and-trade regime is hard to imagine, both because the global "caps" would be too high and because the allocation of permits to domestic agents would invite corruption in many countries, leading other countries to decline to trade permits with them-for similar views, see Nordhaus (2013), Weitzman (chapter 8, this volume), and Cramton et al. (chapter 12, this volume). Agreement on harmonized national carbon charges would not be easy, but at least agreement on common actions would have some chance to succeed if the relevant international community decided there needed to be a serious attempt to mitigate climate change. It would have several advantages: providing an appropriate universal price signal to reduce consumption of fossil fuels, generating needed revenue, and dealing directly with widespread concerns about international competitiveness and even stimulating growth-an important point for developing countries.

\section{References}

Cooper, R. N. 2010. The case for charges on greenhouse gases. In Post-Kyoto International Climate Policy, ed. Joseph E. Aldy and Robert N. Stavins. Cambridge, UK: Cambridge University Press.

Nordhaus, W. 2013. The Climate Casino. New Haven, CT: Yale University Press.

Stiglitz, J. E. 2006a. A new agenda for global warming. Economists' Voice 3:7.

Stiglitz, J. E. 2006b. Saving the planet. In Making Globalization Work. New York: W. W. Norton \& Company. 



\title{
6 Overcoming the Copenhagen Failure with Flexible Commitments*
}

\author{
Joseph E. Stiglitz
}

\section{Introduction}

There is by now widespread agreement that climate change represents an existential threat, that only by global action can the accumulation of greenhouse gases in the atmosphere be stymied, and that there has to be some appropriate form of burden sharing (see, in particular, Stiglitz, 2011). There is even broad consensus over the urgency of action; that unless we act soon, there is a serious likelihood of an increase in temperature well above the $2^{\circ} \mathrm{C}$ that was at the core of the Copenhagen agreement. Yet despite the broad consensus, there has been little progress. There has been some-but the voluntary measures taken by various countries simply don't add up to what is needed. This chapter (like others in this book) attempts to explain why that may be the case and points to an alternative framework for negotiations that, I believe, is more promising than that on which the world has embarked since the Rio agreement of 1992.

The fundamental issues are simple to state but hard to resolve: the global environment is a global public good-all benefit from a good environment, and all suffer from climate change (Stiglitz, 1995, 2006a, 2006b, 2006c). As in the case of any public good, there is a problem of undersupply: everyone would like to "free-ride" off the efforts of others in supplying the public good. In the case of global warming (climate change), there is an additional problem: some suffer more from the consequences of climate change than others, the adjustments needed to avoid climate

* This article is an updated version of an article that appeared in Economics of Energy \& Environmental Policy, Vol. 4, No. 2, pages 29-36, 2015, DOI: http://dx.doi.org/ 10.5547/2160-5890.4.2.jsti, reproduced by permission of the International Association for Energy Economics (IAEE). 
change are greater for some than for others, and the ability to take action to reduce emissions and adapt to the consequences are greater for some than for others. Indeed, it used to be thought that countries such as the United States, which are the largest contributors to climate change, would suffer the least from it. As we have become more aware of the multiple effects of climate change (including on weather variability), that view is no longer held so strongly: rich countries such as the United States are vulnerable to more property damage from events like Hurricane Sandy. Moreover, poor countries today are responsible for an increasing share of carbon emissions.

Still, the central issue in reaching a global agreement entails burden sharing-who should pay the price associated with reducing greenhouse gas emissions? Should it be the large developed countries that have so far contributed most to the increase in greenhouse gases over the past 200 years? Should poorer developing countries be asked to sacrifice their growth potential so that the advanced countries can continue in their emissionsintensive lifestyle?

Some suggest that it should be easy to arrive at an agreement. Whenever there are large externalities-and greenhouse gases give rise to a huge externality-there are arrangements that are Pareto superior, where all would be better off compared to carrying on in a "business-as-usual" manner. But the problem in this case is that these Pareto improvements would entail developing countries making significant sacrifices that they view they can ill afford so that developed countries can continue in their profligate patterns-or so that developed countries could be compensated for not continuing in their profligate patterns. This is because those in the developing world, disproportionately located in the tropics, are likely to be hurt most by climate change. However, there is increasing evidence that some of the extreme weather events associated with climate change will affect even those living in more moderate climates, many of these countries will be adversely affected by sea level changes, and all could be affected by disease vectors.

Perhaps, in the end, when developing countries face the bleak alternative of desertification, droughts, flooding, and so on, they will be willing to make sacrifices, as unfair as they may seem. Perhaps in the end citizens of more developed countries will feel a stronger moral obligation to bear their fair share of the burden. This chapter, however, is written in the 
hope that there is scope for arriving at a negotiated solution sooner rather than later.

\section{The Failure of the Current Approach}

The Kyoto approach, based on allocating "emission rights" (which could be traded) to different countries, has an inherent problem. It is now widely recognized that emission rights have a monetary value-probably on the order of $\$ 80$ to $\$ 100$ per ton in an emissions control scheme achieving the $2^{\circ} \mathrm{C}$ goal. Giving a country emission rights is equivalent to giving the country money. A global agreement has to decide on how to allocate an asset worth some trillion dollars a year. No wonder it is hard to reach such an agreement.

Inevitably, if there is to be an agreement, the world will have to decide on some principles of allocation-a formula. The debate will focus on the terms of the allocation formula.

Kyoto seemed based on a principle that worked imperfectly among developed countries but will simply not work when developing countries are brought in: countries were asked to make a given percentage reduction relative to their prior levels of emissions. Negotiations focused on adjustments up or down from the base rate, defended on the grounds of particular circumstances facing particular countries. But this principle essentially says that those who emitted more in the past have the right to emit more in the future. No developing country would or should agree to this principle.

Alternative principles seem more ethically justifiable. One would divide the world's carbon "space" according to population in 1992, when the problem of global warming was globally recognized. Some countries, such as the United States, have essentially already used up their carbon space. Thus, they either need to move to zero net emissions or purchase emission permits from others.

There are, of course, more "progressive" allocations. Conventional principles would allocate a global asset such as emission rights in a progressive manner, with poorer countries getting a larger allocation. Many would argue that in allocating carbon space, one should go back in time well before 1992. Since developed countries were responsible for the overwhelming proportion of the increase in carbon concentration over the 
past 250 years, they would have to reduce their carbon emissions going forward even more.

The approach suggested here implies avoiding any attempt at a grand solution to the fair allocation of emission rights, but recasting the problem in ways that minimize the redistributive aspects of the negotiations.

\section{The Costs of Adjustment}

Fair burden sharing requires some notion of the costs of mitigation-the societal costs of lowering emissions. Although there have been extensive calculations on the costs to different societies, a simple approach suggests why those costs will be limited. By most accounts, the adjustments to a low carbon economy could be achieved through the imposition of a moderate carbon tax (or an equivalent cap-and-trade system). Such a carbon charge, say at the rate of $\$ 80$ to $\$ 100$ per ton, would, of course, raise substantial revenue and allow a reduction in other taxes. The standard approach for estimating the societal cost of such a carbon charge is the dead weight loss associated with the charge, the sum of the consumer and producer surpluses associated with raising the price of carbon from its current level to $\$ 80$ or $\$ 100$ per ton. (These calculations do not include the societal benefit of the reductions in climate change, just the direct economic cost of the "tax.") These numbers are referred to as Harberger triangles and are typically relatively small (although perhaps they might not be when emission reductions exceed 80\%). But the reduction of the other taxes (say on labor or capital) would have a corresponding benefit, an increase in consumer and producer surplus. Thus, the net societal cost of reducing emissions is the difference between the Harberger triangles; the difference is a number that is likely to be small for most countries and in many cases will even be positive; the difference in the differences can be even smaller.

Thus, it is plausible that most would see their own private gains from the reductions in climate change more than offsetting the costs (possibly negative) that they would bear. Although some might see themselves gaining more than others, most would see the agreement as positive.

But within many countries, there would be large losers: in the oilproducing countries, for instance, oil producers and owners of oil assets would be worse off. Although in principle, again, the winners could more than compensate the losers, such compensation is seldom made. Thus, the fact that the country as a whole might be better off does not necessarily 
mean that the country's government would actually support the agreement: the losers (the oil industry) may have a disproportionate voice in many countries. (That is evidently the case, for instance, in the United States.)

Still, the approach we have outlined has even a political economy advantage: an argument that the country as a whole would be better off, even if particular special interests would be worse off, should carry weight. Arguments from the oil industry against an agreement would be seen for what they are: self-serving.

But one approach would provide even more impetus to a global agreement. If those countries without a large fossil fuel lobby could agree to a common level of a carbon price, then none would be viewed as having an unfair advantage over the other. In effect, a country that does not charge the full social cost of carbon is subsidizing carbon-emitting industries, an unfair trade/competitive advantage, not unlike that of a country that subsidizes labor. These countries could impose trade sanctions-a crossborder tax-on those that do not implement the common carbon price (Helm, 2010; Stiglitz, 2006a). (As I explain in Stiglitz [2006b], such a crossborder adjustment would likely be WTO legal.) This would be an effective mechanism for ensuring compliance with a global agreement, and it would provide a strong argument for those not adopting a carbon tax or an equivalent mechanism to do so. Any country not doing so would, in effect, be granting the tax revenue associated with its carbon emission to its trading partners.

\section{Partial versus General Equilibrium}

At a deeper level, there would be significant distributive consequencesconsequences that would arise no matter what approach was taken to reduce carbon emissions. The intent of any global agreement is to reduce the demand for fossil fuels, and that necessarily must reduce the rents associated with fossil fuels; the recipients of those rents-the owners of the fossil fuels-will be worse off. That will be the case even taking into account any benefits they directly receive from the reduction in the threat of climate change. That is why one should not expect a fully voluntary global agreement among all countries; in the absence of any sense of a global social responsibility framework, any country that is exporting a significant amount of fossil fuels would likely be worse off (Cramton and Stoft, 2012). 
Even countries that import only a limited amount might not sign on simply because of the political influence of the fossil industries.

That is why the target should be more limited: an agreement among a "coalition of willing," countries without a large domestic fossil fuel sector, with cross-border adjustments on all other countries. I suspect the combination of social consciousness and self-interest on the part of the citizens of other countries would expand the membership in this coalition until most, if not all, countries joined the coalition.

\section{Voluntary versus Enforceable Agreements}

The current approach seeks voluntary reductions. Each country would "offer" up actions it would take to reduce carbon emissions. There have been significant reductions on this basis, and if all countries fulfill their intentions, the results would be impressive, but they would still fall far short of what is needed. Indeed, it would be remarkable if they did not. In no other area has voluntary action succeeded as a solution to the problem of undersupply of a public good. This is especially so when there are global public goods, the benefits of which are shared by everyone in the world. There is simply insufficient "solidarity" at the global level. Social pressure works to some extent-but only to a limited extent. That is especially true when there are large groups within our societies for whom the direct cost of taking action (the loss in value of the fossil fuel assets they own) exceeds any direct gain from reduced global warming. It is not a surprise that such groups try to convince others that there is no real danger of climate change.

That is why the soft approach advocated in recent years by the United States, among others, based on voluntary contributions simply will not work. Agreements have to be enforceable. In the absence of a global government able and willing to impose direct fines, the most effective enforcement mechanisms are trade sanctions, including the cross-border adjustments described in previous paragraphs.

\section{Flexibility in Making Commitments}

But countries should be given flexibility in the manner in which they meet their obligations - whether through a carbon tax or a cap-and-trade system 
(Cooper, chapter 5, this volume), which could be complemented with regulatory mechanisms when their results are sufficiently measurable. Systems of auctioned emission rights are equivalent to a carbon tax. In practice, over time, there will have to be adjustments in the "caps" and the price of carbon. The notion that there is less risk to the global environment with a cap-and-trade is based on the presumption that we have good knowledge of the level of emissions necessary to achieve any objective in terms of changes in temperature.

Some countries seem to believe that the political economy problems posed by climate change can best be solved by compensations provided through the grants of emission rights. Others worry that such systems are subject to unwanted political pressures-and corruption.

Auctioned emission rights or a carbon tax can have large distributive consequences within a country, which is why regulatory mechanisms may have some advantages: restrictions on housing, urban design, transportation, and electricity generation can achieve a substantial fraction of what is needed; the requisite changes in carbon prices, with the associated distributive consequences, may be quite large to elicit corresponding changes. It is worth noting that much of the efforts of the international community have been directed at creating such regulatory standards (e.g., in terms of fuel efficiency in cars). However, such an approach opens up difficult questions: should an industry that does not pay a carbon charge be viewed as subsidized if it faces a regulatory constraint that forces it to achieve the same level of carbon emissions? It is as if the industry has faced a carbon charge but with the proceeds reimbursed to those in the industry as a lump sum payment. Clearly, the lump sum payment is a subsidy although it is not a carbon subsidy. Firms in countries facing a carbon charge will rightly argue that this is unfair competition. Moreover, there are difficult issues in transparency and comparability: if there were an agreement about a global carbon price of, say, $\$ 80$ per ton, and some country were to combine tight regulations with a $\$ 70$ per ton general price, then how would we assess whether it was complying with the regulation? It might argue that it should be given the flexibility of imposing, in effect, a higher carbon price in some industries (for some technologies) and a lower carbon price for others. Put aside for the moment charges of unfair competition to which such differential pricing might give rise (which arguably would be of limited relevance if the goods in question were nontraded goods). 
In principle, if we had enough information about the demand and supply curves, then we could calculate the reduction in emissions and compare that reduction to what would have happened had there been a uniform $\$ 80$ per ton carbon price.

\section{Common and Differentiated Responsibilities}

The approach delineated previously does not, however, adequately differentiate among the circumstances of different countries. Such differentiation was central to earlier approaches to climate change.

It is inefficient and likely to be viewed as inequitable for producers in developing countries to face a different carbon price from those confronting firms in developed countries, giving rise to charges of unfair competition. At the same time, those from poor countries struggling to develop rightfully feel that any extra costs are taking away funds that could otherwise be used for advancing developmental objectives.

This leads to two suggestions:

1. A global green fund could be financed by allocating $20 \%$ of the funds from the carbon tax (or the equivalent) imposed in developed countries. Because the magnitude of these revenues would be proportional to emissions of those countries, it would arguably be an appropriate basis for raising funds for a global green fund. This would be particularly so because current emission levels would be highly correlated with past emissions. This is not the only basis on which one might raise money for a global green fund. One might, alternatively, impose a charge based on consumption on the carbon associated with the goods that individuals in different countries consume. (In a competitive equilibrium, of course, charges on production and consumption are equivalent. In practice, they may not be. There may, however, be more technical difficulties in levying a charge on consumption than production.)

The revenues from a global green fund would be used to help finance expenditures in developing countries on adaptation and on the incremental costs associated with mitigation measures reducing carbon emissions. The funds could also be used to help developing countries pursue objectives of carbon sequestration-paying them to maintain forests (which would have additional global benefits in terms of biodiversity) and even not to extract hydrocarbons. The contribution to each of the developing countries from 
the green fund should be large enough to compensate them for accepting the global carbon price. (It may, however, be problematic to ask each country what contribution from the green fund would induce them to participate; that would give rise to a bargaining problem where some developing countries might claim that they need large compensation. Equity may require establishing a rule-based allocation mechanism.)

2. Improvements in technology are likely to play an important role in meeting the goals of reductions in carbon emissions. Developing countries rightly worry that, should they sign on to an enforceable agreement concerning reductions in carbon emissions, meeting those reductions would necessitate paying developed countries large amounts to use their technology. In effect, a global carbon agreement would be an arrangement to transfer large amounts from developing countries to the developed. Developing countries understandably are reluctant to sign on to an international convention that would have that as a result.

In the 1992 Rio agreement, there was a provision for compulsory licenses. Yet the United States (and other developed countries) continues a stance that entails, in effect, a renegotiation of this provision.

The developed countries are in a better position to finance and conduct research leading to technologies that reduce carbon emissions and lead to carbon storage at affordable costs. They should provide this technology freely to developing countries (perhaps on a sliding scale, with reduced charges for middle-income countries). Some of the costs might be met out of the global green fund: research expenditures to reduce carbon emissions are a double global public good-research is a global public good, and climate change is a global public good.

\section{Conclusion}

It is now more than two decades since the world recognized the threat of climate change. Yet there has been little progress-too little progressbeyond a global agreement that we should take actions to limit the increase in temperature to $2^{\circ} \mathrm{C}$. We are now set on a course in which we will almost surely miss even this modest goal.

We have explained why the approaches of the past-voluntary caps and actions-will almost surely fail, falling far short of what is needed. We have outlined another approach, based on a global agreement around a common 
carbon price, with flexibility on how each country implements that agreedon price. With strong border adjustments, this is more likely to result in an agreement. Perhaps the agreement will initially be only among a large number of countries, a coalition of the willing, in which some recalcitrant countries refuse to join in-most likely those in which fossil fuel industries play an important role in the political economy. But we have explained how, over time, even many of these will find it desirable to join the coalition. We have explained too how we can incorporate within this approach the recognized principal of "common but differentiated" responsibility.

It is time to give this alternative approach a chance. Climate change is too important to allow the current impasse to continue.

\section{References}

Cramton, P., and S. Stoft. 2012. Global climate games: How pricing and a green fund foster cooperation. Economics of Energy \& Environmental Policy 1:2.

Helm, D. 2010, September 5. A carbon border tax can curb climate change. Financial Times.

Stiglitz, J. E. 1995, July 8-10. The theory of international public goods and the architecture of international organizations. Background Paper No. 7, Third Meeting, High-Level Group on Development Strategy and Management of the Market Economy, UNU/WIDER, Helsinki, Finland.

Stiglitz, J. E. 2006a. A new agenda for global warming. Economists' Voice 3:7.

Stiglitz, J. E. 2006b. Saving the planet. In Making Globalization Work. New York: W. W. Norton \& Company.

Stiglitz, J. E. 2006c. Global public goods and global finance: Does global governance ensure that the global public interest is derved? In Advancing Public Goods, ed. J.-P. Touffut, 149-164. Great Britain: Edward Elgar Publishing.

Stiglitz, J. E. 2011. Sharing the burden of saving the planet: Global social justice for sustainable development. In Protection without Protectionism and the Challenge of Global Governance, ed. M. Kaldor and J. E. Stiglitz, 161-190. New York: Columbia University Press.

Trenberth, K. E., J. T. Fasullo, and T. G. Shepherd. August 2015. Attribution of climate extreme events. Nature 5:725-730. 


\title{
7 Climate Clubs and Carbon Pricing*
}

\author{
William Nordhaus
}

Much progress has been made by scientists and economists in understanding the science, technologies, and policies involved in climate change and reducing emissions. Notwithstanding this progress, up to now it has proved difficult to induce countries to join in an international agreement with significant reductions in emissions.

The Kyoto Protocol was an ambitious attempt to construct an international climate-change agreement to harmonize the policies of different countries. High-income countries agreed to limit their emissions to 5\% below 1990 levels for the 2008-2012 budget period. Under the Protocol, important institutional features were established, such as reporting requirements and methods for calculating the relative importance of different greenhouse gases.

However, countries did not find the Kyoto Protocol economically attractive. The United States withdrew in 2001. The Protocol did not attract any new participants from middle-income and developing countries. As a result, there was significant attrition in the coverage of emissions under the Protocol. Also, emissions grew more rapidly in noncovered countries, particularly developing countries such as China. The Protocol as first designed would have covered $63 \%$ of global emissions in 1990, but the actual scope in 2012 was barely one-fifth of world emissions. Analyses showed that, even if indefinitely extended, the Kyoto reductions would have a limited impact on future climate change. It died a quiet death, largely unnoticed and mourned by few, on December 31, 2012.

It was apparent even before its demise that the Kyoto Protocol would not make a substantial contribution to slowing climate change or, indeed, that

* This chapter is drawn from the author's article in Issues, Summer 2015, as well as other works in the references. 
it would meet its limited goals. Nations have struggled through a series of summits and conferences to find a replacement, with the Paris meeting in late 2015 being the latest attempt to reach an agreement that would replace Kyoto with an effective international agreement.

The present chapter suggests that the Kyoto Protocol ran aground, and that current approaches are unlikely to do better, because of the tendency of countries to free-ride on the efforts of others for global public goods. The chapter suggests that a "club" model is the most fruitful approach to overcoming free-riding and describes a Climate Club. The current approaches, starting with the Kyoto Protocol, have little chance of success unless they adopt some of the strategies associated with the club model of international agreements.

But the abstract idea of a club is insufficient; many architectural and practical details of club design need careful analysis. One important aspect is the question of exactly what the international agreement is to agree on. In Kyoto, nations agreed on quantity limits. I suggest here that price agreements-more specifically, agreements on an internationally harmonized minimum carbon price-will be the most fruitful way to organize an international club agreement.

\section{The Nature of Global Public Goods}

Most of economic life involves voluntary exchange of private goods, such as bread or blue jeans. These commodities are consumed by one person and directly benefit no one else. However, many activities involve spillovers or externalities among producers or consumers. An extreme case of an externality is a public good. Public goods are commodities where the cost of extending the benefits to an additional person is zero and where it is impossible or expensive to exclude individuals from enjoying.

More precisely, public goods have two key properties: nonrivalry and nonexcludability. Nonrivalry denotes that the consumption of the public good by one person does not reduce the quantity available for consumption by another person. Take global positioning systems (GPSs) as an example. These systems are used for hiking, missile guidance, and finding a restaurant. These goods are public because people who use them are not reducing the value of signals for others. The second feature of a pure public good is nonexcludability. This means that no person can be 
excluded from benefiting from or being affected by the public good (or can only be excluded at a high exclusion cost). In the case of smallpox eradication, once smallpox was eradicated, no person could be excluded from the benefits. Herd immunity from vaccines is an important and little-understood public good that is one of the important reasons for mandatory vaccination.

The important economic point about public goods is that private markets do not guarantee efficient production. In this respect, then, production of public goods such as GPS signals or herd immunity differs from production of bread. Efficient production of public goods requires collective action to overcome the inability of private agents to capture the benefits.

The inefficiencies are the greatest for global public goods, whose benefits are spread most widely across space and time. Consider issues as different as greenhouse warming and ozone depletion, terrorism and money laundering, the discovery of antibiotics and nuclear weapons. These are global public goods because their impacts are indivisibly spread around the entire globe. These are not new phenomena. However, they are becoming more important in today's world because of rapid technological change and the sharp decline in transportation and communication costs.

\section{Global Public Goods, Federalism, and the Westphalian Dilemma}

Although global public goods raise no new analytical issues, they do encounter a unique political hurdle because of the structure of international law. Whenever we encounter a social, economic, or political problem, one of the first questions concerns the level at which the problem should be addressed. We expect households to deal with children's homework assignments and take out the trash; we expect local or regional governments to organize schools and collect the trash; we expect national governments to defend their borders and manage their currencies.

For the case of global public goods, there exist today no workable market or governmental mechanisms that are appropriate for the problems. There is no way that global citizens can make binding collective decisions to slow global warming, curb overfishing of the oceans, efficiently combat Ebola, form a world army to combat dangerous tyrants, or rein in dangerous nuclear technologies. 
The decision-making difficulties of global public goods raise what might be called the Westphalian dilemma. National governments have the actual power and legal authority to establish laws and institutions within their territories; this includes the right to internalize externalities within their boundaries and provide for national public goods. Under the governing mechanisms of individual countries, whether they are acts of democratic legislatures or despotic decrees, they can take steps to raise taxes or armies and command their citizens to clean their air and water.

By contrast, under international law as it has evolved in the West and then the world, there is no legal mechanism by which disinterested majorities or supermajorities short of unanimities can coerce reluctant free-riding countries into mechanisms that provide for global public goods. Participants of the Treaty of Westphalia recognized in 1648 the Staatensystem, or system of sovereign states, each of which was a political sovereign with power to govern its territory. As the system of sovereign states evolved, it led to the current system of international law under which international obligations may be imposed on a sovereign state only with its consent.

Because nations, particularly the United States, are deeply attached to their sovereignty, the Westphalian system leads to severe problems for global public goods. The requirement for unanimity is in reality a recipe for inaction. Particularly where there are strong asymmetries in the costs and benefits (as is the case for nuclear nonproliferation or global warming), the requirement of reaching unanimity means that it is extremely difficult to reach universal, binding, and effective international agreements. Whether bargaining can lead to such treaties is examined shortly.

To the extent that global public goods are increasingly important in the decades ahead, one of our major challenges is to devise mechanisms that overcome the bias toward the status quo and the voluntary nature of current international law in life- or civilization-threatening issues. Just as national laws recognize that consumer sovereignty does not apply to children, criminals, and lunatics, international law must come to grips with the fact that nations acting under the Westphalian system cannot deal effectively with critical global public goods. 


\section{Free-Riding as the Key Obstacle for Climate-Change Treaties}

As we look at climate change, the dilemmas raised by their global nature take a particular form. Slowing climate change requires expensive national investments in reducing $\mathrm{CO}_{2}$ and other greenhouse gas emissions. But the benefits are diffuse in space and time. Emissions reduced anywhere benefit people everywhere, and indeed most of the benefits come to generations in the future, perhaps distant future.

The concentrated costs and dispersed benefits provide strong incentives for free-riding in current international climate agreements. Free-riding occurs when a party receives the benefits of a public good without contributing to the costs. In the case of the international climate-change policy, countries have an incentive to rely on the emissions reductions of others without taking proportionate domestic abatement. The failure of the Kyoto Protocol, and the difficulties of forging effective follow-up regimes, is largely due to free-riding.

As suggested by the earlier discussion, although free-riding is pervasive, it is particularly difficult to overcome for global public goods. Arrangements to secure an international climate treaty are hampered by the lack of ability to induce reluctant nations to join international agreements. In essence, all international agreements are essentially voluntary (see the Treaty of Vienna, 1969, article 34).

\section{Clubs as a Mechanism to Overcome Free-Riding}

In light of the failure of the Kyoto Protocol, it is easy to conclude that international cooperation is doomed to failure. This is the wrong conclusion. Despite the obstacles of international law, nations have in fact overcome many transnational conflicts and spillovers through international agreements. There are more than 200,000 UN-registered treaties and actions that are presumptive attempts to improve participants' welfare. Countries enter into agreements because joint action can take into account the spillover effects among the participants. Although global warming is to date a failed club, there are many examples of successes. Important examples are the international trading system, international financial arrangements, military alliances, and the protocols to reduce ozone-depleting chemicals. These achievements are a reminder that patient efforts to improve relations 
among nations are not a fruitless task. In these and other cases, the tendency toward free-riding associated with the Westphalian system has been overcome through the mechanism of clubs.

So what is a club? Although most of us belong to clubs, we seldom consider their structure. A club is a voluntary group deriving mutual benefits from sharing the costs of producing a shared good or service. The gains from a successful club are sufficiently large that members will pay dues and adhere to club rules to gain membership benefits.

The theory of clubs is a little-known but important corner of the social sciences. The major conditions for a successful club include the following: (1) there is a public good-type resource that can be shared (whether the benefits from a military alliance or the enjoyment of a golf course); (2) the cooperative arrangement, including the dues, is beneficial for each of the members; (3) nonmembers can be excluded or penalized at relatively low cost to members; and (4) membership is stable in the sense that no one wants to leave.

The basic idea suggested here is that we can make progress in international climate agreements if we adopt the club model rather than the current voluntary model. The idea of a Climate Club should be viewed as an idealized solution of the free-riding problem. Like free trade or physics in a vacuum, the Climate Club described here will never exist in its pure form. Rather, it is a blueprint that can be used to understand the basic forces at work and sketch a system that can overcome free-riding.

\section{A Sketch of the Climate Club}

Here is a brief description of the proposed Climate Club: an agreement by participating countries to undertake harmonized emissions reductions. The agreement envisioned here centers on an "international target carbon price" that is the focal provision of an international agreement. For example, countries might agree that each country will implement policies that produce a minimum domestic carbon price of $\$ 25$ per ton of $\mathrm{CO}_{2}$. Countries could meet the international target price requirement using whatever mechanism they choose-carbon tax, cap-and-trade, or a hybrid.

A key part of the club mechanism (and the major difference from all current proposals) is that nonparticipants are penalized. The penalty analyzed here is uniform percentage tariffs on the imports of nonparticipants into 
the club region. Calculations suggest that a relatively low penalty tariff rate will induce widespread participation among countries as long as the target carbon price is in the range up to $\$ 50$ per ton.

\section{Games and International Behavior}

An important aspect of the Climate Club-and a major difference from current proposals-is that it creates a strategic situation in which countries acting in their self-interest will choose to enter the club and undertake high levels of emissions reductions because of the structure of the incentives. To understand the nature of the incentives and strategies, I discuss the application of game theory to international environmental treaties.

There is a large literature on the strategic aspects of international environmental agreements, including those focused on climate change. One important strand is the analytical work on global public goods. The clear message is that without special features, the outcome will be a prisoners' dilemma or tragedy of the commons, in which there is too little abatement.

This analysis usually takes place in the framework of noncooperative (NC) game theory. In the NC framework, countries act in their national self-interest. Hence, when a country designs its environmental, macroeconomic, or labor-market policies, it considers the impacts on its own citizens and largely ignores the impacts on other countries. Although the idea of countries acting in their self-interest may seem narrow-minded or parochial, it is actually the foundation of democratic theory. Most of the world's ills (think particularly of wars) arise because countries, or more often their leaders, do not act in their countries' national self-interest. For national public goods with minimal cross-border spillovers, the world's welfare is appropriately optimized when countries act in their self-interest. The problems we consider here arise for global public goods, where the NC approach leads to inefficient outcomes.

Analysis of NC agreements (either one-shot or repeated) leads to three major conclusions for climate change. First, the overall level of abatement in the NC equilibrium will be much lower than in the efficient (cooperative) strategy. A second and less evident point is that countries will have strong incentives to free-ride by not participating in strong climate-change agreements. Finally, the difficulty of escaping from a low-level, NC equilibrium 
is amplified by the intertemporal trade-off because the current generation pays for the abatement while future generations are the beneficiaries of lower damages. To a first approximation, international climate policy as of 2015 looks like a NC equilibrium.

\section{Elements of Treaties}

NC outcomes assume that countries never bargain to improve the outcomes. Might coalitions of countries form cooperative arrangements or treaties that improve on NC arrangements? This question has been extensively studied analytically using game theory, through modeling, and by examination of history.

Theoretical and empirical studies indicate that coalitions concerned with global public goods tend to be fragile and unstable. More precisely, these studies find virtually universally that coalitions tend to be either small or shallow, a result I will call the "small coalition paradox."

Here is the background. Suppose that countries can form treaties to provide global public goods, whether for climate change, public health, financial regulation, or whatever. A successful agreement would require the participation of most countries. However, to be stable, each country must determine that participation-which requires investments with large national costs but diffuse benefits-has a higher payoff than nonparticipation. The problem is that stable coalitions tend to have few members; therefore, as the number of countries rises, the fraction of global emissions covered by the agreement declines. Studies by Scott Barrett have found, based on a comprehensive review of existing environmental treaties, that few treaties for global public goods succeed in inducing countries to increase their investments significantly above the NC levels. Moreover, the ones that do succeed include external penalties.

This point was foreseen more than three centuries ago in a discussion by David Hume on collective action and free-riding:

Two neighbors may agree to drain a meadow, which they possess in common; because 'tis easy for them to know each other's mind; and each must perceive, that the immediate consequence of his failing in his part, is, the abandoning the whole project. But 'tis very difficult, and indeed impossible, that a thousand persons shou'd agree in any such action; it being difficult for them to concert so complicated a design, and still more difficult for them to execute it; while each seeks a pretext to 
free himself of the trouble and expence, and wou'd lay the whole burden on others. (Hume, A Treatise of Human Nature, Section VII, 1739)

How can we understand the small coalition paradox? Here is the intuition for climate change. Clearly, two countries can improve their welfare by combining and raising their abatement (or carbon price) to the level that would maximize their joint welfare. Just as with Hume's neighbors, either country is worse off by dropping out. The 2014 agreement between China and the United States to join forces in climate policy might be interpreted as an example of a small bottom-up coalition.

Does it follow that, by increasing the number of countries in the treaty, this process would accumulate into a grand coalition of all countries with efficient abatement? That conclusion is generally wrong. The problem arises because, as more countries join, the level of abatement, and its costs, becomes ever higher and ever further from the NC level. The discrepancy gives incentives for individual countries to defect. When a country defects from an agreement with many countries, the remainder coalition (of manyminus-one countries) would reoptimize its levels of abatement. The revised levels of abatement would still be well above the NC levels for the remainder coalition, while the defector free-rides on the abatement of the remainder coalition. The exact size of the stable coalitions would depend on the cost and damage structure as well as the number of countries, but for most analyses using realistic number, stable coalitions are small and perform only slightly better than the NC equilibrium.

As noted previously, the syndrome of free-riding along with the international norm of voluntary participation appears to doom international climate agreements such as the Kyoto Protocol. The suggestion here is that a club structure-where external sanctions are imposed on nonmemberswill be necessary to induce effective agreements.

\section{Sanctions for International Agreements about Global Public Goods}

Although it is easy to design potential international climate agreements, the reality is that it is difficult to construct ones that are effective and stable. Effective means abatement that is close to the level that passes a global cost-benefit test. The concept of stability used here is that a coalition is stable if no group (subcoalition) among the countries can improve its welfare by changing its participation status. The small coalition paradox motivates 
the current approach. The goal here is to find a structure that is stable and has a large number of participants for a wide variety of country preferences, technologies, and strategies.

Both theory and history suggest that some form of sanction on nonparticipants is required to induce countries to participate in agreements with high levels of abatement. A sanction is a governmental withdrawal, or threat of withdrawal, of customary trade or financial relationships. A key aspect of the sanctions analyzed here is that they benefit senders and harm receivers. This pattern contrasts with most cases, where sanctions impose costs on senders as well as receivers and thereby raise issues of incentive compatibility.

The major potential instrument is sanctions on international trade. Two approaches to trade sanctions might be considered. A first approach, and one that has been widely advocated and examined, is called carbon duties; it would put tariffs on the imports of nonparticipants in relation to the carbon content of these imports. For technical reasons, I do not suggest this route. A second approach, called uniform penalty tariffs and discussed here, would apply uniform percentage tariffs to all imports from nonparticipating countries. Under this approach, participating countries would levy a uniform percentage tariff (perhaps $2 \%$ ) on all imports from nonparticipants. This mechanism has the advantage of simplicity and transparency, although it does not relate the tariff specifically to the carbon content of the import.

A major feature of tariff sanctions is that they are incentive-compatible. Many sanctions have the disadvantage that they penalize the penalizer. For example, if Europe puts sanctions on Russian energy companies, then this is likely to raise energy prices in Europe, hurt European consumers, and therefore have costs on Europe as well as Russia. The tariff-sanction mechanism analyzed here imposes costs on the nonparticipating country but benefits participants that levy the penalty tariffs. Moreover, because tariffs apply bilaterally, they can support an efficient equilibrium for global public goods for a large number of countries.

\section{The Central Role of Carbon Prices}

There are many issues in club design. A central question is how to harmonize countries' policies. What exactly are countries negotiating over? In a 
Kyoto design, and all the linear descendants through Paris, the negotiations are about quantities. This has proved a slippery slope without much to hold on to. A more promising approach is harmonizing carbon prices, and the proposed Carbon Club follows this route.

Start with the positive reasons to use carbon prices: The economics of climate change is straightforward. Virtually every activity directly or indirectly involves combustion of fossil fuels, emitting carbon dioxide into the atmosphere. If there is a single bottom line from economics, it is that we need to correct this market failure by ensuring that everyone, everywhere, and for the indefinite future faces a market price of carbon that reflects the social costs of their activities. Economic participants-thousands of governments, millions of firms, billions of people, all taking trillions of decisions each year-need to face realistic carbon prices if their decisions about consumption, investment, and innovation are to be appropriate.

The most efficient strategy for slowing or preventing climate change is to impose a universal and internationally harmonized carbon tax levied on the carbon content of fossil fuels. An alternative would be a hybrid capand-trade system, but this approach has many subtle flaws.

Move next to the negative reasons not to use quantitative targets: Quantitative targets in the form of tradable emissions limits have failed in the case of the Kyoto Protocol. They have shown excessive price volatility, lose precious governmental revenues, and have not lived up to their promise of equalizing prices in different regions. They are unattractive bargaining tools because they can be tailored to favor the strong and disadvantage the weak. To the extent that carbon-price targets lead to carbon taxes, the administrative aspects of taxes are better understood around the world than marketable emissions allowances, and they are less prone to corruption.

It will be useful to use an analogy. Assume a country wishes to reduce its gasoline consumption. It could do so by issuing ration coupons (either to consumers or companies) and then having a market in tradable coupons. This would give a firm idea of the quantity reduction, but the history of rationing shows that it is highly inefficient and tends to become increasingly distorted over time. No country in the modern world takes this approach. A simpler approach would be to tax gasoline. This is administratively simple, raises revenues for governments, can have unfavorable 
distributional impacts offset through income-tax changes, and is clearly a system that can endure decade after decade.

Now go a step further and assume that countries desire to harmonize their gasoline policies. Harmonization of gasoline taxes is simple. By contrast, the design of a harmonized rationing system would be challenging and subject to endless games and lawyerly disputes. The same logic applies to negotiating tax treaties or international trade regimes.

\section{Modeling a Climate Club}

To understand how a Climate Club would operate, it is necessary to move beyond description to analytical and numerical modeling of the incentives and behavior of regions with realistic economic and geophysical structures. The challenge of analyzing and modeling the science and policy associated with global warming is particularly difficult because it spans many disciplines and parts of society. An important approach to bringing the different fields together has been the development of integrated assessment models (IAMs). These pull together in a single model a wide variety of geophysical, economic, and political relationships so that projections, analyses, and decisions can consider simultaneously all important endogenous variables at work. IAMs generally do not aspire to have the most detailed and complex representation of each of its components. Rather, they aspire to have at a first level of approximation the most important relationships and ones that can operate simultaneously and with reasonable accuracy.

In the major study on which this article is based, I describe an integratedassessment model (the Coalition-DICE [C-DICE] model) of economics, tariffs, and climate change that examines the effects of different potential Climate Clubs. I will not give a detailed report on the results of those simulations but refer interested readers to the original source for an extended discussion.

The C-DICE model is designed to find whether countries join a coalition of high-abatement countries and to find stable coalitions. It examines 44 different "regimes," where a regime is defined as an international target carbon price and a penalty tariff rates. The assumed target prices are $\$ 12.5$, $\$ 25, \$ 50$, and $\$ 100$ per ton of $\mathrm{CO}_{2}$, and uniform penalty tariffs range from $0 \%$ to $10 \%$. For reference purposes, the US government estimates the global social cost of carbon (or the damage imposed by an additional ton of $\mathrm{CO}_{2}$ 
emissions) to be around $\$ 35$ per ton of $\mathrm{CO}_{2}$. In most models, a carbon tax of this magnitude would lead to emissions reduced $15 \%$ to $20 \%$ relative to a business-as-usual path in the near term. Most economic studies would recommend that the carbon price rise over time to reduce more sharply and even eliminate greenhouse gas emissions over this century.

\section{Some Illustrative Results}

I close by highlighting some of the conclusions of the modeling studies of a Climate Club. The first major result is to confirm that a regime without trade sanctions will dissipate to the low-abatement, NC equilibrium. A second surprising result is that, when trade sanctions are imposed, the Climate Club structure generates stable coalitions for virtually all sets of parameters.

A next set of results concerns the impact of different Climate Club parameters on the participation structure. For the lowest target carbon prices ( $\$ 12.5$ and $\$ 25$ per ton of $\mathrm{CO}_{2}$ ), full participation and efficient abatement are achieved with relatively low tariffs ( $2 \%$ or more). However, as the target carbon price rises, it becomes increasingly difficult to achieve full participation. For a $\$ 50$ per ton target carbon price, the Club can attain $90 \%+$ efficiency with a tariff rate of $5 \%$ or more. However, for a target carbon price of $\$ 100$ per ton, it is difficult to induce more than the NC level of abatement. Figure 7.1 illustrates these results.

What is the pattern of gains and losses? The benefits of a Climate Club are widely distributed among countries. A few regions have losses in some regimes. However, the losses are small relative to gains for other regions. There are no regimes with aggregate losses.

A paradoxical result is that all regions would prefer a Climate Club regime with penalties and modest carbon prices to a regime with no penalties. This is even the case for countries that do not participate. The reason is that the gains from strong mitigation measures of participants outweigh the losses from the tariffs for nonparticipants-as long as the tariff rate is not too high. This powerful result indicates that a regime with sanctions should be attractive to most regions.

The analysis shows how an international climate treaty that combines target carbon pricing and trade sanctions can induce substantial abatement. The modeling results indicate that modest trade penalties on 


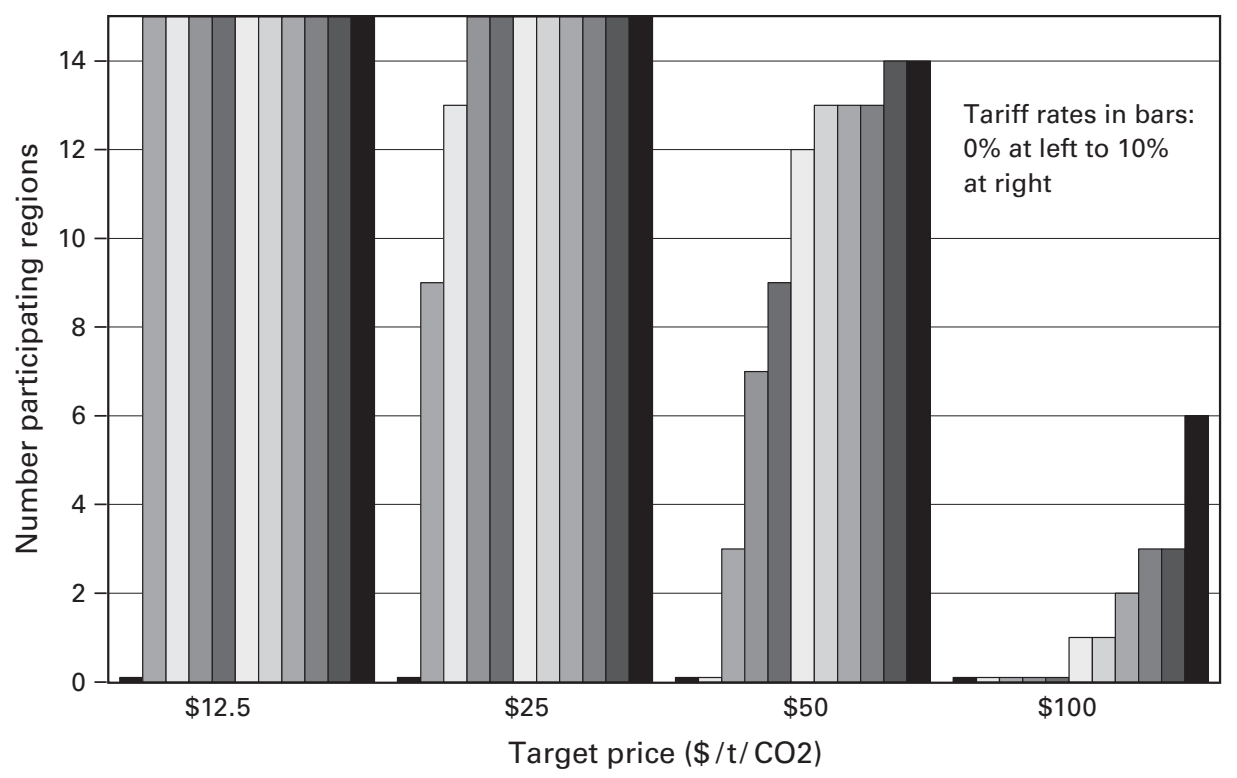

Figure 7.1

Number of participating regions by international target carbon price and tariff rate: The four sets of bars are the model results for four different international target carbon prices, running from left to right as shown at the bottom. The 11 bars within each set are the penalty tariff rates, running from $0 \%$ to $10 \%$. Note that each set has zero participants for a $0 \%$ tariff. The vertical scale shows the number of participants. These results are based on the author's C-DICE model. For the source, see Nordhaus, "Climate Clubs," in the references.

nonparticipants can induce a coalition that approaches the optimal level of abatement as long as the target carbon prices are not too high. The attractiveness of a Climate Club must be judged relative to the current approaches, where international climate treaties are essentially voluntary and have little prospect of forging agreements that can effectively slow climate change.

\section{References and Historical Notes}

The germinal article on public goods is Paul Samuelson, "The Pure Theory of Public Expenditure," The Review of Economics and Statistics, Vol. 36, No. 4, Nov. 1954, pp. 387-389. Many of the ideas in this article are drawn from William Nordhaus, "Paul Samuelson and Global Public Goods," in Michael Szenberg, Lall Ramrattan, and Aron Gottesman, eds., Samuelsonian 
Economics, Oxford University Press, Oxford, UK, 2006, pp. 88-98. A fine survey of the theory of clubs is in Todd Sandler and John T. Tschirhart, "The Economic Theory of Clubs: An Evaluative Survey," Journal of Economic Literature, 1980, 18(4), 1481-1521.The concept of a Climate Club and the modeling results for the C-DICE model are based on William Nordhaus, "Climate Clubs: Overcoming Free-riding in International Climate Policy," Presidential Address to the American Economic Association, published in American Economic Review, 2015, 105(4): 1339-1370, available at http:// dx.doi.org/10.1257/aer.15000001. Additional material is drawn from William Nordhaus, The Climate Casino, Yale University Press, New Haven, CT, 2013. This article is drawn from William Nordhaus, "Climate Clubs to Overcome Free-Riding," Issues in Science at Technology, Volume XXXI Issue 4, Summer 2015. 



\title{
8 How a Minimum Carbon-Price Commitment Might Help to Internalize the Global Warming Externality
}

\author{
Martin L. Weitzman
}

\section{Introduction}

Throughout this chapter, I use the terms "climate change" and "global warming" interchangeably. The term "climate change" is currently in vogue and is a more apt description overall. But the term "global warming" is more evocative of this chapter's main theme. Global warming is a global public-goods externality whose resolution requires an unprecedented degree of international cooperation and coordination. This international climate-change externality has frequently been characterized as the most difficult public goods problem that humanity has ever faced. I concentrate in this chapter on carbon dioxide emissions, but in principle the discussion could be extended to emissions of all relevant greenhouse gases. Throughout the chapter, I blur the distinction between carbon dioxide and carbon because the two are linearly related. ${ }^{1}$

The core problem confronting the political economy of climate change is an inability to overcome the obstacles associated with free-riding on an important international public good. The "international" part is significant. Even within a nation, it can be difficult to resolve public-goods problems. But at least there is a national government, with some governance structure, able to exert some control over externalities within its borders. A national government can (at least in principle) impose targets on national public goods. With climate change, there is no overarching international governance mechanism capable of coordinating the actions necessary to overcome the international problem of free-riding. Instead, instruments of control, such as prices and/or quantities, must be negotiated among sovereign nations. 
My point of departure throughout all of what follows is the critical centrality of the international free-rider problem as a cause (really the cause) of negotiating difficulties on carbon emissions. Negotiators here are playing a game in which self-interested strategies are a crucial consideration. It turns out that negotiating rules define an important part of the game and can thereby change self-interest for better or for worse.

In this chapter, I try to argue that a uniform minimum global tax-like price on carbon emissions, whose revenues each country retains, can provide a focal point for a reciprocal common commitment, whereas quantity targets, which do not as readily present such a single focal point, have a tendency to rely ultimately on individual commitments. As a consequence, negotiating a uniform minimum global carbon tax or price can help to solve the externality problem, whereas individual caps essentially incorporate it. I will try to explain why negotiating a uniform minimum carbon price embodies what I call a "countervailing force" against narrow selfinterest by automatically incentivizing all negotiating parties to internalize, at least approximately, the global warming externality. The basic challenge, as I see it, is to construct a relatively simple and acceptable one-dimensional international quid-pro-quo mechanism, which automatically embodies the principle of "I will if you will."2

\section{Some Brief History of Climate Negotiations}

In the decade from the actual entering into force of the Kyoto Protocol in February 2005 to the Paris COP21 agreement of December 2015, the world seemed mired in what has aptly been called global warming gridlock. ${ }^{3}$

The Kyoto agreement, negotiated in December 1997, began by dividing the world into two huge blocs under the so-called "principle of common but differentiated responsibility and respected capabilities." The "Annex I" bloc of countries included most of the world's high-income advanced industrial nations. The rest of the world, the "non-Annex I" bloc of countries, included most of the world's low-income developing nations. The Annex I countries agreed to "legally binding" average emissions reductions in 2008-2012 of approximately 5\% relative to their baseline emissions of 1990. The non-Annex I countries were not constrained by "legally binding" emissions reductions but otherwise agreed to cooperate. 
In reality, the "legally binding"emissions reductions of the Kyoto Protocol were anything but legally binding because there was no provision for a mechanism to enforce compliance. There was no provision for a mechanism to enforce compliance because, essentially, at the end of the day, the parties did not want to be bound by such a mechanism.

Almost from the beginning, the United States and Australia refused to ratify the Kyoto treaty (largely on the grounds that the non-Annex I countries were unfairly exempt from responsibilities). Subsequently, Canada, Japan, and Russia pulled out of their part of the agreement and refused to take on future commitments.

I think it is fair to say that the "spirit" of Kyoto was a top-down intended adherence to something like the following scenario. The Annex I countries agreed to show good faith first by voluntarily lowering their emissions in 2010 by about 5\% relative to their 1990 emissions. Then in a second stage, after around 10 years (approximately by 2012 or so), the hope was that the non-Annex I countries would be impressed by the good faith effort shown over the previous decade by the Annex I countries and would hopefully join by pledging something like an emissions reduction target of $5 \%$ in 2020 (relative to 1990 emissions), while the Annex I countries would agree to a more stringent emissions quota of about $10 \%$. In reality, no such second stage of ratcheted-up commitments ever materialized.

The recently concluded Paris COP21 agreement of December 2015 (by contrast with Kyoto) made no formal dichotomy between developed and developing countries. In principle, all nations were treated symmetrically. The Paris agreement covered countries currently accounting for some 95\% of world carbon dioxide emissions. Countries agreed to make voluntary pledges, now named euphemistically "Intended Nationally Determined Contributions" (INDCs). The INDCs aspired to be transparent in the sense that monitoring, reporting, and verification would be subject to uniform standards. COP21 committed countries to report INDC compliance every five years or so and to set new (and hopefully more ambitious) INDCs for the next five-year period, a policy sometimes labeled "pledge-andreview." There was also provision for possible international linkage via the euphemistically named "Internationally Transferred Mitigation Outcomes" (ITMOs).

All in all, the COP21 agreement seems like an improvement over the Kyoto Protocol. It appears to be essentially a gamble that the modest 
voluntary slowdowns in emissions may buy enough time to develop inexpensive future carbon-free technologies. This seems to be a risky bet. In any event, it will take maybe a decade or more to sort out the effectiveness of the Paris COP21 agreement.

The core weakness of the COP21 Paris Accord is essentially the same as the core weakness of the Kyoto Protocol. Neither approach addresses the central problem of free-riding on an international public good of great importance. There is no penalty for voluntarily setting underambitious national targets, and there is no penalty for noncompliance by a country with its own voluntary self-announced targets. Under COP21, the only mechanism for compliance is "blame and shame," which seems like a weak incentive for cutting back on global emissions.

I think the INDC label says it all. The contributions are chosen by each country. These COP21 contributions are intended and nationally determined. It is hard for me to envision how the labels could more strongly emphasize the strictly voluntary nature of the entire exercise. This does not seem to me like a formula for overcoming the free-riding problem associated with an international public good of great importance.

If the Paris COP21 approach fails to halt "dangerous anthropogenic global warming," which takes the form of a perception of an impending climate catastrophe that is felt on a grassroots level, then I think there may be more pressure on creating a top-down international mechanism that actually works. If climate change becomes sufficiently threatening to an "average" citizen of the world, public opinion may support relinquishing some national sovereignty in favor of the greater good. This chapter is targeted to such an eventuality.

I will try to explain why negotiating a uniform minimum carbon price empowers what I will call a "countervailing force" against narrow selfinterest by automatically incentivizing all negotiating parties to internalize, at least approximately, the global warming externality. Again, the basic challenge, as I see it, is to construct a relatively simple and relatively acceptable one-dimensional international quid-pro-quo mechanism, which automatically embodies the principle of "I will if you will."

\section{Negotiating Prices versus Quantities}

At first, for simplicity of exposition, I assume that a commitment to a uniform global price of carbon will be implemented as an internationally 
harmonized but nationally retained carbon tax. Later I indicate that the commitment is actually to an internationally equal minimum price on carbon emissions, which could be met in a variety of ways, including, in principle, imposing a uniform price floor in a cap-and-trade system. But for expositional purposes here, I pretend that the uniform price takes the form of an equal self-imposed tax on carbon emissions.

An internationally harmonized but nationally retained carbon tax (or price) has already been proposed as a potential solution to the global warming externality and has been examined on its merits. ${ }^{4}$ In what follows, I briefly summarize some of the possible virtues of an internationally harmonized but nationally collected carbon tax (or price) that have already been noted in the literature. My foil here is an internationally harmonized cap-and-trade system (without a uniform price floor). This kind of globaldesign comparison is complicated and full of subjective judgments about what might or might not work better in practice and why or why not. Cap-and-trade systems are perhaps more widely used than taxes throughout the world to control pollution and, in that sense, are perhaps more visible or familiar market-like mechanisms than pollution taxes (although fossil-fuel taxes and subsidies are ubiquitous, if somewhat hidden, almost everywhere). My purpose here is merely to indicate that the perhaps lessfamiliar uniform carbon tax already has some significant arguments in its favor-as a prelude to some new arguments for negotiating a uniform price on carbon that I will later develop in this chapter.

Both quantity- and price-based controls are inherently uncertain for the period during which they apply (in between times of periodic review), but the uncertainty takes different forms. With cap-and-trade, total emissions are known, but the price or (marginal) cost is uncertain. With a carbon tax, the price or (marginal) cost of carbon emissions is known, but total emissions are uncertain. On the basis of economic models of climate change that include uncertainty, carbon taxes outperform tradable permits, both theoretically and in numerical simulations. ${ }^{5}$ In the real world, above and beyond theory and numerical simulations, I think that energy price volatility is poorly tolerated by the general public. Swings in carbon prices, especially in extreme cases, could sour public opinion and discredit for some time thereafter (decades, generations) the entire idea of a market-based approach to the climate change problem. However, it is difficult for me to imagine the broad public getting quite so upset because total emissions fluctuate. 
It has been argued, I think convincingly, that a carbon tax is more easily administered and transparent than a cap-and-trade system. This consideration is especially important in a comprehensive international context that would include all major emitting countries. Under international capand-trade, governments will allocate valuable emissions permits to their nation's firms and residents. In some places, under some circumstances, there may be a great temptation for kleptocrats to effectively steal these valuable emissions permits and sell them on the international market.

The collected revenues from an internationally harmonized carbon tax remain within each country and could be used to offset other taxes or even be redistributed internally as lump-sum payments. This, I think, is a desirable property. By contrast, the revenues generated from an internationally harmonized cap-and-trade system flow as highly visible external transfer payments across national borders, which might be less easily tolerated by countries required to pay other countries large sums of taxpayer-financed money to buy permits. ${ }^{6}$

This extremely brief discussion of the advantages of an internationally harmonized carbon tax (compared with cap-and-trade) is not intended to be comprehensive. There are also legitimate arguments in favor of internationally harmonized tradable permits and against a carbon tax. ${ }^{7}$

A point in favor of tradable permits, frequently emphasized by its advocates, is the political appeal of giving free allowance permits to carbonintensive industry groups (as contrasted with taxing them directly on their carbon emissions). As was pointed out, carbon taxes that are internally levied and collected by a national government could be used to reduce other, more distortionary, taxes-or they could even be distributed directly to the citizenry as lump-sum payments. But this redistribution aspect of a carbon tax is hidden behind the scenes as it were. Individual firms will prefer, and typically strongly prefer, what they perceive as the lesser burden to them of freely allocated permits over the greater perceived burden to them of pollution taxes. Indeed, studies show that the market value of the free allowances is typically significantly greater than the higher compliance costs of decarbonization that are incurred. ${ }^{8}$ Firms and countries in a capand-trade regime will therefore struggle hard for a larger share of the total amount of freely distributed emissions allocations. The political appeal of freely distributed tradable permits is a double-edged sword. When negotiating emissions caps, a serious income distortion is introduced because a 
nation is much more concerned with the revenues from its own free quota allocations than it is concerned with overall international social optimality. Auctioning off the allowances would eliminate this income-effect distortion on the individually desired level of free permit allocations, but then we are effectively back in a tax-like system.

Both approaches (an internationally harmonized but domestically collected carbon price and freely distributed marketable permits) are subject to immense-sometimes seemingly overwhelming — criticisms. In both cases, innumerable practical details must be attended to and worked out. In both cases, an effective international treaty needs to be binding, which raises uncomfortable issues of enforcement mechanisms and international sanctions. Additionally, there might be mixed hybrid systems, such as capand-trade with a uniform floor on the carbon price. I merely want to establish a level playing field where the idea of an internationally harmonized carbon tax already commands at least as much intellectual respect as an internationally harmonized cap-and-trade system (without a uniform price floor).

Throughout this chapter, I argue that it is difficult to resolve the global warming externality problem by directly assigning individual quantity targets. A meaningful, comprehensive, quantity-based treaty involves specifying as many different binding emissions quotas (whether in the form of tradable permits or not) as there are national entities. Each national entity has a self-interested incentive to negotiate for itself a high cap on carbon emissions-much higher than would be socially optimal. The resulting free-rider problem plagues a quantity-based approach. Even if there were a collective commitment to negotiate or vote on a second-stage worldwide total emissions cap, which I will later assume for the sake of argument, disagreements over the first-stage fractional subdivision formula (for disaggregating the negotiated or majority-voted aggregate worldwide quantity cap into individual quantity caps) would make it difficult to enact such a quantity-based approach. ${ }^{9}$

The inspiration for this chapter is the perception of a desperate need for some radical rethinking of international climate policy. As a possibly useful conceptual guide for what negotiations might accomplish, I sometimes ask the reader to temporarily suspend disbelief by considering what might happen in a "World Climate Assembly" (WCA) that votes on global carbon emissions via the basic principle of one-person-one-vote majority rule. In 
this conceptualization, nations would vote along a single dimension for their desired level of emissions stringency on behalf of their citizen constituents, but the votes are weighted by each nation's population.

Right now, anything like a WCA seems hypothetical and hopelessly futuristic. It presumes a state of mind where the climate-change problem has become sufficiently threatening on a grassroots level that world public opinion is ready to consider novel governance structures that involve relinquishing some national sovereignty in favor of the greater good. What might be the justification for a new international organization like the WCA? The ultimate justification is that big, new problems may require big, new solutions. For a world desperately wanting new solutions to the important externality of climate change, perhaps it is at least worth considering establishing a new organization along the lines of the WCA. After all, it is useful to have some concrete fallback decision mechanism behind vague "negotiations" because even with the focus on a one-dimensional harmonized carbon price (or with the focus on a one-dimensional quantity of total emissions), there are bound to be disagreements whose resolution is unclear. I merely assume that it is in the interest of enough nations to forfeit their rights to pollute in favor of a WCA voting solution of the global warming externality. This is truly a heroic assumption at the present time because the WCA does not correspond to any currently existing international body. Taken less literally, the thought experiment of a hypothetical WCA can still help us to concentrate our thinking and intuition on what negotiations should be trying to accomplish. In other words, I am hoping that the fiction of a WCA might be useful in indicating what might be the outcome of less formal international negotiations.

It could be objected that a "consensus" voting rule, not a majority voting rule, is employed in negotiations under the UN Framework on Climate Change. This "consensus" voting rule has been widely interpreted as requiring near unanimity. With such a restrictive voting rule, significant progress on resolving the global warming externality seems virtually impossible. Surely, a less restrictive voting-like rule, such as majority rule, would render progress more likely and is at least worth considering.

One aspect should perhaps be emphasized above all others at the outset. The global warming externality problem cannot be resolved without a binding agreement on some overall formula for dividing emissions responsibilities among nations. Voluntary altruism alone will not solve 
this international public-goods problem. Of necessity, there must be some impingement on national sovereignty in the form of an international mechanism for determining targets, verifying fulfillment, and punishing noncompliance. The question then becomes: Which collective-commitment frameworks and formulas are more promising than which others?

\section{Theory of Negotiating a Uniform Carbon Price}

In this chapter, I examine the theoretical properties of a natural onedimensional focus on negotiating a single binding price on carbon emissions, the proceeds from which are domestically retained. As previously mentioned, for expositional simplicity, I identify this single binding price on carbon as if it were an internationally harmonized, nationally collected carbon tax. At a theoretical level of abstraction, I blur the distinction between a carbon price and a carbon tax. However, in actuality, the important thing is acquiescence by each nation to a common binding minimum price on carbon emissions, not the particular mechanism by which this common binding minimum price is attained by a particular nation.

A system of uniform national carbon taxes with revenues kept in the taxing country is a relatively simple and transparent way to achieve internationally harmonized carbon prices. But it is not necessary for the conclusions of this chapter. Nations or regions could meet the obligation of a minimum price on carbon emissions by whatever internal mechanism they choose-a tax, a cap-and-trade system, a hybrid system, or whatever else results in an observable price of carbon above the internationally agreed minimum. I elaborate further on this issue in my concluding remarks.

At a theoretical level, I would suggest that the instruments of negotiation for helping to resolve the global warming externality should ideally possess three desirable properties.

1. Induce cost-effectiveness.

2. Be of one dimension based on a "natural" focal point to facilitate finding an agreement with relatively low transactions costs.

3. Embody "countervailing force" against narrow self-interest by automatically incentivizing all negotiating parties to internalize the externality via a simple, reciprocal, I will if you will, common-climate commitment formula. 
Using these theoretical properties as criteria, I now compare and contrast an idealized binding harmonized tax-like price with an idealized binding cap-and-trade system (without a uniform price floor).

On the first desirable property, in principle, both a carbon price and tradable permits achieve cost-effectiveness (provided agreement can be had in the first place).

The second desirable property (low dimensionality) argues in favor of a one-dimensional, harmonized, tax-like carbon price over an $n$-dimensional, harmonized, cap-and-trade system among $n$ nations. Alas, this argument is elusively difficult to formulate rigorously or articulate coherently. My argument here is necessarily intuitive or behavioral and relies on empirical counterexamples. In this situation, two important empirical counterexamples are the breakdown of the quantity-based Kyoto approach and the hugely underambitious "intended nationally determined contributions" actually volunteered by nations under the COP21 Paris Accord.

With $n$ different national entities, a quantity-based treaty involves assigning $n$ different binding emissions quotas (whether tradable or not). Treaty making can be viewed as a coordination game with $n$ different players. Such a game can have multiple solutions, often depending delicately on the setup, what is being assumed, and, most relevant here, the choice of negotiating instrument. In the case of Kyoto, the world had in practice arrived at a bad quantity-based solution that essentially devolved to regional volunteerism. The ultimate outcome of the COP21 Paris Accord remains to be seen, but so far the INDCs actually volunteered by the parties seem grossly underwhelming, even leaving aside the near impossibility of achieving the stated goal of keeping global warming below $2^{\circ} \mathrm{C}$.

Thomas Schelling ${ }^{10}$ introduced and popularized the notion of a focal point in game theory. Generally speaking, a focal point of an $n$-party coordination game is some salient feature that reduces the dimensionality of the problem and simplifies the negotiations by limiting bargaining by the parties to some manageable subset, hopefully of one dimension. The basic idea is that by limiting bargaining to a salient focus, there may be more hope of reaching a good outcome. In a somewhat circular definition, a focal point is anything that provides a focus of convergence. The "naturalness" or "salience" of a focal point is an important aspect of Schelling's argument that is difficult to define rigorously and is ultimately intuitive. 
The concept of "transactions cost" is associated with the work of Ronald Coase. ${ }^{11}$ The basic idea is that $n$ parties to a negotiation can be prevented from attaining a socially desirable outcome by the costs of transacting the agreement among themselves. One could try to argue that, other things being equal, transactions costs increase proportionally with the number of parties $n$. Negotiating a one-dimensional price with singlepeaked preferences has the important additional property of allowing a majority-rule voting equilibrium, which avoids the Arrow impossibility theorem.

In the case of international negotiations on climate change, I believe that both Schelling's concept of a salient focal point and Coase's concept of transactions costs can be used as informal arguments to support negotiating a single harmonized carbon price whose proceeds are nationally rebated. Put directly, it is easier to negotiate one price than $n$ quantities-especially when the one price can be interpreted as "fair" in terms of equality of marginal effort. I cannot defend this claim rigorously. At the end of the day, this is more of a plausible conjecture than a rigorous theorem. Whether justly or not, throughout this chapter, I assume that the essential contrast is between one binding price assignment versus $n$ binding quantity assignments-and I then proceed to examine the consequences.

The third desirable property is that the instrument or instruments of negotiation should embody a "countervailing force" against narrow freeriding self-interest by incorporating incentives that automatically internalize the externality. Such incentives should ideally take the form of a simple, reciprocal, common climate commitment based on the quid-pro-quo principle of "I will if you will." I believe this third property is arguably the most important property of all. This "countervailing force" property is inherently built into a price-based harmonized system of emissions charges, but it is absent from a quantity-based international cap-and-trade system, at least as traditionally formulated.

If I am assigned a cap on emissions, then it is in my own narrow freeriding self-interest to want my cap to be as large as possible (regardless of whether my cap will be tradable as a permit). The self-interested part of me wants maximal leniency for myself. Other than altruism, there is no countervailing force on the other side encouraging me to lower my desired emissions cap because of the externality benefits I will be bestowing on others. 
Within a nation, the government assigns binding caps. But among sovereign nations, binding caps must be negotiated. I believe this is a crucial distinction for the success or failure of a cap-and-trade regime. A quantitybased international system fails because no one has an incentive to internalize the externality and everyone has the self-interested incentive to free-ride. What remains is essentially an erratic pattern of altruistic individual volunteerism that is far from a socially optimal resolution of the problem.

An internationally harmonized, domestically collected carbon price is different. If the price were imposed on me alone, then I would wish it to be as low as possible so as to limit my abatement costs. But when the price is uniformly imposed, it embodies a countervailing force that internalizes the externality for me. Counterbalancing my desire for the price to be low (to limit my abatement costs) is my desire for the price to be high so that other nations will restrict their emissions, thereby increasing my benefit from worldwide total carbon abatement. A binding uniform minimum price of carbon emissions has a built-in self-enforcing mechanism that countervails free-riding. ${ }^{12}$

In previous work, I have tried to model formally the role of this third "countervailing force" property of an internationally harmonized but nationally collected carbon price. ${ }^{13}$ I constructed a basic model indicating an exact sense in which each agent's extra cost from a higher international minimum emissions price is counterbalanced by that agent's extra benefit from inducing all other agents to simultaneously lower their emissions via the higher international minimum price (which might well take the form of a uniform price floor on a cap-and-trade system).

With further restrictions, the model showed that population-weighted majority rule for an internationally harmonized tax-like carbon price can come as close to an optimal price on emissions as the median per capita marginal benefit is close to the mean per capita marginal benefit. The key insight from this way of looking at things is that in voting on (or more generally negotiating) a universal minimum carbon price, various nations are, to a greater or lesser degree, internalizing the externality. Loosely speaking, an "average" nation is fully internalizing the externality because its extra cost from a higher emissions price is exactly offset by its extra benefit from inducing all other nations to simultaneously lower their emissions via the higher price. 
On the price side, a uniform carbon price automatically has the desirable property that cost-effectiveness is guaranteed. I think that the formal WCA voting result of the model might perhaps be interpreted somewhat less formally as indicating that negotiating an internationally harmonized (but nationally collected) carbon price may have an important desirable property on the quantity side as well. If the median marginal benefit (per capita) equals the mean marginal benefit (per capita), then the socially optimal carbon price in the model has the property that, roughly speaking, half of the world's population wants the price to be higher, whereas the other half of the world's population wants the price to be lower. In this situation, the desirable quantity-side property is that the total worldwide output of all emissions might be "close" to being optimal to the extent that the outcome of negotiations mimics the outcome of majority voting. Although the real world is a far more complicated and nuanced place than the restrictive theoretical model that was constructed, I think this voting result is trying to indicate something positive (even if only at an abstract level) about how a negotiated uniform carbon price might possess some overall potential to counteract via internalization the externality of global warming.

\section{Might a Modified Cap-and-Trade Work as Well?}

Previously I listed three desirable features that climate change negotiation instruments should ideally possess: (1) cost-effectiveness, (2) a natural onedimensional focal point, and (3) a built-in countervailing-force mechanism that internalizes the externality by embodying "I will if you will" behavior. I then explained that an internationally harmonized but nationally retained carbon price possesses all three properties, whereas an $n$-dimensional, quantity-based cap-and-trade system at best (if it can be negotiated in the first place) possesses only the first property of cost-effectiveness. With $n$ sovereign nations, there will be difficult bargaining over $n$ different caps, with no force other than altruism countervailing each nation's selfish desire to be a free-rider and secure for itself a large cap on emissions.

But maybe I am being unfair to tradable permits. Suppose we imagine trying to convert the $n$-dimensional problem of allocating carbon emissions permits into some one-dimensional aggregate-quantity analogue of a uniform tax-like price on carbon emissions. We might imagine a thought experiment where the cap-and-trade negotiators are sitting around a 
negotiating table limiting themselves to simple linear formulas for allocating individual emissions caps as a fraction of total world emissions. ${ }^{14}$

Suppose the cap-and-trade negotiators must decide the total amount of world emissions $E$, given a suballocation formula for deciding the fraction of emissions permits allotted to each nation. A standard way of conceptualizing this allocation problem for each country is in terms of an assigned fractional emissions reduction from an assigned baseline level. Here I think it is most instructive to view the essence of such an assignment process in terms of a simple linear reduced form that allots emissions permits $E_{i}(E)=a_{i}+b_{i} E$ to nation $i$ (where $\sum a_{i}=0, b_{i}>0$, and $\left.\sum b_{i}=1\right)$.

If each nation $i$ would accept as given the assigned distributional coefficients $\left(a_{i}, b_{i}\right)$ and the above suballocation formula $E_{i}(E)=a_{i}+b_{i} E$, one might then imagine negotiating over (or even voting for) the total emissions $E$. Contingent on the distribution of coefficients being accepted as given, this system would seemingly possess the desirable property of having a onedimensional locus of negotiations (here the level of total worldwide emissions $E$ ). There is also countervailing force against negotiating for a higher value of worldwide total emissions $E$. Although each nation $i$ 's automatic assignment of a higher individual emissions cap $E_{i}$ when total emissions $E$ are higher helps that nation directly by lowering its emissions costs, this domestic effect is counteracted by the benefits that each nation would lose from a higher total worldwide emissions level because then everyone else would also emit more. It appears that such a cap-and-trade system might in principle have desirable focal-point and countervailing-force properties if the assigned distribution coefficients were accepted and bargaining were restricted to negotiating total emissions.

But now follow the thought experiment further by asking: Where do the distributional suballocation coefficients $\left(a_{i}, b_{i}\right)$ come from in the first place? They are presumably the result of an $n$-party negotiating process where there is no countervailing force to the selfish desire of each country to make its own fractional allocation coefficients as high as possible. With $n$ different nations, there will be the usual difficult bargaining over $n$ different distributional coefficients, with no externality-internalizing incentive countervailing each nation's desire to secure for itself a high fraction of emissions.

When a cap-and-trade system is used to control pollution within a nation, the government of that nation assigns the caps (or the fractions of 
emissions). ${ }^{15}$ In this intranational case, there is a natural symmetry between a one-dimensional price $p$ and a one-dimensional total quantity of emissions $E$. But there is no international government that has the unilateral power to assign caps or fractions. These caps or fractions must be negotiated among sovereign nations. This breaks the one-dimensional symmetry because now one tax-like price $p$ is contrasted with the asymmetry of $n$ vested sovereign interests jockeying for the $n$ initial fractional distributions. There is thus a critical distinction between intranational and international cap-and-trade systems. In the international case, the initial distribution of caps is explicitly distributive, resulting in a war of words about who caused the global warming problem and who should bear the burden of remedying it, who is rich and who is poor, what is fair and what is unfair, and so on. There could also be a war of words about the green-fund transfers required to induce participation in a uniform-price treaty, but for reasons elaborated in footnotes 5 and 8 regarding the difference between first- and secondorder transfers, I think that an internally retained price treaty takes a lot of pressure off the green-fund payments.

But perhaps a formulation of this generality is biased against capand-trade. We might try to imbue the distribution coefficients with dimensionality-reducing salient qualities by imagining "naturally symmetric" focal allocations of the fractional coefficients. One such seemingly symmetric formula might be that each country is assigned the same fractional reduction of emissions from some agreed-on baseline year. The Kyoto Protocol of 1997 adopted just a little of the spirit of this idea for developed countries alone, with the hope that some variant of it might later be extended to developing countries. The high-income industrialized countries (Annex I) agreed to "binding" commitments (but without any enforcement mechanism) to reduce greenhouse gas emissions in 2010 by an average of 5\% relative to 1990 levels (although allowing some individually negotiated variations around that $5 \%$ average). Developing countries were exempt from any "binding" commitments. Overall, the Kyoto Protocol did not come close to fulfilling its initial aspirations. The United States and Australia did not ratify; Canada, Japan, and Russia eventually dropped out; and individual compliance was at best spotty. ${ }^{16}$ Furthermore, and perhaps most distressingly, non-Annex I countries did not formally agree to any actual future "binding" commitments going forward from 2012. The Kyoto experience is subject to multiple interpretations. For me, it largely 
testifies to the great difficulty of negotiating binding international quantity caps on the major emitters. In the language employed here, it has been overwhelmingly problematic to assign binding quantity-like distributional coefficients on a worldwide basis. The Paris COP21 agreement of December 2015 "solved" this problem only by making all targets completely voluntary as "intended nationally determined contributions." In COP21, there was no pressure for nations to cut back emissions by $5 \%$ or any other uniform amount.

Other seemingly symmetric quantity formulas might also be examined. For example, one might entertain the idea of assigning the same worldwide emissions level per capita. This symmetric formula embodies a certain concept of worldwide fairness, but a cap-and-trade system based on such an initial distribution of caps would involve massive transfers from the developed to the developing countries, which would likely prove politically unacceptable. Besides, even this formula does not address concerns regarding historical responsibility for the cumulative stock of emissions, which would surely be raised. Alternatively, one might imagine negotiating (or even voting on) an identical percentage reduction from some base case of emissions. In this situation, I think everyone would first argue about the fairness of the baseline emissions that they were initially assigned.

I abstain from further speculation. My point here is that no matter what quantity-like initial allocation mechanism I can imagine, an attempt to modify an international cap-and-trade system by making it one dimensional seems likely to founder for essentially the same reasons that an unmodified international cap-and-trade system founders. In a quantitybased system with $n$ different sovereign nations, I fear there will be intractable negotiations for $n$ different distributional assignments $\left(a_{i}, b_{i}\right)$, with no force countervailing each nation's free-riding desire to secure for itself a selfishly lenient emissions fraction of the total emissions $E .^{17}$

Here is what I think is the essence of the one-price versus $n$-quantities negotiation problem as elaborated in this section. A quantity-type system based on a formula like $E_{i}(E)=a_{i}+b_{i} E$ involves two layers of negotiations. First, the $n$ parties must agree on the quantity-like distributional coefficients $\left(a_{i}, b_{i}\right)$.Second, the parties must agree on the single worldwide aggregate level of emissions $E$. By contrast, a price-based system involves only one layer of negotiation, focused on agreeing to a single one-dimensional uniform price $p$. The latter is not an easy task, but it would seem generally 
easier to negotiate one price layer than two quantity layers (whose first layer involves assigning $n$ quantity-like distributional coefficients). Admittedly, this argument depends on a particular way of framing the issue, but it seems to me that, in international negotiations among $n$ sovereign nations, there may be an irreducible asymmetry between one price instrument versus $n$ quantity instruments.

While acknowledging that it only involves one layer of negotiations (as opposed to two on the quantity side), one could ask on the price side what might induce $n$ countries to agree to a single harmonized charge for carbon emissions. We have been over this ground before. If climate change becomes sufficiently threatening on a grassroots level, then public opinion may support relinquishing some national sovereignty over carbon emissions in favor of the greater good of binding, enforceable international agreements. It all begins with the recognition that any resolution of the global warming free-rider problem requires a collective commitment to some binding restriction on the sovereign right of nations to freely emit as much carbon dioxide as they wish. Why might nations restrict their own sovereignty by collectively committing to a common price regime for resolving the global warming externality? Perhaps because enough of them come to realize (or are made to realize) that the international climatechange public good is sufficiently important to outweigh national rights to pollute the global commons-and that a radical collective problem may call for a radical collective solution. Without such a realization and the will to act on it, progress on resolving the global warming externality will be limited to voluntary altruism, which seems to me not nearly enough to overcome the free-rider problem.

\section{Concluding Remarks}

At the end of the day, there is no air-tight logic in favor of a negotiated price over negotiated quantities, only a series of partial arguments. One argument is that the revenues from a tax-like carbon price are nationally collected, so that the contentious distributional side is somewhat hidden, and there is at least the appearance of fairness as measured by equality of marginal effort. A second desirable feature, I have argued, is the natural salience and relatively low transaction costs of negotiating one price as against negotiating $n$ quantities, which, although somewhat imprecise, is in my opinion 
an important distinction. A third argument is the self-enforcement mechanism that constitutes the main theme of this chapter, namely, the built-in countervailing force of an imposed uniform price of carbon, which tends to internalize the externality and gives national negotiators an incentive to offset their natural impulse to otherwise bargain for a low price.

Of necessity, my argument has been sprinkled with subjective judgments. This, unfortunately, is the nature of the subject. To repeat yet again, this time after examining somewhat more carefully the alternatives, I judge it difficult to escape the conclusion that, in the context of an international treaty that covers all major emitters, it is more politically acceptable and it comes closer to a social optimum to negotiate one binding price than $n$ binding quantities or quantity-like distributional coefficients.

My argument here is sufficiently abstract that it is open to enormous amounts of criticism on many different levels. There are so many potential complaints that it would be incongruous to list them all and attempt to address them one by one. These potential criticisms notwithstanding, I believe the argument here is exposing a fundamental countervailing-force argument that deserves to be highlighted.

Because the formulation is at such a high level of abstraction, it has blurred the distinction between a carbon price and a carbon tax. As previously noted, the important thing is acquiescence by each nation to a binding minimum price on carbon emissions, not the particular internal mechanism by which this obligation is met. A system of national carbon taxes with revenues kept in the taxing country is a relatively simple and transparent way to achieve internationally harmonized carbon prices. But it is not absolutely necessary for the conclusions of this chapter. In principle, nations or regions could meet the obligation of a minimum price on carbon emissions by whatever internal mechanism they choose-a tax, a cap-and-trade system with a tax floor, some other hybrid system, or whatever else results in an observable price of carbon above the uniform minimum. ${ }^{18}$

Of course any nation or region could choose to impose a carbon tax or price above the international minimum. The hope is that even a low positive initial value of a universal minimum carbon tax or price could be useful for gaining confidence and building trust in this price-based international architecture.

The purpose of this chapter is primarily expository and exploratory. Any proposal to resolve the global warming externality will face a seemingly 
overwhelming array of practical administrative obstacles and will need to overcome powerful vested interests. That is the nature of the global warming externality problem. The theory of this chapter seems to suggest that negotiating a uniform minimum price on carbon can have several desirable properties, including, especially, helping to internalize the global warming externality. To fully defend the relative "practicality" of what I am proposing would probably require a book not a chapter. In any event, this article is not primarily about practical considerations of international negotiations. I leave that important task mostly to others. ${ }^{19}$ However, I do want to mention just a few real-world considerations that have been left out of my mental model yet seem especially pertinent.

An example of a relatively small practical issue that I am waving aside is just where in the production chain a carbon price should be collected. I think the presumption would be that the carbon price should be collected by the country in which the carbon dioxide is actually released into the atmosphere. One might try to argue that a carbon price should be collected downstream as close as possible to the point where the carbon is burned. But this would involve an impractically large number of collection points. It is much easier to collect the price upstream at various chokepoints where the carbon is first introduced into the carbon-burning economy. ${ }^{20}$

A truly critical issue is that a binding international agreement on a uniform minimum carbon tax or price requires some serious compliance mechanism. To begin with, the carbon price must be observable. For enforcement, perhaps there is no practical alternative to using the international trading system for applying tariff-based penalties on imports from noncomplying nations. Nordhaus (2015) advocates such an approach with uniform border tariffs on imports from nonmember countries imposed by a "Climate Club" of member nations who agree to impose a harmonized carbon price on themselves. Cooper (2010) has argued for an expansive interpretation, whereby the internationally agreed charge on carbon emissions would be considered a cost of doing business, such that failure to pay the charge would be treated as a subsidy that is subject to countervailing duties under existing provisions of the World Trade Organization. ${ }^{21}$

An efficient carbon price naturally produces more winners than losers (by the metric of the modified Pareto criterion). In the case of the global warming externality, which has been characterized as the greatest public 
goods problem of all time, it seems reasonable to suppose that there might be many times more winners than losers from imposing a uniform carbon price. Because countries here get to keep their own carbon price-generated revenues, welfare-compensating transfers, to the extent that they are made at all, should, at least for small changes, be relatively modest second-order, deadweight-loss triangles instead of the relatively immodest first-order rectangle transfers associated with tradable permits from, say, an initial assignment of caps that are equal per capita. ${ }^{22}$

I close by noting again that global warming is an extremely serious as-yet-unresolved international public goods problem. With the failure of a Kyoto-style quantity-based approach, the world has seemingly given up on a comprehensive global design, settling instead in the 2015 Paris COP21 agreement for completely voluntary and sporadic national, subnational, and regional "contributions." These partial measures seem far from constituting a socially efficient response to the global warming externality. Perhaps, as previously suggested, a quantity-based focus on negotiating emissions caps embodies a bad design flaw. The arguments of this chapter suggest a way in which negotiating a binding internationally harmonized, nationally collected minimum tax or price on carbon emissions might help to internalize the global warming externality by empowering an "I will if you will"approach.

\section{Notes}

1. One ton of carbon equals 3.67 tons of carbon dioxide. My default unit is carbon dioxide $\left(\mathrm{CO}_{2}\right)$.

2. For more about the coherence of this quid-pro-quo mechanism, see chapters 2 and 4.

3. Global Warming Gridlock is the title of a book by David Victor (2011), who popularized the phrase. For more information on the Kyoto Protocol, see the Wikipedia entry for "Kyoto Protocol" and the many other references cited there. For more information on the Paris COP21 Accords, see the Wikipedia entry for "Paris Agreement" and the many other references cited there.

4. There is actually a fair-sized literature on a carbon-tax (or carbon-price) approach (see e.g., Cooper, 2010; Cramton and Stoft, 2012; Metcalf and Weisbach, 2009; Nordhaus, 2007, 2013; and the many further references cited in these works).

5. See Hoel and Karp (2002), Pizer (1999), and Weitzman (1974). 
6. Of course, persuading nations to commit to negotiating a uniform price of carbon in the first place might well involve some "green-fund" equity transfers. Because the imposed "carbon tax" is internally retained within each nation, then at least for small changes, the green-fund transfers needed to offset increased costs of compliance for price changes are deadweight-loss, second-order Harberger triangles of the relatively modest form $(\Delta P \times \Delta Q) / 2$. The corresponding international transfers in a cap-and-trade system (which can be either positive or negative, depending, among other things, on initial cap assignments) are first-order immodest rectangles of the form $P \times \Delta Q$.

7. For a critical review of carbon taxes versus cap-and-trade for carbon emissions, see Goulder and Schein (2013) and the many further references they cite.

8. See Goulder et al. (2010) and the further cited references therein.

9. One could try to argue that binding green-fund equity payments are required to get $n$ countries to agree in the first place to negotiate a uniform carbon price, also representing an $n$-dimensional problem. However, footnotes 5 and 7 suggest that the required green-fund payments may be smaller than the absolute value of the (positive or negative) transfers involved in a cap-and-trade regime that starts off, say, with equal per capita permit assignments. Cramton, Ockenfels, and Stoft (chapter 12 , this volume) argue additionally that choosing a green-fund equity-payment formula for a uniform price can be reduced to a one-dimensional focal problem.

10. See Schelling (1960). Also see the 2006 special issue of the Journal of Economic Psychology devoted to Schelling's psychological decision theory, especially the introduction by Colman (2006). Three of the seven articles in this issue concerned aspects of focal points, testifying to the lasting influence of the concept.

11. Coase (1960) did not invent or even use the term "transactions cost," but he prominently employed the concept. For an application of the transactions cost approach to controlling greenhouse gas emissions, see Libecap (2013).

12. Later I discuss negotiating one worldwide aggregate emissions cap (contingent on a previous-round subdivision formula for $n$ fractional targets, set, for example, by a preceding agreement on various target reductions from various baselines). A system based on negotiating aggregate emissions (given a subdivision formula) could, in principle, embody countervailing force against the global warming externality. But again, I will conclude that negotiating the extra layer of $n$ first-round Kyoto-like fractional subdivision target reductions will likely founder politically when applied on a worldwide scale.

13. See Weitzman (2014).

14. This approach is spelled out in more mathematical detail in Weitzman (2014). 
15. Admittedly, this is often done in a way that eases special-interest acceptance, such as being allocated for free or almost for free based on something like a uniform reduction of previous pollution levels.

16. The one bright spot might be considered the European Union (EU), whose emissions trading system could perhaps be interpreted as evolving toward an EU-wide cap (declining annually) with member-state shares increasingly being determined by auctioning permits. I am unsure and somewhat skeptical about the extent to which this EU model might be extended to the world as a whole. For a generally favorable assessment of this possibility, see Ellerman (2010).

17. Bosetti and Frankel (2012) propose a constructive and imaginative allocation formula for emissions permits, but it still looks complicated and contentious to me.

18. A minimum carbon price could theoretically be attained in a cap-and-trade system by setting it as a floor, which could be enforced by making it a reserve price of permits actualized by a hypothetical international agency that buys up excess permits whenever the price falls below the floor. (Alas, such a mechanism invites its own free-rider problem because each nation has an incentive not to spend its own money but for other nations to spend their money to buy up excess permits.) Alternatively, a hypothetical worldwide consignment auction for carbon permits with a uniform reserve price might work in theory but seems highly impractical in practice. Again here, there is a marked distinction between the simplicity of a onedimensional price tax and the complexity of negotiating a $n$-dimensional quantitybased binding agreement among $n$ different nations.

19. See Bodansky (2010) or Barrett (2005).

20. This set of issues and its distributional consequences (including references to other literature) are discussed extensively in Asheim (2012).

21. See also the discussion of the legality of such sanctions under WTO provisions in Metcalf and Weisbach (2009).

22. Cramton, Ockenfels, and Stoft (2015) make an analogous argument in the form of a numerical example indicating that committing to a price tends to be less risky than quantity targets. Thus, according to this reasoning, equity transfers under capand-trade would have to be larger than equity transfers under a uniform price because of the increased risk imposed by caps. In a separate argument, they also indicate that choosing a particular green-fund equity-payment formula to encourage participation in a uniform price regime can be reduced from a seemingly $n$-dimensional to a one-dimensional focal problem.

\section{References}

Asheim, G. B. 2012, August 11. A distributional argument for supply-side climate policies. Environmental and Resource Economics. Published online. 
Barrett, S. 2005. Environment and Statecraft: The Strategy of Environmental Treaty Making. Oxford: Oxford University Press.

Bodansky, D. 2010. The Art and Craft of International Environmental Law. Cambridge: Harvard University Press.

Bosetti, V., and J. Frankel. 2012, August. Sustainable cooperation in global climate policy: Specific formulas and emissions targets. Mimeo.

Coase, R. H. 1960. The Problem of Social Cost. Journal of Law \& Economics 3:1-44.

Colman, A. M. 2006. Thomas C. Shelling's psychological decision theory: Introduction to a special issue. Journal of Economic Psychology 27:603-608.

Cooper, R. N. 2010. The case for charges on greenhouse gas emissions. In Post-Kyoto International Climate Policy: Architectures for Agreement, ed. J. Aldy and R. Stavins. Cambridge, England: Cambridge University Press.

Cramton, P., A. Ockenfels, and S. Stoft. 2015. An international carbon-price commitment promotes cooperation. Economics of Energy \& Environmental Policy 4 (2): $51-64$.

Cramton, P., and S. Stoft. 2012. Global climate games: How pricing and a green fund foster cooperation. Economics of Energy \& Environmental Policy 1 (2): 125-136.

Ellerman, A. D. 2010. The EU's emissions trading scheme: A prototype global system? In Post-Kyoto International Climate Policy: Architectures for Agreement, ed. J. Aldy and R. Stavins. Cambridge, England: Cambridge University Press.

Goulder, L. H., M. A. C. Hafstead, and M. Dworsky. 2010. Impacts of alternative emissions allowance allocation methods under a federal cap-and-trade program. Journal of Environmental Economics and Management 60 (3): 161-181.

Goulder, L. H., and A. R. Schein. 2013. Carbon taxes vs. cap and trade: A critical review. Climate Change Economics 4 (3): 1-28.

Hoel, M., and L. Karp. 2002. Taxes vs. quotas for a stock pollutant. Resource and Energy Economics 24:367-384.

Libecap, G. D. 2013. Addressing global environmental externalities: Transaction costs considerations. Journal of Economic Literature 52 (2): 424-479.

Metcalf, G. E., and D. Weisbach. 2009. The design of a carbon tax. Harvard Environmental Law Review 33 (2): 499-556.

Nordhaus, W. D. 2007. To tax or not to tax: Alternative approaches to slowing global warming. Review of Environmental Economics and Policy 1 (1): 26-44.

Nordhaus, W. D. 2013. The Climate Casino: Risk, Uncertainty, and Economics for a Warming World. New Haven, CT: Yale University Press. 
Nordhaus, W. D. 2015. Climate Clubs: Designing a mechanism to overcome freeriding in international climate policy. American Economic Review 105 (4): 1339-1370.

Pizer, W. 1999. Optimal choice of policy instrument and stringency under uncertainty: The case of climate change. Resource and Energy Economics 12:255-287.

Schelling, T. C. 1960. The Strategy of Conflict. Cambridge, MA: Harvard University Press.

Victor, D. 2011. Global Warming Gridlock. Cambridge, England: Cambridge University Press.

Weitzman, M. L. 1974. Prices vs. quantities. Review of Economic Studies 41 (4): 477-491.

Weitzman, M. L. 2014. Can negotiating a uniform carbon price help to internalize the global warming externality? Journal of the Association of Environmental and Resource Economists 1 (1/2): 29-49. 


\title{
9 Climate Policy at an Impasse
}

\author{
Ottmar Edenhofer and Axel Ockenfels*
}

Global greenhouse gas emissions must decrease if climate change is to be slowed. Yet they are increasing and at an ever-faster pace. Despite the global economic crisis over the last decade, the growth rate of emissions has never been higher (IPCC, 2014b). At the same time, global population growth and the economic ambitions of emerging markets are proving to be a continually increasing challenge for climate policy. More than 20 years of negotiations and numerous summits have done little to reduce greenhouse gas emissions. Unfortunately, the UN Climate Change Conference in Paris in 2015 is no exception (Cooper et al., chapter 1, this volume), and a major breakthrough is hardly in sight.

Climate change policy is at an impasse, and getting out of it will require an effective international climate agreement. For this to happen, policymakers must first agree on a realistic assessment. In the first part of this chapter, we present the climate problem and expose common misconceptions regarding climate policy. In the second part, we propose solutions to overcoming the impasse, focusing in particular on Germany's and Europe's perspective.

\section{Climate Change}

Greenhouse gas emissions that have accumulated in the atmosphere are driving up the global mean temperature due to the greenhouse effect. The fact that this phenomenon is caused by the burning of coal, oil, and gas and deforestation (that has been ongoing since the onset of industrialization) is

* Financial support of the German Research Foundation (DFG) through the Research Unit "Design \& Behavior" (FOR 1371) is gratefully acknowledged. 
no longer scientifically disputed (IPCC, 2013). This global increase in temperature has negative impacts. However, considerable uncertainties exist as to how these impacts are distributed across different regions, as well as their frequency and severity. This means that science does not know exactly what will happen. Some argue that, deeming certain findings to be too unreliable to allow for definitive conclusions, climate policy should abstain from recommending any and all courses of action. Yet such an approach is imprudent. Climate policy is inherently risk management; although a given scenario may be too pessimistic, it could just as well be too optimistic. Thus, a more rational approach would be to take precautions to attenuate the risk of catastrophic damage (Edenhofer et al., 2015a). In that sense, climate policy could be seen as a type of insurance, such as disability, fire, or health insurance.

One can distinguish between two classes of uncertainty in the climate debate. The first concerns uncertainty about the consequences of climate change, the frequency and intensity of which increases gradually. Weather events such as droughts, floods, and crop failures belong to this class. The second class concerns uncertainty about how or when the climate may trigger more abrupt types of damages to the Earth system-damages that, once triggered, are irreversible for any length of time and can impact the human species (Edenhofer et al., 2015a). The melting of the Antarctic and the Greenland ice sheet, the loss of the Amazon rainforest and its transformation from a net carbon sink into a carbon source, and the change in the monsoon dynamics in China and India are all examples of events that have potentially irreversible physical, social, and economic consequences (IPCC, 2014a).

The amount of $\mathrm{CO}_{2}$ stored in the atmosphere is contributing to the increase in the global mean temperature and thereby to irreversible climate change. This can be expressed in terms of fundamental atmospheric scarcity.

\section{The Atmosphere and the Fundamental Scarcity Problem}

Humankind uses the atmosphere as a dumping ground for greenhouse gases. This is understandable because the use of the atmosphere is still free of charge. Yet as a storage site, the atmosphere is limited. Because its storage space has thus far been free, it has been overused, resulting in increased 
climate change. The same overuse phenomenon can be observed in traditional local commons in the mountains or with protected fisheries.

From this follows a fundamental insight: climate policy must be judged above all by whether it succeeds in limiting greenhouse gas emissions, thereby protecting the limited space remaining in the atmosphere from overuse. The scale of this challenge becomes evident when considering how small the atmosphere's capacity to absorb additional greenhouse gases actually is. The world may only emit roughly another 1,000 gigatons of $\mathrm{CO}_{2}$ if it is to-with a probability of at least $66 \%$ - meet the goal of staying below a $2^{\circ} \mathrm{C}$ global mean temperature increase (IPCC, 2014c). If annual emissions stay at their present levels, then the remaining carbon budget will be exhausted within the next 20 to 30 years. To use the remaining budget in a cost-efficient way, annual greenhouse gas emissions would have to be reduced by between $40 \%$ and $70 \%$ by 2050 . Toward the end of the century, emissions would have to decrease approximately to zero. Eventually, the world will probably have to rely on technologies that are able to withdraw more carbon from the atmosphere than they emit (IPCC, 2014c).

The significance of these figures, beyond indicating the limited carbon storage capacity of the atmosphere, reaches another dimension altogether when juxtaposing them to the approximately 16,000 gigatons of $\mathrm{CO}_{2}$ that the Earth still has in the form of fossil resources and reserves. In other words, the supply of carbon is many times greater than the capacity of the atmosphere to absorb it. This fact is of critical importance, even if rising prices for carbon fuels may slow the pace at which these resources are extracted from the ground.

The European environmental movement and the public at large appear to believe that (1) there is an impending shortage of fossil fuels, and (2) this could solve the climate problem and justify or even force the restructuring of the energy supply. From a climate change perspective, the opposite is true. The supply of fossil fuels is not only large but it has even increased in the last two decades. Rising oil and gas prices have made investments in the exploration of new oil and gas fields profitable. The currently low price of oil is slowing such investments temporarily. However, this will not lead to a permanent restriction of further investments in exploration because fossil fuel prices are anticipated to increase in the long run. At the same time, technological progress in the exploration and production of fossil 
fuels has been dramatically underestimated. The so-called shale gas revolution in the United States has contributed to an additional supply of gas and a decline in the price of coal. As a result of such developments, the global economy is in the midst of the largest coal renaissance since the beginning of industrialization.

\section{The Coal Renaissance}

The community concerned with climate change sometimes hopes that zero-emission technologies will become cheap so quickly that it will no longer be worthwhile to continue extracting fossil fuels, especially coal, in large quantities. This hope is deceptive. Renewable energies are not cost-efficient to the point that the extraction of coal would be no longer attractive. It is true that wind power, when generated in locations with a strong resource, has already reached the same cost level as electricity generated from coal. However, when the fluctuation of wind power is factored in, additional system costs make wind more expensive. The costs of fluctuation increase as larger shares of wind power are integrated in the grid (Hirth et al., 2015; Ueckerdt et al., 2013). The same is true for solar energy. Thus, although further breakthroughs in renewable energies can be expected, they are unlikely to make the use of coal unprofitable in one fell swoop.

Instead, the world is witnessing a breathtaking coal renaissance (Steckel et al., 2015). Between 2005 and 2013, three times as many coal power plants were built worldwide than in any previous decade. Since 2010, five Chinese provinces alone built more new coal power facilities than any other country. The focus on coal in China has since slowed. However, in India and other rapidly emerging countries such as Vietnam and Indonesia, the construction of new coal power plants is in full force. Even in Europe, including Turkey, additional new coal capacities are planned. Africa is also investing in this form of energy. Worldwide, about 1,000 gigawatts of coal power capacity are currently in the planning stage (Edenhofer, 2015). If only one-third of this capacity is built, then an additional 100 gigatons of $\mathrm{CO}_{2}$ would be dumped into the atmosphere over the lifespan of these facilities in the next 40 years. The existing infrastructure will already emit more than 700 gigatons of $\mathrm{CO}_{2}$ in the coming decades. These figures show how incongruous climate policy targets can be with reality: the coal renaissance 
alone threatens to use up all of the atmosphere's remaining carbon storage capacity (Edenhofer, 2015).

\section{A Reasonable Climate Protection Target}

This enormous challenge raises the question of whether the $2^{\circ} \mathrm{C}$ target is a reasonable and achievable goal. The answer is yes. Given the uncertainties about the costs and benefits of avoiding emissions, and the evaluation of those uncertainties in terms of distribution and discounting issues, the $2^{\circ} \mathrm{C}$ target corresponds to the precautionary principle. Many studies that attempt to quantify the various risks arrive at temperature targets between $2^{\circ} \mathrm{C}$ and $3^{\circ} \mathrm{C}$. There are also analyses that argue-in light of the irreversible risks - for a limit well below $2^{\circ} \mathrm{C}$. Given that climate change may also trigger abrupt and catastrophic damage to the Earth's system, robust and meaningful cost-benefit analyses are hardly possible (Weitzman, 2011).

Commitment to the $2^{\circ} \mathrm{C}$ target appears to be a precautionary and pragmatic compromise that considers both the normative conflicts and the scientific uncertainties. It calls for the rapid adoption and implementation of an effective climate policy, although care must be taken that achieving the $2{ }^{\circ} \mathrm{C}$ target does not put an intolerable burden on present and future generations. This can be done but only if an appropriate climate policy is adopted and the necessary technologies are sufficiently available.

According to current knowledge, the $2^{\circ} \mathrm{C}$ goal can be achieved through substantial improvements in energy efficiency, a three- to four-fold increase in the share of low-carbon technologies by 2050 (including renewable energy and nuclear energy), the use of carbon capture and storage (CCS), and the use of bioenergy with carbon capture and storage (BECCS). Reforestation and the use of BECCS are important measures for removing $\mathrm{CO}_{2}$ from the atmosphere over the long term. Some of these technologies are controversial and not without risks (Edenhofer et al., 2015a; IPCC, 2014b).

With such packages of mitigation options, the cost of remaining below the $2^{\circ} \mathrm{C}$ threshold can be kept in check even without major technological breakthroughs in the next few decades. The IPCC has assessed all cost studies on climate change in recent years and concluded that reaching the $2^{\circ} \mathrm{C}$ target would most likely decelerate economic growth by only $1.5 \%$ per year from now until 2050. 


\section{An Effective Climate Policy}

Thus far, the use of the atmosphere as a dumping ground has been largely free of costs, although this causes damages. The overuse of this space could be prevented if its use were associated with a fee. There is a broad consensus among economists and beyond that emission fees are the best climate policy instrument because they make low $\mathrm{CO}_{2}$-emitting technologies more profitable and the burning of fossil fuels less attractive. In this way, emissions can be effectively avoided at little cost. Such a price on carbon could be implemented through emissions trading or taxation. It creates scarcity where there was none and eliminates inefficiencies as well as the injustice of cost-free $\mathrm{CO}_{2}$ emissions. Carbon pricing is all the more pressing as fossil fuels are subsidized in many parts of the world today, to the extent that the average global carbon price is negative (Edenhofer, 2015). With such prices, there is no hope that global temperature rise can be kept within acceptable bounds.

Much of the climate debate revolves around indirect and complicated instruments. In Germany, renewable energies in the electricity sector are generously subsidized with feed-in tariffs. However, this path leads in the wrong direction as countless opportunities to advance efficient climate protection are missed. A carbon price that increases over the long term would impact all relevant decisions in an effective, transparent, and fair manner. Every measure in favor of climate protection-from a homeowner's decision to install a new heating system, to investments in renewables, to pioneering research in battery technology-is equally encouraged with a carbon price and the resulting incentives and market forces. With subsidies, by contrast, politics determines the winners and losers. Renewable energy subsidies in the German electricity sector do not avoid any $\mathrm{CO}_{2}$ emissions beyond what is already accomplished by the EU Emissions Trading System. In an emissions trading scheme, a fixed number of allowances for emitting one ton of $\mathrm{CO}_{2}$ are traded. For example, if a coal power plant emits one ton of $\mathrm{CO}_{2}$ less due to additional power supplied by a wind power plant, the overall system is left with an allowance to emit one ton of $\mathrm{CO}_{2}$. This allowance is sold at a profit to another user, whereby the total amount of emissions remains the same throughout Europe. Because the supply of allowances within the market is capped by means of political regulations, the demand for allowances dropped because of the additional supply of 
renewables, which has in part led to a decline in prices in the European emissions market.

The price in the emissions trading scheme is also influenced by many other factors. After 2008, the main reason for the drastic $\mathrm{CO}_{2}$ price decline was primarily the financial crisis: actual emissions have since even been below the permitted ceiling. Because the European Commission could not decide to take the surplus of permits off the market, traders began assuming that the European emissions market would not necessarily experience significant shortages until 2020. Traders were even skeptical of European Commission announcements that the upper ceiling would be continuously lowered in the long term, with the consequence that future European emissions allowance prices for 2020 have collapsed as well (Edenhofer et al., 2015b).

One consequence of this price collapse is that the relatively clean but expensive gas power plants have been pushed out of the electricity market, whereas the relatively cheap but environmentally harmful coal power plants have proliferated. This and other undesirable consequences of low $\mathrm{CO}_{2}$ prices and indirect climate policies have led to an unmanageable patchwork of politically motivated attempts at reform and many other costly subsidies. Despite all efforts and financial expenditures, the German energy transition has not effectively taken place to date. The share of renewable energy has risen, but this has not led to a significant decline in greenhouse gas emissions.

It is often argued that a carbon price creates undue competitive disadvantages when compared with measures implemented in the German energy transition. The opposite is true. A carbon price not only reduces costs but also generates revenues that could be used to offset politically undesired outcomes and burdens. As we shall see, a carbon price will also likely be a condition in any agreement that seeks to protect participants against free-riders at the international scale. As a result, a carbon price can massively reduce the competitive disadvantages arising in Germany from subsidizing renewables.

Without a substantial carbon price, effective climate protection is unthinkable, and the German energy transition will fall short of its goal. To avoid any misunderstandings, renewable energy will surely play an important role in climate protection, and research in this area is certainly recommendable. The problem arises in the conviction that the large-scale 
subsidization of renewables is equally justified and effective in mitigating greenhouse gas emissions as the direct pricing of greenhouse gas emissions. The German energy transition is a showcase of this phenomenon.

\section{Paris and the Climate Policy Challenge}

It is undisputable that unabated climate change is likely to have dramatic consequences for humanity. Governments are striving for a reasonable climate target, and the economic instruments with which such a target can be effectively and efficiently achieved without causing unwarranted burden are well understood. What, then, is the problem? The central challenge of climate policy is to discipline free-riders throughout the world in their use of the atmosphere as a dumping ground (MacKay et al., 2015; Cramton et al., chapter 4, this volume; Cramton, Ockenfels, and Tirole, 2017). Why should one country spend major sums of money on climate protection if it stands to gain only a fraction of the benefits of those efforts? Let the others do some work! Canada intends to continue exploiting the tar sands in Alberta; many African countries are hoping to become net exporters of oil within the next decade; China and India are building new coal power plants to keep up with growth, challenged only by local environmental protests; and the United States is focusing on shale gas, which may reduce domestic emissions but will lead to rising coal exports.

In Europe, greenhouse gas emissions generated from domestic production have dropped (IPCC, 2014b). However, emissions generated from European consumption have risen due to its net imports of emissions from China. China has become the workshop of the world, as well as the largest net exporter of $\mathrm{CO}_{2}$ emissions (Jakob and Marschinski, 2012; Jakob et al., 2014; Peters et al., 2007). Thus, although decreasing greenhouse gas emissions in Europe may ease the European conscience, this plays no significant role at the global scale.

International cooperation has not made significant progress thus far (Cramton et al., chapter 12, this volume). At present, climate talks are based on the principle that each state defines for itself what efforts it wants to contribute to climate protection. However, the climate challenge cannot be solved with a patchwork of nonaligned commitments.

In Paris, many countries announced their respective climate commitments for the 2030 time horizon. These pledges, despite being delivered 
with strategic optimism, are sobering. Calculations show that the various countries' pledges, taken together, will continue to lead to rising emissions and miss the efficient path to $2^{\circ} \mathrm{C}$ target by far. Not surprisingly, politicians and climate diplomats sketch more positive pictures of the outcome of Paris, but those pictures are almost entirely based on assumptions about what happens after 2030. Because there are no pledges for the period after 2030, many scenarios are conceivable. Although the aim of the Paris climate conference was to insist that each country also commit to gradually increase individual contributions after 2030, it remains completely unclear how this may be actually negotiated and implemented. The only serious hint about what comes after 2030 that is not based on speculation and wishful thinking comes from cooperation research. This research suggests that without a shared commitment, cooperation would be rather fragile and eventually collapse even if it were to start out with several forceful contributions (Brosig et al., 2003; Ledyard, 1995; Ostrom, 1990, 2009). Anyone who has ever participated in climate negotiations and monitored the developments after Kyoto would realistically agree. New mechanisms are needed to solve the cooperation problem.

\section{Toward a Common Price Target}

There are two underlying principles that are put forward throughout most of this book and explained in more detail in other chapters: (1) pricing carbon is the most effective policy to curb emissions, and (2) reciprocity is the most effective policy to promote international cooperation. The good news is that these two fundamental principles, which are concluded from two different research agendas, can be knotted together to fix the broken climate negotiations.

The key to understand this is that a shared commitment is needed to promote cooperation among countries. Only if countries have a common understanding of what can be expected from others and from themselves can they be protected against exploitation by free-riders. The common commitment binds a country only to the extent that other countries also live up to the agreement. This kind of reciprocity creates incentives for cooperation and, ultimately, mutual trust (Bolton and Ockenfels, 2000; Bowles and Gintis, 2013; Fudenberg and Tirole, 1991; Kosfeld et al., 2009; Kraft-Todd et al., 2015; Ostrom, 1998, 1990). 
As explained thoroughly elsewhere in this book, a quantity commitment, which distributes the global carbon budget across countries, has proved infeasible. Although it is relatively easy to agree on a global emissions target, the breakdown of this global goal into national obligations is simply impossible. Entitlement to a higher carbon budget essentially represents money in the form of valuable carbon credits. In such a context, during negotiations about the global emissions target, countries try to find ways to maximize their respective budgets, which leads to an inflation of the overall carbon budget-producing the opposite of the expected outcome. In practice, at no point in time were participating countries able to agree on a distribution of the carbon budget or even a distribution principle. The underlying reasons for the failure of quantity commitments have nothing to do with uncertainty about the carbon budget: Even if the "optimal" carbon budget would be known with certainty in the future, negotiators would be unable to distribute the budget among all countries because of inherent free-riding and fairness issues. That is, what might seem obvious from a climate science perspective can be a complete failure from the perspective of incentive and negotiation design.

A global price target such as an internationally agreed minimum carbon price, however, can do the trick. A carbon price could be negotiated such that it is consistent with the $2^{\circ} \mathrm{C}$ objective. It could also be flexibly adapted as uncertainties about costs and damages are resolved. At the national level, the price target could then be achieved in a flexible way, for example, by means of emissions trading schemes or fuel taxes.

An international minimum price target has many advantages, most of which are described in various chapters in this book. For instance, because the burden created by a price target is proportional to the emissions produced, it is also proportional to a country's level of development. Compared with quantity targets, a price target carries fewer financial risks for individual countries because business-as-usual emissions and abatement costs are both highly uncertain. A price instrument such as a global minimum price for $\mathrm{CO}_{2}$ also allows the efforts of different countries to be measured and made comparable. In this way, shared commitment allows for a system of reciprocal rewards and punishments that are essential for stable cooperation: "I will cooperate for as long as the others are also sticking to our shared commitment." All experiences with negotiations concerning climate protection (as well as countless other field and laboratory contexts) 
strongly demonstrate the ubiquitous importance of the principle of reciprocity for stable cooperation. Only when the international community can agree on a shared and comparable benchmark of climate protection efforts can cooperation be rewarded and free-riding disciplined.

\section{How the Burden Could Be Distributed}

Although a price target reduces the barriers to a joint international commitment, not all countries will want to agree on an ambitious price target. Some poorer countries are, for understandable reasons, focused on poverty alleviation or rapid growth, whereas other countries stand to lose considerable revenues from the sale of coal, oil, and gas. Thus, we support the proposal to implement the Green Climate Fund, which collects money with the purpose of realizing an international climate policy, generating incentives for ambitious price targets. In this way, the Fund could reward cooperation while taking into account differences in costs and willingness to pay for greenhouse gas emission reductions. Recent research suggests that strategically selected distribution mechanisms of the Green Climate Fund could allow the establishment of an ambitious global minimum price target on which all countries would voluntarily agree (Cramton and Stoft, 2012). This global minimum price is associated with transfer payments that induce a politically acceptable redistribution of funds from rich to poor (Cramton et al., chapter 12, this volume; Kornek and Edenhofer, 2015; Roolfs et al., 2015).

A global minimum carbon price that is implemented by national governments (e.g., as tax or an emissions trading system) leads to revenues that can be used to invest in local infrastructure, lower distortionary taxes (especially for low-income groups), and reduce government debt. Even without consideration of the climate, it would be better to generate revenue for a country through the correction of inefficient scarcity indicators than through distortionary taxes on labor income. This would also invalidate the frequently made objection that climate protection and poverty reduction are mutually exclusive. Especially in emerging markets, carbon pricing could mobilize means with which to make investments in the provision of clean water, sanitation, roads, and mobile networks.

An ambitious carbon price drives a wedge between the revenues generated by countries supplying fossil fuels and the revenues generated 
by consumer states. Essentially, profits generated by those who produce fossil fuels are funneled to countries with carbon prices (Franks et al., 2015). Could carbon prices give supplier states an incentive to get coal, oil, and gas out of the ground more quickly to circumvent the impending loss of revenues from their own resources? This so-called Green Paradox effect can be prevented if the rate at which the carbon price increases is slower than that of the long-term interest rate in the capital market (Edenhofer and Kalkuhl, 2011). Countries with coal, oil, and gas reserves would then no longer have an incentive to extract resources more quickly and profitably invest the proceeds in the capital market. In this way, a carbon price would ensure that these resources are kept in the ground. A global carbon price gives nation-states, but also cities and communities, the leeway to design their own flexible climate policy. With a global minimum carbon price, additional efforts of a wide range of players would actually lead to global emissions reductions. These reductions would not be feasible in a global emissions trading scheme, where local efforts would not affect the global carbon budget and the corresponding certificate quantity-instead leading merely to additional emissions elsewhere. In other words, a minimum carbon price does not induce a shift of emissions. The price remains unchanged by additional unilateral efforts.

Although climate policy requires global governance, it needs local solutions as well. Technical and social innovations are not made at megaconferences. International negotiations should provide a regulatory framework that ensures local efforts and innovations are not meaningless or, worse, counterproductive. A commitment to a carbon price will accomplish this goal.

\section{The European Emissions Trading Scheme and National Preferences}

Should an agreement on a global minimum carbon price be made, to comply with international obligations, common European climate policy would need to be reformed to adopt a minimum price within the EU Emissions Trading System. However, such a minimum price in the European emissions market would be beneficial even prior to the introduction of a global carbon price agreement. First, the price decline in the European emissions market would not persist because traders can count on an increasing minimum price for their carbon-free investments. Second, a minimum price 
would give member states more leeway to implement their own climate policies. Countries with a greater willingness to pay for climate protection could express their preference for a more ambitious national climate policy without it leading to a mere shift of emissions. In Europe, Germany is pursuing its own climate change targets and is promoting renewable energy, but Sweden also has a national carbon tax, and the United Kingdom promotes nuclear power plants. At present, these unilateral efforts only lead to a shift of emissions - a minimum price would ensure that additional emissions are avoided (Edenhofer et al., 2015b).

Targeted transfer payments can facilitate ambitious international climate policy (including a minimum carbon price) in both international climate negotiations and the European Union. Transfer payments across European countries can even facilitate the implementation of a European-wide minimum $\mathrm{CO}_{2}$ price (Edenhofer et al., 2015b). Of course, the goal is to achieve a shared commitment beyond European borders. However, as a first step, this policy restructuring would get Europe out of its climate policy impasse. At the same time, Europe could demonstrate, as a multilateral laboratory, how to implement effective global climate protection. On the basis of this proposed structure, Europe could operate a smart, reciprocal pricing policy that would also help to get an international price target on its feet.

\section{What's Left to Do?}

On the path to an ambitious, effective, and politically feasible global climate policy, many questions remain unanswered. For example, international climate negotiations will not be able to persuade all countries to back a given outcome. It would be a terrific breakthrough if, for a start, the largest emitters could agree on an initially modest carbon price target. This would constitute an effective climate policy instrument that would allow the community to act, gradually increase the carbon price, and adapt it to newly obtained knowledge. For this, it will be necessary for the public and governments to stand up against strong interest groups that benefit from the failure of international cooperation and the inefficiency of massive redistribution programs.

The basic principle of effective climate policy is simple, direct, and indispensable: those who emit $\mathrm{CO}_{2}$ have to pay. A carbon price generates adequate incentives for innovation and effectively reduces greenhouse gas 
emissions. Luckily, this principle is fully in line with the basic principle of effective cooperation: reciprocity. A price target (unlike a quantity target) is an agreeable common commitment of the international community, which in turn is necessary for any reciprocity to evolve, thereby breaking the deadlock of failed climate negotiations. The international community is now facing perhaps the greatest dilemma of human history. Whether it can learn to collaborate and build trust or whether it will lose itself in an ineffective patchwork of self-centered actions will depend on whether it chooses to utilize or ignore these two fundamental principles of effective climate policy and human cooperation.

\section{References}

Bolton, G. E., and A. Ockenfels. 2000. ERC-A theory of equity, reciprocity and competition. American Economic Review 90 (1): 166-193.

Bowles, S., and H. Gintis. 2013. A Cooperative Species: Human Reciprocity and Its Evolution. Princeton, NJ: Princeton University Press.

Brosig, J., A. Ockenfels, and J. Weimann. 2003. The effect of communication media on cooperation. German Economic Review 4 (2): 217-241.

Cramton, P., A. Ockenfels, and J. Tirole. 2017. Policy Brief-Translating the collective climate goal into a common commitment. Review of Environmental Economics and Policy. In press.

Cramton, P., and S. Stoft. 2012. Global climate games: How pricing and a Green Fund Foster cooperation. Economics of Energy \& Environmental Policy 1:2.

Edenhofer, O. 2015. King Coal and the queen of subsidies. Science 349 (6254): 1286-1287.

Edenhofer, O., S. Kadner, C. von Stechow, and J. Minx. 2015a. Beyond the $2^{\circ} \mathrm{C}$ limit: Facing the economic and institutional challenges. In Towards a Workable and Effective Climate Regime, ed. Scott Barrett, Carlo Carraro and Jaime de Melo, 49-68. London: CEPR Press and Ferdi.

Edenhofer, O., and M. Kalkuhl. 2011. When do increasing carbon taxes accelerate global warming? A note on the green paradox. Energy Policy 39 (4): 2208-2212.

Edenhofer, O., C. Roolfs, B. Gaitan, P. Nahmmacher, and C. Flachsland. 2015b. Agreeing on an EU ETS minimum price to foster solidarity, subsidiarity and efficiency in the EU. Working paper.

Franks, M., O. Edenhofer, and K. Lessmann. 2015. Why finance ministers favor carbon taxes, even if they do not take climate change into account. Environmental and Resource Economics. doi:10.1007/s10640-015-9982-1. 
Fudenberg, D., and J. Tirole. 1991. Game Theory. Cambridge, MA: MIT Press.

Hirth, L., F. Ueckerdt, and O. Edenhofer. 2015. Integration costs revisited-An economic framework for wind and solar variability. Renewable Energy 74:925-939.

IPCC. 2013. Climate Change 2013: The Physical Science Basis. Contribution of Working Group I to the Fifth Assessment Report of the Intergovern-mental Panel on Climate Change. Ed. T. F. Stocker, D. Qin, G.-K. Plattner, M. Tignor, S. K. Allen, J. Boschung, A. Nauels, Y. Xia, V. Bex, and P. M. Midgley. Cambridge, United Kingdom; New York: Cambridge University Press.

IPCC. 2014a. Climate Change 2014: Impacts, Adaptation, and Vulnerability. Part B: Regional Aspects. Contribution of Working Group II to the Fifth Assessment Report of the Intergovernmental Panel on Climate Change. Ed. C. B. Field, V. R. Barros, D. J. Dokken, K. J. Mach, and M. D. Mastrandrea. Cambridge, United Kingdom; New York: Cambridge University Press.

IPCC. 2014b. Climate Change 2014: Mitigation of Climate Change. Contribution of Working Group III to the Fifth Assessment Report of the Intergovernmental Panel on Climate Change. Ed. O. Edenhofer, R. Pichs-Madruga, Y. Sokona, E. Farahani, S. Kadner, K. Seyboth, A. Adler, et al. Cambridge, United Kingdom; New York: Cambridge University Press.

IPCC. 2014c. [Synthesis Report. Contribution of Working Groups I, II and III to the Fifth Assessment Report of the Intergovernmental Panel on Climate Change. Ed. R. K. Pachauri and L. A. Meyer. Geneva, Switzerland: IPCC.] Climatic Change.

Jakob, M., and R. Marschinski. 2012. Interpreting trade-related $\mathrm{CO}_{2}$ emission transfers. Nature Climate Change 3 (1): 19-23.

Jakob, M., J. C. Steckel, and O. Edenhofer. 2014. Consumption- versus productionbased emission policies. Annual Review of Resource Economics 6 (1): 297-318.

Kornek, U., and O. Edenhofer. 2015. The strategic dimension of international climate finance in climate change mitigation. Mimeo.

Kosfeld, M., A. Okada, and A. Riedl. 2009. Institution formation in public goods games. American Economic Review 99:1335-1355.

Kraft-Todd, G., et al. 2015. Promoting cooperation in the field. Current Opinion in Behavioral Sciences 3:96-101.

Ledyard, J. 1995. Public goods: A survey of experimental research. In The Handbook of Experimental Economics, ed. J. H. Kagel and A. E. Roth, 111-194. Princeton, NJ: Princeton University Press.

MacKay, D. J. C., P. Cramton, A. Ockenfels, and S. Stoft. 2015. Price carbon-I will if you will. Nature 526:315-316. 
Ostrom, E. 1990. Governing the Commons: The Evolution of Institutions for Collective Action. Cambridge, UK: Cambridge University Press.

Ostrom, E. 1998. A behavioral approach to the rational choice theory of collective action: Presidential address. American Political Science Review 92 (1): 1-22.

Ostrom, E. 2009. World Bank Report, "A Polycentric Approach for Coping with Climate Change," WPS5095.

Peters, G. P., C. L. Weber, D. Guan, and K. Hubacek. 2007. China's growing $\mathrm{CO}_{2}$ emissions-A race between increasing consumption and efficiency gains. Environmental Science \& Technology 41 (17): 5939-5944.

Roolfs, C., G. Beatriz, O. Edenhofer, M. Pahle, and B. Knopf. 2015. How a federal government can improve upon national climate policies with (simple) transfers. Mimeo.

Steckel, J. C., O. Edenhofer, and M. Jakob. 2015. Drivers for the renaissance of coal. Proceedings of the National Academy of Sciences of the United States of America 112 (29): E3775-E3781.

Ueckerdt, F., L. Hirth, G. Luderer, and O. Edenhofer. 2013. System LCOE: What are the costs of variable renewables? Energy 63:61-75.

Weitzman, M. 2011. Fat-tailed uncertainty in the economics of catastrophic climate change. Review of Environmental Economics and Policy 5:275-292. 


\title{
10 Effective Institutions against Climate Change
}

\author{
Christian Gollier and Jean Tirole*
}

We are faced now with the fact that tomorrow is today. Over the bleached bones and jumble residues of numerous civilizations are written the pathetic words "Too late."

—Martin Luther King, New York, April 4, 1967

\section{Climate Change Is a Global Commons Problem}

Before discussing efficient institutions against climate change, let us restate the obvious.

\section{We Must Put an End to the Waiting Game}

If no strong collective action is undertaken soon, then climate change is expected to dramatically deteriorate the well-being of future generations. Although the precise consequences of our inaction are still hard to quantify, there is no question that a business-as-usual scenario would be catastrophic. The 5th Report of the IPCC (IPCC, 2014) estimates that the average temperature would increase by somewhere between $2.5^{\circ} \mathrm{C}$ and $7.8^{\circ} \mathrm{C}$ by the end of this century, after having already increased by almost $1^{\circ} \mathrm{C}$ over the last century. Our emissions of greenhouse gases (GHGs) have never been larger than today. Limiting the increase in temperature to $2^{\circ} \mathrm{C}$ is thus an immense challenge, with a still increasing world population and, hopefully, more

* We are grateful to François-Marie Bréon, Dominique Bureau, Bruno Bensasson, Frédéric Chevalier, Peter Cramton, Axel Ockenfels, Christian de Perthuis, Steven Stoft, and Martin Weitzman for helpful comments. This chapter is an extended version of another article, "Negotiating Effective Institutions Against Climate Change," which appeared in Economics of Energy \& Environmental Policy, Vol. 4, No. 2, pages 5-27, 2015, http://dx.doi.org/10.5547/2160-5890.4.2.cgol. Reproduced by permission of the International Association for Energy Economics (IAEE). 


\section{Box 10.1}

Past and Current Emissions of Anthropogenic $\mathrm{CO}_{2}$

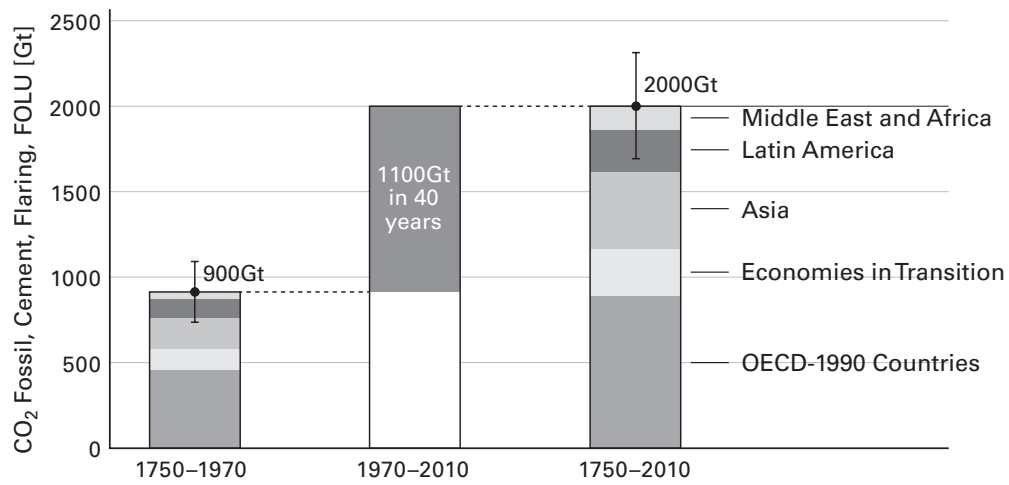

\section{Figure 10.1}

Emissions of $\mathrm{CO}_{2}$ since 1750.

Source: IPCC (2014).

Despite the emergence over the last three decades of solid scientific information about the climate impacts of increased $\mathrm{CO}_{2}$ concentration in the atmosphere, the world's emissions of GHG have never been larger, rising from 30 $\mathrm{GtCO}_{2}$ eq/year in 1970 to $49 \mathrm{GtCO}_{2}$ eq/year in 2010. According to the IPCC, about half of the anthropogenic $\mathrm{CO}_{2}$ emissions between 1750 and 2010 occurred during the last four decades, due mainly to economic and population growth and to the dearth of actions to fight climate change.

countries accessing Western standards of living. It will require radical transformations in the way we use energy, heat and locate our houses, transport people, and produce goods and services.

\section{Two "Good" Reasons for Inaction}

Most benefits of mitigation are global and distant, whereas costs are local and immediate. The geographic and temporal dimensions of the climate problem account for the current inaction.

Climate change is a global commons problem. In the long run, most countries will benefit from a massive reduction in global emissions of GHGs, but individual incentives to do so are negligible. Most of the benefits of a country's efforts to reduce emissions go to the other countries. In 
a nutshell, a country bears $100 \%$ of the cost of a green policy and receives, say, $1 \%$ of the benefits of the policy if the country has $1 \%$ of the population and an average exposure to climate-related damages. Besides, most of these benefits, however small, do not accrue to current voters but to future generations.

Consequently, countries do not internalize the benefits of their mitigation strategies, emissions are high, and climate changes dramatically. The freerider problem is well known to generate the "tragedy of commons" (Hardin, 1968), as illustrated by a myriad of case studies in other realms. When herders share a common parcel of land on which their herds graze, overgrazing is a standard outcome because each herder wants to reap the private benefit of an additional cow without taking account of the fact that what he gains is matched by someone else's loss. Similarly, hunters and fishers do not internalize the social cost of their catches; overhunting and overfishing led to the extinction of species, from the Dodo of the island of Mauritius to the bears of the Pyrenees and the buffalos of the Great Plains. Diamond (2005) shows how deforestation on Easter Island led to the collapse of an entire civilization. Other illustrations of the tragedy of commons can be found in water and air pollutions, traffic congestion, or international security.

Ostrom (1990) showed how small and stable communities are in some circumstances able to manage their local common resource to escape this tragedy, thanks to built-in incentives for responsible use and punishments for overuse. These informal procedures to control the free-rider problem are obviously not applicable to climate change, whose stakeholders include the 7 billion inhabitants currently living on this planet and their unborn descendants. Addressing the global externality problem is complex because there is no supranational authority that could implement the standard internalization approach suggested by economic theory and often employed at the domestic level. ${ }^{1}$

A country or region that would contemplate a unilateral mitigation strategy would be further discouraged by the presence of the so-called "carbon leakages." Namely, imposing additional costs to high-emission domestic industries makes them noncompetitive. This tends to move production to less responsible countries, yielding an international redistribution of production and wealth with negligible ecological benefit. Similarly, the reduction in demand for fossil energy originating from the virtuous countries tends to reduce their international price, thereby increasing the demand and emissions in nonvirtuous countries. This other carbon leakage also reduces 
the net climate benefit of the effort made by any incomplete club of virtuous countries. Its intertemporal version is called the green paradox. It states that a commitment to be green in the future leads oil producers to increase their production today to cater to today's nonvirtuous consumers. Because carbon sequestration is not a mature technology, mitigation is a threat to the oil rent, and its owners should be expected to react to this threat.

\section{We Must Accept That Climate Mitigation Is Costly in the Short Run}

The good news is that an efficient international climate agreement will generate an important social surplus to be shared among the world's citizens. The political economy of climate change, however, is unfavorable: The costs of any such agreement are immediate whereas most benefits will occur in the distant future, mainly to people who are not born yet and a fortiori do not vote. In short, climate mitigation is a long-term investment. Many activists and politicians promote climate mitigation policies as an opportunity to boost "economic growth." The fact that no country (with the exception of Sweden) comes remotely close to doing its share should speak volumes here: Why would countries sacrifice the consumption of goods and leisure to be environment-unfriendly? The reality is bleaker, in particular for economies in crisis and in the developing world. In reality, fighting climate change will imply reducing consumption in the short run to finance green investments that will generate a better environment only in the distant future. It diverts economic growth from consumption to investment, not good news for the well-being of the current poor. Carbon pricing, if implemented, will induce households to invest in photovoltaic panels on their roof or purchase expensive electric cars, actions that yield no obvious increase in their own well-being, to the detriment of spending the corresponding income on other goods.

To be certain, countries may perceive some limited "co-benefits" of climate-friendly policies. For example, green choices may also reduce emissions of other pollutants (coal plants produce both $\mathrm{CO}_{2}$ and $\mathrm{SO}_{2}$, a regional pollutant); in a similar spirit, countries may encourage their residents to eat less red meat not so much from a concern about global warming but because they want to reduce the occurrence of cardiovascular diseases. Substituting dirty lignite by gas and oil as the main source of energy had enormous sanitary and environmental benefits in Western countries after World War II, for example by eliminating smog from London. Therefore, some 


\section{Box 10.2}

\section{Climate Change and the Oil Rent}

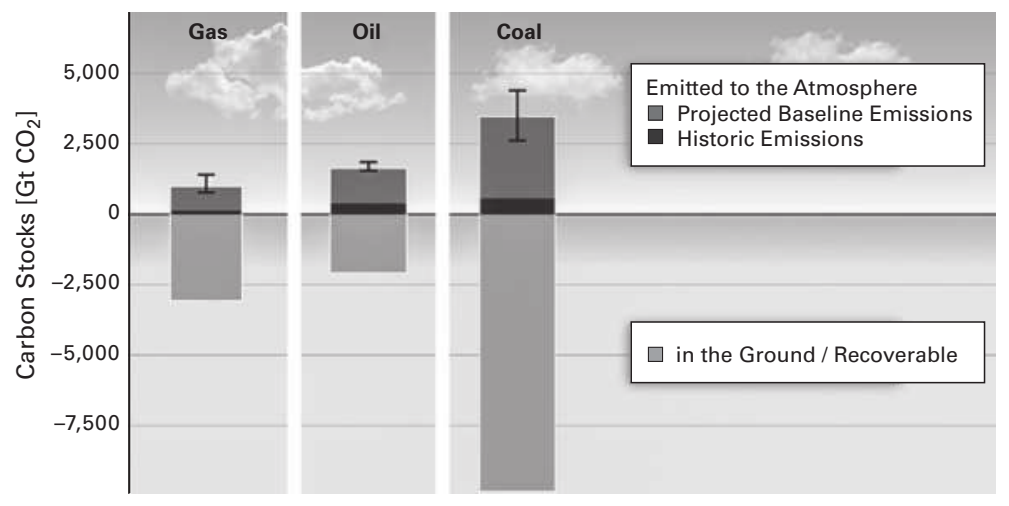

\section{Figure $\mathbf{1 0 . 2}$}

Past consumption and current reserves of fossil fuels.

Source: Figure 1.7 in IPCC (2011)—simplified by Working Group 3 Technical Support Unit.

One of the most difficult challenges of climate change comes from the existence of a large fossil fuels rent currently owned by resource-rich countries. This rent exists because of the relative scarcity of the reserve of these nonrenewable resources and the expectation of a future exhaustion or at least steeply increasing marginal costs of extraction. The problem is that these reserves are large, as shown in figure 10.2. The cumulated consumption (dark blue) of gas, coal, and oil since the beginning of the Industrial Revolution has been quite limited compared with the stock of these resources. Adding consumption until the end of this century (light blue) in the business-asusual scenario will still leave most of the stock in the ground. The burning of the entire stock of fossil resources on this planet within the next two centuries or so would certainly devastate our planet by raising GHG concentration way above the acceptable limits. If an efficient and a credible climate policy would be implemented one day, this would imply the annihilation of the fossil fuels rent. Its strategic and geopolitical consequences shed some light on the difficulty to reach an international agreement involving oil-rich countries. 
actions are to be expected from countries with an eye on national interest only (not to mention the political benefits of placating domestic and international opinion). But these "zero ambition" actions (to use a phrase coined by Robert Stavins) will be insufficient to generate what it takes to keep global warming manageable.

Overall, fighting climate change yields short-term collective costs, thereby creating a political problem for benevolent decision makers who support an ambitious international agreement. To sum up, without a collective incentive mechanism, one's investment in a responsible mode of living will hardly benefit one's well-being. Rather, and assuming away leakages, it will benefit distant generations who mostly will live in other countries. It is collectively efficient to act but individually optimal to do little.

\section{A Uniform Carbon Price Is Necessary}

\section{Economic Approach versus Command-and-Control}

As we have discussed, the core of the climate externality problem is that economic agents do not internalize the damages they impose on other economic agents when they emit GHGs. The approach ${ }^{2}$ that economists have long proposed to solve the free-rider problem consists of inducing economic agents to internalize the negative externalities they impose when they emit $\mathrm{CO}_{2}$ ("polluter pays principle"). This is done by pricing it at a level corresponding to the present value of the marginal damage associated with the emission and by forcing all emitters to pay this price. Because GHGs generate the same marginal damage regardless of the identity of the emitter and the nature and location of the activity that generated the emissions, all tons of $\mathrm{CO}_{2}$ should be priced equally. By imposing the same price to all economic agents around the world, one would ensure that all actions to abate emissions that cost less than that price will be implemented. This least-cost approach guarantees that the reduction of emissions that is necessary to attain the global concentration objective will be made at the minimum global cost. In contrast with this economic approach, "command-andcontrol" approaches (source-specific emissions limits, standards and technological requirements, ${ }^{3}$ uniform reductions, subsidies/taxes that are not based on actual pollution, vintage-differentiated regulations, industrial policy, etc.) usually create wide discrepancies in the implicit price of carbon 
put on different emissions. This has been shown empirically to lead to substantial increases in the cost of environmental policies.

Western countries have made some attempts at reducing GHG emissions, notably through direct subsidization of green technologies: generous feed-in electricity tariffs for solar and wind energy, bonus-malus systems favoring low-emission cars, subsidies to the biofuel industry, and so on. For each green policy, one can estimate its implicit carbon price (i.e., the social cost of the policy per ton of $\mathrm{CO}_{2}$ saved). A recent study by the Organization for Economic Co-operation and Development (OECD) (2013) showed that these implicit prices vary widely across countries and also across sectors within each country. In the electricity sector, OECD estimates range from less than 0 to $800 €$. In the road transportation sector, the implicit carbon price can be as large as 1,000 €, in particular for biofuels. The high heterogeneity of implicit carbon prices in actual policymaking is a clear demonstration of the inefficiency of this command-and-control approach. Similarly, any global agreement that would not include all world regions in the climate coalition would exhibit the same inefficiency by setting a zero carbon price in nonparticipating countries.

Although economists are broadly suspicious of command-and-control policies for good reasons, they also understand that these policies may occasionally be a second-best solution when measurement or informational problems make direct pricing complex and/or when consumers discount the future too much. This is the classic justification for housing insulation standards for instance, but command-and-control is best avoided when feasible.

\section{Carbon Pricing and Inequality}

Income and wealth inequality at the domestic and international levels is often invoked to dismiss uniform carbon pricing. The problems raised by inequality around the world are ubiquitous in analyses of climate change, as discussed by Posner and Weisbach (2010). On the one hand, if poor people emit proportionally more $\mathrm{CO}_{2}$, carbon pricing will worsen inequality starting today (Cremer et al., 2003). On the other hand, poor people may also be more vulnerable to climate change, so reducing emissions will reduce inequalities in the future. However, because international and national credit markets are imperfect, poor people may face large discount rates, making them short-termist and focused on their immediate survival 
to the detriment of the long-term climate risk. This means that the social cost of carbon will be smaller in these countries, even when accounting for future damages abroad.

International inequality raises the question of the allocation of the climate-mitigation burden. For example, the principle of common but differentiated responsibility is redistributive because wealthier countries typically contribute more to the accumulation of GHGs in the atmosphere. This issue is certainly important, but its solution should not be found in a Kyoto Protocol-like manipulation of the law of a single carbon price. The non-Annex 1 parties of the Kyoto Treaty had no binding obligation, and their citizens faced no carbon price. This derailed the ratification of the protocol by the US Senate. The Clean Development Mechanism (CDM) designed in Kyoto was aimed at alleviating the imperfect coverage problem; it met with limited success and anyway was not a satisfactory approach due to yet another leakage problem. For example, Annex 1 countries' paying to protect a forest in a less developed country increases the price of whatever the deforestation would have allowed to sell (beef, soy, palm, or wood) and encourages deforestation elsewhere. The CDM mechanism also created the perverse incentive to build, or maintain in operation longer than planned, polluting plants to later claim $\mathrm{CO}_{2}$ credits for their reduction. ${ }^{4}$

The Kyoto Protocol's attempted solution to the equity problem was to exonerate non-Annex 1 countries from carbon pricing. But using price distortions to reduce inequalities is always a second-best solution. Policies around the world that manipulate agricultural prices to support farmers' incomes end up generating surpluses and highly inefficient productions. The same hazard affects climate policies if one lets redistributive considerations influence carbon price signals to economic agents. At the national level, one should instead use the income tax system to redistribute income in a transparent way when this is possible. At the international level, one should organize lump-sum transfers to poor countries. This can be done by using the revenues generated by carbon pricing. Given that today we emit approximately $50 \mathrm{GtCO}_{2}$ yearly, a carbon price at $\$ 40 / \mathrm{tCO}_{2}$ would generate a rent of $\$ 2,000$ billion per year, or approximately $3 \%$ of the world GDP. 


\section{Computing the Right Price Signals}

Most infrastructure and R\&D investments to reduce GHG emissions have in common that they are irreversible (sunk) costs and yield a delayed reduction of emissions over an extended time span. Energy retrofit programs for residential building reduce emissions for decades, and hydroelectric power plans last for centuries. As a consequence, what triggers an investment in these sectors is not the current price of $\mathrm{CO}_{2}$ but the expectation of high prices in the future. The right price signal is thus given by an entire path of carbon prices. Two factors call for a carbon price that is increasing with time. First, if the damage function is convex, our inability to stabilize the concentration of $\mathrm{CO}_{2}$ within the next 100 years would imply that the marginal climate damages of each ton of $\mathrm{CO}_{2}$ will rise in the future. Second, if we impose a cap on GHG concentration in the atmosphere that we should never exceed, then the determination of the optimal emission path under this maximum quantity constraint is equivalent to the problem of the optimal extraction path of a nonrenewable resource. From Hotelling's rule, the carbon price should then increase at the risk free rate (Chakravorty et al., 2006). Any climate policy must also address the various commitment and credibility problems associated with the fixation of the long-term carbon price schedule. This challenge is reinforced by the current uncertainties affecting the marginal damage function, the optimal GHG concentration target, and the speed at which green R\&D will produce mature low-carbon energy technologies. This question is addressed later.

Over the last two decades, governments have commissioned estimates of the social cost of carbon (SCC). In France, the Commission Quinet (Quinet, 2009) used a real discount rate of $4 \%$ and recommended a price of carbon $\left(/ \mathrm{tCO}_{2}\right)$ at $32 €$ in 2010 , rising to $100 €$ in 2030 and between $150 €$ and 350 $€$ in 2050. In the United States, the US Interagency Working Group (2013) proposed three different discount rates $(2.5 \%, 3 \%$, and $5 \%)$ to estimate the SCC. Using a 3\% real discount rate, their estimation of the SCC is $\$ 32$ in 2010, rising to $\$ 52$ and $\$ 71$, respectively, in 2030 and 2050.

\section{Two Economic Instruments for Price Coherence}

Two prominent strategies for organizing an efficient, uniform pricing of $\mathrm{CO}_{2}$ emissions involve a carbon price and a cap-and-trade mechanism, respectively. ${ }^{5}$ Both proposals allow subsidiarity, and neither directly 


\section{Box 10.3}

\section{The Social Cost of Carbon}

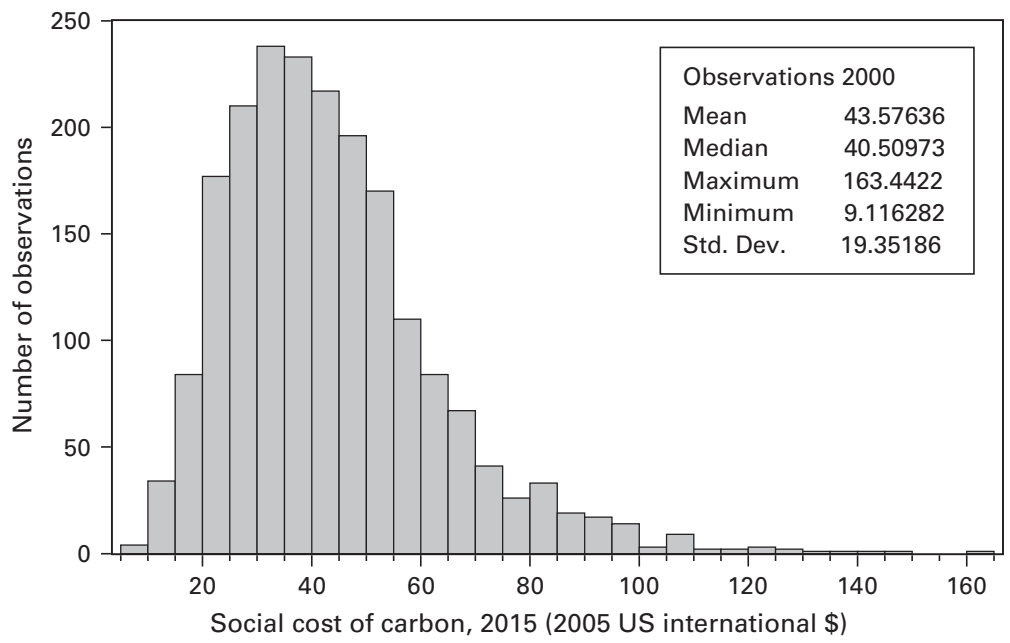

Figure $\mathbf{1 0 . 3}$

Density function for the SCC (in \$/tC).

Source: Nordhaus (2011).

Although the fifth report of the IPCC (IPCC, 2014) does not contain much information about it, there is now a sizable literature on the social cost of carbon. To send the right signal to economic agents, the carbon price must be equal to the present value of the marginal damages generated by the emission of one more ton of $\mathrm{CO}_{2}$. Estimating the SCC is complex because most of these damages will materialize only in the distant future and are uncertain. The time and risk dimensions raise the problem of the choice of the discount rate. If future climate damages were statistically independent of world GDP growth, a relatively low real discount rate of $1 \%$ should be used to discount these damages to the present (Gollier, 2012; Weitzman, 1998, 2001). However, most standard integrated assessment models such as the DICE model are such that climate damages are positively linked to consumption growth (Dietz et al., 2015). For example, Nordhaus (2011) uses the outcome of Monte-Carlo simulations of the RICE-2011 model with 16 sources of uncertainty to conclude that "those states in which the global temperature increase is particularly high are also ones in which we are on average richer in the future." Using technical terms from finance theory, this implies that the climate consumption-based CAPM beta is positive and the relevant climate 
discount rate is closer to the mean return of equity than the risk-free rate (Gollier, 2014).

To illustrate the uncertainty affecting the SCC, we reproduce in figure 10.3 an analysis performed by Nordhaus (2011). He used his RICE integrated assessment model with uncertain parameters related to the discount rate and the climate sensitiveness. Figure 10.3 reproduces the density function for the SCC of 2015, expressed in dollar per ton of carbon. Notice that 1 ton of carbon generates 3.7 tons of $\mathrm{CO}_{2}$, so that the Nordhaus's mean estimate of the SCC at $\$ 44 / \mathrm{tC}$ corresponds to $\$ 12 / \mathrm{tCO}_{2}$, which is considered relatively small compared with other estimates existing in the literature.

concerns national taxes or national cap-and-trade. Both rely on an international agreement that is reasonably encompassing and therefore on an "I will if you will" approach discussed in this book. They both require some strategy for enforcement; indeed, the implementation of credible and transparent mechanisms to measure emissions is a prerequisite to any efficient approach to climate change mitigation or, for that matter, to any policy.

Carbon price Under the first strategy, a minimum average price by country on all emissions around the world would be agreed on and collected by individual countries. All countries would be using the same price for GHG emissions. ${ }^{6}$ The carbon price of a country would be computed as the carbon revenue divided by the country's emissions; the price could correspond to a carbon $\operatorname{tax}^{7}$ in the special case of a taxation approach, but quite generally it could emerge from a variety of policies (tax, cap-andtrade, standards, etc.). Indeed, not all emissions in practice are subject to a carbon tax or Emission Trading Scheme (ETS) price. As Cooper (chapter 5 , this volume) notes, less than half of the European emissions are subject to EU ETS trading.

An international negotiation on a global carbon price has the advantage of linking each region's mitigation effort to the efforts of the other regions. As explained in Cramton, Ockenfels, and Stoft (chapter 12, this volume) and Weitzman (chapter 8 , this volume), each country will internalize in its vote for the level of a uniform price the positive impact of a larger equilibrium price on the global reduction of emissions, thereby raising the potential ambition of the international agreement. Under this scheme, a supranational supervision of the national carbon-pricing requirement at 
the internationally agreed level is thus necessary, as we discuss later. The compensation issue would be dealt with through a green fund.

Cap-and-trade Under the alternative cap-and-trade strategy, the agreement would specify a worldwide, predetermined number (the cap) of tradable emission permits. The tradability of these permits would ensure that countries face the same carbon price, emerging from mutually advantageous trades on the market for permits; the cross-country price here would not result from an agreed-on price of carbon but rather from clearing in this market. To address compensation, permits would be initially allocated to the different countries or regions, with an eye on getting all countries on board (redistribution).

\section{Failed or Unsatisfactory Attempts at Pushing the Economic Approach}

The cap-and-trade system was adopted, albeit with a failed design, by the Kyoto Protocol. The Kyoto Protocol of 1997 extended the 1992 UNFCCC that committed participating countries to reduce their GHG emissions. The Treaty entered into effect on February 16, 2005. The Annex-B parties committed to reduce their emissions in 2012 by 5\% compared with 1990 and to use a cap-and-trade system. Kyoto participants initially covered more than $65 \%$ of global emissions. But the nonratification by the United States and the withdrawal of Canada, Russia, and Japan, combined with the boost of emerging countries emissions, reduced the coverage to less than 15\% in 2012. The main real attempt to implement a carbon pricing mechanism within the Kyoto agreement emerged in Europe, with the EU ETS. In its first trading period of 2005-2007 ("phase 1"), the system was established with a number of allowances (the so-called Assigned Amount Units [AAUs]) based on the estimated needs; its design was flawed in many respects and in any case far inferior to that which had been adopted in the United States in 1990 to reduce $\mathrm{SO}_{2}$ emissions by half. In the second trading period of 2008-2012, the number of allowances was reduced by $12 \%$ to reduce the emissions of the industrial and electricity sectors of the Union. This crackdown was offset by the possibility given to the capped entities to use Kyoto offsets (mostly from the CDM described earlier) for their compliance. In addition, the deep economic crisis that hit the region during the period reduced the demand for permits. Moreover, large subsidies in the renewable energy sector implemented independently in most countries of the 
Union reduced further the demand for permits. In the absence of any countervailing reaction on the supply of permits, the carbon price went down from a peak of $30 € / \mathrm{tCO}$ to around $5 € / \mathrm{tCO}_{2}$ today. This recent price level is without a doubt way below the social cost of carbon. Therefore, it has a limited impact on emissions. It even let electricity producers substitute gas by coal, which emits 100\% more carbon (not counting dirty microparticles) per kWh. An additional problem came from the fact that the ETS covered only a fraction of the emissions of the region. Many specific emitters (e.g., the transport and building sectors) faced a zero carbon price. During the third trading period (2013-2020), the EU-wide cap on emissions is reduced by $1.74 \%$ each year, and a progressive shift toward auctioning of allowances in substitution of cost-free allocation is implemented.

Over the last three decades, Europeans have sometimes believed that their (limited) commitment to reduce their emissions would motivate other countries to imitate their proactive behavior. That hope never materialized. Canada, for example, facing the prospect of the oil sands dividend, quickly realized that their failure to fulfill their commitment would expose them to the need to buy permits ${ }^{8}$ and preferred to withdraw before having to pay them. The US Senate imposed a no-free-rider condition as a prerequisite for ratification, although the motivation for this otherwise reasonable stance may well have been a desire for inaction in view of a somewhat skeptical public opinion. Sadly enough, the Kyoto Protocol was a failure. Its architecture made it doomed to fail. Nonparticipating countries benefited from the efforts made by the participating ones, in terms of both reduced climate damages (free-rider problem) and improved competitiveness of their carbon-intensive industries (carbon leakage).

Other cap-and-trade mechanisms have been implemented since Kyoto. A mixture of collateral damages (we mentioned the emissions by coal plants of $\mathrm{SO}_{2}$, a local pollutant, jointly with that of $\mathrm{CO}_{2}$ ), the direct self-impact of $\mathrm{CO}_{2}$ emissions for large countries like China (which has $20 \%$ of the world population and is exposed to serious climate change risk), and the desire to placate domestic opinion and avoid international pressure all lead to some carbon control. Outside the Kyoto Protocol, the United States, Canada, and China established some regional cap-and-trade mechanisms. In the United States, where per capita GHG emissions are 2.5 times larger than in Europe and China, two initiatives are worth mentioning. In the Regional Greenhouse Gas Initiative (RGGI), nine Northeast and Mid-Atlantic US states 
Box 10.4

$\mathrm{CO}_{2}$ Price on the EU ETS Market

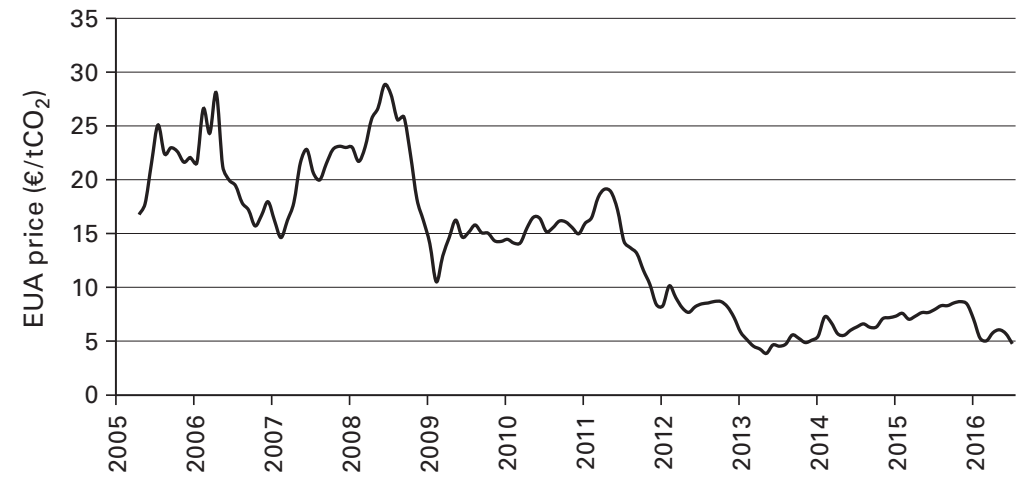

Figure 10.4

Evolution of carbon price on the EU ETS.

Source: Climate Economics Chair from ICE ECX data.

Figure 10.4 illustrates the failure of the EU ETS to establish a stable and an ambitious carbon price in the EU. The instability of the Kyoto coalition is one plausible explanation for why the EU did not attempt to push the price of permits up on the ETS market after the failure of the Copenhagen Conference in December 2009 in a depressed economic environment.

created a common cap-and-trade market to limit the emissions of their electricity sector. Here also, the current carbon price is way too low at around $\$ 5 / \mathrm{tCO}_{2}$ (up from the price floor level of $\$ 2 / \mathrm{tCO}_{2}$ during 2010-2012). From 2015 to 2020 , the $\mathrm{CO}_{2}$ cap will be reduced by $2.5 \%$ every year. The system will release extra carbon allowances if the carbon price on the market exceeds $\$ 6 / \mathrm{tCO}_{2}$. A similar system exists in California to cover the electricity sector, large industrial plants, and more recently fuel distributors, thereby covering more than $85 \%$ of the State's emissions of GHGs. ${ }^{9}$ In 2014 , China established seven regional cap-and-trade pilots officially to prepare for the implementation of a national ETS. The fragmented cap-and-trade systems described earlier cover almost $10 \%$ of worldwide emissions, and observed price levels are low. This is another illustration of the tragedy of commons. 
These regional or national ETSs could be used in the future under any international commitment regime, either a universal carbon price or a cap-andtrade mechanism.

Some countries have implemented a carbon tax. The most ambitious country is Sweden, in which a carbon tax of approximately $100 € / \mathrm{tCO}_{2}$ was implemented in 1991. France recently set its own carbon tax at $14.5 € / \mathrm{tCO}_{2}$. Both of these taxes are used for various purposes, such as raising revenue or addressing congestion externalities and road safety. They also now can be used to comply with an international commitment to cap-and-trade or to a carbon price. Outside Europe, some modest carbon taxes exist in Japan and Mexico, for example. Except for the Swedish case, these attempts put a carbon price that is far too low compared to the SCC.

\section{Pledge-and-Review: The Waiting Game in the Current International Negotiation}

The Copenhagen conference in December 2009 was expected to deliver a new Kyoto Protocol with more participating countries. In reality, the conference delivered a completely different project. The central idea of a unique carbon price induced by international cap-and-trade was completely abandoned, and the secretariat of the UNFCCC became a chamber of registration of noncommittal pledges by individual countries. This change of vision was upheld at the Cancun Conference in 2010 and more recently at the COP 20 in Lima in 2014. The new "pledge-and-review" approach was employed at the Paris COP 21 conference in December 2015. The so-called "Paris Agreement" will be implemented as soon as more than 55 parties to the agreement representing more than $55 \%$ of global emissions will have ratified the agreement. Voluntary climate actions (or "intended nationally determined contributions") will be registered without any coordination in the method and in the metric of measurement of the ambition of these actions. Although they are crucial to the credibility of the system, the reporting on and verification of the pledges were not formally decided. ${ }^{10}$

The pledge-and-review strategy has four main deficiencies and definitely is an inadequate response to climate change. First, if implemented, the agreement yields an inefficient allocation of efforts by inducing some economic agents to implement high-cost mitigation actions while others 
will emit GHGs that would be much cheaper to eliminate. ${ }^{11}$ Because the marginal costs of emission reduction are likely to be highly heterogeneous within and across countries, it will be almost impossible to measure the ambition of each country's pledge. In fact, individual countries have a strong incentive to "green wash" their actions by making them complex to measure and price.

Second, the pledge-and-review promises, even if they were credible, are voluntary, so free-riding is bound to prevail. These pledges are expected to deliver much less effort than would be collectively desirable. Following Buhr et al. (2014), "pledge-and-review means that climate change is dealt with the lowest possible level of decision making." As Stiglitz (chapter 6, this volume) notes, "in no other area has voluntary action succeeded as a solution to the problem of undersupply of a public good." In a sense, the pledge-and-review process is similar to an income tax system, in which each household would be allowed to freely determine its fiscal contribution.

Third, even if the pledges were large enough to put the global emission trajectory back on track, the absence of commitment to the pledges would limit their long-term credibility. This fragility makes it tempting for countries to deviate from their pledges. The absence of credibility of longterm pledges will reduce the innovators' incentive to perform green $R \& D$ and implement mature technologies, yielding reductions of emissions for a long period of time.

Fourth, the pledge-and-review regime can be analyzed as a waiting game, in which the global negotiation on formal commitments is postponed. Under the Paris Agreement (articles 4 and 14), the parties will meet every five years starting in 2023 to renegotiate their pledges, hopefully in a more ambitious manner. Beccherle and Tirole (2011) show that the freeriding in this waiting game is magnified by the incentive to achieve a better deal at the bargaining table in the future. Building on both theory and past experiences, countries will realize that staying carbon-intensive will put them in a strong position to demand compensation to join an agreement later: the carbon-intensity of their economy making them less eager to join an agreement, the international community will award them higher transfers (either monetary or in terms of free pollution allowances) so as to bring them on board. Moreover, when the damage function is convex, a country committing to a high emission level before this negotiation raises the marginal damages of all other countries and therefore induces them 
to reduce their emissions more heavily. All in all, these strategic considerations increase the cost of delay beyond what would be obtained in the traditional free-riding model with no expectation about a future negotiation.

Indeed, there has been concern that the current pledges are at a "zero ambition" level, or perhaps even below that level, where "zero ambition" refers to the level that the country would choose simply because of codamages (local pollutants) and the direct impact of GHG on the country, that is, in the absence of any international agreement.

To conclude this section on a more positive note, the pledge-and-review process might be useful in the second half of this year, provided that (1) ambitions turned out to be strong enough (a big "if" at this stage), and (2) one were to call the countries' bluff and transform or modify their pledges into real commitments. Suppose indeed that the various pledges are in line with a reasonable trajectory for GHG emissions (asserting this requires being able to aggregate/compare the various pledges, as some concern mitigation and others adaptation, and current pledges have rather different time horizons). One could then transform the predicted global trajectory of emissions into an equivalent number of permits; in a second stage, one could allocate permits under the requirement so that countries receive the same welfare as they would if their pledge were implemented. Countries that are sincere about their pledge could only gain from having all countries commit.

\section{Negotiating a Price/Quantity and Negotiating Transfers}

Let us now turn to the more satisfactory approach of picking an economic instrument together with measurement and enforcement strategies.

\section{The One-Dimensional Negotiation: Uniform Carbon Price or a Global Emission Target}

We can imagine two negotiation processes "I will if you will" with only one decision variable. Negotiators could try to agree on either a universal carbon price or a global emission target. For the sake of the argument, suppose first that all countries were similar in terms of their exposure to climate change, degree of development, endowment in natural resources, tastes, and so on. The free-rider problem inherent to the international negotiation on climate change could then be resolved by negotiating a uniform 
carbon price. ${ }^{12}$ Under this negotiation framework, a "world climate assembly" would vote for a uniform carbon price whose implementation would be left to its individual members. The claimed virtue of this framework is to align the constituents' private interests. Let us illustrate this claim with an example inspired from Cramton, Ockenfels, and Stoft (chapter 12, this volume). Suppose that the world is composed of 100 countries with the same characteristics (population, economic prosperity, growth expectations, industrial structure, etc.). Each ton of $\mathrm{CO}_{2}$ in the atmosphere generates $\$ 1$ of damage in each country. The business-as-usual scenario yields a uniform emission of $10 \mathrm{tCO}_{2}$ per capita. Suppose also that $80 \%$ of each country's emission can be eliminated at a unit abatement cost of $\$ 50 / \mathrm{tCO}_{2}$. The abatement cost of the remaining $20 \%$ is $\$ 200 / \mathrm{tCO}_{2}$. In this context, it is desirable that each country abates its emissions by $80 \%$ because the global damages of $\$ 100 / \mathrm{tCO}_{2}$ exceed the cheaper marginal abatement cost of $\$ 50 / \mathrm{tCO}_{2}$. But the tragedy of commons would prevail in the absence of a binding international agreement because the marginal abatement cost is 50 times larger than the local marginal damages. Suppose that the 100 countries accept to join an international coalition in which they cooperate to enforce the domestic imposition of an internationally harmonized carbon price that is voted by a majority rule. Participants are required to impose the common price as long as all signatories do too. The domestic revenues of the scheme are recycled internally. In this framework, all countries will be in favor of a carbon price of, say, $\$ 100 / \mathrm{tCO} 2$, which will induce them to abate their emissions by $80 \%$. This dominant strategy yields the first-best solution and makes all countries better off.

As Cramton and Stoft (2012) point out, an equivalent negotiation process exists that is based on quantities. Suppose that all countries in the coalition accept to negotiate a uniform emission per capita that is voted on by a majority rule. The same subsidiarity rule applies for which green policy should be implemented to attain the national target, and countries are allowed to trade their emissions with others. In this alternative framework, all countries will understand the benefit of imposing an ambitious target for themselves as long as the other countries do the same. It is an optimal for each country to vote for an $80 \%$ reduction of emissions. In this example, the two negotiation mechanisms yield the same efficient solution and have the same simple structure of a one-dimensional negotiation, on either a uniform price or a uniform per capita quantity. 
Alas, the real world does not look at all like this description. Indeed, countries differ markedly by their exposure to climate change, abatement costs, economic dependence to fossil fuels, willingness to invest in the future, emissions per capita, and so on. These sources of heterogeneity of costs and benefits make the negotiation dramatically more complex.

Consider, for example, the case in which only 10 of the 100 countries are responsible for all emissions. The other countries emit nothing. Under the uniform price mechanism as under the quantity mechanism, conditional on all countries ratifying the treaty, the median voter will be in favor of a $\$ 200 / \mathrm{tCO}_{2}$ and a zero-emission target for all countries, respectively. This example illustrates two difficulties with the two simple negotiation mechanism examined in this section. First, in line with Weitzman's (chapter 8, this volume) result, there is too much abatement at equilibrium, so these mechanisms do not guarantee a first-best solution. ${ }^{13}$ Second, the 10 highemission countries are likely to quit the coalition because they bear all the cost of mitigation and receive a tiny fraction of the benefits. In economics parlance, their participation constraint is binding. This is why the economists supporting a price negotiation recognize that, due to the heterogeneity among countries, the system is feasible only if some mechanism for side transfers (such as a green fund or an allocation of permits) is designed so as to bring the reluctant countries on board. We concur. Observe that the sizes of the transfers from the 90 green countries to the 10 others that would induce the latter to participate are exactly the same for the two negotiation mechanisms.

Unfortunately, but unavoidably, the green fund (under a carbon price) or the unequal allocation of permits (under cap-and-trade) destroys the simplicity of a single-dimensional negotiation. The green fund must set the net (positive or negative) transfer to the fund for each country and therefore involves dimensionality $n+1$ (the number of countries, $n$, plus 1 , the carbon price). In the cap-and-trade mechanism, an unconstrained allocation of permits yields the same dimensionality ( $\mathrm{n}$ allowances, plus the carbon price). This sharp increase in dimensionality can be avoided by adopting a common formula as the Kyoto negotiators attempted to do. Cramton and Stoft (2012) propose doing this and argue that, by making this the first stage of a two-stage negotiation, countries would find it easier to agree (more on this below). 
Summing up, whether the international architecture adopts a uniform carbon price or a cap-and-trade mechanism, cross-country transfers will thus be needed so as to bring reluctant countries on board. As we just discussed, under the carbon pricing approach, the proposed transfer mechanism is to use a fraction of the collected revenue to help developing countries adopt low-carbon technologies and adapt to climate change. This is illustrated by the green fund, which was created at the COP-15 of Copenhagen in 2009. Under a cap-and-trade protocol, transfers operate through the distribution of free permits.

Either way, the design of compensation poses a complex problem: each country will want to pay the smallest possible contribution to the green fund or receive the maximum number of permits. ${ }^{14}$ This negotiation is complex and of course a major impediment to reaching an agreement on a carbon tax or a cap-and-trade. However, it must be realized that most international negotiations involve give-and-take, and there have been successful negotiations in the past. A case in point is the 1990 Clean Air Act Amendment in 1990. This arrangement was not imposed by a centralized authority but rather was the outcome of a protracted negotiation, in which the Mid-west states, high emitters of $\mathrm{SO}_{2}$ and $\mathrm{NO}_{\mathrm{x}}$, delayed jumping on board until they received sufficient compensation (in the form of free permits in that case). ${ }^{15}$

\section{Simplifying the Compensation n-Dimensional Negotiation (Green Fund or Allocation of Permits)}

Transparency considerations A green fund may be too transparent to be politically acceptable. The transparency argument requires further thought, but experience here suggests a serious concern. The Green Climate Fund established at COP-16 aims at a flow transfer of $\$ 100$ billion per year by 2020 , and four years later had received promises of less than $\$ 10$ billion in stock. ${ }^{16}$ As is known from other realms (such as humanitarian relief after a natural disaster or health programs in developing countries), parliaments are known to be reluctant to appropriate vast amounts of money to causes that benefit foreigners. Even successful programs such as the Vaccine Alliance GAVI-which involves a much smaller amount of money-took off only when the Bill \& Melinda Gates Foundation brought a substantial financial commitment. Politicians often pledge money at international meetings, only to downsize or renege on their pledge. Substantial free-riding is 
expected to continue, jeopardizing the build-up of the green fund. In Article 9 of the Paris Agreement, the developed world promised nothing more than to "continue to take the lead in mobilizing climate finance," and this mobilization will "represent a progression beyond previous efforts," whatever that means. Strikingly, the promise is a collective one, which therefore commits no one.

We believe that the transparency issue is one of the reasons that many pollution-control programs around the world adopted cap-and-trade and handled the compensation issue through the politically less involved distribution of tradable permits (often in a grandfathered way). The large transfers to the Midwest implied by the 1990 Clean Air Act Amendment never really made the headlines. To be certain, the transfers made under national cap-and-trade programs are different in their economic and political nature from international payments for international permits; however, in the EU ETS, billions of euros could have been potentially transferred to Eastern European and former Soviet Union countries ("Hot Air") through the allocation of permits in order to convince them to sign the Kyoto Protocol. ${ }^{17}$

The strength of the opaqueness argument in favor of the allocation of permits remains to be tested, and no one has the answer as to whether it would work for climate change. On the one hand, transfers associated with an allocation of free permits are not that hard to compute, and one would imagine that politicians (privately or publicly) opposed to an ambitious climate change agreement would quickly publicize the numbers (if unfavorable to the country) so as to turn their domestic public opinion against the agreement. In fact, the public uproar over the sale of Hot-Air AAUs was such that the UN was forced to restrict their sale. On the other hand, some of the cap-and-trade transfers failed to make the headlines in the past. The jury is still out on this question.

Finally, it should be noted that countries routinely transfer a sizeable fraction of their GDP to foreign investors in reimbursement of their sovereign debt. It would be useful to have estimates of likely shortfalls/surpluses of permits (which of course depend on the initial distribution) so as to have a better assessment of the sums involved.

Reducing the dimensionality of the compensation negotiation Rich and poor countries have always had opposite views on the compensation issue. 
Developing countries correctly emphasize ethics and their desire to develop, whereas in the past rich countries were allowed to develop without being hindered by environmental concerns; they demand equal rights per capita or a variant of it. Rich countries invoke Realpolitik and explain that they will not get on board unless permits are grandfathered (as they were in many other instances), or they will contribute only modestly to the green fund. The developing countries' being morally right does not mean they should overstress the equity concern for their own sake; inducing the rich countries to refuse to get on board will make poor countries much worse off. The politics of negotiations are not always aligned with the ethical view, unfortunately; in the driver's seat lay the countries with a high-projected GDP (they will be the high polluters), those with a high abatement cost, and finally those that will suffer the least-or even slightly gain from-global warming. These countries have low incentives to get on board. The Paris Agreement is particularly weak on this by stating, "developing country Parties should continue enhancing their mitigation efforts, and are encouraged to move over time towards economy-wide emission reduction [...] in the light of differential national circumstances" (article 4).

The green fund allocation or the formula for the allocation of free permits in the cap-and-trade approach must be acceptable by all. ${ }^{18}$ The expectations must also be convergent, and unrealistic demands are to be avoided. Rich countries must be much less selfish and accept to bear a large share of the burden (in reality and not through cheap pledges as they sometimes do). Conversely, a common per capita emission is a complete nonstarter for the developed world. This would involve massive wealth transfers to the less-developed world. As Cramton et al. (2013, chapter 12 in this volume) stress furthermore, the basis for the determination of such transfers is unclear; developed countries will argue that although they are responsible for anthropogenic global warming so far, they also have developed numerous technologies (medical, agricultural, communications, etc.) that are benefiting the less-developed countries. Such an acrimonious debate is unlikely to foster a decent solution to climate change. Moreover, the inconsistent expectations that we observe today are, needless to say, dangerous. As in the case of an impending war, we hope that the various sides will become more reasonable and come to terms with the huge collective gains from reaching an ambitious agreement. 
Freestyle negotiations among n countries are exceedingly complex. They are likely to lead to a deadlock, whether the countries negotiate about who will be a contributor or a recipient (and by how much) of the green fund or the allocation of free permits among countries under cap-and-trade. There is a complex trade-off between a simple rule, which prevents individual countries from demanding a special treatment, and a more complex rule, which better accounts for individual willingness to get on board but also make the negotiation captive of specific demands.

To illustrate this, consider the following (simple) rule, which reflects the trade-off described earlier between ethics and Realpolitik in the case of a common carbon price approach. The transfer scheme in this approach is based on a green fund. Cramton, Ockenfels, and Stoft (chapter 12, this volume), Weitzman (chapter 8, this volume), and De Perthuis and Jouvet (2015) propose to finance the green fund on the basis of a one-dimensional bonus-malus system where countries whose per capita emissions lie above a predetermined threshold would transfer funds to countries whose emission is below the threshold. More specifically, let $p_{i}$ and $P$ denote country i's and the world's populations, and let $x_{i}$ and $X=\sum_{i=1}^{n} x_{i}$ denote the current emissions of country $i$ and the world. The contribution $C_{i}$ to the green fund by country $i$ would then be determined as follows:

$C_{i}=g\left(x_{i}-p_{i} \frac{X}{P}\right)$

where $g$ is a generosity parameter (i.e., how many dollars are transferred per ton of excess emission). Note that the sum of these contributions is equal to 0 , as it should.

In a cap-and-trade approach, the transfer is implicit in the allocation of free permits. For conciseness, we state it in terms of intertemporal (total) pollutions. Let $q_{i}$ denote country $i$ 's number of free permits and $Q=\sum_{i=1}^{n} q_{i}$ denote the total number of permits (as discussed earlier, $Q$ would be computed so as to contain the temperature increase to $2^{\circ} \mathrm{C}$ ). With grandfathering coefficient $\hat{g}$ in $[0,1]$, the free permits would be allocated according to formula:

$\frac{q_{i}}{Q}=\hat{g} \frac{x_{i}}{X}+(1-\hat{g}) \frac{p_{i}}{P}$. 


\section{Box 10.5}

Per Capita Emissions

Table 10.1

National Emissions per Capita in 2011.

\begin{tabular}{lc}
\hline Country & $\mathrm{tCO}_{2} /$ cap \\
\hline Uganda & 0.11 \\
Republic of the Congo & 0.53 \\
India & 1.70 \\
Brazil & 2.23 \\
World & 4.98 \\
France & 5.19 \\
China & 6.71 \\
Germany & 8.92 \\
Japan & 9.29 \\
Russian Federation & 12.65 \\
United States & 17.02 \\
Qatar & 43.89 \\
\hline
\end{tabular}

Source: World Bank.

One of the most challenging aspects of the international negotiation on climate change is the extremely heterogeneous per capita emissions of $\mathrm{CO}_{2}$, from around $0.1 \mathrm{tCO}_{2}$ in the poorest countries to $17 \mathrm{tCO}_{2}$ in the United States (table 10.1). The principle of common but differentiated responsibility has many possible interpretations in this unequal world, which has had disruptive effects on the negotiation process since 1992. Because emissions per capita and GDP per capita are strongly positively correlated, the international negotiation on climate change cannot be disconnected from the problems of economic development and worldwide inequalities. 
So, the ethical approach prevails if $\hat{g}$ is close to 0 , and the Realpolitik concerns are reflected by a large $\hat{g}$ value.

There are many potential criticisms to and improvements on such formulae. For instance, the formulae need not hold in each year but only overall. Under cap-and-trade, developing countries' endowment might be backloaded so as to avoid a situation in which initially they are in expectation big net suppliers of permits in the market for allowances.

But the point we want to make here is that such rules may be a bit too simple. Realpolitik suggests accounting at least somewhat for the exposure to climate change, even if this may be rather unfair. Countries such as Canada and Russia may not get on board under formula (1) or (2), whereas other high-income, high-pollution countries would, provided that the generosity coefficient $g$ is not too high or the grandfathering coefficient $\hat{g}$ not too low.

\section{Price versus Quantity}

Given that the pledge-and-review approach was still favored by policymakers at the COP 21, it may be premature to enter the intricacies of "prices versus quantities" (to use Weitzman's 1974 terminology) or "carbon price versus cap-and-trade" (by cap-and-trade we mean the setting of a global volume of emissions, not of individual countries' targets, which would be highly inefficient). We feel that either approach clearly dominates the current alternative. Besides, the question is far from being settled among economists. However, because post-COP 21 negotiations need to be engaged quickly, it is important to discuss these second-stage issues right away.

The choice of instruments has two dimensions: the purely economic question of which system best accommodates scientific and demand uncertainty, a complex question that was treated at a theoretical level in Weitzman's article but on which limited empirical evidence is available ${ }^{19}$; and a political economy dimension, on which we now focus. ${ }^{20}$

On the political economy front, of which we developed one dimension (the transparency of transfers) earlier, we would like to make two points. First, like for any other public policy, international commitments must be feasible; that is, its implementation must not be prevented by the lack of information. 
Second, and perhaps more controversially, ${ }^{21}$ one may want to leave scope for national policies, although we know that these policies may then deviate from least-cost abatement. Imagine, for instance, that some countries with limited tax-collection-and-redistribution capabilities would want to opt for a low carbon price on cement to make housing affordable to the poorest; then they would want to deviate from the single-price rule; to be certain, governments may be weak and grant excessively low carbon prices to some lobbies, but this is by and large a matter of domestic politics (unless the practice is so widespread that it becomes unlikely that the country will abide by its overall commitment, whatever the agreement is). The rationale for subsidiarity is twofold. First, it gives leeway for governments to convince their domestic opinion (or themselves). Second, other countries care only about how much $\mathrm{CO}_{2}$ is emitted by the country, not how the number came about.

\section{The Enforceability Problem}

Enforcement under a carbon-price commitment

Price implementation. Carbon-pricing proposals allow a large array of regulatory mechanisms that get carbon-pricing credit. To fulfill their price commitment, countries could levy a carbon tax or set a cap-and-trade system and value carbon permits at their market price. Some countries' carbon price will also reflect their green standards (with an implicit carbon value) or count their public investments that have an impact on emissions. Under the principle of subsidiarity, we believe that all these actions should indeed be accounted for to determine the national carbon price, which is the ratio of the carbon revenue over the carbon emission. ${ }^{22}$ The net effect is to generate efforts to curb national emissions.

Because most of the climate benefits of this policy accrue abroad, countries currently have no incentive to impose strict carbon usage constraints on their citizens, firms, and administrations; and by and large, except for Sweden, they do not. This will also be the case under any international agreement. Thus, even if enforcement were costless, authorities would still turn a blind eye on certain polluters or underestimate their pollution, thereby economizing on the cost of green policies. This form of moral hazard is particularly hard to avoid in countries that are on the spending side of the compensation scheme (say the green fund), but it also applies to countries on the receiving side, which could be threatened by a 
withholding of transfers in case of noncompliance. To envision the difficulties faced by the monitoring of compliance, one can refer to the current debate on poor tax collection in Greece. ${ }^{23}$ To sum up, the imposition of a common carbon price faces the standard free-rider problem, with local costs and global benefits. Its management requires a strong international monitoring system.

Undoing. Second, another form of moral hazard consists of undoing the carbon tax through compensating transfers; presumably the countries would do this in an opaque way so as not to attract the attention of the international community.

Monitoring local externalities associated with fossil fuels. Burning fossil fuels generates various local externalities, such as the emission of nanoparticles (cardiovascular diseases, asthma, etc.), and, in the case of gasoline, road congestion and the deterioration of road infrastructure. This justifies specific Pigovian taxes whose level depends on the density of population, the value of life, the burning technology, or the average atmospheric conditions, for example. Countries also take advantage of the relative inelasticity of demand to raise revenue. Proponents of the carbon-price approach propose a "zero baseline" in defining the carbon price. That is, they define the carbon price to include all taxes and subsidies on each fossil fuel on each market, implicitly ignoring all other externalities or more generally other motivations for taxing fossil fuels. One problem with this pragmatic strategy is that these other Pigovian prices differ much around the world. Take again gasoline taxation: the distribution of the price of the liter of gasoline at the pump around the world has huge variance: 2 cents in Venezuela, 97 cents in the United States, and 209 cents in Belgium. ${ }^{24}$ Under the previously mentioned definition, imposing the same "carbon price" at the world level forces all countries to price local externalities and embody revenue concerns equally, a contradiction with the basic idea of subsidiarity. Monitoring this by the international community is a serious challenge.

Nonprice policies. Third, the carbon-price approach requires finding conversion rates for various policies that impact climate change but are not subject to an explicit price, such as road and housing construction standards, no-till farming, or afforestation and reforestation. These conversion rates may need to be country-specific: a construction standard will impact GHG 
emissions differently depending on the country's climate; similarly, afforestation may increase rather than decrease emissions in high-latitude areas, in which trees may cover (high-albedo) snow.

Enforcement under a cap-and-trade mechanism Enforcing an international quantity mechanism is relatively straightforward when countries, rather than economic agents, are liable for their national emissions. The anthropogenic emissions of $\mathrm{CO}_{2}$ by a nation can be derived from a simple carbon accounting by adding extraction and imports and by subtracting exports and the variation of stocks. Carbon sinks from forests and the agricultural sector can already be observable by satellite. Experimental projects from the National Aeronautics and Space Agency (NASA) and the European Space Agency (ESA) to measure the global emission of $\mathrm{CO}_{2}$ at the country level are promising in the long run. ${ }^{25}$ We believe that monitoring the country's $\mathrm{CO}_{2}$ emissions is easier than monitoring emissions at the point source. Like for existing cap-and-trade mechanisms, agents (here countries) with a shortage of permits at the end of the year would have to buy extra permits, whereas those with a surplus would sell or bank them.

There is one concern about permit trading among nations: some countries (one has in mind China and the United States here) may well enjoy market power due to their share of world emissions. This is a potentially serious issue, which requires oversight and offers some similarity to the control of market power in production or financial rights over transmission on a power grid. ${ }^{26}$ In particular, one would want countries to be as close as possible to zero net supply so as to reduce their incentive to affect the world price for permits by restraining the demand or supply.

\section{Price Volatility Under a Carbon Price and Under Cap-and-Trade}

Attention should be paid to the question of how to accommodate uncertainty. A cap-and-trade approach would compute and issue a worldwide number of permits consistent with the $2^{\circ} \mathrm{C}$ target. However, there is scientific uncertainty about the link from emissions to global warming. There is also uncertainty about the abatement technology, consumer demand, and so forth. So the number of permits will probably have to be adjusted over time. The market price of permits will be volatile (although presumably less so than under the flawed and unstable attempts at pricing $\mathrm{CO}_{2}$ so far). ${ }^{27}$ 
The same concern holds for a carbon price. Due to the same sources of uncertainty, there is no guarantee that the price will initially be set at the "right level," consistent with the overall global warming target. Thus, the tax will need to be adjusted over time as well.

More generally still, any proposal must confront the volatility question because price volatility is likely to be unpopular. One possibility, which a priori does not require public intervention, is to transfer risk through hedging instruments to those who can bear that risk more easily. Another complementary approach is to intervene in markets to stabilize prices. For example, in 2014, the European Commission proposed a "Market Stability Reserve," in which the auction volumes will be adjusted in phase 4 of the EU ETS starting in 2021, so as to create a soft target corridor for banking of EU Allowance units (EUAs). The mechanism will reduce the amount of EUAs that are auctioned if an upper threshold of EUAs in circulation is exceeded and releases them if the EUAs in circulation fall short of a lower threshold. This scheme is meant to be automatic, but its efficiency can be questioned. ${ }^{28}$ In particular, one can wonder how it can be made responsive to news in a way that guarantees that the $2^{\circ} \mathrm{C}$ target is reached. This brings us to the question of the trade-off between flexibility and commitment.

\section{The Potential Time Inconsistency of Carbon-Price and Cap-and-Trade Policies}

Whether one opts for a carbon price or for cap-and-trade, one should be concerned by the possibility that, conditional on the accruing news about the climate change process, technology, or demand, the ex-post adjustment be too lax (too low a carbon price, too high a number of tradable permits). To understand why, note that the carbon-price or tradable rights path is designed so as to incentivize long-term investments: in carbon-light housing, transportation infrastructures or power plants, and in green R\&D. Expost price incentives have served their purpose and now impose undue sacrifices; put differently, optimal environmental policies are not timeconsistent. Furthermore, the possibility of administration turnover or news about other aspects (say, public deficit or indebtedness, economic opportunities) may transform climate policy into an adjustment variable, adding to the overall time inconsistency. 
This time inconsistency is studied in Laffont and Tirole (1996a, 1996b), who look at the optimal mechanism designed by a centralized authority (the world's nations here) when news will accrue that may vindicate a change of course of action. The optimal mechanism must trade off commitment and adaptation. It can, for example, be implemented through a generalized cap-and-trade mechanism. This mechanism consists of providing authorities with flexibility, provided that the latter commit to compensate permit owners (in cash or Treasury securities). More precisely, authorities must issue a menu of permits with different redeeming values that limit the authority's ability to expropriate their owners by flooding the market with pollution permits. For example, if news led the authority to lower the price of permits (or the carbon tax) from $\$ 50$ to $\$ 40$, some $\$ 50$ and $\$ 45$ strike price put options on the Treasuries (with agreed-on country keys) would become in the money; at \$35, some other options (with a \$40 strike price) would also be in the money, and so forth. This approach creates flexibility but constrains it by forcing the authority to partly compensate permit owners. It obviously requires a governance mechanism, whose existence is inescapable in any international agreement.

Cap-and-trade mechanisms can obviously accommodate various automatic mechanisms that react to news accrual. We have not studied when the Market Stability Reserve mentioned earlier or a variant thereof can approximate the optimal adjustment mechanism described in LaffontTirole, ${ }^{29}$ and we think that economists have not paid enough attention to this aspect, whether they favor carbon pricing or cap-and-trade.

\section{Enforcing a Stable International Agreement: The Carrot-and-Stick Approach to Promote International Cooperation}

An efficient international agreement should create a grand coalition in which all countries and regions will be induced to set the same carbon price in their jurisdiction. Under the principle of subsidiarity, each country or region would be free to determine its own carbon policy, for instance, through a tax, a cap-and-trade, or a hybrid. The free-rider problem raises the question of the stability of this grand coalition. ${ }^{30}$ An analogy is sovereign borrowing. Sanctions for defaulting are limited (fortunately, gunboat diplomacy has waned), which raises concerns about countries' commitment to repay creditors. The same applies to climate change. Even if a good 
agreement is reached, it must still be enforced with limited means. The La La Land of international climate negotiations most often ignores this central question.

Naming and shaming is an approach and should be used; but as we have seen with the Kyoto "commitments," it has limited effects. Countries always find a multitude of excuses (choice of other actions such as R\&D, recession, insufficient effort by others, commitment made by a previous government, etc.) to not abide by their pledge.

There is no bullet-proof solution to the enforcement problem, but we think that at a minimum two instruments should be employed. First, countries care about gains from trade; the World Trade Organization (WTO) should view noncompliance with an international agreement as a form of dumping, leading to sanctions. Needless to say, the nature of these sanctions should not be decided by individual countries because the latter would then gladly take this opportunity to implement protectionist policies.

In the same spirit, one could penalize nonparticipants through punitive border taxes. This policy would incentivize reluctant countries to jump on board and be conducive to the formation of a stable world climate coalition. Nordhaus (2015) examines the formation of stable climate coalitions when coalitions are able to impose internally a uniform carbon price together with uniform trade sanctions against nonparticipants. For a carbon price around $\$ 25$ per ton of $\mathrm{CO}_{2}$, a worldwide climate coalition is stable if a uniform tax of $2 \%$ is imposed by the coalition for any good or service imported from a nonparticipating country.

Second, noncompliance with a climate agreement should be treated as committing future administrations and treated as sovereign debt. This policy would involve the International Monetary Fund (IMF) as well. For example, in the case of a cap-and-trade approach, a shortfall of permits at the end of the year would add to the public debt; the conversion rate would be the current market price.

Of course, we are aware of the potential collateral damages associated with such linkages with other successful international institutions. But the real question is that of the alternative. Proponents of nonbinding agreements hope that the countries' good will suffice to control GHG emissions. If they are correct, then the incentives provided through institutional linkages will also suffice a fortiori, without any collateral damage on these institutions. 


\section{Putting the Negotiation Back on Track}

Despite the mounting evidence about global warming, the international mobilization has been most disappointing. The Kyoto Protocol failed to build an international coalition supporting a carbon price in line with its social cost, and it illustrates the intrinsic instability of any international agreement that does not seriously address the free-rider problem. ${ }^{31}$ An international agreement must satisfy three properties: economic efficiency, incentive compatibility, and fairness. Efficiency can be attained only if all countries face the same carbon price. Incentive compatibility can be attained by penalizing free-riders. Fairness, a concept whose definition differs across stakeholders in the absence of a veil of ignorance, can potentially be reached through lump-sum transfers.

The noncommittal Paris agreement was hailed as a diplomatic success. However, it was reached because it opted for the least common denominator, accommodating demands even of some oil-rich countries that are opposed to any carbon pricing. We feel further that the pledge-and-review strategy is doomed to fail. It does not address the fundamental free-rider problem of climate change. The pledge-and-review process is another illustration of the waiting game played by key countries, which are postponing their real commitment to reduce emissions. Countries made sure that their pledge is hard to compare with other pledges and is nonverifiable and nonenforceable. The predicted outcome of this waiting game in terms of emissions of GHGs is potentially worse than the business-as-usual, zero-ambition outcome. We should tackle the climate challenge more seriously.

The Paris agreement did not deliver anything close to a credible, fair, and efficient solution. So what's next? All contributors to this book consider the efficiency objective of a universal carbon price the top priority for the post-Paris negotiation process. We should get the fundamentals right and face the thorny issue of equity. The latter issue is daunting, but any negotiation will have to confront it, and discussing many other topics simultaneously does not facilitate the task. Because national interests are paramount, sooner or later the international community will be confronted with the failure of the voluntary approach used in the Paris negotiations. An alternative roadmap can be described as follows: 
- Agree on a single-carbon-price principle and the need to in the measurement infrastructure so to allow for an independent monitoring of countries' overall pollution.

- Agree on a governance and enforcement mechanism (we have proposed that nonparticipating countries be imposed penalties through punitive border taxes administered by the WTO and that participating countries recognize a "climate debt" accounting for the uncovered emissions of the nonabiding countries and administered by the IMF).

If the choice for a single-price policy is carbon pricing:

- Find a price that is agreeable to the international community and limits global warming to the $2^{\circ} \mathrm{C}$ objective.

- Put in place the monitoring environment, as well as the general principles for conversion of nonprice policies into the price realm, and define criteria that limit undoing.

If the choice for a single-price policy is cap-and-trade (the option we favor because we believe it is easier to monitor):

- Fix a trajectory of emissions that scientists deem consistent with the $2^{\circ} \mathrm{C}$ objective, and agree on the principle of this worldwide cap trajectory.

- Agree that permits will be allocated to participating countries in line with the aggregate cap.

- Agree on a trading mechanism in which countries will have to match pollution and permits at the end of the year to avoid creating unfulfilled climatic debt.

Under the current circumstances, the implementation of any of these two approaches would constitute a formidable achievement. If none of these solutions works, then let us hope that green innovations will emerge that will make renewable energy cheaper to produce than current fossil energy sources. Otherwise the immensely risky adaptation strategy will be the only alternative remaining solution for future generations.

\section{Notes}

1. See, for example, Bosetti et al. (2013). According to Nordhaus (2015), the equilibrium average carbon price that would prevail in a simple global noncooperative game is equal to a fraction $h$ of the first-best price, where $h$ is the Herfindahl index of country sizes (the Herfindahl index $\mathrm{h}$ is the sum of the squares of each country's 
share in global output; for example, if there are 10 identical countries, $\mathrm{h}$ equals $10 \%$ ). He concludes that the equilibrium average carbon price in the absence of a coordination mechanism to solve the free-rider problem will be in the order of one-tenth of the efficient level.

2. A liability system would not solve the problem. Because of the diffuse and intertemporal nature of the pollution, it is impossible to link current individual emissions to future individual damages. Therefore, a liability system cannot fix the problem. Besides, even if such a link could be established, one would need an international agreement to prevent free-riding.

3. Let us emphasize that we are not necessarily opposed to standards. For example, one could use an economic instrument to encourage insulation by embodying the carbon price into the price of heating fuel and gas housing. However, insulation standards may overcome an informational problem (consumers may be poorly informed about the energy efficiency of their dwelling) and, for owners, do not require a complex computation of intertemporal savings on a carbon price. Our point is that standards are often enacted without a clear analysis of whether the goals could have been achieved more efficiently and a computation of the implicit carbon price involved in their design.

4. The best example is the hydrofluorocarbon-23 (HFC-23), which has a warming effect 11,000 times greater than $\mathrm{CO}_{2}$, so that destroying one ton of HFC-23 earns 11,000 more $\mathrm{CDM}$ certificates than destroying one ton of $\mathrm{CO}_{2}$. From 2005 to June 2012, 46\% of all certificates from the CDM were issued for the destruction of HFC-23. Projects for destroying HFC-23 were so profitable it is believed that coolant manufacturers may have built new factories to produce the coolant gas. As a consequence, the EU banned the use of HFC-23 certificates in the EU ETS from May 1, 2013.

5. Many other variants use an economic instrument. For example, countries could agree on a universal carbon tax (as opposed to a carbon price), leaving no scope for subsidiarity. To do so, a possible strategy would be to set up an international carbon tax collection entity. This, however, is not discussed in existing proposals probably because it could be perceived as too large an infringement on sovereignty or because there are returns to scope in tax collection. Thus, the implementation of the carbon tax would likely be left to individual countries, and the proceeds from the carbon tax would go to the country. We will here focus on the two commonly advocated strategies.

6. This is naturally the same absolute level of a carbon price; adding a common carbon price onto the one already in place in each country would not only be inefficient (carbon prices would differ across the world) but also unfair to a country such as Sweden, which has been virtuous prior to the agreement and whose extra contribution relative to other countries would thereby be made perennial. 
7. Since Weitzman's (1974) seminal paper, a sizable literature has compared the relative merits of the tax-and-cap approaches, focusing on the economic aspects and often leaving enforcement and political economy aspects aside (the two systems have different implications along these dimensions, as we will discuss later). When the various parameters of the climate change equation (climate science, abatement technologies, demand) are known, a carbon tax and a cap-and-trade system are equivalent because, for a given price target, it is always possible to determine the supply of permits that will support this equilibrium price and conversely. Not so under uncertainty.

8. Under some estimation, it would have cost Canada $\$ 14$ billion to buy enough carbon credits to make its target.

9. Since early 2014 , this market is linked to a similar one established by the Province of Québec. The current price of permits in California is $\$ 12 / \mathrm{tCO}_{2}$ at the minimum legal price. This fragmented scheme illustrates the strange economics of climate change in the United States, where the minimum carbon price in California is larger than the maximum carbon price in RGGI.

10. Article 13 of the Paris Agreement is particularly problematic from this viewpoint, stating that the transparency framework should recognize "the special circumstances of the least-developed countries [...] and be implemented in a facilitative, non-intrusive, non-punitive manner."

11. Notice that Article 6 of the Paris agreement allows for the use of transferable Intended Nationally Determined Contributions (INDCs) through voluntary "Internationally Transferred Mitigation Outcomes" (IMTOs). This is reminiscent of the inefficient Clean Development Mechanism (CDM) contained in the Kyoto Protocol. But some experts see in this Article 6 a hidden intention in favor of an international market for INDCs. This could be feasible only if INDCs were legally binding. Market solutions cannot work in the absence of transparent and legally enforceable property rights.

12. See Cramton and Stoft (2012), Cramton, Ockenfels, and Stoft (chapter 12, this volume), Weitzman (2013, chapter 8, this volume), and the other chapters in this book. Cramton et al. (2013, chapter 12, this volume) suggest defining a country's carbon price as its carbon revenue divided by its carbon emissions. Others recommend a uniform carbon tax. Still others advocate a global cap and trade system leading to a uniform carbon price. At this stage, there is no need to distinguish among the various approaches.

13. Weitzman (chapter 8, this volume) derives an analytical solution for this majority voting scheme on the carbon price when the damage function and the marginal abatement cost function are linear. In that case, the equilibrium price is efficient if and only if the mean and median of the distribution of the country-specific marginal damages are the same. 
14. In either case, there is also an issue regarding whether the governments will not steal or make use of the transfers for their own well-being: they may cash in the green fund receipts (or for that matter the carbon tax) or sell permits in the international market to the same effect. This difficulty is inherent to the respect of sovereignty and is not specific to climate policies.

15. See Ellerman et al. (2000) for an extensive analysis of these negotiations.

16. However, Cramton and Stoft (2012) claim that a far smaller amount would be needed to support a carbon price of $\$ 30 /$ ton and that donor countries would receive much more for their money than with the current green fund.

17. This a priori gave Eastern European countries the choice between making money by selling permits and not exerting any abatement effort; other countries became reluctant to buy the permits, and the second option became the leading one.

18. Cramton, Ockenfels, and Stoft (chapter 12, this volume) make a similar point for the cap-and-trade initial negotiating approach attempted by Kyoto negotiators, who tried to agree on a uniform reduction of $\mathrm{x} \%$ relative to 1990 emissions; no such $\mathrm{x}$ could be found.

19. Besides, the Weitzman framework does not allow for more complex but reasonable mechanisms, such as dynamic adjustment mechanisms to cope with uncertainty. For instance, the European Commission has recently proposed to create a market stability reserve starting in 2021. The reserve would cope with the current surplus of emission allowances and improve the system's resilience to shocks by adjusting the supply of allowances to be auctioned. It would operate according to predefined rules that would leave no discretion to the Commission or member states.

An economic debate also exists regarding whether price or quantity schemes best insulate countries against uncertainty about climate risk or technology. In theory, hedging instruments should provide an efficient allocation of risk worldwide, but little is known about to the extent to which markets would actually deliver this.

20. We will not expand on another political economy dimension here. Another issue with a carbon tax is the legal process. This obstacle is certainly not insurmountable but requires specific attention. First, taxes are usually set every year. What is needed for climate change control is a long-term commitment (think about the $\mathrm{SO}_{2}$ tradable permits in the United States, which are issued 30 years ahead). Second, taxes are generally the prerogative of parliaments. For example, in Europe, setting up the ETS cap-and-trade scheme required only a majority vote, whereas tax harmonization is subject to the unanimity rule, and therefore a carbon tax would have been almost impossible to achieve. So an exception needs to be made to prevent individual parliaments from undoing the international agreement. 
21. Cramton et al. (2013; and chapter 12, this book) also argue in favor of subsidiarity, although on slightly different grounds.

22. We have not studied and therefore will not discuss the question of aggregation of the various efforts along different dimensions. The choice of weights and their relationship to technological progress has been discussed in the literature on price indices (e.g., Diewert 1993); relevant here is also the embryonic literature on price caps (here floor) (Armstrong and Vickers, 2000; Laffont and Tirole, 1999). The optimal response of a country, even in the absence of political economy/favoritism considerations, will not satisfy the law of one price, both within the country (the country-optimal tax depends on good-specific cost and local pollution characteristics) and across countries. However, we do not have an educated guess as to whether these deviations from price coherence impose sizable costs; in comparison with the distortions attached with current pledge-and-review approach, this is without doubt a second-order issue.

23. All symposium authors agree that enforcement should work in two steps: (1) monitor, and (2) impose trade sanctions if necessary. Of course, this is not straightforward. In the last few years, and despite the existence of a program and the presence of the Troika in the country, Greece made little progress in curbing tax evasion. It is difficult for foreigners to impose a tax when the government is reluctant to strengthen it. Although in both cases (sovereign debt and climate agreements), the foreigners have a strong vested interest in domestic tax collection, one could argue that the problem is even more complex in the climate context and that there is no reason to believe that the international community would be much more successful in obtaining compliance of the carbon tax agreement. Indeed, some complianceprone factors are not even present in the case of climate change: there is no troika in each country threatening to cut the flow of lending; countries are not under a program (and therefore carefully monitored); they also derive some benefits from compliance (prospect of no longer being under a program, of not facing international sanctions in case of default), whereas for most countries almost $100 \%$ of the benefits of good behavior are enjoyed by foreigners.

24. http://data.worldbank.org/indicator/EP.PMP.SGAS.CD/countries/1.

25. For example, the NASA Orbiting Carbon Observatory-2 (OCO-2) is already orbiting the planet. The ESA CarbonSat project is also promising.

26. See Green and Newbery (1992) and Joskow andTirole (2000).

27. Even in a well-designed, long-term-oriented system, such as the acid rain program in the United States, $\mathrm{SO}_{2}$ prices have been volatile. They were stable in the first 10 years but then exhibited substantial volatility from 2005 through 2009, for instance. 
28. The precise implementation of this mechanism has been criticized for being asymmetric and failing to have the desired dampening effect (Trotignon et al., 2015).

29. For instance, suppose that scientists demonstrate that the climate is deteriorating faster than had been thought. Then permits must be withdrawn. The Market Stability Reserve mechanism reacts to an intertemporal use of permits ("is permit use more frontloaded or backloaded than expected?") rather than to the overall target. So it is likely to miss some desirable adjustments.

30. In an asymmetric information framework, Martimort and Sand-Zantman (2016) describe the optimal mechanism that prevents the free-riding problem with local co-benefits when participation is voluntary.

31. Incidentally, we are not convinced that the Onusian framework is optimal either, as bargaining among 195 nations is incredibly complex. A coalition of the current and future high emitters (say the G20) might prove more effective, both to negotiate and then put pressure on other countries, including through the WTO.

\section{References}

Armstrong, M., and J. Vickers. 2000. Multiproduct price regulation under asymmetric information. Journal of Industrial Economics 48:137-160.

Beccherle, J., and J. Tirole. 2011. Regional initiatives and the cost of delaying binding climate change agreements. Journal of Public Economics 95 (11/12): 1339-1348.

Bosetti, V., C. Carraro, E. De Cian, E. Massetti, and M. Tavoni. 2013. Incentives and stability of international climate coalitions: An integrated assessment. Energy Policy $55: 44-56$.

Buhr, K., S. Roth, and P. Stigson. 2014. Climate change politics through a global pledge-and-review regime: Positions among negotiators and stakeholders. Sustainability 6:794-811.

Chakravorty, U., B. Magne, and M. Moreaux. 2006. A hotelling model with a ceiling on the stock of pollution. Journal of Economic Dynamics \& Control 30 (12): 2875-2904.

Cramton, P., A. Ockenfels, and S. Stoft. 2013. How to negotiate ambitious global emissions abatement. Mimeo, carbon-price.com.

Cramton, P., and S. Stoft. (April 2012). How to fix the inefficiency of global cap and trade. Economists' Voice: 9.

Cremer, H., F. Gahvari, and N. Ladoux. 2003. Environmental taxes with heterogeneous consumers: An application to energy consumption in France. Journal of Public Economics 87 (12): 2791-2815. 
De Perthuis, C., and L.-A. Jouvet. 2015. Routes to an Ambitious Climate Agreement in 2015. Paris: Institut Louis Bachelier, Opinions et Débats.

Dietz, S., C. Gollier, and L. Kessler. 2015. The climate beta. Mimeo. London School of Economics.

Diamond, J. 2005. How Societies Choose to Fail or Succeed. New York: Viking Books.

Diewert, W. E. 1993. Index numbers. In Essays in Index Number Theory. vol. 1. Ed. W. E. Diewert and A. O. Nakamura. New York: Elsevier Science Publishers.

Ellerman, A. D., P. L. Joskow, R. Schmalensee, J. P. Montero, and E. M. Bailey. 2000. Markets for Clean Air: The U.S. Acid Rain Program. Cambridge, UK: Cambridge University Press.

Gollier, C. 2012. Pricing the Planet's Future: The Economics of Discounting in an Uncertain World. Princeton, NJ: Princeton University Press.

Gollier, C. 2014. Evaluation of long-dated investments under uncertain growth trend, volatility and catastrophes. Mimeo. Toulouse School of Economics.

Green, R., and D. Newbery. 1992. Competition in the British electricity spot market. Journal of Political Economy 100 (5): 929-953.

Hardin, G. 1968. The tragedy of commons. Science 162 (3859): 1243-1248.

IPCC. 2011. IPCC Special Report on Renewable Energy Sources and Climate Change Mitigation. [Edenhofer, O., R. Pichs-Madruga, Y. Sokona, K. Seyboth, P. Matschoss, S. Kadner, T. Zwickel, P. Eickemeier, G. Hansen, S. Schlömer, C. von Stechow (eds.)] Cambridge, United Kingdom and New York, NY, USA: Cambridge University Press.

IPCC. 2014. Climate Change 2014: Mitigation of Climate Change, Contribution of Working Group III to the Fifth Assessment Report of the Intergovernmental Panel on Climate Change. [Edenhofer, O., R. Pichs-Madruga, Y. Sokona, E. Farahani, S. Kadner, K. Seyboth, A. Adler, I. Baum, S. Brunner, P. Eickemeier, B. Kriemann, J. Savolainen, S. Schlömer, C. von Stechow, T. Zwickel and J.C. Minx (eds.)] Cambridge, UK; New York: Cambridge University Press.

Joskow, P., and J. Tirole. (Autumn 2000). Transmission rights and market power on electric power. Rand Journal of Economics 31 (3): 450-501.

Laffont, J. J., and J. Tirole. 1996a. Pollution permits and compliance strategies. Journal of Public Economics 62:85-125.

Laffont, J. J., and J. Tirole. 1996b. Pollution permits and environmental innovation. Journal of Public Economics 62:127-140.

Laffont, J. J., and J. Tirole. 1999. Competition in Telecommunications. Cambridge, MA: MIT Press. 
Martimort, D., and W. Sand-Zantman. 2016. A mechanism design approach to climate-change agreements. Journal of the European Economic Association 14 (3): 669-718.

Nordhaus, W. D. 2011, October. Estimates of the social cost of carbon: Background and results of the RICE-2011 model. Cowles Foundation Discussion Paper.

Nordhaus, W. D. 2015. Climate clubs: Overcoming free-riding in international climate policy. American Economic Review 105 (4): 1-32.

OECD. 2013. Climate and Carbon: Aligning Prices and Policies, OECD Environment Policy Paper 1. Paris: OECD Publishing.

Ostrom, E. 1990. Governing the Commons: The Evolution of Institutions for Collective Action. Cambridge, UK: Cambridge University Press.

Posner, E., and D. Weisbach. 2010. Climate Change Justice. Princeton, NJ: Princeton University Press.

Quinet, A. 2009. La valeur tutélaire du carbone. Paris: La Documentation Française, Rapports et Documents 16.

Trotignon, R., P. A. Jouvet, B. Soliera, S. Quemina, and J. Elbezea. 2015. European carbon market: Lessons on the impact of a "market stability reserve" using the Zephyr Model. Mimeo. Chaire Economie du Climat, University Paris Dauphine.

US Interagency Working Group. 2013. Technical Update of the Social Cost of Carbon for Regulatory Impact Analysis under Executive Order 128666.

Weitzman, M. L. 1974. Prices vs. quantities. Review of Economic Studies 41 (4): $477-491$.

Weitzman, M. L. 1998. Why the far-distant future should be discounted at its lowest possible rate? Journal of Environmental Economics and Management 36:201-208.

Weitzman, M. L. 2001. Gamma discounting. American Economic Review 91:260-271.

Weitzman, M. L. 2013. Can negotiating a uniform carbon price help to internalize the global warming externality? Journal of the Association of Environmental and Resource Economists 1 (1/2): 29-49. 


\title{
11 From the Paris Agreement to the Carbon Convergence
}

\author{
Éloi Laurent*
}

\section{Introduction: Reducing Climate Inconsistency}

The 32-page Paris agreement (and the related decisions) adopted on December 12,2015 , by COP 21 is the result of an undeniable diplomatic success. The French presidency and countries that, like Canada, acted positively during these difficult negotiations played their cards properly under the circumstances.

But from a scientific point of view, Paris is short of what would be needed to really protect humankind against climate change and its worrying consequences. This is the foreseeable paradoxical outcome of the Paris Conference: an unprecedented universal climate agreement that is unable to solve our climate crisis.

The basic reason why diplomacy cannot deliver scientific requirements is that the negotiating parties do not feel that there is, under the current rules, a fair, level playing field. Creating a negotiating framework which may lead to an effective climate agreement requires the institution of a world carbon price. This is what I intend to demonstrate in this chapter, based on the Dion-Laurent proposition (see Dion and Laurent, 2015).

Ideally, COP 21 would have extended to the emerging markets, starting with China and India, the binding commitments agreed in Kyoto 18 years earlier by the developed countries. What took place was exactly the opposite: every country is now effectively out of Annex 1 of the Kyoto Protocol, released from any legal constraints on the nature of their commitments in the fight against climate change, which now amount to voluntary

* Éloi Laurent is a senior economist at OFCE/Sciences Po (Paris) and a Visiting Professor at Stanford University. 
contributions ("Intended Nationally Determined Contribution," or INDC) that countries determine on their own and without reference to a common goal.

The Paris agreement gives rise to a new global variable, which we can accurately track over the coming years: the factor of climate inconsistency, which compares objectives and means. At the end of COP 21, this ratio was in the range of 1.35 to 2 (the climate objective chosen, specified in Article 2 , lies between $1.5^{\circ} \mathrm{C}$ and $2^{\circ} \mathrm{C}$, whereas the sum of national voluntary contributions pledged to reach this would lead to warming of $2.7^{\circ} \mathrm{C}$ to $3^{\circ} \mathrm{C}$ ). In a more positive version, the factor of climate lucidity lies between $50 \%$ and $74 \%$. The question facing us now is thus: How do we deal with this climate inconsistency by bringing the means deployed into line with the ambitions declared (bringing the climate inconsistency factor to 1 or the climate lucidity factor to $100 \%)$ ?

The need to put a price on carbon (and thus give it social value), which had been gaining momentum prior to COP 21, as was highlighted from the opening of the summit under the aegis of Angela Merkel and François Hollande, still appeared in the penultimate version of the Paris agreement. It disappeared from the final version (under the combined pressure of Saudi Arabia and Venezuela). Yet there is no doubt that by internalizing the price of carbon, we will put the economy at the service of the climate transition. But it seems at this point that the world's governments have decided to outsource this internalization function to the private sector. It is necessary to quickly take this in hand, both internally and globally.

Climate inconsistency can indeed be reduced in large part by introducing into climate negotiations the goal to develop a robust global carbonpricing system. The new system would rely on a few simple principles:

- The common climate objective is now officially to limit global warming between $1.5^{\circ} \mathrm{C}$ and $2^{\circ} \mathrm{C}$ above preindustrial levels; a global carbon price must therefore aim to meet that objective;

- Whatever one's opinion on the debate regarding the best way to levy a carbon price-tax or emissions trading_various countries have already picked their own path, and trying to get them to fit the same mold would be unrealistic ${ }^{1}$;

- Several countries have pledged to meet quantitative reduction targets (pledge-and-review strategy); rather than asking these countries to abandon 
those targets in favor of a global carbon price, it would be better to show them that negotiating such a price would be a powerful means to meet-or even exceed-their targets;

- Because the internationally agreed principle of "Common but Differentiated Responsibilities" would make it difficult to set a single price immediately, it would be more realistic to consider a price convergence-based process stretching over a number of years, as proposed by such international bodies as the International Energy Agency; and

- Given that the developed countries have pledged to provide $\$ 100$ billion yearly to help the most vulnerable countries deal with climate change, global carbon-price negotiations cannot be used to cancel that commitment: on the contrary, they are a good means to meet-or even surpassthe commitment.

Before reviewing those points in more detail, let's see by the numbers why the current climate negotiation system is fundamentally flawed.

\section{The Unflattering Carbon Footprint of Climate Negotiations Thus Far}

It is a well-known fact today-at least in academic circles and a significant segment of the international community-that greenhouse gas emissions (responsible for the climate changes observed in the second half of the 20 th century and predicted to continue until the end of the 21st century) have increased during the last 25 years. The average annual increase went from 1\% between 1990 and 1999 to 3.3\% between 2000 and 2009. After a slight decrease during the great recession, greenhouse gas (GHG) emissions began rising again at an annual rate of $2.5 \% .^{2}$ True, the latest news is surprisingly good: in a March 2015 communiqué, the International Energy Agency (IEA) announced that emissions had decreased in 2014, and for the same year, data released by BP in June 2015 showed a slight increase of 0.5\%. On March 16 2016, the IEA announced that for 2015 as well (a second year in a row), global emissions had stabilized (energy-related $\mathrm{CO}_{2}$ emissions amounted to 32.14 gigatons in 2015 compared with 32.13 in 2014 and 32.87 in 2013).

But that decrease, largely due to China's economic slowdown and reduction in coal consumption, should not be used to distract from the obvious observation that since 1997 and the signing of the Kyoto Protocol, the world's countries have been doing the opposite of what climate science 
recommends, causing global emissions to rise by more than $60 \%$ since 1990. As highlighted in the latest report of the Intergovernmental Panel on Climate Change (IPCC, 2014), the disconnect between the intensifying climate crisis and stagnating international negotiations has never been wider.

With so much scientific evidence warning us against the catastrophic impact of climate change on human welfare, how can this discrepancy be explained if not by the inefficiency and inefficacy of the current climate negotiation framework?

The thinking today is that the 1997 Kyoto Protocol, which guided these negotiations following the UN Framework Convention on Climate Change (decided at the 1992 Rio Summit), has been a resounding failure. However, that is not the case: in fact, protocol-bound Annex 1 countries $^{3}$ did live up to their commitments-albeit only by resorting to a sleight of hand that led us to understand why we must now change the system.

In Kyoto, the most economically developed countries made a first-and supposedly binding-GHG emission reduction commitment, whereas the less developed countries were exempted from such commitments due to their lower development levels and lower GHG emissions. In 1990-the baseline year for calculating emissions-the first-group nations (former Soviet Union members and OECD countries) were deemed responsible for $60 \%$ of the total GHG emissions. Under the Kyoto Protocol, these countries committed to reduce their emissions by approximately $5 \%$ by 2012 , compared with 1990 levels. What is not always known today is that this objective was met. Even better, the latest available data show that the reduction almost reached 10\% (even 15\% according to some estimates): thus, Annex 1 countries did twice as well as expected but almost entirely because of the collapse of the USSR, which biased outcomes. ${ }^{4}$ Although these dubious reductions were taking place, a much more significant increase was rearing its head in the rest of the world. Between the early 1990s and early 2010s, the emission ratio of Annex 1 countries versus exempted countries reversed itself, with the Annex 1 share of emissions going from $60 \%$ of global emissions to less than $40 \%$ (see table 11.1).

Therefore, the economic vision that informed the Kyoto Protocol is now totally obsolete. The problem that ails the current climate action framework, defined in 1997, is fourfold:

- An efficiency problem: the targets set in 1997 and instruments deployed since then (which are called "flexibility mechanisms" in the Protocol and 
Table 11.1

$2013 \mathrm{CO}_{2}$ Emissions

\begin{tabular}{lccc}
\hline & Emissions Per Capita & Total $^{*}$ & \% of Total \\
\hline Annex 1 & 7.5 & 13.05 & \\
United States & 16.4 & 5.23 & 14.5 \\
EU-28 & 6.8 & 3.48 & 9.6 \\
Russia & 12.7 & 1.81 & 5.0 \\
Japan & 9.8 & 1.25 & 3.4 \\
Canada & 14.3 & 0.50 & 1.4 \\
China & 7.2 & 9.98 & 27.6 \\
India & 1.9 & 2.41 & 6.7 \\
South Korea & 12.5 & 0.62 & 1.7 \\
Iran & 7.9 & 0.61 & 1.7 \\
Saudi Arabia & 18.0 & 0.52 & 1.4 \\
\hline
\end{tabular}

* Emissions in $\mathrm{GtCO}_{2}$, from fossil energy consumption and cement production. Source: Global Carbon Project.

include markets in pollution rights) are unable to stem the global GHG emission dynamics;

- A transparency problem: the quantitative, volume-based emission targets approach suffers from result-skewing biases. The baseline date that was chosen (generally 1990) is problematic for former USSR countries, some of which have since joined the European Union (EU). Furthermore, the Kyoto Protocol keeps account of production-based emissions (emissions generated within a given territory) but not consumption-based emissions (emissions from a country's production that are included, as incorporated carbon, in products consumed by other countries); thus, the paradox of a text of which the letter has been complied with while the problem that text was supposed to solve was made worse by "carbon leaks" ;

- An inclusiveness problem: henceforth, a binding international climate agreement must without fail include all major GHG emitters, includingand especially-emerging economies (starting with China, which is responsible for almost one-third of global emissions, and India, which could well see its still modest emissions increase significantly as the country develops its production and consumption of coal); and

- An incentive problem: volume-based emission reductions are seen by developing countries as a "carbon constraint," an unfair impediment to 
their economic development; and during economic crises, quantitative targets may become difficult to accept by developed countries.

Any reform proposal that aims to outgrow the current negotiation system must therefore offer solutions to the four problems. However, as was expected, the Paris agreement operates within the Kyoto framework, the shortcomings of which all countries participating in the negotiations know well but are fearful to challenge given the fragility of the global climate consensus.

\section{The Paris Agreement: Missing the Wrong Targets Softly?}

\section{A Legally Weak Agreement}

The key factor in achieving an appearance of success at COP 21 was to manage expectations beforehand. That has been the major failure of the 2009 Copenhagen Conference, where negotiators promised a global, legally binding agreement but could not deliver it in the end, causing a huge disappointment. This is why Paris negotiators adopted a flexible position on the legal form of the final text. Contrary to the Kyoto Protocol, the Paris text is an "agreement" instead of a "treaty," meaning that its legal power will be even weaker. As is well known in diplomatic circles, having an international text labeled as an "agreement" is rarely a good sign.

This can indeed be seen as a victory for the US negotiators, who have insisted that a legally binding text-which would require the Republicancontrolled Senate's approval-had no chance of being adopted. Although the Obama administration had convinced other parties that it could act on the basis of executive force (the rationale behind the US Environmental Protection Agency's (EPA's) final ruling on cutting emissions from coal-fired plants released in early August 2015), it was hard not to consider climate policy in the United States as conditional, the conditionality being that the legal challenges of the states are overturned by the US Supreme Court. The US Supreme Court decision on February 9, 2016, to freeze EPA rules cutting carbon emissions from power plants until the Washington, DC, circuit court of appeals hears challenges from 29 mainly Republican-led states and dozens of corporations and industry groups has confirmed this fear. The US political polarization, not unrelated to the damaging effect of income inequality, is thus a drag on global climate policy. There are strong reasons to believe that the Trump administration will only exacerbate this political 
polarization and move away from a lucid climate policy domestically and globally.

\section{The Stubborn Ambition-Science Gap}

At the 2011 Durban Conference (COP 17), the parties acknowledged the gap between their commitments and achieving the $2^{\circ} \mathrm{C}$ objective. In the preamble of their joint statement, they expressed "grave concern" and promised to "raise the level of ambition" to bridge this gap. At the Lima Conference (COP 20) in December 2014, the parties reiterated ${ }^{6}$ the same "grave concern" about "the significant gap between the aggregate effect of Parties' mitigation pledges" and the goal of holding the increase in global average temperature below the $2^{\circ} \mathrm{C}$ limit. But the ambition-science gap has so far survived all virtuous proclamations.

Climate negotiations have revolved crucially around volumes of carbon emitted: under the Kyoto Protocol, a country's climate performance is assessed in terms of emission reduction targets compared with their 1990 levels, and climate commitments are being framed in terms of emission reductions up to 2030 or 2050.

There are two reasons that this volume-based approach can be insufficient: it does not specify the instruments that are supposed to be used to match the volume targets, and it does not take into account carbon flows, which are emissions resulting not only from national production but also from national consumption. The gap between the two can be quite large: the EU has reduced its GHG emissions by close to $20 \%$ in terms of production since 1990 but by only 5\% when consumption emissions are considered. A country such as France sees its climate performance since 1990 completely turned upside down when consumption emissions are considered instead of production emissions.

But even if one withholds judgment on the potential efficiency of the volume approach, it appears to fall short on its own ambitions: Climate Action Tracker experts, assessing the announcements and commitments to track their compatibility with the $2^{\circ} \mathrm{C}$ threshold, conclude that existing and announced measures lead to an increase above $3^{\circ} \mathrm{C}$ and possibly as high as $3.7^{\circ} \mathrm{C}$ in global temperatures, much higher, as previously noted, than the objectives of the Paris agreement. The latest IEA assessment indicates that given the INDCs submitted, the path would be "consistent with an average temperature increase of around $2.6^{\circ} \mathrm{C}$ by 2100 and $3.5^{\circ} \mathrm{C}$ after $2200^{\prime \prime}$ 
(the scenario assumes that countries will fulfill their climate commitments, which is doubtful).

\section{The Perils of Commitments without Instruments}

The agreement reached by the EU Member States in the fall of 2014 is a good illustration of the limitations of any strategy based on emission reduction targets alone, with no efficient and effective carbon-pricing system. Indeed, the European "climate-energy package" can be considered a baseless pyramid: the GHG emission reduction target of $40 \%$ by 2030 is only supported by nonbinding energy efficiency and renewable energy targets, which are not underpinned by a true carbon-pricing reform.

At the basis of the European agreement lies a dysfunctional, derelict carbon-pricing system. The end result is commitments without instruments and "ambitious" emission reduction targets suspended over a sea of ambiguity. The same can be said of most current national commitments that are lacking adequate instruments.

National emission reduction targets must absolutely be accompanied by adequate and coordinated implementation tools, including a trial global carbon price. In other words, negotiators should aim for a "commitments + instruments" strategy up to 2020 rather than a "commitments-only" agreement.

\section{The Need for Climate Justice}

In Copenhagen (COP 15) and Cancún (COP 16), the developed countries committed to a contribution of $\$ 100$ billion per year beginning in 2020 to help developing nations fight—and adapt to-climate change. A fund-the "Green Climate Fund"-has been createdto provide developing countries with the substantial financial and technological assistance they require.

Developing countries take this commitment seriously. They have made it known that no agreement will be possible in Paris without the conclusion of a clear plan for the delivery, through the Green Climate Fund, of the committed $\$ 100$ billion per year by 2020 .

Unfortunately, despite years of ongoing discussion over this agreed-on $\$ 100$ billion target, nobody knows how much each developed country is supposed to contribute, and the Paris agreement has done little to clarify this question. What we do know, however, is that raising such a sum will 
require private-sector contributions. This will not happen in the absence of a fully functional, robust, and comprehensive carbon-pricing system.

Focusing negotiations on a world carbon price in addition to quantitative reductions of emissions can alleviate all four problems. First, it can strengthen the Paris agreement by providing economic incentives so that countries take charge of their climate commitments rather than engage in carbon freeriding. Second, it can serve as a tool for adjusting climate commitments and hence gradually increase the level of ambition of nation-states so that the gap between commitments and science-based requirements can be progressively closed; note that such a tool can also enhance the efficiency of the agreement by controlling carbon flows. Third, it can provide a credible instrumental basis for climate commitments. Fourth, it can provide the source of the $\$ 100$ billion pledged by developed countries to fight climate change globally.

\section{Building the Carbon Convergence}

Governments and businesses are unlikely to realize their climate-change goals if they have no definite assurance that their competitors will play by the same rules. To address this stalemate, we need an international agreement that gives them that assurance, one that changes the rules of the game so they apply to every player. We need to create a system whereby every decision maker, public or private, is responsible for taking into account the true cost of global warming and is secure in the knowledge that the competitors are doing the same.

This explains why more and more experts-including every author of the Symposium on International Climate Negotiations ${ }^{8}$ - agree that putting a price on carbon is essential to the success of any serious, comprehensive climate plan. The International Monetary Fund now recommends it, ${ }^{9}$ as does the OECD. ${ }^{10}$ The World Bank ${ }^{11}$ convinced 73 countries, 22 subnational jurisdictions, and more than 1,000 companies and investors to declare their support for a price on carbon. The Global Commission on the Economy and Climate $^{12}$ has also pointed out that a carbon price may be beneficial for the economy.

There are opportunities to explore linkages between carbon pricing and the new international climate change agreement ${ }^{13}$ to be reached in Paris. But the main challenge facing us is how to evolve from a hodge-podge of 
local or national carbon prices to a global, harmonized carbon-pricing system. The IPCC recommends ${ }^{14}$ a solution: adopting a "single global carbon price." The price should be high enough to create the necessary incentives to limit global warming to about $2^{\circ} \mathrm{C}$. The International Energy Agency $(\text { IEA })^{15}$ recommends that the price of one ton of $\mathrm{CO}_{2}$ be gradually raised by 2040 to $\$ 140$ for developed countries and $\$ 125$ for China, Russia, Brazil, and South Africa (in US 2013 dollars). According to the IEA, ${ }^{16}$ this goal can be reached without harming economic development.

It is impossible to reach a global carbon price of $\$ 125$ or $\$ 140$ per ton of $\mathrm{CO}_{2}$ without first having negotiated an international agreement that ensures all economic agents that their competitors will play by the same climate rules. Indeed, carbon pricing will not reach the desired level as long as individual countries fear that carbon price setting within their respective jurisdictions will scare away businesses and investors will send them off to countries where carbon dioxide emissions are cheaper or free of charge. The idea is to refocus these international efforts on negotiating a global, harmonized carbon-price signal.

All countries would pledge to introduce, in their respective jurisdictions, a gradually evolving carbon price based on a scientifically validated international standard, in order for the world to keep global warming as close as possible to $2^{\circ} \mathrm{C}$ over preindustrial levels. Countries may levy this price through carbon taxes or emission quotas. Governments would be free to invest, as they see fit, any revenues accruing from carbon emission levies and the corresponding — and necessary—gradual elimination of fossil energy subsidies.

In keeping with the principle of "Common But Differentiated Responsibility," developed countries would be required to set aside part of their carbon pricing revenues to help developing countries introduce policies to lower their emissions, adapt to climate change impacts, and create carbon sinks (e.g., through reforestation). This requirement would help fund the yet unsourced $\$ 100$ billion annual injection into the Green Climate Fund that was promised to developing countries for 2020 to help them deal with climate change. That amount could even be increased. The Dion-Laurent plan proposes that the contributions of individual developed countries be set according to the proportion of total developed country emissions that their respective GHG emissions represent. The lower a country's emission level, the lower its share of the financial effort. This would serve as a further 
incentive for emission reductions. Other formulas are also conceivable, such as making the contributions proportional to emissions in excess of the global average per capita rate, but the argument will likely be made that the most advanced economies - those that have the best technological capacities—should be the ones helping the others.

This international carbon-pricing agreement would allow countries to levy border taxes on products from countries that have not established a carbon-price signal in accordance with the international standard. That would be a solution of last resort, to be applied after the usual warnings have been issued. In this manner, it will be in each country's interest to comply with the international agreement, levy a carbon price on its own emissions, and use the resulting revenue as it sees fit.

\section{Conclusion: From Climate Science to Climate Justice}

Climate negotiations are not only a technical discussion based on scientific data but also a political dialogue ultimately based on ethical criteria.

The fight against climate change must not only be presented as an opportunity for economic development but also as a lever to reduce inequalities in human development between countries and within countries. The case of China shows how the constraint of reducing $\mathrm{CO}_{2}$ emissions can be a way to limit coal consumption and limit damage on the health of Chinese, unevenly distributed within the Chinese population. The same applies to the limitation of car traffic in France, which represents both a health gain and reduction of $\mathrm{CO}_{2}$ emissions. This double climate-health dividend must be at the heart of state contributions to the reduction of global $\mathrm{CO}_{2}$ emissions. Climate justice highlights the equality potential of the fight against climate change at the national and international levels. This is why we need to follow up on the Paris agreement with two sets of criteria: climate science and climate justice must be combined in a single plan. That is precisely why the Dion-Laurent proposition brings together the logic of science-based efficiency and ethics-based justice:

1. Science-based efficiency: a carbon budget set to the $2^{\circ} \mathrm{C}$ limit leads to the establishment of a differentiated trajectory of gradually converging global pricing of carbon, each country freely determining the mix of instruments used to raise its price; and 
2. Ethics-based justice: the proposed carbon-price system addresses inequalities between countries (through modulations and compensations) and within countries (accelerating adaptation of financing).

An international carbon-price agreement would provide the world with an excellent instrument for sustainable development. After decades of international stalemate, carbon emitters would have to acknowledge the obvious social and environmental costs of pollution. Consumers and manufacturers would have an incentive to choose lower carbon-content goods and services and invest in new energy-saving and emission-reducing technologies. Governments and legislators would have the tools to achieve the scientific climate targets they have endorsed.

This plan is necessary-more so than ever-to protect humankind from the threat of a $3^{\circ} \mathrm{C}$-or more-global warming. Current initiatives are not without merit, but they are insufficient. Our world leaders must champion what a comprehensive and effective climate/energy policy needs: a worldwide, harmonized carbon price.

\section{Notes}

1. In 2015,40 national entities and 20 local jurisdictions adopted a carbon price according to various modalities. For the details of those measures, see World Bank, 2015, http://www-wds.worldbank.org/external/default/WDSContentServer/WDSP/ IB/2015/08/26/090224b08309a09a/4_0/Rendered/PDF/Carbon0pricing0e Oreleased0late02015.pdf

2. According to the Global Carbon Project (http://www.globalcarbonproject.org/), which records emissions from fossil fuel consumption and cement production.

3. The Kyoto Protocol reinforces the 1992 Convention by committing Annex 1 countries to individual, legally binding greenhouse gas emission reduction or limitation objectives. The individual objectives of Annex 1 countries are listed in Annex B of the Kyoto Protocol, which explains why the term "Annex B countries" is sometimes used instead of "Annex 1 countries."

4. According to UN figures, if emissions of all Annex 1 countries fell by $10.6 \%$ between 1990 and 2012 (almost exactly double the 5.2\% commitment made in 1997), the so-called transition economies (Russia and its then satellites) emissions were down more than 38\%, this reduction being acquired in 1995. Meanwhile, OECD Annex 1 countries (EU 15, United States, Japan, Canada, Australia) have seen their emissions rise by $2 \%$, this increase being as high as $10 \%$ before the great recession of 2009. In other words, two recessions explain that the Kyoto target was reached and even surpassed. 
5. Although the Protocol-controlled, production-based emissions have decreased since 1990, consumption-based emissions for the same period have increased by $0.5 \%$. In the end, the increase in consumption-based emissions more than balanced the decrease in production-based emissions in Annex 1 countries. Emissions were transferred not reduced.

6. Report of the Ad Hoc Working Group on the Durban Platform for Enhanced Action, Further Advancing the Durban Platform: Draft Decision -/CP.XX, by the President (Lima, Peru: Conference of Parties, United Nations Framework Convention on Climate Change, December 2014). Available at: http://unfccc.int/resource/docs/ 2014/cop20/eng/114.pdf.

7. World Energy Outlook Special Report, Energy and Climate Change (Paris, France: International Energy Agency, 2015), p. 12. Available at: https://www.iea.org/ publications/freepublications/publication/WEO2015SpecialReportonEnergyand ClimateChange.pdf.

8. The Carbon Price Project, Carbon-Price.com: A Strategy for International Climate Negotiations, 2016. Available at: http://carbon-price.com/.

9. IMF Survey, Fiscal Policy to Address Energy's Environmental Impacts (Washington, DC: International Monetary Fund, July 2014). Available at: http://www.imf.org/ external/pubs/ft/survey/so/2014/POL073114A.htm.

10. OECD Environmental Outlook, OECD Environmental Outlook to 2050: The Consequences of Inaction (Paris, France: OECD, 2012).

11. Statement, Putting a Price on Carbon (Washington, DC: The World Bank, June 2014). Available at: http://www.worldbank.org/content/dam/Worldbank/ document/Carbon-Pricing-Statement-060314.pdf.

12. The Synthesis Report, Better Growth Better Climate: The New Climate Economy Report (Washington, DC: The Global Commission on the Economy and Climate, September 2014). Available at: http://static.newclimateeconomy.report/TheNew ClimateEconomyReport.pdf.

13. Robert Stavins, "The UN Climate Summit and a Key Issue for the 2015 Paris Agreement," The Energy Collective (September 2014). Available at: http:// www.theenergycollective.com/robertstavins/1199961/un-climate-summit-and-ke y-issue-2015-paris-agreement.

14. Summary for Policy Makers, Climate Change 2014, Mitigation of Climate Change, Contribution of Working Group III to the Fifth Assessment Report of the Intergovernmental Panel on Climate Change (Cambridge, UK; New York: International Panel on Climate Change, 2014). Available at: http://www.ipcc.ch/pdf/assessment-report/ar5/wg3/ ipcc_wg3_ar5_summary-for-policymakers.pdf. 
15. Executive Summary, World Energy Outlook 2014 (Paris, France: International Energy Agency, 2014). Available at: http://www.iea.org/publications/ freepublications/publication/WEO_2014_ES_English_WEB.pdf.

16. Ibid.

\section{References}

BP Statistical Review. 2015, June. BP Statistical Review of World Energy. London, UK: British Petroleum Global.

Dion, S., and É. Laurent. 2015, September. Climate action beyond the Paris Accord. Working paper, Observatoire Français des Conjonctures Économiques 2015-22. Available at: http://www.ofce.sciences-po.fr/pdf/dtravail/WP2015-22.pdf .

Executive Summary. 2014. World Energy Outlook 2014. Paris, France: International Energy Agency; Available at http://www.iea.org/publications/freepublications/ publication/WEO_2014_ES_English_WEB.pdf.

IMF Survey. 2014, July Fiscal Policy to Address Energy's Environmental Impacts. Washington, DC: International Monetary Fund. Available at: http://www.imf.org/ external/pubs/ft/survey/so/2014/POL073114A.htm.

Intended Nationally Determined Contribution Submission. 2015, March. Intended Nationally Determined Contribution of the EU and its Member States. Riga, Latvia: Latvia and the European Commission on behalf of the European Union and its Member States. Available at: http://ec.europa.eu/clima/news/docs/2015030601_eu_indc_en .pdf.

OECD Environmental Outlook. 2012. OECD Environmental Outlook to 2050: The Consequences of Inaction. Paris, France: OECD.

Policy Study. 2015. Enhanced Policy Scenarios for Major Emitting Countries: Analysis of Current and Planned Climate Policies, and Selected Enhanced Mitigation Measures. The Hague, Netherlands: PBL Netherlands Environmental Assessment Agency.

Report of the Ad Hoc Working Group on the Durban Platform for Enhanced Action. 2014, December. Further Advancing the Durban Platform: Draft Decision -/CP.XX, by the President. Lima, Peru: Conference of Parties, United Nations Framework Convention on Climate Change. Available at: http://unfccc.int/resource/docs/2014/ cop20/eng/114.pdf.

Statement. 2014, June. Putting a Price on Carbon. Washington, DC: The World Bank. Available at: http://www.worldbank.org/content/dam/Worldbank/document/ Carbon-Pricing-Statement-060314.pdf.

Stavins, R. 2014, September. The UN Climate Summit and a key issue for the 2015 Paris Agreement. The Energy Collective. Available at: http://www 
.theenergycollective.com/robertstavins/1199961/un-climate-summit-and-key -issue-2015-paris-agreement.

Summary for Policy Makers. 2014. Climate Change 2014, Mitigation of Climate Change, Contribution of Working Group III to the Fifth Assessment Report of the Intergovernmental Panel on Climate Change. Cambridge, UK; New York: International Panel on Climate Chance. Available at: http://www.ipcc.ch/pdf/assessment-report/ar5/wg3/ipcc_wg3 _ar5_summary-for-policymakers.pdf.

The Carbon Price Project. 2016. Carbon-Price.com: A Strategy for International Climate Negotiations. Available at: http://carbon-price.com/.

The Synthesis Report. 2014, September. Better Growth Better Climate: The New Climate Economy Report. Washington, DC: The Global Commission on the Economy and Climate. Available at: http://static.newclimateeconomy.report/ TheNewClimateEconomyReport.pdf.

World Energy Outlook Special Report. 2015. Energy and Climate Change. Paris, France: International Energy Agency; Available at https://www.iea.org/publications/ freepublications/publication/WEO2015SpecialReportonEnergyandClimateChange .pdf. 



\title{
12 An International Carbon-Price Commitment Promotes Cooperation
}

\author{
Peter Cramton, Axel Ockenfels, and Steven Stoft*
}

\section{How a Common Commitment Promotes International Agreement}

For 20 years, climate negotiators have been stymied by the most challenging tragedy of the commons ever encountered. The central problem is well understood. All countries can use the atmospheric commons for free, but only a small fraction of the benefits of investing in $\mathrm{CO}_{2}$ reductions accrue to the country that incurs the cost of such an investment. As a result, self-interested countries rationally invest too little in $\mathrm{CO}_{2}$ abatement and instead attempt to free-ride on the hoped-for investments of others. Indeed, "climate change is a public good (bad) par excellence" (Arrow, 2007).

The Kyoto process started with a natural approach to breaking the freerider deadlock: agree on a common commitment. A common commitment helps realign self-interest with the common good by assuring all parties that they will only be required to contribute to the common good if all are required to follow the same commitment rule. This "I will if you will" feature is critical for solving problems of the commons. ${ }^{1}$

A common commitment needs to be enforced like any other commitment. Yet the fairness that comes with protection from exploitation offered

* Financial support of the German Research Foundation (DFG) through the Research Unit "Design \& Behavior" (FOR 1371) is gratefully acknowledged. Ockenfels thanks the Economics Department at Stanford University for their generous hospitality. We thank Ken Arrow, Ottmar Edenhofer, Larry Goulder, Charlie Kolstad, Ulrike Kornek, and Massimo Tavoni for helpful discussions and the Stanford Institute for Economic Policy Research for providing a productive setting for discussions. This chapter is an updated version of another article that appeared in Economics of Energy \& Environmental Policy, Vol. 4, No. 2, pages 51-64, 2015, DOI: http://dx.doi.org/10.5547/ 2160-5890.4.2.aock-Reproduced by permission of the International Association for Energy Economics (IAEE). 
by a reciprocal common commitment removes one reason to defect. Also, because defecting will weaken the common commitment and hence jeopardize the contributions of others, a well-structured common commitment automatically embodies some enforcement. ${ }^{2}$ Moreover, as we show later, a price commitment reduces risks compared with quantity commitments and thus reduces the needed size of the enforcement penalty.

In a nutshell, a common commitment facilitates the collective reciprocity that is the only known way of overcoming free-riding-the central problem of climate negotiations (Weitzman, chapter 8, this volume). Moreover, it is likely a necessary precursor to the implementation of effective enforcement. Yet Kyoto failed to find such a commitment. This failure was no accident. The quantity commitments needed for international cap-and-trade preclude a common commitment. This chapter suggests this is the foundation underlying the proposals for an international price commitment by Cooper (2004, chapter 5, this volume), Nordhaus (2013), Stiglitz (chapter 6, this volume), Weitzman (chapter 8, this volume), and ourselves.

\section{Why Kyoto Failed}

Initially, many countries supported a common commitment by all to reduce their emissions by an equal, agreed percentage below their 1990 emission levels. Such a general percentage-reduction rule-as opposed to individually pledged percentages - would constitute a common commitment. But many disagreed, and at least 10 other formulas were developed and considered. After many failed attempts, the resolve to forge a common commitment was broken and replaced with a resignation to accept individual commitments. Indeed, even before concluding the negotiations, Chairman Estrada allowed parties "to negotiate their own targets" and finally "invited Annex I Parties to submit their revised, final, numbers to the podium" without any restrictions (Depledge, 2000, p. 214).

The European Union (EU) offered a 15\% emission cut with a common commitment but accepted only $8 \%$ when that failed. ${ }^{3}$ Russia accepted $0 \%$, Australia and Iceland accepted $8 \%$ and 10\% increases, respectively, and the United States accepted a 7\% cut, which was not serious. Of course the developing countries accepted nothing and with the EU masked cuts that ranged from $30 \%$ to an increase of $40 \%$. The 95 to 0 rejection by the US Senate was explicitly linked to the fear of free-riding, although there were 
other motives as well. The lack of an acceptable common commitment meant there was little check on free-riding, but if any common commitment had been forced on the parties, the outcome would have been worse, which is why none was agreed to. The Kyoto negotiations were right to focus on the search for a common commitment, but what they proved, after more than a year of searching, was that no common quantity commitment can be found. The result was a weak and fragile international cap and the mistaken conclusion that a common commitment is impossible. The mistake was accepting the international-cap-and-trade straight jacket as inevitable.

Interestingly, the Kyoto Protocol also failed to achieve its second goal: equalized prices. International permits were implemented in the form of Assigned Amount Units (AAUs). The Soviet Bloc's AAUs are referred to as "hot air" in the popular press, and, in fact, some AAU trades that took place simply enriched those in Eastern Europe who faced no burden from the Kyoto Protocol. Because trading was seen as inappropriately redistributional and evasive of climate commitments, AAU trading became so controversial that Japan had to publicly deny purchasing AAUs from countries previously in the Soviet Bloc. ${ }^{4}$ Now the UN has restricted AAU trading. ${ }^{5}$ As a result, and because of political uncertainties (Edenhofer et al., 2014) and various regulatory interventions (Marcantonini and Ellerman, 2014), quantity commitments did not lead to anything like the hoped-for equalization of carbon prices.

Stiglitz (2006b, chapter 6, this volume) has explained why there is no reason to believe anyone will ever come up with a quantity-based emissions rule. The history of the Kyoto negotiations strongly confirms that requiring quantity targets will block any hope of a broad common commitment even without including the developing countries. The US government has now come to the same conclusion. ${ }^{6}$ Without a common commitment, any agreement, if one could be reached, would again be weak and fragile. It would not produce anything like a uniform price on carbon. Kyoto was a useful experiment, but the world learned the wrong lesson.

\section{Kyoto's Legacy for International Climate Negotiations}

In response to Kyoto's dramatic failure and then Copenhagen's, the idea of striving for a common global commitment was abandoned on the way to Paris. Rather, it was hoped that individually selected quantity targets 
will cover the bulk of global emissions with sufficient stringency. Indeed, the plan for Paris was to let every country simply pledge to do whatever it wants. There will be reviews without consequences for hundreds of incomparable proposals (Gollier and Tirole, chapter 10, this volume). If countries fall short of their pledges, then there still will be no consequences.

This pledge-and-review approach is unlikely to work (Cooper et al., chapter 1 , this volume). As the Kyoto Protocol demonstrates, individually adopted targets do not change self-interest, at least not by enough to notice. The reason is that such agreements are not of the "I will if you will" type (MacKay et al., chapter 2, this volume; Cramton et al., chapter 4, this volume). In fact, under the Kyoto Protocol, several countries, including the United States, Canada, New Zealand, Japan, and Russian, have said "We won't" while the others continue to say "We will." So the Protocol is an "I will even if you won't" agreement. This is an agreement of nations acting altruistically-a coalition of the politically willing. But as explained by Gollier and Tirole (chapter 10, this volume), among others, there is no reason to suppose that altruism can solve the tragedy of the commons. Conditional cooperation in the vein of "I will if you will," in contrast, provides a strong source of cooperation, as explained by Weitzman (chapter 8, this volume). Indeed, conditional cooperation is the most robust pattern of cooperation seen in laboratory, field, and theoretical studies of free-rider situations and is-unlike unilateral altruism-consistently found to stabilize higher cooperation levels. Numerous studies show that conditionally cooperative strategies can promote cooperation levels well beyond what is theoretically sustainable among selfish players. One reason is that conditional cooperation-unlike unilateral altruism-is considered fair (see Hauser et al., 2014; Kraft-Todd et al., 2015; MacKay et al., 2015, and references therein).

This is why we advocate that negotiations again focus on a common commitment. Although a common quantity commitment proved infeasible, we argue that a common price commitment can substantially mitigate many of the problems associated with quantity commitments (see also Stiglitz, chapter 6 , this volume; Weitzman, chapter 8 , this volume). One reason is that there is near-unanimous agreement that each country should commit to the same price, which thus constitutes what Schelling (1960) calls a focal point. Such a common commitment makes possible the type of agreement that changes self-interests for the better: "I will commit to the common price if you will." 
The difference between the two commitments—price and quantity-has been overlooked in part because the two can be economically equivalent in a world without uncertainty. A global cap induces a carbon price, and taxing carbon at that price would limit emissions to that cap. But for reaching agreements, the two targets are substantially different. Before exploring that in more depth, it is useful to review why international commitments do not automatically induce specific national policies.

\section{International Commitments Are Not National Policies}

Economists sometimes imagine that caps or taxes could be implemented by an international tax-collection agency or international cap-and-trade market covering a large majority of each country's carbon emissions. Such plans assume a dose of top-down regulation that is presently infeasible.

However, a different pair of alternatives requires no such top-down apparatus and would allow countries tremendous flexibility. Under these alternatives, countries simply commit to a set of quantity commitments (regarding carbon permits) or a price. Either type of commitment could be met by national or regional cap-and-trade markets, fossil-fuel taxes, or any mixture of these along with bonus-malus systems applied to, for example, auto emissions estimated at the time of sale. An example of a mixture is the EU's reliance on a weak cap-and-trade market and a strong tax on carbon in the form of an oil tax. Another possibility is cap-and-trade with a floor price. This flexibility should minimize the acrimonious debate over caps and taxes to the extent possible because all countries could adopt linked cap-and-trade markets under either a global price commitment or a set of global quantity commitments. Countries also comply with either commitment by using fossil-fuel taxes.

\section{Defining a Global Price Commitment}

A country that commits to the global price only needs to meet the commitment on average. The average carbon price is simply the country's carbon revenues divided by its emissions. The revenue can, of course, come from selling permits under cap-and-trade, fossil fuel taxes, or calculations on other pricing-compatible regulation.

There should be some restrictions on how unevenly a country prices its carbon. For example, exports should face a price rather close to the global 
price. (The same is true under an international cap.) But we will not get into such details.

Also, our definition leaves a question of how to count preexisting taxes. There are at least two views on this. For accounting simplicity, all carbon charges would be counted toward compliance. We prefer this approach for pragmatic reasons. Another view is that this would be true after some base year, say 2015, and the fossil-fuel tax rate in that base year (excluding any taxes imposed for climate reasons) would be subtracted from all future carbon-price measurements. Both approaches are quite simple, and from an implementation point of view, the only difference is that the second approach requires a one-time accounting of fossil-fuel tax revenues at the start. There is no need to untangle taxes by purpose after the initial accounting, and even that may be unnecessary. So there is no possibility of gaming the commitment by saying a nonclimate tax is for the climate. Going forward, all taxes count.

Of course, it is inefficient to credit a new tax to pay for highways as if it were a carbon tax for the climate (Gollier and Tirole, chapter 10, this volume). But this is simply the minor inefficiency of not having a perfectly uniform tax, which seems even more out of reach with an international cap-and-trade scheme, as we will explain later.

\section{Price versus Quantity Commitments: A Comparison}

This chapter argues for correcting the flaw that derailed the Kyoto process and for returning to Kyoto's sound fundamental principle: agree on a common commitment that leads to (fairly) uniform carbon pricing. It proposes to do so in the most straightforward way-by using a global price commitment. Similar views have been expressed by Cooper $(2004,2008)$, Nordhaus (2013), Weitzman (2014), and Cramton and Stoft (2012a, 2012b), as well as throughout most of this book.

Although a single price commitment would be effective and is within reach, as we discuss throughout this chapter, it appears impossible to agree on $n$ national quantity commitments. Stiglitz (chapter 6, this volume) has made the case that there is no way to achieve a compromise between rich and poor countries regarding quantity commitments, and Weitzman (chapter 8, this volume) argues that quantities cannot be successfully negotiated. We add that history confirms this. The hope of finding a common 
quantity commitment was high at the start of the Kyoto treaty but has declined steadily ever since to the point where no one any longer mentions the possibility. Neither is there any discussion of how individual quantity commitments might be negotiated, even in this book, which raises this as the central topic for discussion. This explains why we will not attempt to refute any arguments that quantity commitments, common or individual, could be successfully negotiated. Rather, we will focus on comparing the two negotiation processes in terms of reciprocity and common commitments.

Importantly, cap-and-trade advocates and tax proponents nearly always agree that a uniform global price is the desired outcome. So unlike quantity, for which there is little if any agreement on the appropriate common commitment rule, there is nearly universal agreement that a common price commitment should be a uniform price commitment (or more precisely a uniform price floor). That is, a uniform price is a natural focal point. This facilitates negotiations about the price commitment (Schelling, 1960; Weitzman, chapter 8 , this volume).

There is an apparent but not actual symmetry between the global cap of Gollier and Tirole (chapter 10, this volume) and the global price of our approach. Gollier and Tirole suggest a cap corresponding to $2^{\circ} \mathrm{C}$, which is likely a focal point. Also, as they point out, negotiating a cap avoids the free-rider problem, much like negotiating a price. However, there is an important difference. Although a global price is a common commitment, a global quantity is only a common aspiration. Individual countries can implement the global price, and their commitment to the price is in principle enforceable. But no country can implement the global cap. An aspiration cannot be enforced.

The practical benefit of a price commitment is that it takes us most of the way to the set of final commitments. It resolves who will do how much for the climate, and of course it can also strive to reach the $2^{\circ} \mathrm{C}$ goal or any other focal climate goal. It leaves only the question of equity transfers to be resolved. This is still a crucial and difficult question (and we will get to it below), but focusing on price helps to disentangle it from the larger question of climate efforts.

Another advantage is that price is an inherently fairer measure of effort intensity than is a Kyoto-style quantity measure. The United States has tried to persuade India to commit to a cap in the vicinity of its emissions 
level, which would have been lower than the per capita emission of the United States in 1880. Not surprisingly, India rejected this idea. Accepting a carbon price would not limit India to any lower emission rate or "intensity rate" than the United States, and it would even allow India to emit as much or even more per capita than the United States. A price treats India more equitably and is at least as efficient as a cap that induces the same carbon emissions.

\section{Monitoring and Corruption}

For the two global commitments (as opposed to national policies), two main questions will determine which is best. The first concerns reaching an agreement (discussed earlier), and the second concerns whether compliance can be verified. Here we discuss verification.

Local monitoring and corruption. Under a commitment to either price or quantity, it is possible for emitters to bribe the carbon-tax collector or the carbon-permit collector (Tirole, 2012; Victor, 2001). Such corruption will impose inefficiency on the country but will not disrupt the enforcement of the international commitment, which only requires information of a more aggregate nature. If a power plant dodges its carbon charge, national carbon revenues are reduced. So the country must charge other emitters more to meet its average-price commitment, but the national commitment is still verifiable.

National monitoring and corruption. Emissions should be measured by monitoring the inflow of fossil fuel from extraction and net imports. Even so, with more than 500 coal mines in India and more than 18,000 in China, emissions monitoring could be poorly enforced or deliberately distorted. Similarly, under a price commitment, national carbon-pricing revenues could be falsely reported. Although this could be a serious problem in a number of countries, there are several ways to mitigate such problems. There could be monitoring by the International Monetary Fund, World Bank, International Energy Agency, or World Trade Organization, all of which do some similar monitoring already. Countries receiving green funds could be required to open their national accounting books to receive such funds. 
Finally, most real carbon pricing will be reflected in visible prices at gas stations, in home heating bills, and in retail electricity prices. These prices could be easily monitored. So verification is possible under either commitment, but in a few countries, it may require a significant effort. Both commitments would include a requirement to allow verification, and any country that did not cooperate would be considered to be out of compliance and would be sanctioned as if it had not met its price or quantity commitment.

International monitoring and corruption. On a global level, the corruption problem is asymmetric. Suppose a local official, on behalf of a kleptocratic ruler, allows a company to underreport emission so that it needs fewer carbon permits. The kleptocrat then sells supposedly surplus international carbon permits to a perfectly honest country. As Nordhaus (2008) explained, both the government and private company benefit because this shifts money from honest to corrupt countries. It also crowds out the honest country's abatements.

Conclusion on monitoring. Proponents of international cap-and-trade claim a carbon price cannot be monitored. Yet they claim that cap-and-trade will solve the export-import problem that results from international carbonprice differentials. But as we saw earlier, equality of nationally traded permit prices says nothing about the price of carbon emissions from exporters or anyone else. So the export-import problem can only be solved by monitoring the carbon prices paid by exporters. In other words, a crucial claim of cap-and-trade proponents relies on the assumption that carbon prices can be monitored accurately under the worst of conditions-at the local level, in industries where (unlike at gas stations) the price can be camouflaged, and where there is perhaps the strongest incentive for corruption.

Overall, looking at the various arguments in favor and against each commitment type with respect to monitoring and corruption, we tend to agree with Nordhaus (2008), who concludes, "Quantity-type systems are much more susceptible to corruption than price-type regimes," and with Cooper (2008), who concludes that a global cap-and-trade system "will unavoidably foster rampant corruption." 


\section{Will Carbon Emission Actually Be Priced?}

The point of international cap-and-trade is usually viewed as imposing on "all $\mathrm{CO}_{2}$ emitters the cost of their damage to the climate." ${ }^{7}$ The result of this would be an economically efficient reduction in emissions. This efficiency is a central goal of the policy partly because cost reduction is a great help in making a strong policy sustainable. Environmentalists, however, generally have quite a different goal for cap-and-trade. Their view is that the price doesn't matter but that the cap is a good old-fashioned commandand-control mechanism.

So the question is, will international cap-and-trade induce a uniform and an efficient carbon price as economists would like, or will it produce an inefficient mix of national command-and-control policies? Let us look at the Kyoto Protocol, which priced international permits and allowed any national policy. Gollier and Tirole (chapter 10, this volume) note that within the Organization for Economic Co-operation and Development countries, there were direct subsidies to green technologies, which resulted in implicit carbon prices that range from "less than 0 " to "as large as 1,000 $€ . "$ It is likely that most of this range was spanned within countries that were under the Kyoto Protocol. Gollier and Tirole conclude that such policies demonstrate "the inefficiency of this command-and-control approach."

In other words, in the only test case, the outcome was, by and large, not what economists hoped for but rather the inefficient command-and-control policies. Two conclusions seem evident. International cap-and-trade need not induce much if anything in the way of actual carbon pricing, and it may leave the current command-and-control approaches untouched. In other words, international cap-and-trade may not achieve the central objective of its proponents but rather the opposite.

\section{Committing to a Price Is Less Risky}

Quantity targets are favored because they supposedly remove the risk of emission and climate uncertainty and shift that risk to nations in the form of price and cost uncertainty. Although their success at limiting climate risk has been dismal, in part due to the uncertainty of the resulting quantity agreements and disagreements, quantity targets do impose risks on the countries that adopt them. 
More specifically, accepting a quantity commitment entails risk because future business-as-usual (BAU) emissions and abatement costs are both highly uncertain. Suppose that a country expects BAU emissions of $100 \mathrm{Mt}$ and considers two commitments: (1) a quantity reduction to $90 \mathrm{Mt}$, and (2) a price of $\$ 20 / t$. Assume these are equivalent (they both cause the same price and same emission quantity). Furthermore, assume that the global carbon price will be $\$ 20 / \mathrm{t}$.

Now suppose that the country's BAU emissions turn out to be $110 \mathrm{Mt}$ (10 Mt higher than expected). Under the quantity commitment, the $\$ 20 / \mathrm{t}$ global price will reduce emissions $10 \%$ to $99 \mathrm{Mt}$. But the country will only have been issued $90 \mathrm{Mt}$ of permits, so it will need to buy $9 \mathrm{Mt}$ of permits on the world market for a cost of $\$ 180 \mathrm{M}$. Under a price commitment, the country simply sets its carbon price to $\$ 20 / t$ as if nothing had changed.

Although the price-commitment policy specifies that countries keep all of the carbon revenues from pricing carbon, there is still a social cost. To find that cost, note that the more that is abated, the greater the cost per ton is abated, with the per-unit cost starting at $\$ 0 /$ ton and reaching a maximum of $\$ \mathrm{P} /$ ton. So the standard estimate of the cost of abatement, $\mathrm{A}$, under carbon price, $\mathrm{P}$, is $\mathrm{A} \times \mathrm{P} / 2$, or in this case, $11 \mathrm{Mt} \times(\$ 20 / \mathrm{Mt}) / 2$, which equals $\$ 110 \mathrm{M}$. This cost occurs under either policy because the global price of $\$ 20$ causes $11 \mathrm{Mt}$ of abatement in both cases.

Hence, the total cost under the quantity commitment is $\$ 180 \mathrm{M}+\$ 110$ $\mathrm{M}=\$ 290 \mathrm{M}$. That's 2.6 times as much as the $\$ 110 \mathrm{M}$ cost under the price commitment. But some cost was expected to occur under the expected BAU emission of $100 \mathrm{Mt}$. That expected cost was $10 \mathrm{M} \times \$ 20 / 2$, or $\$ 100$ M. So the unexpected cost under the quantity policy is $\$ 290 \mathrm{M}-\$ 100$ $\mathrm{M}=\$ 190 \mathrm{M}$, whereas the unexpected cost under the price commitment is $\$ 110 \mathrm{M}-\$ 100 \mathrm{M}=\$ 10 \mathrm{M}$. The financial risk from a possible $10 \%$ shock to BAU emissions in this example is 19 times greater than under a price commitment. ${ }^{8}$

This example does not exaggerate the risks of quantity commitments. In 2000, the US Department of Energy's International Energy Outlook predicted China's 2010 emissions would be $1.5 \mathrm{Gt}$, but in the event, emissions were more than $7 \mathrm{Gt}$-nearly a 400\% error rather than the $10 \%$ error assumed in the previous example. Quantity targets generally have been set 10 to 15 years in advance. Moreover, quantity errors can have high political sensitivity. If China had committed to a cap in 2000 equal to its expected 
BAU emissions (not reduced by any cooperative climate efforts), it would have been purchasing more than 5 billion tons of permits annually by 2010 from perhaps the United States and the European Union. This would have likely caused a dramatic permit shortage and high carbon prices, but even at $\$ 20 /$ ton, this comes to $\$ 100$ billion per year in highly visible transfers to foreign countries. If China had made anything like the quantity commitments desired of it by cap-and-trade advocates at that time, quantity risks would have likely destroyed that international quantity commitment and any associated cap-and-trade treaty. China was right to reject such quantity commitments.

\section{Enforcement}

Measurement delays. A major advantage of monitoring and enforcement of a price commitment is that it is an annual rather than a once-in-15year event, such as the Kyoto Protocol or China's recent commitment to cap emissions in 2030. This creates free-riding incentives and diffuses responsibilities among successive governments within countries and makes it difficult to repair noncompliance. Annual price commitments have the advantage that cheating can be quickly detected and quickly corrected because full compliance can be achieved simply by increasing the carbon charge. Indeed, frequent monitoring is known to be one of the most critical aspects of self-enforcing cooperation (Ostrom, 1990).

Gollier and Tirole (chapter 10, this volume) propose a fix for this problem: "Countries will have to match pollution and permits at the end of the year to avoid creating unfulfilled climatic debt." Unfortunately, this proposal blocks banking and borrowing of permits, the standard method of mitigating the volatility of permit prices. Such price volatility is likely to be unpopular with investors and the public. ${ }^{9}$

Successful enforcement is one key to successful cooperation (Nordhaus, 2015 and chapter 7, this volume). We have argued before that cooperation based on a common commitment is relatively easy to enforce because the common commitment enables a reciprocal relationship, which is known to promote cooperation. Here we argue that a common price commitment facilitates enforcement compared with a quantity commitment. One reason is that a price commitment is continuously monitored and thus more easily. Another reason is that it reduces risks. Risks can produce strong 
incentives to leave or avoid a quantity commitment. Without such strong negative incentives, the needed size of the enforcement penalty is reduced. Finally, price commitments reduce the required size of equity transfers (as we describe later), which also reduces the needed size of the enforcement penalty.

Various complementary mechanisms can further ease the enforcement of price commitments (e.g., efficient performance, which we borrow from modern electricity markets, where deviations from plans are settled at the market price for carbon revenues). In other words, a country that exceeds its commitment can sell its excess performance to a country that falls short. This guarantees that plans are met in aggregate and yet gives countries the flexibility to easily and efficiently react in an uncertain environment. Efficient resolution of deviations from plans greatly reduces risks, facilitates performance, and encourages participation.

\section{The Waiting Game}

Gollier and Tirole (chapter 10, this volume) explain that negotiations which are currently ineffective but are likely to eventually result in individual pledges contribute to what they call the "waiting game." The result of this game is that present behavior, while waiting for an agreement on individual commitments, can be even worse than the outcome of the noncooperative Nash equilibrium of the public goods game-worse than without any thought of cooperation.

The problem does not arise if a common commitment is expected to be the eventual outcome. Yet if individual climate commitments are expected, then it pays countries to jockey now for position in the final round of commitments. For example, if it is expected that commitments will be made relative to 2020 emissions or some future BAU emissions, then it pays to not take easy actions to reduce emissions before 2020 .

But if the eventual commitment will be a common price, then having higher emissions in 2020 will simply mean more emissions will be taxed at the global price. This confers no advantage on the recalcitrant country. That is, deciding now to agree on a common price ends the waiting game now, although there is still a wait for the actual agreement. 


\section{The Role of the Green Fund and Equity Transfers}

\section{Equity Transfers Are Less Expensive With Price Commitments}

Agreeing on price as the indicator of global action opens the door to a common commitment. However, poorer countries, such as India, will feel that they should receive significant help with it. Fortunately, this is relatively inexpensive. Because India's carbon-pricing revenues would stay in India, pricing India's two billion tons of emissions at \$20 per ton will have a net cost to India of only about $\$ 2$ billion if emissions were reduced $10 \%$-far less than the planned $\$ 100$ billion per year Green Climate Fund. This is not to suggest that India should be given an exception to the common commitment. Rather, the common commitment should include a Green Fund formula for providing assistance from richer, high-emission countries to poorer, low-emission countries. In this way, the common pricing commitment would respect the UN's principle of "common but differentiated responsibilities."

Equity transfers need not be as high with price commitments because risk is lower. As seen in the previous example of price and quantity risk, if a country expects a $\$ 100$ million cost of abatement, but there is a risk that its BAU emissions will be unexpectedly high by 10\%, then this would add $\$ 190$ million in the case of a quantity commitment and only \$10 million in the case of a price commitment. If the country demands that this risk be covered by equity transfers, then these will need to be $\$ 180$ million larger in the case of a quantity commitment. Politically, it seems difficult for a poor country to risk having its equity transfer obliterated by a miscalculation of future BAU emissions.

\section{Choosing a Green Fund Formula}

By committing to a uniform global price, we have confined the differentiatedresponsibilities problem to the Green Fund formula. This makes possible a natural and less-divisive principle for national differentiation. The new design principle is to choose the Green Fund formula that maximizes global emissions abatement.

This suggests a two-step design: select the Green Fund formula and then choose the common price. This is similar to many political processes in which it is common to specify the payment and benefit structure before deciding how much to spend on a program, say a school system. When 
voters are pleased with the payment-benefit structure, they will be generous in voting for a strong program. If they are displeased, then they will be less generous. This arrangement gives those designing the paymentbenefit structure, in this case, the Green Fund structure, a strong incentive to design the structure to please all of those whose support is needed. It also allows the funders to have peace of mind when the funders delegate authority to those negotiating the structure-first because they know that they can reject or minimize the proposed structure if it is not to their liking, and second because they know the negotiator/designers will be well aware of this.

Compare this to the cap-and-trade alternative, which is also a two-step approach. First, the global cap $Q$ is selected and then the permit allocations $\left\{A_{i}\right\}$ are negotiated. But, as noted earlier, $Q$ is an aspiration and not a commitment, so all of the work of solving the climate-effort and equity-transfer problems is bundled into the single step of negotiating $\left\{A_{i}\right\}$. In contrast, the two-step approach of pricing breaks the problem in two-choosing climate effort $(P)$ and negotiating equity transfers $\left\{G_{i}\right\}$-this simplifies both negotiations. Then it links the two halves so that the availability of the step-two price decision provides good incentives for, and confidence in, the Green Fund design process, and the Green Fund design is properly focused on making the price negotiation successful. This is why the " $\left\{G_{i}\right\}$ then $P$ " negotiation process can outperform the " $Q$ then $\left\{A_{i}\right\}$ " process.

We now describe, for the sake of concreteness, a possible pair of negotiating procedures, beginning with the step-two price negotiation. To set the price, countries pledge their highest acceptable global price target, taking the step-one Green Fund formula into account. Then the highest price target acceptable to, say, 70\% of the countries (population-weighted) determines the global price commitment. ${ }^{10}$ Only countries that have pledged at least that price would sign the global-pricing agreement and participate in the green fund. ${ }^{11}$ (This "club" could then implement enforcement that could induce additional members to join; see Stiglitz, chapter 6, this volume.)

Before describing step one, the Green Fund negotiation, we note that, as pointed out by Gollier and Tirole (chapter 10, this volume), it is an $n$-dimensional negotiation and hence difficult. As with the climateeffort negotiations, a common formula is needed, but here we are not lucky enough to have something as simple and well-agreed-on as a 
uniform price. Nonetheless, it pays to look for an equity formula that is focal and has a single parameter that can differentiate responsibilities to the extent required. Of course, in reality, no simple formula will be sufficient. However, this example will serve to illustrate the value of looking for a common-commitment formula, even if the actual one needs to weight multiple relevant variables.

The formula that we propose as simplest and most focal for Green Fund transfers is to make transfers proportional to a country's excess emissions. These are defined as emissions that are in excess of what the country would emit if it had world-average per capita emissions. Countries pay into the green fund in proportion to their excess emissions and receive payments from the green fund in proportion to their negative excess emissions.

There seems little doubt that this formula would work if accepted because perfection is not required. But it would likely not achieve as high a price as a more detailed and thoughtfully designed formula. The formula should be judged by how high a price results from its use in the stage-two voting process.

The excess-emissions formula must also include a generosity parameter, $G$, that determines its strength - how many dollars per ton of excess emissions will be transferred. If the Green Fund formula is too generous, rich countries will hold down the global price to reduce Green Fund payments. If the formula is too miserly, then poor countries will hold down the carbon price to reduce the burden of carbon pricing. Only a compromise on generosity will lead to the highest agreed global carbon price and maximize abatement ambition. Hence, the objective of maximizing ambition leads naturally to a reasonably fair compromise on differentiation of responsibilities.

To ensure that the generosity of the Green Fund formula is set objectively to maximize climate ambition, it will be best to rely on countries that have the least stake in Green Fund payments. Such countries will base their recommendations on climate rather than Green Fund considerations. Within such a group, the median (not the average) opinion should determine the outcome. This prevents any one country from having too much influence (Cramton and Stoft, 2012a, 2012b).

When proposing individual commitments, the United States (2013) argues that it is "hard to imagine that Parties would be willing to have other Parties dictate their contributions." But the prior illustrative agreement shows the U.S. argument is irrelevant. Under such an agreement, no 
country will ever be asked to commit to a price higher than it nominates voluntarily with full knowledge of the generosity of the green fund. Nothing is "dictated" by other parties. Despite the completely voluntary nature of this treaty, the resulting agreement captures the "I will if you will" effect of a common commitment that modifies self-interest within the agreeing group. Hence, each country's self-interest in naming a high price will be increased dramatically relative to the individual commitments the United States is proposing.

\section{Why Opaqueness Is Not an Argument for Quantity Commitments}

Some observers argue that a green fund is too transparent to be politically acceptable and that a supposed lack of transparency is a major advantage of cap-and-trade. However, the cap-and-trade programs often referred to are domestic and are opaque for a different reason. Their transfers are not in the form of traceable money. Companies get paid mainly by raising commodity prices by an amount that is hard to measure and that most people cannot comprehend. In contrast, international purchases of AAUs-the real standard of comparison-have been extremely controversial, as we described in our introduction. Indeed, we find it difficult to believe that large cross-border money transfers through perfectly transparent markets would not catch the public's attention. It seems even more likely that the transfer will become obvious at an earlier stage. To give India a large transfer, India must receive a cap that is far above its BAU emissions level. This part of the transfer will be highly visible, and past comments have shown that environmentalists will find this highly objectionable. It will also make it impossible to explain to the US public why the United States is giving a multibillion dollar climate transfer to a country that is required to do less than nothing.

That said, even if the supposed opaqueness of permit transfers is something worth taking advantage of, this might be possible under a price commitment without incurring the political risk premiums associated with quantity commitments. For example, instead of the US government paying India $\$ 100$ million, it could allow US businesses to purchase offsets from the Indian government at the global price of carbon, and India could be issued a package of say 5 million one-ton permits. Although these would be just as visible as permits under cap-and-trade, they would not cause the financial risks of cap-and-trade. 


\section{Conclusions}

Despite much rhetoric, there is almost no hope that the Paris pledge-andreview approach, if based on individual pledges, can solve the climate dilemma. Rather, to address the dilemma, we agree with all experts in this book that a common commitment is necessary. In this chapter, we reiterate Weitzman's plea that price and quantity commitments be compared on a level playing field. This seems eminently reasonable because quantity commitments have had the field to themselves for more than 20 years and failed repeatedly. Quantity commitments have been favored partly because of the misperception that caps provide stronger incentives and more certainty than a price, together with an incorrect analogy between an easily enforced domestic cap and unenforced international caps. Yet for reasons that we and other contributors to this book explain, a price commitment is likely a much more promising basis for a common commitment; it is a fair focal point, reduces risks, is easier to enforce, and is consistent with climate policies already in place. Indeed, one beauty of a carbon-price commitment is that it will not interfere with the current, dispersed cap-and-trade experiments, thereby leaving the door open to a future rehabilitation of caps and keeping alive the fundamental idea of using price.

Promoting cooperation in international climate negotiations is the crux of the climate problem. We hope that our chapter, along with the other contributions in this book, will provide guidance to those shaping international climate policy after Paris. After more than 20 years of failure, surely it is worth attempting a fresh approach, one that is guided by insights from the science of cooperation.

\section{Notes}

1. We will return to this later. For the moment, observe that democracies habitually solve national public-goods problems by voting on a common commitment. Usually this is a commitment to pay a uniform tax with revenues used for public goods, such as parks, highways, education, defense, or cleaning up toxic waste. Voting for a tax is an organized approach to saying, "I will adhere to the common commitment if you will."

2. In other words, a treaty based on a common commitment is a partially selfenforcing treaty. 
3. Kyoto Chairman Estrada personally suggested the target of " $8 \%$ below 1990 emissions" for many countries, and many countries adopted his suggestion when submitting their final pledges.

4. "Japan is defending itself against criticism that it's exploiting a surplus of Kyoto assigned credits and using 'hot air' to meet emission targets." Bloomberg, July 23, 2009. The importance of high-profile political ramifications caused by unpredictable public transfers between rival countries was anticipated by Cooper (2004): "What US Senator, once s/he understands the full implications of a trading regime, can vote for a procedure which could result in the unconditional transfer of billions of dollars, even tens of billions, to the government of communist China, or to Castro's Cuba, or even to Putin's Russia?"

5. See carbonmarketwatch.org/doha-on-aaus-the-future-of-the-phantom-menace.

6. In its March 11, 2013, submission, the United States stated, "It is hard to imagine agreement on any formula or criteria for imposition of contributions, as this would get into the most controversial issues."

7. From https://sites.google.com/a/chaireeconomieduclimat.org/tse-cec-joint-initiative/ some-economic-perspectives, accessed July 14, 2015.

8. Based on our example, Weitzman (2015) has recently shown in a rigorous and general model that under uncertainty, internationally tradable permits expose a country to unambiguously greater risk than the imposition of a uniform carbon price whose tax proceeds are domestically retained.

9. In that respect, the first trading period in the context of the EU ETS provides a good lesson of undesired price effects when banking and borrowing are not allowed.

10. The higher the coverage of global emissions, the lower the price that will be agreed to by all the countries that must be included to achieve that coverage.

11. Countries may also agree on a price path. In any case, this initial agreement would be updated periodically with the intention of increasing its coverage and strength, and of reflecting the improving estimates of costs and benefits of climate change.

\section{References}

Arrow, K. 2007. Global climate change: A challenge to policy. Economists' Voice: 1-5. Accessible at https://www.staff.ncl.ac.uk/david.harvey/AEF873/Sustainability/Arrow .pdf.

Cooper, R. 2004. A global carbon tax? Council on Foreign Relations. Commissioned Briefing Notes for the CIGI/CFGS L20 Project. 
Cooper, R. N. 2008. The case for charges on greenhouse gas emissions. Discussion Paper 08-10, Harvard Project on International Climate Agreements, Belfer Center for Science and International Affairs, Harvard Kennedy School.

Cramton, P., and S. Stoft. 2012a. Global climate games: How pricing and a Green Fund foster cooperation. Economics of Energy \& Environmental Policy 1:2.

Cramton, P., and S. Stoft. 2012b. How to fix the inefficiency of global cap and trade. Economists' Voice: 1-5. Accessible at ftp://www.cramton.umd.edu/papers2010-2014/ cramton-stoft-how-to-fix-global-cap-and-trade.pdf.

Depledge, J. 2000. The origins of the Kyoto Protocol. Prepared under contract to the UNFCCC, FCCC/TP/2000/2.

Edenhofer, E., et al. 2014. Reform Options for the European Emissions Trading System (EU ETS). Euro-CASE Policy Position Paper. Accessible at: http://www.euro -case.org/images/stories/pdf/position-paper/Euro-CASE-policy-paper-ETS -reform.pdf.

Hauser, O. P., D. G. Rand, A. Peysakhovich, and M. A. Nowak. 2014. Cooperating with the future. Nature. doi:10.1038/nature13530.

Kraft-Todd, G. T., E. Yoeli, S. P. Bhanot, and D. G. Rand. 2015. Promoting cooperation in the field. Current Opinion in Behavioral Sciences 3:96-101.

MacKay, D. J. C., P. Cramton, A. Ockenfels, and S. Stoft. 2015. Price carbon: I will if you will. Nature 526:315-316. doi:10.1038/526315a.

Marcantonini, C., and A. D. Ellerman. 2014. The Implicit Carbon Price of Renewable Energy Incentives in Germany. EUI Working Paper RSCAS 2014/28.

Nordhaus, W. 2008. A Question of Balance. New Haven, CT: Yale University Press.

Nordhaus, W. 2013. The Climate Casino. New Haven, CT: Yale University Press.

Nordhaus, W. 2015. Climate clubs: Overcoming free-riding in international climate policy. American Economic Review 105:4.

Ostrom, E. 1990. Governing the Commons: The Evolution of Institutions for Collective Action. Cambridge, UK: Cambridge University Press.

Schelling, T. C. 1960. The Strategy of Conflict. Cambridge, MA: Harvard University Press.

Stiglitz, J. E. 2006b. Saving the planet. In Making Globalization Work. New York: W W. Norton \& Company, Inc; Accessible at http://garevna.ucoz.com/metod-mat/ books/Joseph_Stiglitz.pdf.

Tirole, J. 2012. Some political economy of global warming. Economics of Energy and Environmental Policy 1:121-132. 
United States. 2013. ADP Workstream 1: 2015 Agreement Submission of the United States. Submissions from Parties to the ADP (2012-2013). Available at https:// unfccc.int/files/documentation/submissions_from_parties/adp/application/pdf/ adp_usa_workstream_1_20130312.pdf.

Victor, D. 2001. The Collapse of the Kyoto Protocol and the Struggle to Slow Global Warming. Princeton, NJ: Princeton University Press.

Weitzman, M. 2014. Can negotiating a uniform carbon price help to internalize the global warming externality? Journal of the Association of Environmental and Resource Economists 1 (1/2): 29-49.

Weitzman, M. 2015. Internationally-Tradable Permits can be Riskier for a Country Than an Internally-Imposed Carbon Price. Cambridge, MA: Harvard University Press. 



\section{Acknowledgments}

Financial support of the German Research Foundation (DFG) through the Research Unit "Design \& Behavior" (FOR 1371) is gratefully acknowledged. 



\section{Index}

Page numbers in italics indicate references to figures.

Abatement costs, 231-232

Affordable Care Act, 79

Afforestation, 85

Air pollution

damages from coal plants, 25-27, 29n10

from motor vehicles, 27-28

Ambition, 3-4, 181, 196

aligned self-interest and, 33-34

carbon pricing rewarding, 81

declines with free-riding, 8

-science gap, 211-212

upward spiral of, 7

Barrett, Scott, 61

Beccherle, J., 180

Bill \& Melinda Gates Foundation, 184

Bioenergy with carbon capture and storage (BECCS), 153

Burden sharing, 100

common and differentiated

responsibilities, 106-107

costs of adjustment and, 102-103

flexibility in making commitments, 104-106

Kyoto Protocol problem and, 101-102

partial versus general equilibrium in, 103-104

price targets and, 159-160 principle, 54-55

voluntary versus enforceable agreements, 104

Business-as-usual (BAU) emissions, 231-232, 237

California cap-and-trade system, 51

Cancún agreement, 212-213

Cap-and-trade system, 7, 46-47, 229-230. See also Kyoto Protocol Chinese permit shortage (1999), 67-70 compared to carbon pricing, 173-176 failures, $176-178$

freestyle negotiations ending in deadlock, 74-75

global, 50-52

for greenhouse gases, 92-93

modified, 137-141, 146n18

not pricing carbon emissions, 72-73

opportunity costs with permits, 72

potential time inconsistency, 193-194

prediction-error trading risk, 66 ,

73-74

problems with, 40-41

profits from permits, but not for

countries, 72

risk of, $65-70$

successes and shortcomings, 71-76 
Cap-and-trade system (cont.)

transparency, 237

treaty negotiation problems, 73

volatility under, 192-193

Carbon, social cost of, $174-175$

Carbon capture and storage (CCS), 153

Carbon convergence, 213-215

Carbon leakages, 167

Carbon pricing

add-on mechanism based on carbon-capture potential, 85

ambition and aligned self-interest in, 33-34, 81

central role in Climate Clubs design, 118-120

as cheap, 48-49

climate externalities and, 13

common price target for, 157-159

compared to other mitigation

instruments, 28n1, 173-176

computing the right price signals in, 173

cooperation and, 31-35

domestic environmental

considerations and, 14-20

in effective climate policy, 154-156

efficiency gains from, 16-17

eliminating huge trading risks, 80

emissions, 50

enforcement, 44-46, 61-65, 77-78, 190-192

EU countries and, 84-85

fairness in, 54-55

fiscal considerations for individual

nations, $20-21$

flexibility of, 10, 105-106

frequently asked questions about,

82-85

global commitment, 10, 41-43, 52-54

governance, 33, 56, 62, 86n2

for greenhouse gases, 93-96

history of climate negotiations and,

126-128 as ideal basis for common

commitment, 4-5, 7-8

inequality and, 171-172

interaction with climate fund, 58-59

international floor arrangements,

13-14, 22-23, 24

legal process, $200 \mathrm{n} 20$

misconceptions about, 24-25

monitoring and corruption, 228-229

multilevel pricing, 86n 8

narrow self-interest and, 31-33, 43

nationally efficient price levels, 18-20

necessity of uniform, 170-179

negotiating quantities versus,

128-133, 141-144

one-dimensional negotiation, 181-184

"pledge and review" approach, 9

potential time inconsistency, 193-194

preventing too low, 55-56

price versus quantity, 60, 128-133,

145n6, 145n9, 189-190, 226-228

pricing carbon emissions, 80

problems with, 76-80

reasons for correct, 47-50

resilience to shocks, 200n19

rewarding environmental ambition,

81

risk reduction through, 230-232

simple global climate model for,

43-44

simplicity of, 81

stopping free-riding, 81

theory of negotiating uniform,

133-137

volatility under, 192-193

welfare gains from, 15-16

Carrot-and-stick approach to

enforcement, 194-195

Certainty equivalent model, 70

Clean Air Act Amendment of 1990, 184, 185

Clean Development Mechanism (CDM), 172 


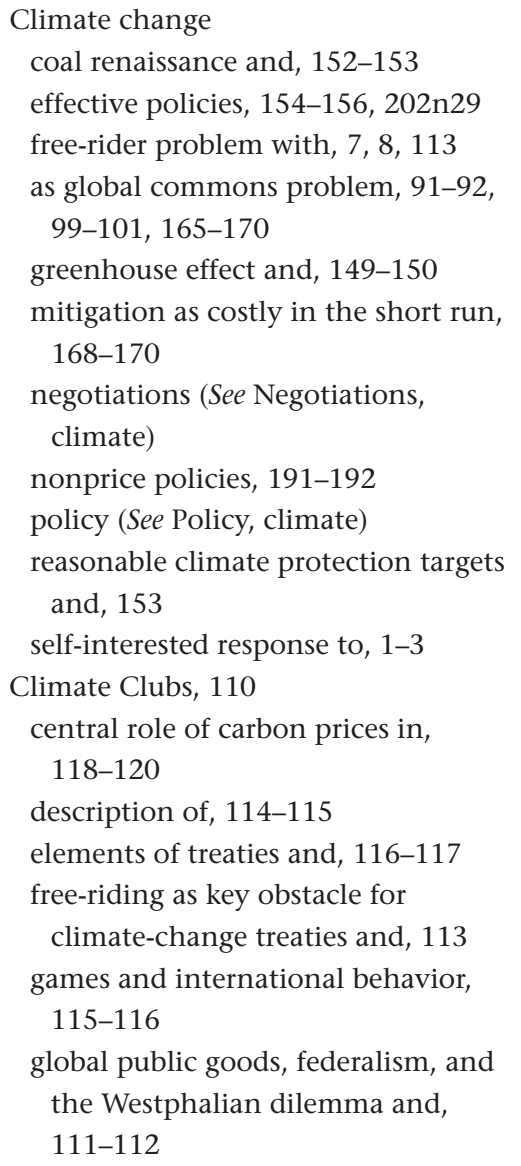

illustrative results, 121-122

as mechanism to overcome free-riding, 113-114

modeling, 120-121

nature of global public goods and, 110-111

sanctions for international agreements about global public goods, 117-118

Climate justice, 212-213, 215-216

Coalition-DICE (C-DICE) model, 120

Coalition of willing, 104

Coal power, 152-153, 154-155

Coase, Ronald, 135, 145n11

Command-and-control approach, 170-171
Commonality of common

commitment, 4

Common commitment, 8-9

carbon pricing, 4-5

costs of adjustment and, 102-103

defining global price, 225-226

enforcement, 44-46, 61-65

flexible (See Flexible commitments)

formula failure for quantities, $75-76$

monitoring and corruption, 228-229

necessity of, 4-5

as not national policies, 225

promoting international agreement,

221-222

protection against free-riding, 9

realistic treaty design, 55-59

real-world coalitions, 62-63

reciprocity of, 4, 33-34

treaty enforcement, 44-46, 61-65

waiting game with, 233

without instruments, 212

Common price targets, 157-159

Commons

commitment game, $\mathrm{x}-\mathrm{xi}$, xiii

cooperation in, ix, $x i$

Elinor Ostrom on, ix, 4, 33

negotiation design and, $\mathrm{x}$

Compliance and carbon charges, 96-97

Convergence, carbon, 213-215

Cooper, R. N., 41, 226

Cooperation, xi, 3-4, 8

ambition and aligned self-interest in, 33-34

enforcement and, 232-233

free-riding and, 34-35, 38-39

narrow self-interest and, 31-33, 43

pledge-and-review approach, xii, 7, 8, 9, 39-40

problem and solution, 38-43

simple global climate model and, 43-44

treaty enforcement, 44-46 
Copenhagen agreement, 9, 99-101, 179, 210-211. See also Flexible commitments

climate justice and, 212-213

Kyoto Protocol problem and, 101-102

Corruption, 228-229

Countervailing force property of carbon pricing, 136

Cramton, P., 38, 54, 57, 74, 182, 183, $186,187,226$

Deniers of free-riding, 35

De Perthuis, C., 187

Domestic environmental benefits of carbon pricing, 14-20

Durban Conference (2011), 211-212

Effective carbon prices, 23, 24

Electricity taxes, 29n15, 87n14, 171

Emission rights, 101-102

auctioned, 105

Enforcement, treaty, 44-46, 232-233

cap-and-trade, 61-65, 192

carbon pricing, 77-78, 190-192

carrot-and-stick approach to, 194-195

Equity transfers, 78-80, 83-84, 234

Ethics-based justice, 216

EU Emissions Trading System, 50-51, $52,160-161,175,178-179$

European Energy Tax Directive, 29n12 European Space Agency (ESA), 192

Fairness, 54-55

Federalism, 111-112

Figueres, Christiana, 33

Fiscal considerations in carbon pricing, 20-21

Flexibility mechanisms, 208-209

Flexible commitments, 99-101, 104-106, 107-108 common and differentiated responsibilities, 106-107 costs of adjustment in, 102-103

failure of current approach to, 101-102

partial versus general equilibrium, 103-104

voluntary versus enforceable agreements, 104

Fossil fuels pricing, 78, 151-152

coal power and, 152-153

local externalities and, 191

Frankel, Jeffrey, 66-68, 75-76, 78

Free-riding, 3, 7, 8, 38-39, 99

carbon charges for greenhouse gases and, 96-97

carbon pricing stopping, 81

Climate Clubs as mechanism to overcome, 113-114

common commitment protection against, 9

cooperation and, 34-35

deniers of, 35

as key obstacle for climate-change treaties, 113, 126

by one country causing breakdown in total cooperation, 35-36

participants' fears of being "suckers" due to, 36

US opposition to, 37-38

Freestyle negotiations, 74-75, 187

Fund, climate. See Green Climate Fund

Fundamental scarcity problem of the atmosphere, $150-152$

Gasoline pricing, 78

Global Burden of Disease project, 26

Global commission on the Economy and Climate, 213

Global emission targets, 181-184

Global positioning systems (GPSs), 110-111

Global public good(s) federalism, and the Westphalian dilemma, 111-112 
global environment as, 99-100

global warming as externality of, 125

nature of, $110-111$

sanctions for international agreements about, $117-118$

Global warming gridlock, 126, 144n3

Gollier, Christian, 40, 57, 74, 230, 232, 233, 235

Gore, Al, 38

Governing the Commons, 36

Green Climate Fund

flexible financing of, 106-107

formula, 56-58, 59-60, 234-237

interaction with carbon price, 58-59, 159-160

transfers, 78-80, 83-84, 234

transparency considerations, 184-185

Greenhouse effect, 149-150

fundamental scarcity problem of the atmosphere and, 150-152

Greenhouse gases (GHGs), 91, 149

benefits of reducing, 166-167

burden sharing and, 100

carbon charges for, 93-96

compliance with carbon charges for, 96-97

economic approach versus command-and-control for, 170-171

fundamental scarcity problem of the atmosphere and, 150-152

international cap-and-trade system for, 92-93

nonprice policies and, 191-192

Green Paradox effect, 160

Group reciprocity, 64-65

Gruber, Jonathan, 79

Harberger triangles, 15, 16, 102-103

Heine, D., 17, 18, 21, 25, 26, 27, 28-29n8

Herfindahl index, 197-198n1

Hiding of transfers, 78-79
Hollande, François, 206

Hot-Air AAUs, 185, 223, 239n4

Hotelling's rule, 173

Hume, David, 116-117

Incentives, carbon pricing, 77, 209-210

Inclusiveness, 209

Individual commitment

game, $\mathrm{x}$

treaty, $44-45$

Inequality, income and wealth, 171-172

Intake fractions, 26

Integrated assessment models (IAMs), 120

Intended Nationally Determined Contributions (INDCs), 2, 39, 127

Intergovernmental Panel on Climate Change (IPCC), 165-166, 174

International Energy Agency (IEA), 77, 207, 213

International Monetary Fund (IMF), 77, $96,195,197,214$

Jouvet, P.-A., 187

Justice, climate, 212-213, 215-216

King, Martin Luther, Jr., 165

Kyoto Protocol, ix, 3, 7, 9, 37, 39, $47,60,80,126,205,207,210$, 216-217nn3-5, 230. See also Cap-and-trade system based on "emission rights," 101-102 Clean Development Mechanism (CDM), 172 failures of, 109-110, 139, 176-177, 196, 208, 222-223

formulas, 75 freestyle negotiations, 74-75 legacy of, 223-225 legally binding emissions reductions, 126-127 
Kyoto Protocol (cont.)

as model for global cap-and-trade,

$50-52,71$

no global government with, 71-72

not pricing carbon emissions, 72-73

safety of business-as-usual targets and, 66-67

Laffont, Jean-Jacques, 194

Li, S., 18, 25, 26, 27, 28-29n8

Liability system, $198 \mathrm{n} 3$

Lis, E., 18, 25, 26, 27, 28-29n8

Market Stability Reserve mechanism, 202n29

Merkel, Angela, 206

Mitigation as costly in the short run, 168-170

Monitoring, carbon pricing, 77-78, 228-229

Mortality rates, 26, 29n17-18

Motor vehicles

emissions, 27

externalities, 27-28

National Aeronautics and Space Agency

(NASA), 192

Nationally efficient carbon prices, 18-20

N-dimensional negotiation, 184-185

Negotiations, climate, $141-144$. See also

Policy, climate

ambition-science gap and, 211-212

brief history of, 126-128

building carbon convergence and,

213-215

design, $\mathrm{x}$

freestyle, 74-75, 187

Kyoto's legacy for, 223-225

legally weak agreements, 210-211

modified cap-and-trade, 137-141,

146n18

n-dimensional, 184-185

one-dimensional, 181-184 prices versus quantities, 128-133,

145n6, 145n9, 189-190

reducing the dimensionality of

compensation, 185-189

renewing commitment to, 196-197

theory of negotiating uniform carbon

price and, 133-137

unflattering carbon footprint of, 207-210

waiting game, 233

1999 International Energy Outlook, 67

Nonbinding agreements, 212

Noncooperative (NC) game theory,

115-116

elements of treaties and, 116-117

Nonexcludability, 110-111

Nonprice policies, 191-192

Nonrivalry, $110-111$

Nordhaus, W., 56, 174, 222, 226, 229

Obama, Barack, 79

Ockenfels, A., 182, 186, 187

One-dimensional negotiation, 181-184

Organization for Economic

Co-operation and Development

(OECD), 171, 230

Organization of Petroleum Exporting

Countries (OPEC), 48

Ostrom, Elinor, ix, 4, 34, 36, 38, 43,

86n 4,167

on common-pool governance, 33, 56, $62,86 \mathrm{n} 2$

on necessary central core, 63

Pareto superior arrangements, 100

Paris agreement, ix, 75, 126-128, 127, 134, 139-140

climate policy challenge and, 156-157

collective goals and inequality in individual contributions, $1-3,38$, 205-207

enforcement, 9, 37

lack of ambition in, 3-4, 196 
as legally weak, $210-211$

omission of built-in reciprocity, 34 pledge-and-review approach adopted at, xii, 7, 8, 9, 39-40, 179-181 transparency and, 184-185

Parry, I. W. H., 17, 18, 21, 25, 26, 27, 28-29n8

Pledge-and-review approach, xii, 7, 8, 9, 39-40, 179-181, 223-225

Policy, climate. See also Negotiations, climate

burden distribution in, 159-160

common price target in, 157-159

as costly in the short run, 168-170

effective, 154-156

enforcement (See Enforcement, treaty)

EU ETS, 50-51, 52, 160-161

international commitments as not national, 225

Paris and, 156-157

reasonable climate protection target and, 153

recommendations for, 161-162

renaissance of coal and, 152-153

Posner, E., 171

Prediction-error trading risk, 66, 73-74

Q global cap, 40-41, 42

Quantity versus price instruments, 60,

128-133, 145n6, 145n9, 189-190, 226-228

Realpolitik, 187

Reciprocity of common commitment, 4, 33-34 common price target and, 157 enforcement and, 63-65 equity transfers, 79-80 group, 64-65

Regional Greenhouse Gas Initiative (RGGI), 51, 177-178

Renewable energies, 152, 155-156 Rosenfeld, Art, 48
Sanctions for international agreements about global public goods, 117-118 Schelling, Thomas, 134, 135, 145n10

Science-based efficiency, 215

Self-governance, 33, 56, 62, 86n2

Self-interest, narrow, 31-33, 43

Shocks, resilience to, 200n19

Social cost of carbon, 174-175

Solar power, 171

Stiglitz, J. E., 103, 222, 223, 226

Stoft, S., 38, 41, 54, 57, 74, 182, 183, $186,187,226$

Subsidies of carbon-emitting industries, 103

Symposium on International Climate Negotiations, 213

Taxes, carbon, 20-21, 48-49, 87n16, 128-133, 145n6, 198n5. See also Carbon pricing

Tax swaps, 48-49

Technology, 4, 201n22

improvements and carbon emission goals, 107

Tirole, Jean, 40, 57, 74, 180, 194, 230, 232, 233, 235

Tragedy of the commons, 182

Transactions cost, 135, 145n11

Transfers, climate fund, 78-80, 83-84, 234

Transparency, 79, 184-185, 209, 237

Treat design, realistic, 55-59

Treaties. See Negotiations, climate

Undersupply, 99

United Nations Framework Convention on Climate Change (UNFCCC), ix, $39,42,56,95,132,179,208$

Veung, C., 17, 21

Victor, David, $144 \mathrm{n} 3$

Volatility, carbon price, 192-193 
Voluntary versus enforceable

agreements, 104

Weisbach, D., 171

Weitzman, M. L., 38, 74, 187, 199n7, 222, 226

Westphalian dilemma, 111-112

Wind power, 152, 154, 171

World Bank, 33, 77, 213

World Climate Assembly (WCA), 131-132, 137

World Health Organization (WHO), 26

World Trade Organization (WTO), 77,

96, 195, 197 